\title{
Wolfgang Girke
}

\section{Studien zum adjektivischen Attribut im Russischen}

Verlag Otto Sagner München · Berlin · Washington D.C.

Digitalisiert im Rahmen der Kooperation mit dem DFG-Projekt „Digi20“

der Bayerischen Staatsbibliothek, München. OCR-Bearbeitung und Erstellung des eBooks durch den Verlag Otto Sagner:

http://verlag.kubon-sagner.de

( $)$ bei Verlag Otto Sagner. Eine Verwertung oder Weitergabe der Texte und Abbildungen, insbesondere durch Vervielfältigung, ist ohne vorherige schriftliche Genehmigung des Verlages unzulässig. 


\section{SPECIMINA PHILOLOGIAE SLAVICAE}

Herausgegeben von

Olexa Horbatsch, Gerd Freidhof und Peter Kosta

Band 75

\section{Wolfgang Girke}

\section{STUDIEN \\ ZUM ADJEKTIVISCHEN ATTRIBUT IM RUSSISCHEN}




$$
z 74.772-75
$$

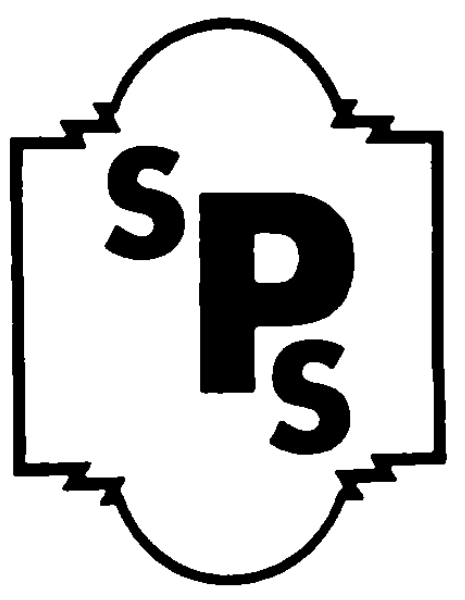

Verlag Otto Sagner, München 1988. Abt. Fa. Kubon und Sagner, München. Druck: Firma Mauersberger, Marburg.

ISBN $3-87690-399-8$

$$
\begin{aligned}
& \text { Rayorlanth } \\
& \text { Ste +trbib io!t ck } \\
& \text { n!uncii-n }
\end{aligned}
$$


Vorbemerkungen

Dieser Band enthält sechs einzelne Aufsätze zur Problematik der adjektivischen Attribute. Sie können unabhängig voneinander gelesen werden, stehen aber nicht zusammenhanglos nebeneinander. Ausgangspunkt aller Arbeiten war die Frage nach der Motiviertheit der Attributssetzung, d.h. die Frage danach, warum uberhaupt Adjektive verwendet werden und warum gerade die gegebenen verwendet werden. Ein solcher Ansatz impliziert, daß auch nach Restriktionen der Attributssetzung bzw. ihrer Distribution gesucht und die Abgrenzung von konkurrierenden Mitteln näher betrachtet wird. Es zeigt sich, daß adjektivische Attribute ein komplexes Phänomen darstellen, das viele interessante Fragen aufwirft. Auf einige von ihnen habe ich versucht eine (vorläufige) Antwort zu geben, andere müssen aber erst noch formuliert werden. 


\section{INHALTSVERZEICHNIS}

Seite

1. Prädikatmotivierende Attribution

2. Zur Attribuierbarkeit zweiterwähnter Substantive

3. Attribution und Teil-Ganmes-Relation

4. Die multiple Attribution

5. Prä-, post- und interponierte isolierte Adjektive (Zum Problem der Merkmalzuweisung )

6. Adjektivische Attribute und Indefinitheit 
So

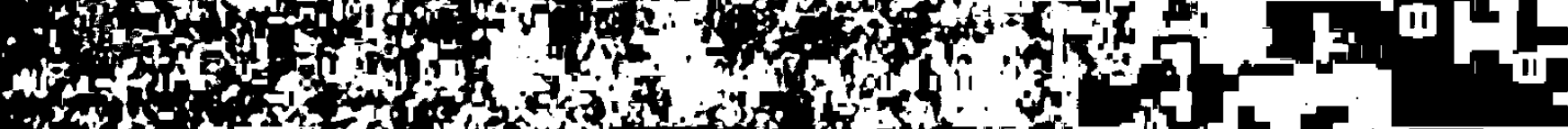

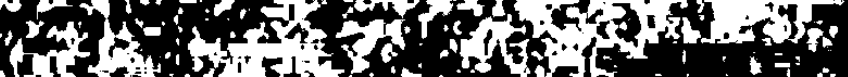

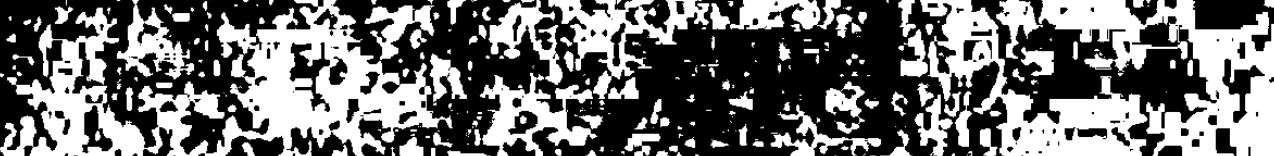

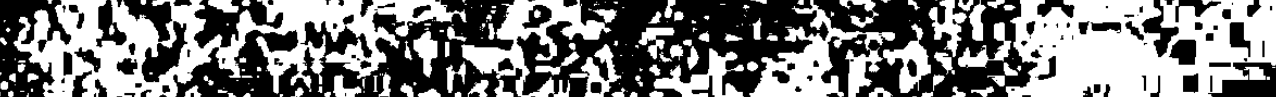

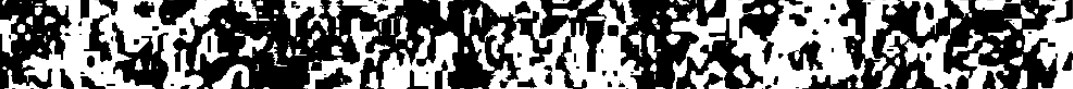

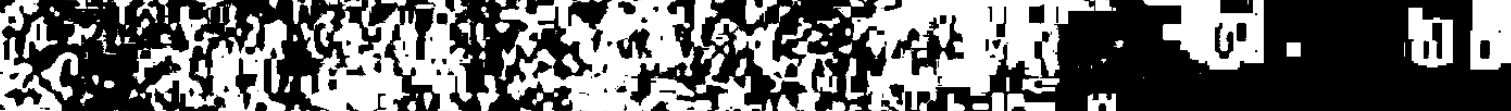

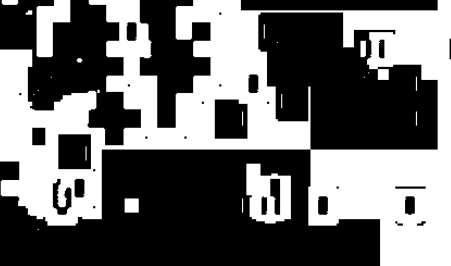

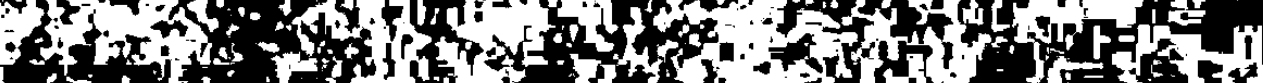

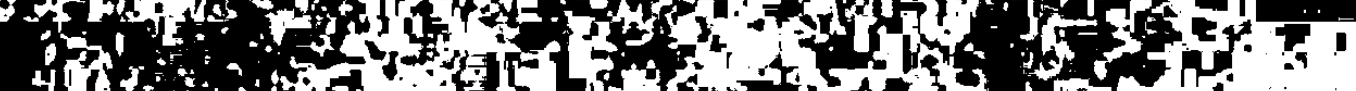

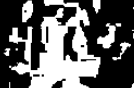

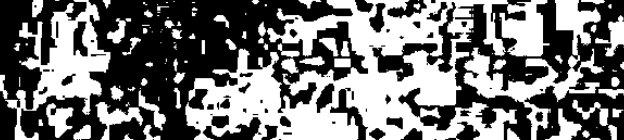

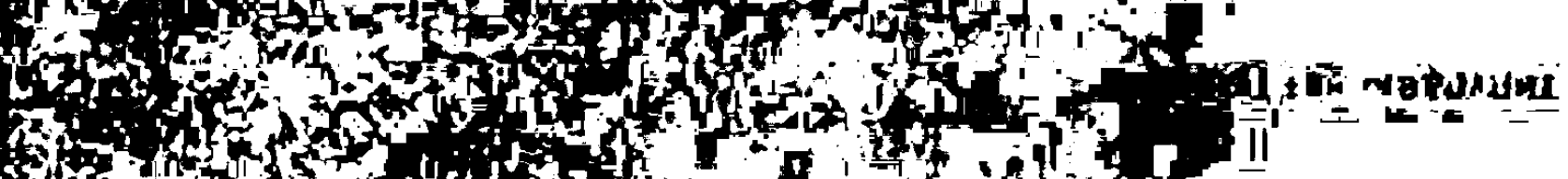

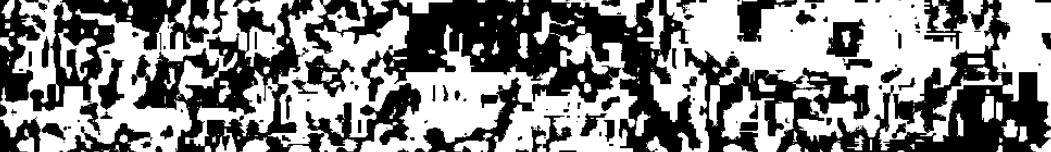

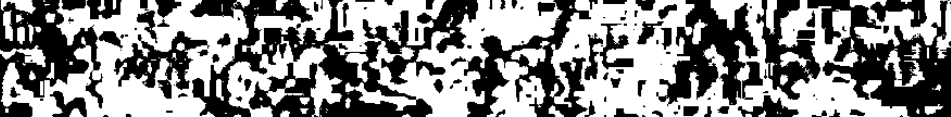

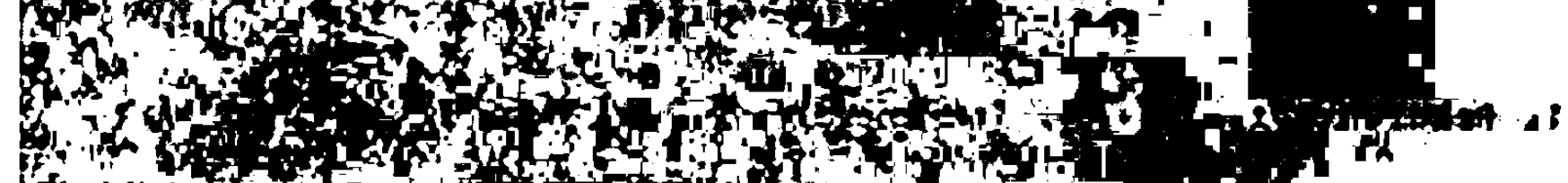

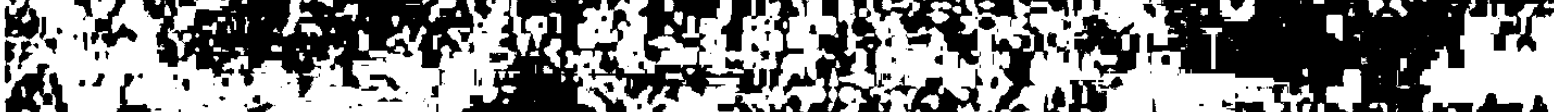

36.

Fis

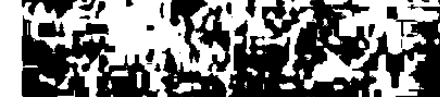

this

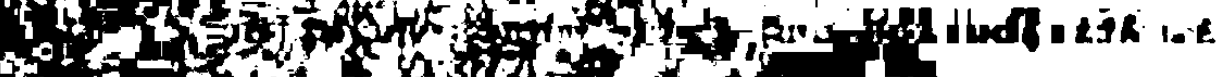

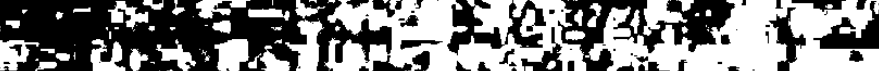

tof

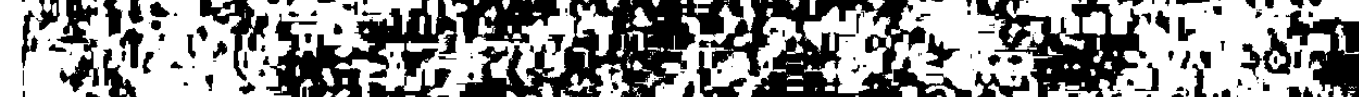

;

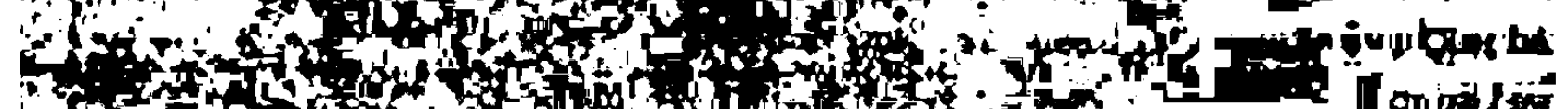

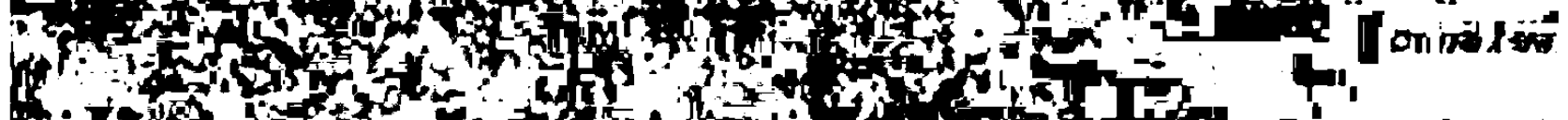

ifor

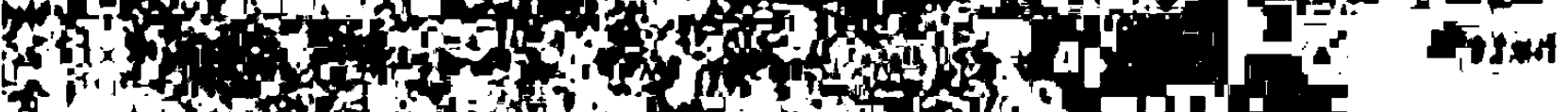

(4)

1.

first

15.

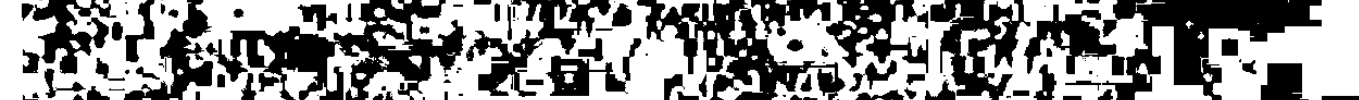

le

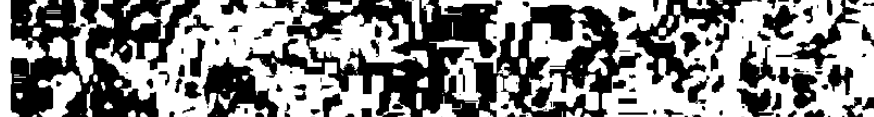

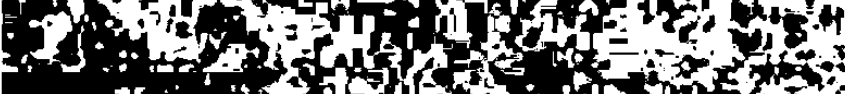

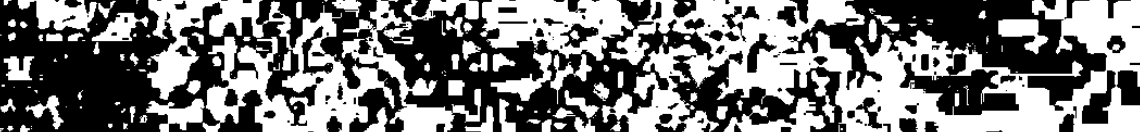

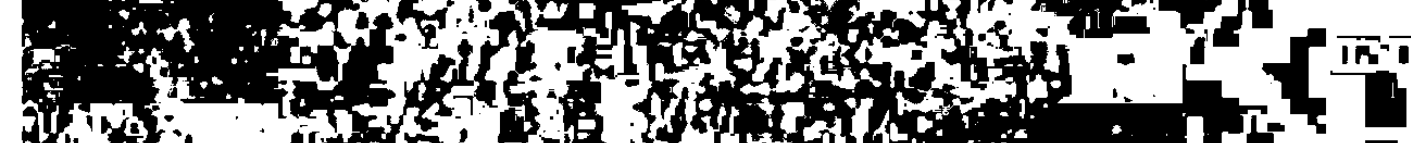

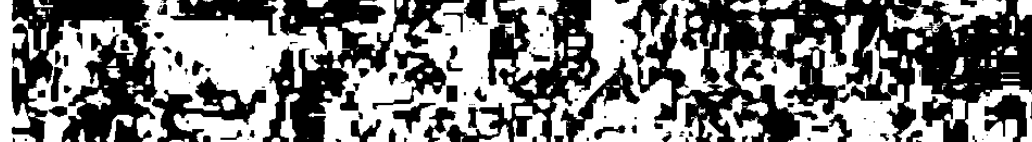

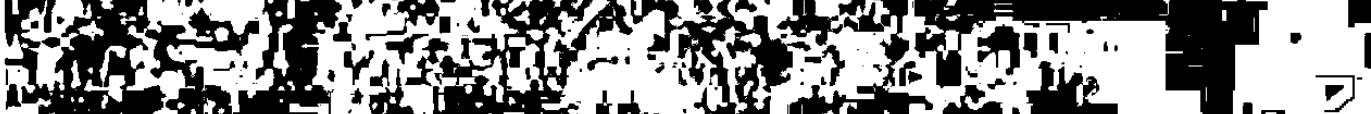

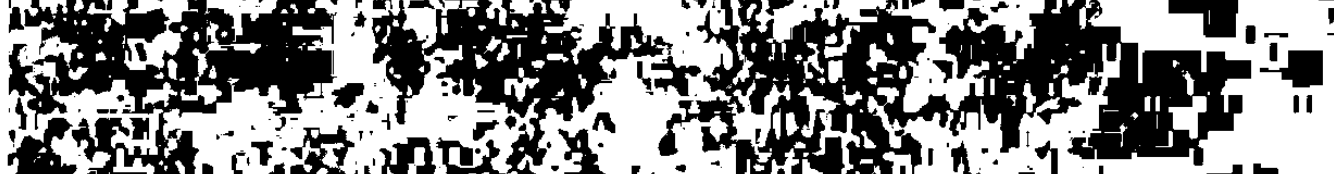

6he 
Prädikatmotivierende Attribution

Gegenstand dieser Untersuchung sind die Beziehungen zwischen Attribut bzw. Attributen und Prädikat eines Satzes $s_{i}$ (ein Sonderfall liegt vor, wenn das Attribut $z u s_{i}$ und das Prädikat $z u s_{j}$ gehört, und vice versal. Einen ersten versuch, diese Beziehung $z u$ beschreiben, habe ich in dem Aufsatz "Motivationelle Restriktionen" [2] unternommen. Dabei habe ich gezeigt, daß die setzung von Attributen in einem gegebenen satz nicht nur von selektionalen Restriktionen, sondern vor allem auch von dem sich aus der Konkurrenz mit dem Prädikat ergebenden Restriktionen abhängt. Diese Restriktionen sind im Gegensatz zu den selektionalen linguistischer Natur. Ich habe in dem oben genannten Aufsatz einen verhältnismäßig aufwendigen Beschreibungsapparat entwickelt, vor allem bin ich davon ausgegangen, daß sich die beobachteten Restriktionen mit Hilfe einer traditionellen Klassifizierung von Adjektiven (Attributen) und Verben (Prädikaten) in genereller Weise formulieren lassen. In dieser Arbeit schlage ich einen anderen weg ein, z.T. aufgrund der Erkenntnis, daß eine Klassifikation der Adjektive und verben/Prädikate nach traditionellen Kriterien in vielen Fällen nicht genügt und andere Klassifikationsmerkmale gesucht werden müssen, z.T. weil ich der Annahme bin, daß im Zentrum der Problematik die Begriffe "Kausalität" und "markiertes Verb/prädikat" stehen.

Ich werde deshalb folgendermaßen vorgehen:

Es werden zunächst einige überlegungen zum Begriff "Kausalität", speziell zur Begründbarkeit von Handlungen und dem status von Begründungen, angestellt, dann werden neben dem Begriff "markiertes prädikat" die Begriffe "prädikatmotivierend", "Objekt-" und "Subjektattribution" eingeführt. Im zweiten Teil werden dann die Motivationsbeziehungen bei einer Reihe von Prädikaten bzw. Situationen an konkreten Beispielen untersucht.

\section{Kausalität/Motivation}

Ich gehe davon aus, daß für bestimmte versprachlichte Sachverhalte eine Begründung für das Gegebensein. Ablaufen an sich oder unter bestimmten Umständen, angegeben werden kann, wenn- 
gleich diese nicht in jedem Fall bereitgestellt werden muß, während für andere Sachverhalte Begründungen nicht möglich sind oder, weil für die Kommunikation keine Rolle spielend, als unangebracht empfunden werden. Man kann deshalb von drei Grundsituationen ausgehen:
a) weil Sachverhalt $t_{i}\left(=S v_{i}\right)$, deshalb Sachverhalt $t_{j}\left(=S v_{j}\right)$,
b) (weil $s v_{i}$ ) (deshalb) $s v_{j}$ '
c) es gibt keinen $\mathrm{Sv}_{i} \mathrm{zu} S v_{j}$.

Fall a) besagt, daß in einem gegebenen Text/Kontext für $S v_{j}$ eine kausale/motivierende vorgeschichte angegeben wird. Sv beseitigt in diesem Fall einen Teil der Vagheit in bezug auf die Umstände von $S v_{j}$. Die Versprachlichung des kausal-motivierenden $\mathrm{Sv}_{i}$ kann auf die unterschiedlichste Weise erfolgen: explizit, mit Hilfe entsprechender Konjunktionen, implizit durch eine entsprechende textuelle Abfolge von Sachverhalten durch Gerundialkonstruktionen, durch die setzung von Attributen bzw. durch andere Mittel. Allen impliziten Mitteln ist gemeinsam, daß sie nicht zwangsläufig im Sinn einer kausal-motivierenden Beziehung interpretiert werden müssen, sondern daß sie mehr oder minder unverbindlich sein können. Daraus ergibt sich, daß der Begründungsstatus von $\mathrm{Sv}_{i}$ in semantisch-logischer bzw. sachverhaltstheoretischer sicht wesentlich klarer sein muß als der von $S_{i}$ bei explizit versprachlichtem Kausalgefüge. Vgl.

(1) Der hungrige Schriftsteller verabschiedete sich.

(2) Der Schriftsteller verabschiedete sich, weil er hungrig war.

Hier ein paar Beispiele für die verschiedenen Möglichkeiten von a).

(3) Galina But'ko pošla rabotat' $v$ tjur'mu potomu, čto ej do étogo ne povezlo $v$ torgovle i na železnodorožnom transporte.

(4) Nebol'šaja komnatka ... pokazalas' emu sovsem krošečnoj iz-za ogromnogo pis'mennogo stola. 
(5) Spektakl' ne ponravilsja Konstantinu Nikolaevič. vpečatlenie bylo takoe, budto vse masterstvo režissera ušlo na svetovye éffekty, na gromozdkuju i vyčurnuju butaforiju.

(6) Nesmotrja na gorjačee vremja, Kornilovu prišlos' ešč na den' vyechat' $v$ Moskvu $v$ ministerstvo. Tam davno uže bylo zaplanirovano soveščanie po obmenu opytom.

[ Hervorhebungen und Auslassungen hier und im folgenden, wenn nicht anders gekennzeichnet, von mir.]

Für die Beispiele (5) und (6) können Kausalgefüge angenommen werden. Dies ist aber keineswegs zwingend.

Fall b) besagt, daß für $S v_{j}$ jederzeit ein verursachender Sachverhalt, sei er auch ziemlich trivial, gefunden werden kann. Sv $_{i}$ wird in diesem Fall entweder ohne textuelle Notwendigkeit oder aufgrund einer textuellen Notwendigkeit nicht realisiert. $\mathrm{Vgl}$.

(7) Mužčina stojal spinoj, no Igor' Vasil'evič uznal ego.

(8) Soglašatelej Igor' Vasil'evič bojalsja.

(9) Bol'še drugich nervničal vtoroj sekretar'obkoma Chochlov.

(10) On zametil, čto Mila, prežde čem vyjti iz-za stola, nalila sebe kon'jaku i vypila zalpom.Vyjdja iz kabineta administratora, ona vzjala Konstantina Nikolaeviča pod ruku.

Für die Aussagen (7) bis (9) kann zweifellos eine motivierende Begründung gefunden werden (bei (7) - woran erkennt er ihn?, bei ( 8 ) - warum fürchtet er Kompromißler?, bei (9) - warum wird er nervös?), allerdings ist wenigstens bei (9) ein allwissender Autor anzunehmen, andernfalls kann die Begründung nur als Vermutung geäußert werden. Beispiel $(10)$ ist dadurch charakterisiert, daß die Abfolge bzw. Gleichzeitigkeit der Handlungen zwar begründet werden kann, im gegebenen Kontext aber uberhaupt keine Notwendigkeit für die Explikation der Handlungsursachen zu erkennen ist.

Fall c) schließlich besagt, daß es $z u S_{j}$ keinen verursachenden Sachverhalt Sv ${ }_{i}$ gibt, zumindest keinen, der ohne Spitz- 
findigkeiten akzeptierbar wäre.

Wann liegt diese situation vor? Sehen wir uns dazu einige deutsche Beispiele an:

(11) Auf dem Bahnhof sah Hans plötzlich ein junges Mädchen vor sich.

(12) Hans kennt Anna seit Jahren.

(13) Hans ist jetzt in der achten Klasse.

(14) Hans ist ein kluger Bursche.

Der in (11) dargestellte Sachverhalt läßt eine weil-Begründung nicht $z u$, auch keine entsprechende Frage:

(111) * Warum sah Hans plötzlich auf dem Bahnhof ein junges Mädchen vor sich?

Diese Frage ist zumindest aus der Sicht von Hans unmotiviert, darauf weist auch das Adverb plötzlich hin.

Auch (12) läßt keine motivierende Begründung $2 u$ :

(12' * Warum kennt Hans Anna seit Jahren?

Ich schließe hier den Fall der besonderen Betonung der Temporalangabe aus, denn diese kann einen weil-Satz motivieren.

Für (13) ist nur dann ein begründender Sachverhalt plausibel, wenn die Aussage "ist jetzt in der achten Klasse" ein nicht normaler, erwartbarer zustand für Hans ist, sei es, daß er zu jung, sei es, daß er zu alt dafür ist.

(13') Hans ist jetzt in der achten Klasse, weil er ein Jahr krank war

- Hans ist jetzt in der achten Klasse, weil er die siebte uibersprungen hat.

Bei (14) ist die Situation etwas anders, obwohl es auf den ersten Blick ein nicht begründbarer Sachverhalt $z$ u sein scheint. Aber es ist ohne weiteres möglich, zu fragen:

(14') Warum ist Hans klug? (= wie kommt der Sprecher zu dem Urteil "klug" in bezug auf Hans?)

Die Antwort darauf kann lauten:

(14") Weil Hans sich so und so verhalten hat.

Es geht hierbei um die Feststellung einer aktualen Eigenschaft. 
Bei konstanten Eigenschaften bzw. Merkmalen wie groß ist eine analoge Begründung nicht möglich. Allerdings ist es denkbar, daß ein Satz wie

(15) Hans ist ein großer Bursche, mit dem Hinweis auf Erbanlagen begründet wird.

(15') Hans ist ein großer Bursche, weil auch seine Eltern sehr groß sind.

Dieses Beispiel zeigt, daß über die Zulässigkeit bzw. Nichtzulässigkeit von begründenden Sachverhalten die konkrete Bedeutung der Aussage und der konkrete Kontext eine wichtige Rolle spielen. Wenn der Sachverhalt von (15) beispielsweise aufgrund einer Beobachtung geäußert wird, etwa in der folgenden Form:

(15') Hans erwies sich als ein großer Bursche, dann ist eine Begründung in Form von (15') nicht akzeptabel.

Sehen wir uns nun noch Beispiel (16) an, das eine gewisse Ähnlichkeit $2 u(10)$ aufweist.

(16) Anna verabschiedete sich und zog ihren Mantel an. Dieser Satz beschreibt eine Sequenz von Handlungen, die bei entsprechenden kontextuellen Bedingungen sozusagen in einem natürlichen Zusammenhang stehen. Eine motivierende Begründung für den koordinierten Satz zog ihren Mantel an ist nicht notwendig und auch schwerlich zu geben:

(16. * ... und 20 g ihren Mantel an, weil es draußen sehr kalt war.

Diese Begründung würde voraussetzen, daß Anna bei ihrer Ankunft beim Gastgeber den Mantel auf dem Arm hatte (weil es zu diesem Zeitpunkt sehr warm war), oder daß sie normalerweise nie Mäntel anzieht, auch wenn sie bei Besuchen immer einen dabei hat usw. Wie immer, die Rekonstruktion eines plausiblen Begründungszusammenhangs würde auf jeden Fall einen besonderen, von dem von (16) abweichenden, Kontext erforderlich machen.

Ganz anders sieht es bei dem Vorderkonjunkt aus. Der Sachverhalt "Anna verabschiedete sich" kann problemlos in einen Bedeutungszusammenhang eingebaut werden. 
(16') Anna verabschiedete sich,

$$
\left\{\begin{array}{l}
\text { weil sie müde war } \\
\text { weil sie es eilig hatte } \\
\text { weil sie hungrig war } \\
\text { usw. }
\end{array}\right.
$$

Welche Begründung im konkreten Fall vernünftig ist, hängt vom Kontext ab.

Ich habe das Problem der motivierenden Begründung von Sachverhalten etwas ausfühlicher, wenngleich keineswegs erschöpfend besprochen, weil es für unser Hauptproblem, die Erforschung des Vorkommens oder Nichtvorkommens von Attributen, eine zentrale Rolle spielt.

Nicht minder wichtig ist die ergänzende Frage danach, welcher Sachverhalt als begründender Sachverhalt für $S v_{j}$ angesehen werden kann, inwieweit objektive kriterien gefunden werden können oder nicht. Ich will vorwegschicken, daß ich hier keine Begründungstheorie entwickeln will, sondern daß es mir vor allem darum geht, eine gewisse Grundlage für die Beurteilung der Plausibilität bzw. Nichtplausibilität von Begründungen zu schaffen. Es ist im Einzelfall oft recht schwierig, beispielsweise bei naturwissenschaftlichen Phänomenen, vom Laienstandpunkt aus, zu entscheiden, ob ein bestimmter Sachverhalt als Begründung für einen anderen Sachverhalt dienen kann. In anderen Fällen scheint eine Entscheidung davon abhängig gemacht werden $z u$ müssen, wie viele Voraussetzungen für das Eintreffen einer potentiellen Begründung angenommen werden müssen.

Ich will versuchen, die Problematik an einigen einfachen Beispielen zu verdeutlichen. Sehen wir uns folgende sätze an:

(17) Es schneit.

(18) Die Mosel hat Hochwasser.

(19) Traben-Trarbach wird überschwemmt.

Mögliche Begründungen für einzelne Aussagen könnten sein:

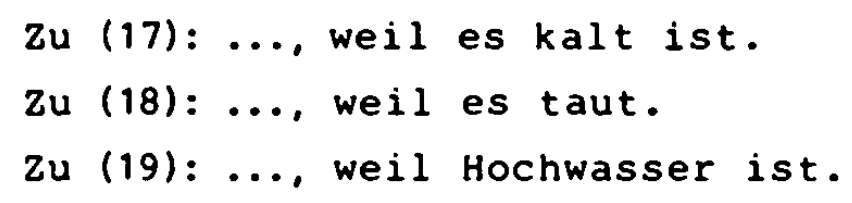

In allen drei Fällen ist die Begründung zwar hinreichend, aber keinesfalls erschöpfend, da die genannten Phänomene wesentlich 
komplexer sind, und deshalb eine Reihe von weiteren in unseren Beispielen nicht genannten Bedingungen erfült sein müssen, bevor der angegebene Zusammenhang zwischen den jeweiligen Ereignissen tatsächlich zutrifft. Trotz der Unvollständigkeit der Angaben sind wir offensichtlich in der Lage, $z u$ entscheiden, ob die durch weil signalisierte Begründung tatsächlich eine Begründung ist. Dies hängt mit unserem Wissen von der Welt zusammen. Allerdings ist dieses wissen von der welt alles andere als zuverlässig, so daß wir in vielen Fällen nicht zu sicheren Entscheidungen kommen. Dieses problem läßt sich mit Hilfe einer Umbildung unserer Beispiele verdeutlichen. Ich vertausche dazu die Begründungen:

(17') *Es schneit, weil es taut.

$(17)^{\star}$ *Es schneit, weil Hochwasser ist.

Während es vermutlich den meisten Menschen einleuchtet, daß die in (17') und (17') angegebenen Begrüdungen nicht akzeptabel sind, ist eine ähnliche übereinkunft bezüglich der folgenden Umbildungen nicht zu erreichen:

(18') ?Die Mosel hat Hochwasser, weil es kalt ist.

(191) ? Traben-Trarbach wira überschwemmt, weil es kalt ist.

Die Schwierigkeiten, die sich hier und vielleicht noch stärker be $i$ anderen Beispielen ergeben, sind darauf zurückzuführen, daß einerseits der kausale Zusammenhang zwischen den jeweiligen Ereignissen nicht ganz klar ist, und andererseits bei dem einen oder anderen Sprecher bzw. Hörer die Ursachen für Hochwasser und überschwemmung nicht oder nur vage bekannt sind. Während (18) und (19) noch auf relativ bekannte Sachverhalte referieren, gibt es wesentlich weniger vertraute Naturerscheinungen, bei denen damit $z$ u rechnen ist, daß ihr Entstehen den meisten Menschen unbekannt ist. Die Akzeptabilität von Begründungen ist in diesem Falle meist nicht diskutierbar.

Wenden wir uns jetzt einem anderen Typ von Sachverhalt $z$, und zwar einer Handlung:

(20) Hans verläßt den Saal.

Für diesen Sachverhalt lassen sich eine Reihe von Begründungen 
anführen :

(20'a) Hans verläßt den Saal, weil inm schlecht ist.

(20'b) Hans verläßt den Saal, weil er Angst hat.

(20'c) Hans verläßt den Saal, weil er hungrig ist.

(20'd) Hans verläßt den Saal, weil er klug ist.

(20'e) Hans verläßt den Saal, weil er blond ist.

Ich habe diese Sätze entsprechend dem Grad ihrer Plausibilität geordnet. Diese kann man danach beurteilen, ob die suggerierte Begründung aus sich heraus verständlich ist oder ob sie zusätzlicher Ausführungen bedarf, bevor ihr Zusammenhang mit dem begründenden Sachverhalt keinem Zweifel mehr unterliegt. D.h. für die Sätze $\left(20^{\prime}\right.$ a) bis $\left(20^{\prime} \mathrm{c}\right)$ sind weitere Erklärungen nicht notwendig, während für die beiden letzten unbedingt zusätzliche Informationen gegeben werden müssen. Der Kontext für $\left(20^{\prime} \mathrm{d}\right)$ und $\left(20^{\prime} \mathrm{e}\right)$ ist in jedem Fall aufwendiger. Wir haben hiermit ein gewisses Kriterium zur Beurteilung der Begründungskraft von Aussagen, vor allem dann, wenn rekonstruierte Kontexte mit tatsächlich gegebenen konfrontiert werden.

Ich will nun noch auf einen anderen Typ von Begründung kurz eingehen. Dazu ersetze ich das vorderkonjunkt von (20') durch "Hans liest ein Buch". Wir erhalten dann folgende Varianten:

(21a) Hans liest ein Buch, weil es inm schlecht ist.

(21b) Hans liest ein Buch, weil er Angst hat.

(21c) Hans liest ein Buch, weil er hungrig ist.

(21d) Hans liest ein Buch, weil er klug ist.

(21e) Hans liest ein Buch, weil er blond ist.

Im Unterschied $z u$ den Varianten von $\left(20^{\prime}\right)$ ist auf den ersten Blick keine Begründung aus sich heraus verständlich. Bei genauerer Betrachtung zeigt sich aber, daß für die Sätze (21a) bis (21c) eine "immer wenn-"Beziehung angenommen werden muß. (21a) läßt sich dann wie folgt interpretieren: "Immer, wenn ihm schlecht ist, liest Hans ein Buch."

Diese Begründung ist offensichtlich nicht mehr allgemeiner Natur. 
Auch (21d) ist nicht problemlos, und es bedarf eines großen kontextuellen Aufwands, um ihn sinnvoll interpretieren $2 u$ können. Ich verzichte darauf, den erforderlichen Kontext zu rekonstruieren.

Für (21e) scheint es innerhalb eines vernünftigen Rahmens keinen Kontext zu geben, d.h. wir würden sagen, daß der zweite Sachverhalt den ersten nicht begründet. (21e) ist somit inakzeptabel. Wie dieses Beispiel zeigt, kann diese Inakzeptabilität nicht auf logischer Basis ermittelt werden (Ausnahmen stellen Antonymien jeder Art dar), sondern aufgrund der Unmöglichkeit, mit einem vertretbaren Aufwand einen Kontext zu rekonstruieren bzw. aufgrund der Unvereinbarkeit von rekonstruiertem und tatsächlich gegebenem Kontext. Diese Entscheidungsgrundlage ist m.E. breit genug, um einen Konsens darüber zu er-

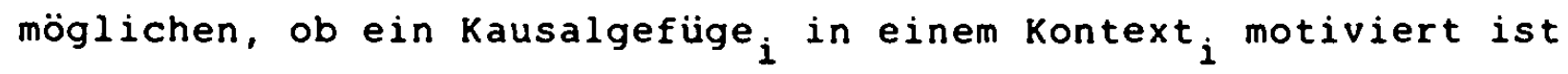
oder nicht. Wenn dies so ist, dann haben wir eine gute Möglichkeit, willkürlich gebildete Kausalgefüge in einem gegebenen Kontext auf ihre Akzeptabilität hin zu überprüfen und Aussagen über mögliche und nicht mögliche Begründungen zu machen.

\section{Prädikatmotivierend}

Gegeben sei ein Satz $S_{i}$ mit dem Prädikat $P_{i}$. Gegeben sei weiterhin ein weiteres Element in $S_{i}$, das einen Grund für die verwendung des Prädikats nennt. Die Beziehung zwischen dem weiteren Element und $P_{i}$ soll prädikatmotivierend heißen.

\section{Markiertes Verb/Prädikat}

Es ist nicht ganz einfach, diesen Begriff zu explizieren, aber ich glaube, daß durch die Gegenüberstellung von markierten und nicht markierten Verben eine Vorstellung davon vermittelt werden kann, was Markiertheit in diesem zusammenhang bedeutet. In der a)-Spalte werden markierte verben, in der b)Spalte unmarkierte aufgefüht:

a)

$\begin{array}{lll}\text { schenken } & : & \text { geben } \\ \text { humpeln } & : & \text { gehen } \\ \text { hinzerren } & : & \text { hinbringen } \\ \text { anbrüllen } & : & \text { sagen } \\ \text { usw. } & & \end{array}$


Die Verben der linken Spalte sind semantisch komplexer, sie enthalten die Bedeutung der Verben aus der b)-Spalte als Grundbedeutung. $\mathrm{zu}$ dieser Grundbedeutung kommt noch ein weiteres Merkmal hinzu, das auf eine spezifische Durchfürung dieser Handlung hinweist:

\begin{tabular}{|c|c|c|c|c|}
\hline schenken & $=$ & "geben" & + & psych. zust.] \\
\hline humpeln & $=$ & "gehen" & + & behindert ] \\
\hline hinzerren & $=$ & "hinbringen" & + & widerstand] \\
\hline nbrüllen & $=$ & "sagen" & + & psych. \\
\hline
\end{tabular}

Die angegebenen Merkmale dienen nicht der exakten Bedeutungsbeschreibung, sondern sollen verdeutlichen, daß die von den Verben der a)-Spalte bezeichnete Handlung in bestimmter Weise markiert ist und deshalb eher als die der rechten spalte einer Erläuterung bzw. einer Motivation bedürfen. Ein Satz wie Fritz zerrt seine Frau in die Küche ist ohne weitere Angaben nicht ganz verständlich, wenn man davon ausgeht, daß Ehemänner ihre Frauen normalerweise nicht irgendwohin zerren. Unter Markiertheit, für die der jeweilige kontext von Bedeutung ist, verstehe ich also eine Eigenschaft, die in mehr oder minder hohem Umfang eine begründende Erläuterung fordert. Diese Erläuterung kann auf ganz unterschiedliche Weise erfolgen, u.a. auch durch die verwendung von Attributen. Und dies ist das eigentliche Phänomen, das uns hier interessiert.

Objekt-und subjektattribution

Diese Begriffe sind eigentlich aus sich heraus verständlich. Bisher ist allerdings diese Unterscheidung nicht getroffen worden, da eine Notwendigkeit dafür nicht vorzuliegen schien. Subjektattribution bedeutet also Attribution des subjekts, Objektattribution Attribution des objekts bzw. der objekte, darunter sollen der Einfachheit halber auch Umstandsbestimmungen fallen.

wie ich noch zeigen werde, spielen die syntaktischen Positionen eine wichtige Rolle für die setzung von prädikatmotivierenden Attributen.

Von den Attributen werden hier nur adjektivische Attribute berücksichtigt, und zwar nur solche, die fakultativ auftreten. 
Epitheta ornantia, die keine aktuelle Beschreibungsleistung erbringen, bleiben dabei außerhalb der Betrachtung.

\section{Prädikatsklassen}

Das Phänomen, um das es in dieser Arbeit geht, sei kurz an drei Beispielsätzen aufgezeigt:

(22) Der hungrige Hans stahl ein Stück Brot.

(23) Der blonde Hans stahl ein Stück Brot.

(24) Der häßliche Hans stahl ein Stück Brot.

Die drei Beispiele unterscheiden sich druch den Grad ihrer Akzeptabilität, der offensichtlich durch die adjektivischen Attribute beeinflußt wird, da sonst nichts an den sätzen verändert wurde. In (22) ist ein motivierender Bezug zwischen dem Attribut hungrig und dem Prädikat stahl (ein stück Brot) festzustellen. D.h., (22) läßt sich auch mit Hilfe einer Kausalkonstruktion wiedergeben:

"Weil Hans hungrig war, stahl er ein Stück Brot."

Eine ähnliche Beziehung ist bei den Beispielen (23) und (24) nicht $z u$ beobachten, es ist vielmehr so, daß blond und häßlich in abnehmendem Maße unmotiviert erscheinen.

Die zentrale Frage dieser Arbeit lautet somit: Wie regulär sind diese Restriktionen und wie können sie bezeichnet werden. Ich habe oben angedeutet, daß offensichtlich ein enger Zusammenhang zwischen Verb/Prädikattyp und Adjektivklassen besteht. Es erscheint mir deshalb sinnvoll, zunächst die schon getroffene Unterscheidung von Prädikaten, die eine Begründung fordern können, und Prädikaten, die keine Begründung/Motivierung fordern können, beizubehalten: $P_{\text {mot }}$ und $P$. Diese Unterscheidung ist allerdings von noch so allgemeiner Natur, daß über mögliche Korrelationen von Prädikats- und Attributsklassen nichts ausgesagt werden kann. Der nächste Schritt besteht somit darin, für beide Typen von Prädikaten, vor allem aber für $P_{\text {mot. Subklassen }}$ zu finden, für die konkrete Restriktionen formuliert werden können. Diese Forderung ist beim gegenwärtigen Forschungsstand nur unvollkommen zu erfüllen, und so begnüge ich mich vorerst 
mit der Aussonderung einzelner Subklassen. Eine Klassifizierung der Adjektivattribute wird erst in bezug auf konkrete prädikatsklassen versucht.

Einer Untersuchung der motivier-bzw. begründbaren Prädikate geht eine Behandlung der nichtmotivierbaren voraus. Ich beginne deshalb mit letzterer, hier mit $P_{0}$ abgekürzt.

Nach einer ersten Analyse enthält $p_{0} u_{. a}$. folgende Subklassen :

Po1: Prädikate des Erscheinens bzw. der Existenz.

$P_{\circ 2}$ : Prädikate, die Besitz anzeigen.

$P_{03}$ : Prädikate der sinnlichen Wahrnehmung.

Die letzte Subklasse ist zunächst nur vorläufiger Natur.

Die folgenden Beispiele betreffen im wesentlichen $\mathrm{P}_{01}$ :

(25) Krome nego i prijatelej, v zale bylo eše mnogo gostej: dva pechotnych oficera, kakoj-to sedoj $i$ lysyj gospodin $v$ zolotych oxkach, dva bezusych studenta iz ... i ox̌en' p'janyj čelovek s akterskim licom.

(26) Zamok ščelknul, i dver' priotkrylas'. Demin uvidel pered soboj polnuju nizkorosluju ženščinu s dlinnymi volosami.

(27) Na zadnem plane, ¿ut' ne v fokuse, iz-za stolika privstal plotnyj mužcina. [Es geht um eine Fotografie]

(28) Podošel molodoj ... ox̌n' smuglyj mužčina.

(29) I vot nakonec Fedor Pavlovic pljuchaetsja v kreslo u stola, za kotorym sidit blagoobrazno lysovatyj chorošo otglažennyj mužčina.

(30) Anna Petrovna ožidala pojavlenija pis'monosca simocki ... a na poroge okazalsja zdoroven'kij molodoj brjunet.

(31) Michail otpravilsja v mériju, i tam tščedušnyj staren'kij činovnik soobščl emu, čto ...

Es bereitet keine Schwierigkeiten, die in diesen Beispielen 
vorkommenden Prädikate den drei angeführten Subklassen zuzuordnen. Lediglich Beispiel (31) scheint eine Ausnahme zu machen. Bei genauer Betrachtung zeigt sich aber, daß es sich bei tščedušnyj staren'kij X̌inovnik um einen indefiniten Ausdruck handelt, was darauf hinweist, daß die damit bezeichnete Person neu in den Text eingefüht wird, was wiederum einer Existenzaussage gleichkommt.

Ich habe bewußt hier nur solche Beispiele angefürt, die ein attribuiertes Nomen enthalten. Es geht mir damit darum, zu zeigen, daß nichtmotivierbare Prädikate die Verwendung von Attributen nicht ausschließen, sondern in ganz bestimmter weise restringieren. Welche Adjektivattribute mit $P_{0}$-Prädikaten gemeinsam auftreten können, sei mit Hilfe einer Ersetzungsoperation ermittelt. Eingesetzt werden sollen folgende Adjektive:

skromnyj, ljubeznyj, ironičnyj, dovol'nyj, serdityj, derzkij, akkuratnyj, umnyj.

Bei (25) beschränke ich mich auf die zweite Phrase:

(25') ...v zale bylo ešče mnogo gostej: dva pechotnych oficera, kakoj-to

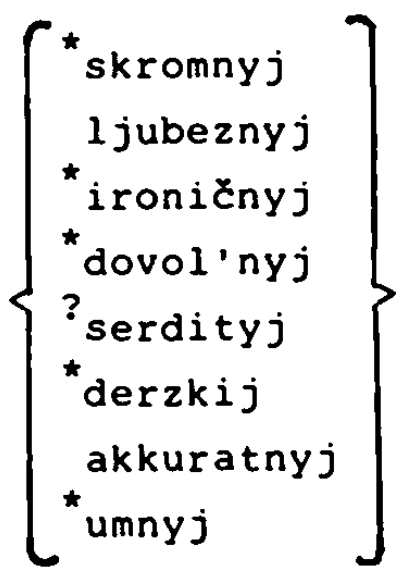

gospodin ...

Für die als nichtakzeptabel markierten Attribute gilt, daß sie allesamt auf nicht direkt beobachtbare Eigenschaften bzw. Merkmale referieren. Die Nichtbeobachtbarkeit dieser Merkmale gerät in Konflikt mit der Existenzaussage des Satzes. Für die ubrigen Attribute gilt, daß die von ihnen bezeichneten Merkmale auf den ersten Blick wahrgenommen und deshalb bei der vorstellung einer Person auch zur Beschreibung herangezogen werden können. An der Grenze der Akzeptabilität stehen dabei 
ljubeznyj und serdityj.

Die gleiche Einsetzungsoperation ergibt bei (26), daß allenfalls ljubeznyj und akkuratnyj zulässig sind. Serdityj käme grundsätzlich auch in Frage, aber da serdityj eine beobachtbare gegen eine zweite Person (?) gerichtete Eigenschaft bezeichnet, erscheint dieses Attribut bei dieser Momentaufnahme relativ unmotiviert.

Die Akzeptabilität der Attribute aus unserer Liste wird in (27) noch dadurch erschwert, daß hier von einer Fotografie die Rede ist, auf der die geschilderte Person nur schlecht zu sehen ist. Keines unserer Attribute scheint voll akzeptabel zu sein.

Die Varianten (28) und (29) erlauben die verwendung von ljubeznyj. serdityj und akkuratnyj, während (30) darüber hinaus auch noch skromnyj und derzkij möglich erscheinen läßt, unter der voraussetzung, daß der nachfolgende Dialog eine Begründung nachliefert.

Für (31) scheint die setzung von ljubeznyj und akkuratnyj problemlos $z u$ sein, allerdings spielt hier der Inhalt der Mitteilung des Beamten eine Rolle. Er könnte auch umnyj motivieren. Umnyj erwiese sich dann ebenfalls als eine beobachtbare, weil erschließbare Eigenschaft.

Diese Beispiele mögen als Beleg für $P_{\circ}$ genügen. Sie zeigen, wenn man die Ausgangssätze mit den modifizierten vergleicht, daß $P_{0}$ grundsätzlich nur solche Adjektive als Attribute zuläßt, die auf beobachtbare oder aus dem Verhalten erschließbare Merkmale von Menschen referieren; auf die Verhältnisse bei unbelebten Gegenständen komme ich noch zu sprechen.

Dies ist eine Regel. Allerdings scheint es Fälle zu geben, die dieser Regel widersprechen. Vgl.

(32) In der Bank war ein dummer Beamter.

(33) Leider kam der dumme Hans wieder zurück.

(32) enthält eine Existenz-Aussage, (33) ein Prädikat des Erscheinens, das in einer Motivationsbeziehung zum Attribut steht. Diese Interpretation ist nur zum Teil richtig. Die Existenzaussage in (32) ist nicht im Sinn eines plötzlichen Erscheinens eines Gegenstandes $2 \mathrm{u}$ interpretieren, sondern sie 
erfaßt einen bestimmten Zeitraum. Dieser Zeitraum erlaubt die Beobachtung der Eigenschaft dumm, so daß die setzung dieses Attributs in (32) durchaus akzeptabel ist.

Auch (33) muß differenzierter betrachtet werden. Es handelt sich bei wieder zurückkehren eigentlich nicht um ein Prädikat des Erscheinens, sondern um ein markiertes Handlungsprädikat. Als solches kann es über den definiten Gegenstand Hans eine Motivationsbeziehung zum Attribut von Hans eingehen. Ersetze ich wieder zurückkommen durch erscheinen und leider durch plötzlich, dann erhalte ich allerdings eine ErscheinenAussage, in der das Attribut dumm nur ein Epitheton ornans darstellt.

Ein wichtiges Ergebnis der Betrachtung der Attribution in Verbindung mit $P_{0}$ ist, daß wir zwei Adjektiv-subklassen in bezug auf das Merkmal [beobachtbar] unterscheiden müssen:

Kl 1: Adj [+ beobachtb. ]

K1.2: Adj [- beobachtb.]

wie wir gesehen haben, ist das Merkmal [beobachtbar] recht weit faßbar.

Die Attributionsbedingungen bei $P_{0}$ in Verbindung mit unbelebten Gegenständen unterscheiden sich wenig von denen mit belebten Gegenständen. Darüber hinaus gilt, daß es ohnehin nur wenig Adjektivattribute gibt, die nichtbeobachtbare Merkmale von unbelebten Gegenständen bezeichnen. Selbst Adjektive wie deševyj, dorogoj können aufgrund von Beobachtungen Gegenstandsbezeichnungen zugeordnet werden. Ein paar Beispiele:

(34) Pis'mennyj stol stojal v dal'nem ot dveri uglu. Dve steny byli sploš' v knižnych stellažach, ot pola do potolka. staryj. vytertyj divan, nakrytyj pledom, zanimaet temnyj ugol u dveri.

(35) Byla u nego tam polovina okna, knižnyj škaf i nebol'šj stol.

(36) Rozoven'koe, sitcevoe, vpervye nadetoe plat'ice dulos' na svežem vetru.

Alle in diesen sätzen vorkommenden Attribute bis auf eines referieren auf beobachtbare Gegenstandsmerkmale. Die Ausnahme 
stellt vpervye nadetoe dar. Dieses Attribut kann nur gesetzt werden, wenn folgende Bedingung erfüllt ist: Der Produzent des Satzes (36) hat ein besonderes Verhältnis zu dem subjektgegenstand, er kennt ihn. Insofern handelt es sich bei (36) nicht um eine einfache Existenzaussage, die allein auf der Möglichkeit der Beobachtung basiert, sondern um eine Aussage, die ein Bekanntsein mit dem Gegenstand impliziert. Dies ist die entscheidende Bedingung für die Setzbarkeit von Adjektiven, die auf nichtbeobachtbare Merkmale referieren.

Einen besonderen Fall stellt noch (35) dar. Im Gegensatz etwa zu (34) können keineswegs alle für diesen Gegenstand in Frage kommenden "beobachtbaren" Adjektive gesetzt werden:

(35') Byla u nego tam polovina okna, knižnyj škaf i

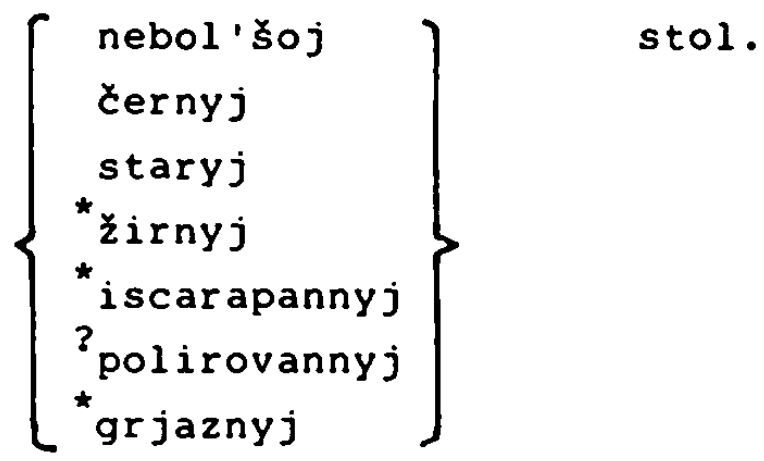

Die Nichtakzeptabilität dieser Attribute hängt offensichtlich damit zusammen, daß sie mit der Prädikatsbedeutung nicht vereinbar sind. Das Prädikat zeigt nicht nur eine Existenz, sondern auch einen Besitz an. Besitz-Prädikate lassen aber nur solche Attribute $z u$, die beim Erwerb und Verkauf von Gegenständen eine Rolle spielen und nicht lediglich aktuelle zustände der Gegenstände widerspiegeln. Man kauft eben normalerweise keinen zerkratzten Tisch, geschweige denn einen schmutzigen.

Es scheint aufgrund dieser Beobachtung sinnvoll, die BesitzPrädikate als eine Sondergruppe $z u$ behandeln und sie nicht mit den Existenz- und Erscheinen-Prädikaten in einen Topf $z$ u werfen.

Wie wir gesehen haben, ist es häufig nicht ganz einfach, reine Existenz- und Erscheinen-Prädikate $z u$ isolieren, denn vielfach überlagern sich die Bedeutungen und ein Verb bzw. Prädikat kann oder muß mehreren verschiedenen Klassen zugeordnet werden. Sobald sich solche überlagerungen feststellen lassen, 
müssen wir mit Motivationsbeziehungen zwischen Attribut und Prädikat rechnen. Dies trifft beispielsweise auf Prädikate $z u$, die eine lokale Existenz bezeichnen. Die Angabe einer Lokalität kann Ausdruck einer Markiertheit sein, die hier einfach die Möglichkeit von Alternativen beinhaltet. Im einzelnen entscheidet der Kontext. Mit zwei Beispielen möchte ich diesen punkt, der noch einer ausführlichen Untersuchung bedarf, abschließen.

(37) Muzykal'naja škola ... stojala v tenistom pereulke, osenennaja lipami.

(38) Zili oni s mater'ju $v$ gustonaselennoj kommunal'noj kvartire.

Das Prädikat in (37) hat eine rein lokale Aussage zum Inhalt. Dies bedeutet, daß der von tenistyj bezeichnete Umstand der lokalen Existenz vom Subjekt nicht beeinflußbar ist. Eine motivierende Bezeichnung zwischen einem Subjektattribut und der Prädikatsphrase ist nicht möglich. Anders dagegen ist die Situation bei (38). Diese Art lokaler Befindlichkeit ist grundsätzlich beeinflußbar, somit kann bei sätzen dieser Art eine motivierende Begründung für das prädikat nicht ausgeschlossen werden.

\section{Motivierbare Prädikate}

Es ist im Augenblick nicht möglich, dies muß einschränkend vorweggeschickt werden, die Menge der motivierbaren Prädikate in eine endliche Liste von Klassen aufuteilen. Die nachstehende Liste ist deshalb nicht mehr als ein Versuch, die Beschreibung in eine gewisse ordnung $z u$ bringen und überschaubar $2 u$ machen. Die der Systematik zugrundegelegten semantischen Merkmale korrespondieren nur z.T. mit traditionellen Klassifizierungsmerkmalen, da für die $z$ u beschreibenden Restriktionen andere semantische Aspekte eine Rolle spielen. In einigen Fällen war es nicht möglich, bestimmte Typen von Prädikaten für gegebene Motivationsbeziehungen verantwortlich zu machen, als entscheidend erwiesen sich in diesen Fällen bestimmte Handlungskonstellationen. Diese werden gesondert betrachtet. 
Liste der Prädikatstypen:

$P_{1}$ - bezeichnet einen psychischen zustand: byt' žal', žalet', sžalit'sja, ljubit', nedoljublivat', ostavit' tjagostnoe čuvstvo

$P_{2}$ - bezeichnet eine psychische Einwirkung: draznit'

$P_{3}$ - bezeichnet eine erschwerte Handlung: vytaščt' kogo, vyvolakivat', zatalkivat', razognut' nogi

$P_{4}$ - bezeichnet einen unerwünschten Prozeß, einen nichtprognostizierbaren Vorgang: zabuchat', bystro sochnut'

$P_{5}$ - bezeichnet "helfen", "unterstützen": pomogat"

$P_{6}$ - bezeichnet eine physische Einwirkung: bit

$P_{7}$ - bezeichnet einen physischen Zustand: padat' $v$ obmorok, cuvstrovat' sebja neujutno

$P_{8}$ - bezeichnet eine erfolgreiche/nichterfolgreiche Handlung: oprokinut' cajnik, imet' uspech, uspevat'

$P_{9}$ - bezeichnet eine unvermittelte Lautäußerung: kričat'

$P_{10}$ - bezeichnet eine reaktive Bewegung von Körperteilen: terebit', kusat' guby

$P_{11-\cdots}$

-

negierte Prädikate

$\underline{P_{1}}$

Beginnen wir unsere Betrachtung mit folgendem Satz:

(39) Emu bylo nemnogo žal' i samoljubivogo dežurnogo, i prosten'kovatogo milicionera.

Es ist keine Frage, daß die Attribute samoljubivyj und prosten'kovatyj eine motivierende Beziehung zum Prädikat eingehen. Sie haben eindeutig explikativen Charakter, da auch der reduzierte Satz

(39') Emu bylo nemnogo žal' i dežurnogo i milicionera. 
absolut akzeptabel ist und lediglich die Begründung für die Verwendung von žal' offen läßt.

Da die Kausalitätsbeziehung zwischen den Attributen und dem Prädikat nicht explizit ausgedrückt wird, ist das Begründungsangebot der Attribute natürlich nicht zwingend. Es bleibt allerdings kaum eine andere Interpretationsmöglichkeit. Festgehalten sei noch, daß jedes Attribut für sich eine prädikatmotivierende Funktion haben kann, vgl.

- Emu bylo nemnogo žal' samoljubivogo dežurnogo.

- Emu bylo nemnogo žal' prosten'kovatogo milicionera.

In unserem Beispiel wird der motivierende Bezug durch eine Objektattribution geleistet, d.h. es werden Merkmale des vom objekt bezeichneten Gegenstandes für die Begründung in Anspruch genommen. Die zweite Begründungsmöglichkeit fällt für den konkreten Satz aus syntaktisch-kategorialen Gründen aus. Das subjektpronomen ist nicht attribuierbar. Es bleibt dennoch die interessante Frage, ob das subjekt grundsätzlich als Träger von Begründungsmerkmalen ausfällt oder ob es ähnlich wie das objekt als kategoriales Bezugselement genutzt werden kann. Im einzelnen können am Beispiel von (39) folgende Probleme untersucht werden:

1) Subjektattribution und Motivation

2) Objektattribution und Motivation

3) Attribution bei zwei Objekten und Motivation

4) Attribution bei einem von zwei Objekten und Motivation

5) objekt - und Subjektattribution

Beginnen wir mit der Subjektattribution. Dazu bilde ich $\left(39^{\prime}\right)$ wie folgt um:

(39") Parnju bylo nemnogo žal' i dežurnogo i milicionera. Folgende Adjektive sollen als Subjektattribute eingesetzt werden: krasivyj, čestoljubivyj, ustalyj, dobroserdečnyj, sočuvstvennyj, chitryj, molodoj, strojnyj.

Es ist sofort $2 u$ sehen, $d a \beta$ aus dieser liste nur zwei Attribute prädikatmotivierend wirken und ein drittes zwar gesetzt werden kann, aber in bezug auf das Prädikat eine neutrale Rolle spielt. Die ubrigen Attribute harmonieren mit ihrem Motivie- 
rungsangebot nicht mit Bedürfnissen des Prädikats. So ergeben sich folgende Varianten von (39''):

(39"a) Dobroserdečnomu parnju bylo nemnogo žal'i dežurnogo i milicionera.

(39"b) Sočuvstuennomu parnju bylo nemnogo žal' i dežurnogo i milicionera.

(39"c) Molodomu parnju bylo nemnogo žal' i dežurnogo i milicionera.

(39"d) * Chitromu parnju bylo nemnogo žal' i dežurnogo i milicionera.

Die (a)- und (b)-Varianten realisieren ohne zweifel eine Attribut-Prädikat-Beziehung: "Weil der Junge mitfülend war, taten ihm der Diensthabende und der Milizionär ein wenig leid." Die (c)-Variante belegt den neutralen status des Attributs, während die übrigen Varianten, hier vertreten durch (d), zu nichtakzeptablen Sätzen führen. Man könnte sagen, daß die zu (d)-Sätzen führenden Attribute, ähnlich wie bestimmte prädikate, markiert sind, d.h. nicht wie molodoj neutral verwendet werden können, sondern entweder eine Explikation ankündigen oder selbst explikationsbedüftig bzw. motivationsbedürfig sind. Im letzten Fall haben sie metasprachlichen Charakter. Ich werde darauf noch zu sprechen kommen.

Ich verzichte zunächst darauf, eine Etikettierung der zulässigen und nichtzulässigen Attribute $z u$ versuchen, und gehe gleich zur objektattribution über. Dabei interessiert mich einmal, welche Attribute Motivationsfunktion haben können, und zum anderen, ob sich die ausgesonderten Attribute mit denen, die in der subjektposition möglich waren, decken oder überschneiden. Ich ziehe dazu folgenden Teilsatz heran, in den zunächst die Adjektive aus unserer oben gegebenen Liste eingesetzt werden.

(3911) Emu bylo nemnogo žal' dežurnogo.

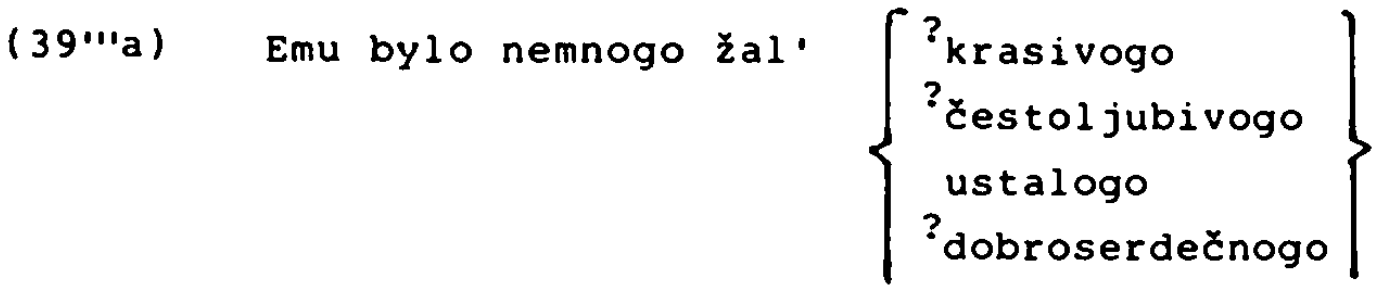


$(39 \cdots \cdot a)$

dežurnogo.

$$
\left|\begin{array}{l}
? \text { socuustvennogo } \\
{ }^{\star} \text { chitrogo } \\
\text { molodogo } \\
{ }^{*} \text { strojnogo }
\end{array}\right|
$$

Ich gehe davon aus, daß im Grunde nur ein Attribut ohne Einschränkung als prädikatmotivierend eingestuft werden kann, und zwar ustalyj: "Ihm tat der Diensthabende etwas leid, weil dieser müde war." Es ist nicht schwierig, sich einen Kontext vorzustellen, in dem diese Interpretation sinnvoll ist. Ein zweiter Kandidat für eine prädikatmotivierende Funktion ist čestoljubivyj. Auch hier muß eigentlich nicht viel vorstellungskraft mobilisiert werden, um eine kausale Interpretation plausibel erscheinen zu lassen. Molodoj scheint wie in der Subjektposition auch hier eine neutrale Rolle zu spielen. Die anderen Attribute sind mehr oder minder inakzeptabel. Zwar könnte man für dobroserdečnyj auch noch einen vernünftigen Kontext finden, aber dazu bedarf es schon eines gewissen Aufwandes ("Ihm tat der Diensthabende ein wenig leid, weil dieser gutmütig war, damit aber keinen Erfolg, sondern Mißerfolg hatte."). Für chitryj und strojnyj sehe ich keine Möglichkeit, mit vertretbarem Aufwand einen Kontext für eine prädikatmotivierende Funktion zu finden. Sie sind unmotiviert.

Unsere erste Liste könnte den Eindruck erwecken, die Restriktionen in der objektposition seien der der Subjektposition gleich. Dies ist mit Sicherheit nicht der Fall, wie die zweite Liste zeigt:

(39''b) Emu bylo nemnogo žal'

$$
\left\{\begin{array}{l}
\text { nekrasivogo } \\
\text { tolstogo } \\
\text { bol 'nogo } \\
? \text { skromnogo } \\
\text { glupogo } \\
? \text { ryžego } \\
\text { *bogatogo }
\end{array}\right\}
$$

dežurnogo. 
Die Liste bedarf keiner ausführlichen Kommentare. Zu ryzij sei angemerkt, daß es sich hier sicherlich um einen Sonderfall unter den Farbbezeichnungen handelt, wenn man davon ausgeht, daß es Menschen gibt, die rote Haare für häßlich und damit für nachteilig halten. Interessant ist noch bogatyj, denn die Inakzeptabilität in (39'b) rührt weniger vom prädikat als vom Bezugswort dežurnyj her.

Wie lassen sich die prädikatmotivierenden Attribute zusammenfassen? Welches gemeinsame Merkmal liegt vor? Zunächst scheinen alle die Adjektive prädikatmotivierend $z u$ sein, die ein negativ konnotiertes Merkmal haben bzw. haben können. Dabei spielt es keine Rolle, ob es sich um körperliche, geistige oder ästhetische Merkmale handelt. Zum zweiten scheinen die Attribute eine Beziehung zum Prädikat eingehen zu können, die auf psychische Merkmale referieren, wobei entscheidend ist, daß das Vorhandensein dieser Merkmale zu einem negativen Erfolg geführt hat. Wie man sieht, bedarf es bei der zweiten Gruppe eines zusätzlichen Kontextes, damit über Erfolg oder Mißerfolg überhaupt entschieden werden kann.

Vergleicht man nun die objektattribute mit den subjektattributen, dann zeigt sich, daß sich die beiden Listen kaum ähneln. Zwar kommt in beiden sočuvstvennyj vor, aber die motivierende Funktion ist jeweils eine andere. Dieses Anderssein zeigt sich grundsätzlich darin, daß die subjektattribute nur explizieren, was ohnehin als Voraussetzung für byt' zal' angesehen werden muß, wobei der Anlaß für die Aktualisierung des vom Prädikat bezeichneten Sachverhalts ungenannt bleibt. Dieser Anlaß wird nur von den objektattributen genannt. Ich möchte deshalb ein Prädikat wie byt' žal' als objektorientiert bezeichnen.

Ich komme nun zur Attribution bei zwei objekten. Aufgrund unserer bisherigen Beobachtungen ist $z$ erwarten, daß die Doppelattribution recht strengen Restriktionen unterliegt. Das Problem besteht nämlich darin, Adjektivattribute zu finden, die auf ein und dieselbe Handlungssituation bezogen werden können, so wie es im originalsatz belegt ist. Sehen wir uns dazu folgende Modifikationen von (39) an: 
(39a) Emu bylo nemnogo žal'i samoljubivogo dežurnogo, i golodnogo milicionera.

(39b) Emu bylo nemnogo žal' i tolstogo dežurnogo, i ustalogo milicionera.

(39c) Emu bylo nemnogo žal' i bol'nogo dežurnogo, i glupogo milicionera.

Es grenzt schon an ein kleines Kunststück, für einen dieser drei Sätze einen Kontext zu rekonstruieren. Auf den ersten Blick zumindest scheint es aussichtslos, etwa für (39c) eine Situation zu finden, in der sowohl die Krankheit des einen als auch die Dummheit des anderen ein Mitleidgefühl zu erregen vermögen. Wenn überhaupt, dann sind sätze der obigen Art am ehesten als eine Art summarische Replik auf zwei Einzelfragen zu interpretieren. Mit Sicherheit gilt: wenn (39) in einem Kontext $K_{i}$ plausibel ist, dann können (39a) bis (39c) im Kontext $K_{i}$ nicht plausibel sein. D.h., selbst wenn den von dežurnyj und milicioner bezeichneten Personen die angegebenen Merkmale zugeschrieben werden können, dann ist ihre versprachlichung in einer (39) analogen Form nicht möglich, weil durch die motivierenden Beziehungen textuelle Gegebenheiten berührt werden.

Wir gehen nun einen Schritt weiter und versuchen zu klären, welche Auswirkungen die Attribution nur eines objekts hat.

(39d) Emu bylo nemnogo žal' i dežurnogo i prosten'kovatogo milicionera.

(39e) Emu bylo nemnogo žal' i dežurnogo i golodnogo milicionera.

(39f) Emu bylo nemnogo žal'i dežurnogo i tolstogo milicionera.

usw.

(39d') Emu bylo nemnogo žal' i prosten'kovatogo dežurnogo i milicionera.

(39e') Emu bylo nemnogo žal' i golodnogo dežurnogo i milicionera.

(39f') Emu bylo nemnogo žal' i tolstogo dežurnogo i milicionera. 
Alle sechs Beispiele machen auf ein sehr interessantes Phänomen aufmerksam. Die Attribuierung nur eines objekts hat zur Folge, daß im Unterschied zur Funktion des gleichen Attributs in einem Satz mit nur einem objekt das Attribut seine motivierend-begründende Beziehung verliert und "lediglich" identifizierende Funktion hat. Für dieses Phänomen bietet sich folgende Erklärung an: Das Prädikat byt' žal' erstreckt sich auf beide objekte, das jeweilige Attribut jedoch nur auf ein objekt. Daraus ergibt sich, daß die Motivierung des Prädikats nicht expliziert werden kann und das vorhandene Attribut zwangsläufig eine andere Funktion übernehmen muß. Anders gesagt, gibt es bei einer Reihung von objekten nur ein potentielles prädikatmotivierendes Attribut, dann dominiert die Beziehung zwischen Prädikat und attributslosem objekt die gesamte Aussage.

Nun zum Verhältnis von subjekt- und objektattribution. Hier lassen sich theoretisch folgende varianten unterscheiden:

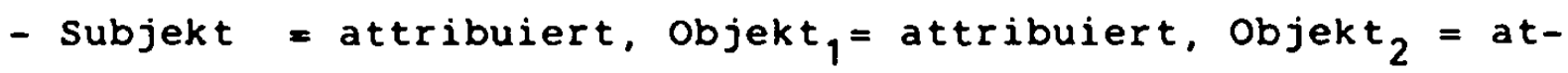
tribuiert

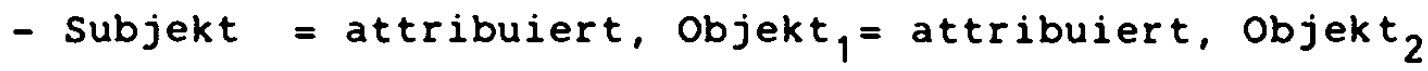

- subjekt = attribuiert, objekt, ${ }_{1}$, objekt ${ }_{2}=$ attribuiert

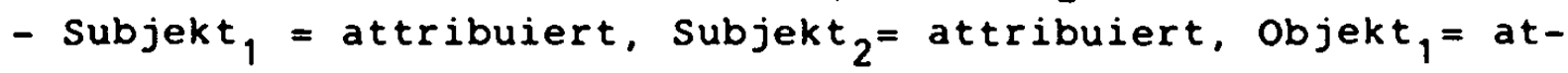
tribuiert, objekt $_{2}=$ attribuiert usw.

(39g) Sočuvstvennomu parnju bylo nemnogo žal' i samoljubivogo dežurnogo, i prosten'kovatogo milicionera.

Auch hier zeigt sich ein interessantes Phänomen. Ich habe oben behauptet, daß Subjektattribute nur eine ohnehin mitverstandene Voraussetzung für das prädikat byt' žal' explizieren, sonst aber als motivierende Begründung nicht ausreichen. ( $39 \mathrm{~g}$ ) offenbart aber daruber hinaus, daß die Existenz eines subjektattributs Auflagen für die objektattribute macht: sie müssen auf "Mitgefühl" erregende Eigenschaften referieren. Samoljubivyj bezeichnet offensichtlich keine solche Eigenschaft, so daß ein Konflikt zwischen sočuvstvennyj und samoljubivyj die Folge ist. $(39 \mathrm{~h})$ ist ein Beleg für eine konfliktlose Kookkurrenz von Sub- 
jekt- und objektattributen.

(39h) Sočuvstvennomu parnju bylo nemnogo žal' i ležaščego $v$ bol'nice dežurnogo, i tjaželo ranenogo milicionera.

Es ist im Augenblick leider nicht möglich, eine Liste von miteinander verträglichen subjekt- und objektattributen für gegebene Prädikate zusammenzustellen. Es ist überhaupt die Frage, ob eine Generalisierung je erreicht werden kann.

Ich tilge nun ein Objektattribut, um $z$ u sehen, inwieweit sich die Motivationsberiehungen verändern.

(39i/a) Sočuvstvennomu parnju bylo nemnogo žal' i dežurnogo, i tjaželo ranenogo milicionera.

$\left(39{ }_{b}\right)$ Sočuvstvennomu parnju bylo nemnogo žal' i tjaželo ranenogo dežurnogo i milicionera.

Mir scheint, daß anders als in der Variante ohne subjektattribut nicht die Beziehung zwischen Prädikat und attributionslosem objekt uber die zwischen Prädikat und Attribut dominiert, sondern daß hier die Motivation zwischen Prädikat und Attribut erhalten bleibt und gleichzeitig eine Art Kontrast zwischen tjaželo ranenyj $x$ und $\underline{Y}$ aufgebaut wird. Y könnte als verursacher von "tjaželo ranenyj" interpretiert werden und auf diese Weise auch in den Bereich von sočuvstvennyj fallen.

Der Vollständigkeit halber ist nun noch der Frage nachzugehen, ob die Reihung von Subjektnomina irgendeine Auswirkung auf die Attributionsmöglichkeiten hat, im subjektbereich ebenso wie im objektbereich.

Ich bilde unser Musterbeispiel entsprechend um:

(39j) Sočuvstvennomu parnju i dobroserdečnoj devuške bylo nemnogo žal' i ležaščego $v$ bol'nice dežurnogo, i tjaželo ranenogo milicionera.

Dieser Satz ist sicherlich nicht schön, aber dennoch akzeptabel. Tilge ich aber ein subjektattribut, dann erscheint das verbliebene Subjektattribut keine prädikatmotivierende Beziehung mehr einzugehen:

(39k) Parnju i dobroserdečnoj devuške bylo nemnogo žal' ... 
Analog $z u(39)$ ist folgendes Beispiel, in dem ebenfalls prädikatmotivierende Attribute vorkommen, $z u$ interpretieren. Ich werde es hier nicht weiter kommentieren.

(40) Pomogat' Zavališinym po chozjajstvu ona načala ešce pri Nine F., žaleja bol'nuju, slabuju, neumeluju ženščinu.

Es stellt sich nun die Frage, ob die Prädikate innerhalb von P, eine homogene Gruppe darstellen, derart, daß die bei (39) gewonnenen Ergebnisse auch für die übrigen Prädikate dieser Gruppe gültig sind. Es ist $z$ u vermuten, daß eine Generalisierung nur im allgemeinen sinne möglich ist. Daß die mit byt' žl' eine Motivationsbeziehung eingehenden Objekt- und subjektattribute auch in den Attributslisten für andere Prädikate innerhalb von $P_{1}$ auftauchen, ist nicht $z$ u erwarten. Sehen wir uns dazu zunächst folgendes Beispiel an:

(41) on [Kogotov] vsegda nedoljublival étogo boltlivogo azartnogo starika.

Es ist leicht nachzuweisen, daß nedoljublivat andere Restriktionen für objekt-bzw. Subjektattribute aufweist. Ich setze dazu Attribute aus unseren obigen Listen ein: On vsegda nedoljublival étogo

starika.

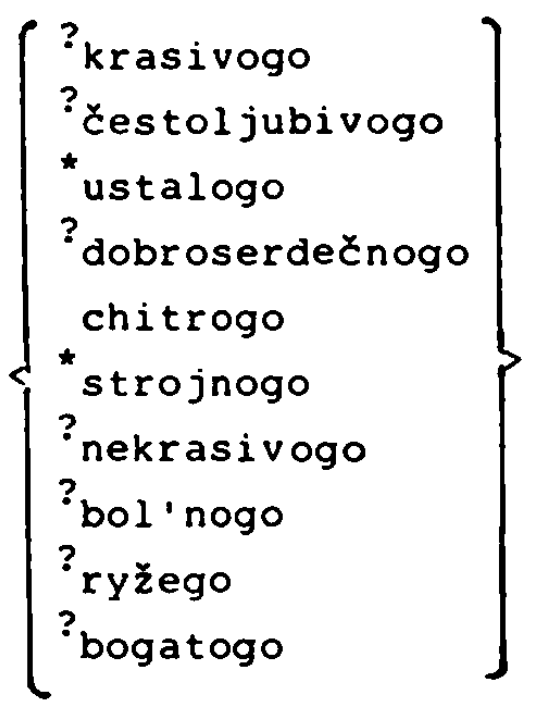

Während chitryj direkt, ohne weiteren Kontext, eine motivierende Beziehung $z$ um prädikat eingeht, bedürfen die anderen mit Fragezeichen versehenen Attribute kontextueller Erläuterungen. Nedoljublivat' ist wie byt' žal' ein objektorientiertes verb, 
deshalb fällt es außerordentlich schwer, ein motivierendes subjektattribut zu finden.

Nun $z u$ einem weiteren subtyp von $P_{1}$ : byt' stydno.

(42) Emu stydno bylo za

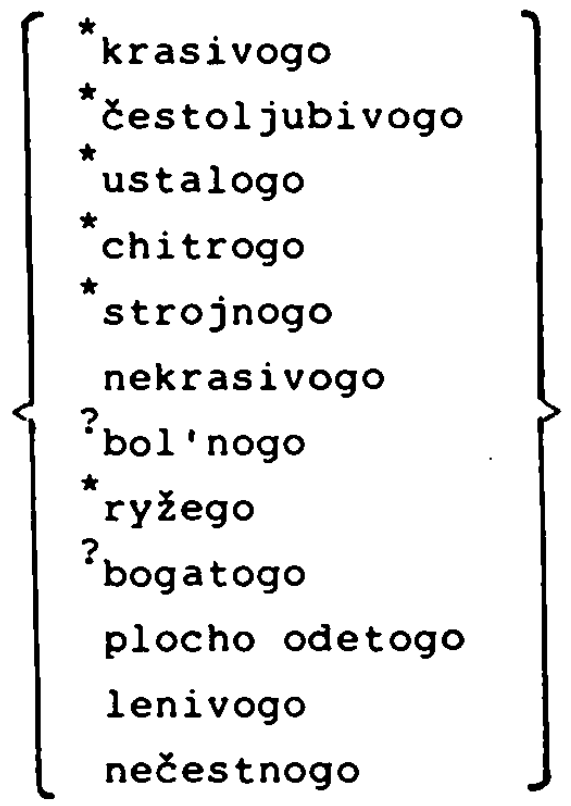

starika.

Es ist nicht einfach, das Merkmal (oder die Merkmale) anzugeben, das allen prädikatmotivierenden Attributen zukommt. Man kann sich schämen für von der Norm abweichende körperliche Eigenschaften, aber auch für negative Verhaltenserscheinungen. Auf jeden Fall signalisieren die entsprechenden Adjektive negativ konnotierte Merkmale bzw. Eigenschaften.

Eine Subjektattribution erweist sich wie im vorherigen Beispiel als ungewöhnlich, es steht kaum ein geeignetes Adjektiv zur verfügung.

Es ist interessant, daß die Motivierungsmöglichkeiten wesentlich größer sind, wenn die objektposition durch eine Bezeichnung für einen unbelebten Gegenstand besetzt wird (mašina, dom usw). Hier können grundsätzlich alle negativ konnotierten Adjektive gesetzt werden, wobei nicht von vornherein festlegbar ist, welche Adjektive eine negative Konnotation aufweisen. Eine besondere Rolle spielen eine ganze Reihe von kontextuellen Faktoren (z.B. soziale Einstellung des Subjektgegenstandes). Vgl.

(43) Emu stydno bylo za bol'šoj dom / bol'šuju kvartiru. Hier ist es die Größe des Hauses / der Wohnung, für die man sich schämt. 
Ich begnüge mich mit diesen Bemerkungen zu stydno und wende mich š̌alit'sja zu, das nicht nur einen psychischen zustand, sondern auch eine daraus resultierende Handlung bezeichnet (auf die Einrichtung einer speziellen Prädikatsklasse habe ich zunächst verzichtet). Interessant bei dem nachstehenden Beispiel ist, daß das prädikatmotivierende Attribut Konstituente eines partizipialen Nebensatzes ist, während das Prädikat zum Hauptsatz gehört.

(43) Mest, konečno, ne bylo, no dežurnaja, uvidev ego otkrytoe lico, nesčastnoe i rasterjannoe, bespomoščno opušennye ruki, sžalilas'.

Die Attribute in (43) spielen eine besondere Rolle, denn sie sind in gewissem sinn obligatorisch. Während ein reduzierter Satz wie (43') durchaus akzeptabel ist, weist (43') ein Defizit auf, da das Motivationsangebot unzureichend ist:

(43') Mest, konečno, ne bylo, no dežurnaja sžalilas'. Die Motivation für š̌alilas' bleibt offen.

(43') Mest, konečno, ne bylo, no dežurnaja, uvidev ego lico, (ego) ruki, sžalilas'.

Die Begründungspotenzen von $\underline{\text { lico }}$ und $\underline{\text { ruki }}$ reichen für das Prädikat nicht aus.

Die Einsetzung von motivierenden Attributen ist in (43) äußerst beschränkt. Aus der großen Menge der für lico und ruki selektional zulässigen Adjektive sind im vorliegenden Zusammenhang nur sehr wenige erlaubt. Nicht zulässig sind Farb- und Formbezeichnungen, aber auch Attribute wie znacitel'noe (1ico), 1jubopytsvujuščee, nepodvižnoe, derevjannoe, bestrastnoe usw. sind nicht setzbar. Es sind, wenn man eine Regel formulieren will. nur die Attribute motivierend, die in verbindung mit lico bzw. ruki "Hilflosigkeit, Enttäuschung, Verwirrung u.ä." signalisieren.

Eine Subjektattribution ist für š̌alilas' zwar möglich, aber es stehen nur wenige Adjektive zur verfügung: z.B. žalostlivyj u. à.

Ein interessantes Beispiel ist (44). In diesem Beispiel wird das formale Subjekt durch einen unbelebten Gegenstand reali- 
siert, während das inhaltliche subjekt im obliquen Kasus eines objekts auftritt.

(44) Predvaritel'naja beseda s Bugrovoj i u Dedkovskogo i u Stežkova ostavila tjagostnoe čuvstvo.

In diesem Satz ist die Motivation der Verwendung des prädikats nicht expliziert. Es ist $z$ vermuten, daß das, was Gegenstand des Gesprächs war, den vom prädikat bezeichneten Zustand motiviert. Dieser Umstand ist seinerseits dafür verantwortlich, daß eine prädikatmotivierende subjektattribution nicht möglich ist. Der nicht genannte Inhalt des Gesprächs läßt sich nicht durch ein Attribut ausdrücken. Attribute haben allenfalls metasprachlichen Charakter, sie stellen ein Prädikat über einer Aussage dar und enthalten eine Bewertung.

(44') ? - Ser'eznaja predvaritel'naja beseda $s$... ostavila tjagostnoe čuvstvo.

- Utomitel'naja predvaritel'naja beseda ... usw.

Eine Kausalbeziehung zwischen Subjektattribut und Prädikat läßt sich nicht feststellen. Die subjektposition kann somit nicht als Aussagepunkt für eine Motivationsbeziehung ausgeschlossen werden. Versuchen wir deshalb eine Attribution der Objekte. Als objekt sehe ich der Einfachheit halber auch die Attributsphrase Bugrovoj an:

(44") Predvaritel'naja beseda s/so

$$
\left\{\begin{array}{l}
\text { staroj } \\
\text { skromnoj } \\
\text { ispugannoj } \\
\text { otčajannoj } \\
\text { zaplakannoj } \\
\text { pridavlennoj vsem } \\
\text { slučivšimsja }
\end{array}\right.
$$

Bugrovoj ... ostavila tjagostnoe Čuvstvo.

Es ist bemerkenswert, daß diese objektattribution keine Motivationsleistung vollbringt. Die angeführten Eigenschaften können in dieser syntaktischen Position keine Beziehung zum Prädikat eingehen: "Das vorbereitende Gespräch mit der Bugrova hinterließ deshalb bei ... ein bedrückendes Gefühl, weil die 
Bugrova verzweifelt war." Daß die beobachtete Restriktion im wesentlichen durch die syntaktische Position und nicht durch die Semantik der Attribute bestimmt wird, läßt sich anhand des Originaltextes zeigen, in dem die oben eingesetzten Attribute als prädikate und Attribute bzw. Adverbien im Postkontext von (44) vorkommen.

(44) Predvaritel'naja beseda s Bugrovoj i u Dedkovskogo i u Stežkova ostavila tjagostnoe čuvstvo. Zenščina byla bukval'no pridavlena vsem slučivšimsja. Ee bila nervnaja drož', spazmy schvatyvali gorlo, zaplakannye, pokrasnevšie ot slez glaza gljadeli udivlenno, ispuganno, s neprochodjaščim otčajaniem.

Die hervorgehobenen Ausdrücke fungieren, neben anderen, zweifellos als prädikatmotivierend bzw. -explizierend. Man kann jedoch nicht ausschließen, daß nur ein Teil der zugrundeliegenden Motivation realisiert worden ist, da der Inhalt des Gesprächs und sein Verlauf nach wie vor offen bleibt.

Gehen wir nun noch einen schritt weiter und untersuchen wir die Motivierungspotenzen des u-Objekts. Ich tilge dazu zunächst ein objekt aus der Koordination, um die oben beschriebenen, sich aus der Reihung ergebenden probleme zu vermeiden:

(44'i) Predvaritel'naja beseda s Bugrovoj u

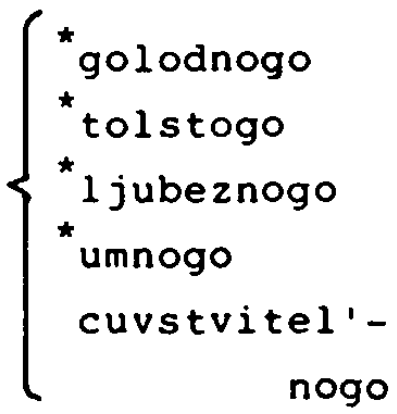

Dedkovskogo ostavila tjagostnoe Čuvstvo.

Die Einsetzung fürt $z$ u einem sehr aufschlußreichen Ergebnis. Das u-objekt erlaubt nur eine Quasimotivation, wie wir sie bereits von der Betrachtung der subjektattribution her kennen. Man kann daraus Schlüsse über die tiefenstrukturellen Gemeinsamkeiten zwischen den u-Objekten und Subjekten ziehen. Da keine weiteren Attribuierungsmöglichkeiten in (44) vorhanden sind, müssen wir feststellen, daß sich ganz offensichtlich die Semantik des formalen Subjekts, also von beseda, prädikatmotivierenden Attributionen in den Weg stellt. 
Die Betrachtung von $P_{1}$, die nur exemplarisch sein konnte, sei hiermit abgeschlossen. Wir haben festgestellt, daß für diese Prädikate die objektattribution eine besondere Rolle spielt, wobei sich zeigte, daß es sinnvoll ist, subtypen von $P_{1}$ zu unterscheiden.

$\underline{P_{2}}$

Zu $P_{2}$ soll nur ein Beispiel kurz behandelt werden.

(45) Ivan draznil tolsten'kogo mal'čika.

Dieser Satz ist insofern bemerkenswert, als eine prädikatmotivierende Funktion des Attributs zwar denkbar, aber keineswegs zwingend ist. Dies hängt offensichtlich mit der Bedeutung des Prädikats zusammen, denn es lassen sich kaum eindeutige Beispiele für prädikatmotivierende Adjektivattribute finden, weder bei den objekt- noch bei den subjektattributen:

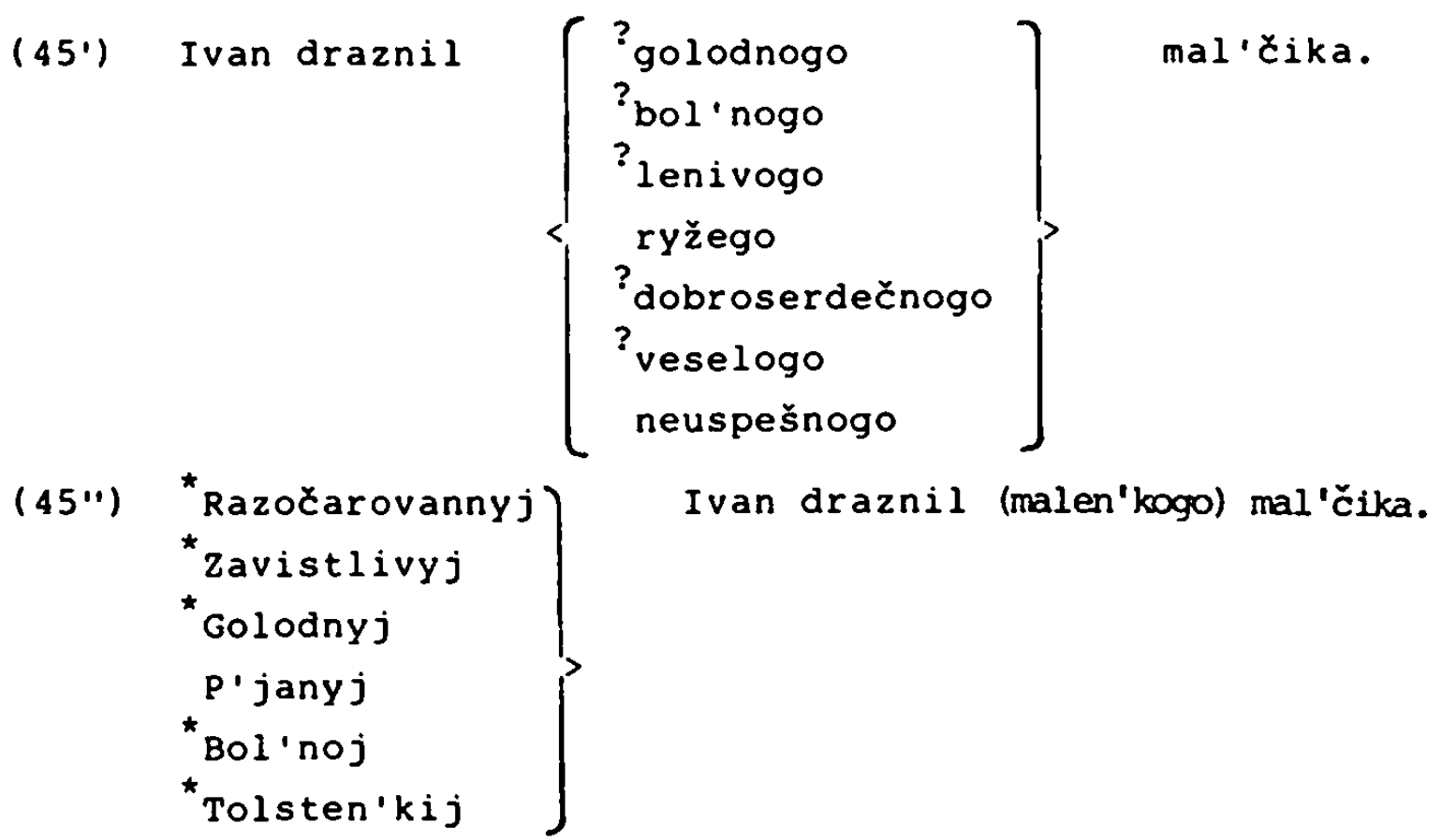

Die hier zu beobachtenden Restriktionen weisen darauf hin, daß die potentielle Beziehung zwischen Attribut und Prädikat bei draznit. nicht eindeutig genug ist, um eine Kausalinterpretatation zu signalisieren. Kausalbeziehungen müssen offensichtlich durch entsprechend ausdrucksstarke Mittel angezeigt werden. Für die subjektposition kommt dafür die Isolierung des 
Adjektivs in Frage, während für die Objektposition konjunktionale Nebensätze angebracht erscheinen:

(45\%) Razočarovannyj, Ivan draznil (malen'kogo) mal'čika.

(45') Ivan draznil mal'čika, potomu čto ...

$\underline{P_{3}}$

Ich beginne die Betrachtung dieser Gruppe, die auf den ersten Blick etwas heterogen erscheint, mit markierten Handlungsprädikaten.

(46) ... i na kriki "avtora, avtora!" [on] nasil'no vytaščil na scenu soprotivljajuščujusja smuščennuju Asju.

(47) Ja sažus' v mašinu, kuda zatalkivajut Mušanskogo.

(48) Ego ne očen' ljubezno vyvolakivajut na trotuar.

Die drei Prädikate gehören deshalb zu den markierten Prädikaten, weil sie in Verbindung mit "belebten" Objekten eine besondere, vom Normalen abweichende Handlung bezeichnen. Es ist nicht üblich, eine Frau auf die Bühne zu "zerren", einen Mann in ein Auto $z u$ "stoßen" oder auf den Bürgersteig zu "schleppen". Diese Handlungsweisen müssen in irgendeiner Weise motiviert werden. In (46) korrespondiert das markierte Prädikat mit einem objektattribut, und zwar mit soprotivljajušcajasja, erst in zweiter Linie mit smuščnnaja, wenn man das Adverb nasil'no berücksichtigt: "Weil Asja verwirrt ist und weil sie sich sträubt, zieht $x$ sie mit Gewalt auf die Bühne." Smuščnnaja allein motiviert nasil'no vytašlil nicht. Bei gegebenem Kontext sind die Restriktionen für die objektattribution relativ streng. Es kommen im Prinzip nur solche Adjektive in Frage, die auf ein Merkmal wie [Widerstand leistend] oder [nicht handlungsfähig] verweisen. Dies ermöglicht z.B. die Setzung von skromnaja, zastenčivaja. In einem anderen Kontext wäre auch eine verträglichkeit zwischen tjaželaja, nepodvižnaja, ranenaja u.ä. und vytaščt' denkbar. Dieses Beispiel zeigt somit sehr deutlich, daß die motivationellen Restrik- 
tionen ihrerseits noch einmal kontextuellen Restriktionen unterliegen.

Wie bei den anderen Beispielen wollen wir hier auch die Möglichkeit der Subjektattribution überprüfen, und zwar zunächst ohne Berücksichtigung von Vortexten.

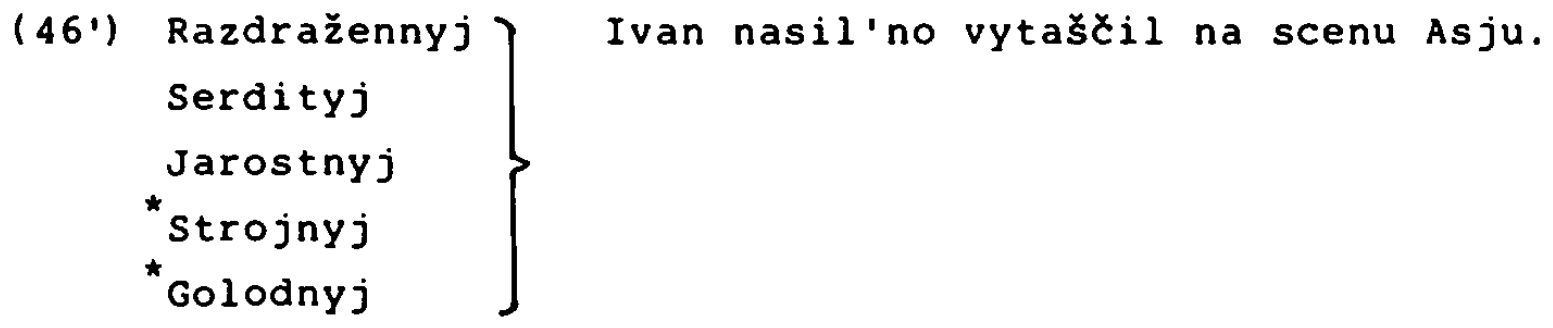

Die Subjektattribution erweist sich auch hier als ziemlich problematisch. Das erste Problem besteht darin, daß sie die objektattribution mit motivierender Funktion nicht ersetzen kann. Das zweite Problem betrifft die Kontextabhängigkeit der Subjektattribution. Ein Attribut wie razdražennyj bedarf selbst erst einer Vorbereitung durch den Kontext ("Warum/woruber ist Ivan erzürnt, wütend ...?"). Es sind somit nur solche subjektattribute akzeptabel, die mit einem gegebenen kontext vereinbar sind. In bezug auf unser Beispiel bedeutet dies, daß keines der in (46') angeführten Attribute kontextkonform ist. Ich glaube, daß dies ein wichtiger Punkt für die Beurteilung von Attribuierungsmöglichkeiten ist.

Nun zu Beispiel (47). Dieser Satz ist eigentlich erst verständlich, wenn man weiß, daß es sich bei dem sprecher um einen Polizisten und bei Mušanskij um einen verbrecher handelt. Aus diesem Kontext ergibt sich ganz selbstverständlich die Motivation für die Verwendung des markierten Prädikats. Dies wiederum bedeutet, daß zusätzliche Motivierungen über Adjektivattribute mehr oder minder überflüsig sind. Ein Subjektattribut, im Fall, wir rekonstruieren das subjekt, müßte speziell vorbereitet werden, ein Objektattribut wirde bei einer Lesart von (47) durch das Merkmal [Verbrecher] Redundanz erzeugen. Man könnte allerdings, wie in (46), ein Attribut wie soprotivljajušcijsja verwenden. Damit würde eine neue Information in den Text eingebracht.

(48) wirft analoge Fragen auf. Vyvolakivat' scheint kontextuell vorbereitet, so daß auch bei eingesetzten subjekt- und objektnomina kaum Attribuierungsmöglichkeiten vorhanden sind. 
Denkbar ist ein subjektattribut razdražennye (druz'ja), das speziell die adverbiale Bestimmung des prädikats motiviert. Objektattribute werden durch Kontextinformationen vorweggenommen.

Gehen wir uber 24 einem anderen Typ von markierten Prädikaten. Es geht dabei um eine Handlung, die eigentlich nur dann erwähnt wird, wenn sie unter besonderen schwierigkeiten oder besonderen Umständen abläuft. Daraus ergibt sich zwangsläufig, daß die entsprechenden Schwierigkeiten bzw. Umstände genannt werden müssen.

(49) On [Ivan]vstal, s trudom razognul zatekšie nogi. Eine Modifizierung von (49) durch Tilgung des Attributs und des Adverbs resultiert in einen Satz, in dem die Aussage razognul nogi einen kommunikativen wert erhält, der ihr nicht zusteht. Die Aussage ist trivial. Diese Trivialität wird erst durch das Adverb $s$ trudom beseitigt. Die bestehende Vagheit bezüglich der Gründe für das Entstehen dieser Situation wird dann durch das Attribut aufgehoben. Es ist interessant, daß die Vagheit des Satzes $s$ trudom razognul nogi die Attribuierungsmöglichkeiten nicht derart bestimmt, daß nur prädikatmotivierende Attribute zulässig sind. Es ist ohne weiteres möglich, auch andere Attribute zu verwenden. Vgl.

(49.) On vstal, s trudom razognul

$$
\left\{\begin{array}{c}
\text { dlinnye } \\
\text { žilistye } \\
\text { krivye } \\
(?)_{\text {strojnye }} \\
(? \text { krepkie }
\end{array}\right\}
$$

nogi.

Diese Besonderheit erklärt sich vermutlich daraus, daß das Objekt auf einen nicht zur eigenen kontrollierten Handlung fähigen Gegenstsand referiert (im Gegensatz zu Personenbezeichnungen) und die zugeordneten Merkmale somit nicht notwendigerweise als handlungsrelevant inerpretiert werden müssen.

wie sieht es mit der Möglichkeit einer Subjektattribution aus? Sie erscheint grundsätzlich problematisch, auch aufgrund der syntaktischen Konstruktion, aber nicht ganz ausgeschlossen. Vgl. 


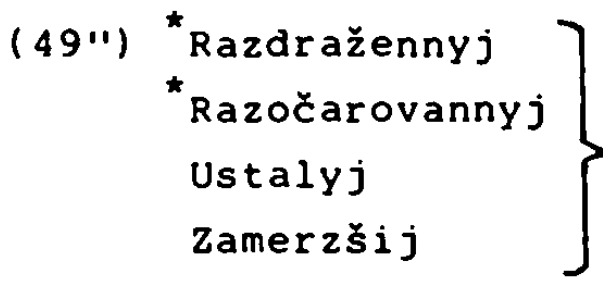

Ivan vstal, s trudom razognul nogi.

Das dritte und das vierte Attribut könnte man als indirekt motivierend interpretieren: "Der müde Ivan stand auf, und weil er müde/schwach war, bereitete es inm schwierigkeiten, die Beine zu strecken." Natürlich haben die Attribute ustalyj. zamerzšij hier primär die Funktion, das prädikat vstal zu motivieren. Als hinderlich für die Attribution erweist sich somit, daß das subjekt von vstal und razognul referenzidentisch ist. Vgl. damit

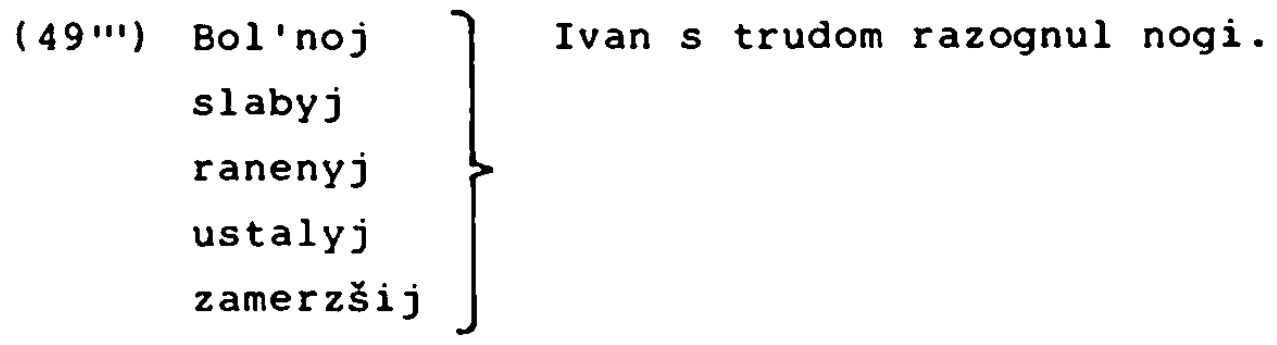

Die Attribute in diesem Satz motivieren allerdings, genau genommen, nicht die prädikatsphrase razognul nogi, sondern die adverbielle Bestimmung:

"Weil Ivan krank war, konnte er nur mit Mühe die Beine strecken."

Interessanterweise bleibt dieser Bezug des Attributs auch bei zusätzlicher Attribution des Subjekts erhalten:

(49iv) Bol'noj Ivan s trudom razognul zatekšie nogi.

Dieser Satz beinhaltet allerdings, daß das Strecken der steifen Beine nur deshalb Mühe macht, weil Ivan krank ist. Das Strecken der steifen Beine erscheint in diesem Zusammenhang als eine nicht markierte Handlung. Mit anderen worten, aus (49.v) können wir entnehmen, daß die Konkurrenz von Prädikatsmotivation durch Objektattribution und Adverb- oder Prädikatsmotivation durch Subjektattribution zugunsten einer Motivationsbeziehung zwischen Subjektattribut und Adverb ausfällt.

Sehen wir uns noch kurz ein anderes Beispiel dieser Art an:

(50) Menja k vam étot napravil ... Stepan Nikolaevič! s trudom vydavlivaet nakonec iz sebja obessilennyj Fedor Pavlovič. 
Das Prädikat vydavlivaet ist sicherlich nicht im gleichen Maß markiert wie razognul. Dies hängt damit zusammen, daß vydavlivaet Merkmale der Lautäußerung selbst wiedergibt und somit einfach einen bestimmten akustischen Eindruck vermittelt. Das Subjektattribut nennt die Gründe für die beschriebene Art Lautäußerung, ist aber keineswegs so notwendig wie das objektattribut in (49). Es ist einsichtig, daß von der vielzahl der Merkmale die Fedor Pavlovič allgemein oder im Moment der Rede zugeschrieben werden können, nur ganz wenige im Kontext von (50) motiviert sind. Akzeptabel erscheinen alle Attribute, die ein Merkmal wie [gestört] in bezug auf physisches oder psychisches Verhalten signalisieren: z.B. smuščennyj.

$\underline{P_{4}}$

Das Gemeinsame der hier $z$ u behandelnden Prädikate besteht darin, daß sie mit Subjekten korrelieren, die unbelebte Gegenstände bezeichnen. Wie haben es also mit natürlichen Erscheinungen bzw. Prozessen zu tun. Wie in der Einleitung angedeutet, sind die Kausalzusammenhänge, was das Zustandekommen dieser Phänomene angeht, objektiv relativ klar, subjektiv allerdings muß dies nicht der Fall sein. Schuld daran ist das eingeschränkte Wissen über die Welt.

(51) V moroz derevjannaja dver' zabuchala.

(52) Zaržavlennyj zamok izdal chriplyj zvuk i dver' skripnula.

(53) Raskalennye podokonniki izlučali žar kak peč'.

Zunächst ist festzuhalten daß alle subjektattribute eine prädikatmotivierende Funktion haben. Sie ist relativ schwach ausgeprägt in (51), besonders stark aber in (52) und (53). Man könnte fast sagen, daß derevjannaja vom Prädikat her voraussagbar ist, denn es gibt keine andere Eigenschaft von dver'. die mit zabuchat' in Einklang zu bringen ist. Vgl.

(511) V moroz $\left\{\begin{array}{l}{ }^{\star} \text { železnaja } \\ \text { ?tjaželaja } \\ \text { ?̌ernaja }\end{array}\right\}$ dver' zabuchala. 


$$
\left\lfloor\begin{array}{r}
\text { ? } \\
(?)_{\text {krjasnaja }} \\
\text { kraja }
\end{array}\right.
$$

Die mit Fragezeichen markierten Attribute stehen mit sicherheit in keiner Motivationsbeziehung zum Prädikat. Gewicht, Farbe und äußerer Zustand der Tür können allenfalls als Identifikationsmerkmale dienen, allerdings können tjaželaja und grjaznaja noch nicht einmal restriktive Funktion haben. Dies gilt im Prinzip auch für das Attribut krasivaja. Dieses kann allerdings, bei einem entsprechenden Kontext, eine Beziehung zum Prädikat eingehen, und zwar derart, daß es einen Konflikt mit dem von zabuchala genannten Merkmal signalisiert. Noch deutlicher ist in dieser Hinsicht ein Attribut wie dragocennyj: "Die Tür ist zwar sehr wertvoll, aber bei frost quillt sie auf" bzw. "Obwohl die Tür sehr wertvoll ist, quillt sie bei Frost auf (und das mindert eigentlich ihren wert)". Die beschriebene Funktion der Attribute, die durch das Merkmal [ ästhetischer bzw. materieller Wert] charakterisiert sind, ist nicht motivierend. Es ist vielmehr so, daß "lediglich" die Attribute motiviert sind.

Beispiel (52) ist dadurch charakterisiert, daß das Attribut im Gegensatz zu dem in (53) für das Verständnis des Satzes nicht erforderlich ist. Seine Leistung besteht darin, eine Information zu liefern, die die Aussage des prädikats motiviert: "Weil das Schloß verrostet ist, gibt es einen heiseren Laut von sich."

Die Ersetzung von zaržavlennyj durch andere Attribute beeinträchtigt die Akzeptabilität von (53) nicht. Attribute wie tjaželyj, černyj oder grjaznyj sind zwar nicht prädikatmotivierend, aber dennoch problemlos setzbar. Dies hängt mit der schwachen Markiertheit des prädikats zusammen.

Von wesentlich größerer Bedeutung für den Satz ist das Attribut in (53). Es gibt eine Eigenschaft des subjektgegenstandes an, die für das Verständnis der Prädikatsaussage absolut notwendig ist. Fensterbänke strahlen normalerweise keine Hitze aus. Wenn sie das dennoch tun, dann muß dies seinen besonderen Grund haben. Dieser Bedingungszusammenhang $z w i s c h e n$ Attribut und Prädikat ist verantwortlich dafür, daß die Attribuierungsmöglichkeiten äußerst restringiert sind, es sei 
denn, der weitere Kontext schafft andere Voraussetzungen.

Nun zu einigen Sätzen, in denen die Objektattribution von besonderer Bedeutung ist. Zunächst die Beispiele:

(54) Ee [ meduzy] studenistoe, zybkoe telo poluzračno nedolgovečno, bystro sochnet na gorjačich kamnjach.

(55) Ekzamenacionnye vedomosti na Černych gorjačich stolach svoracivalis' $v$ trubki.

(56) Skvoz' rešetčatye figurnye okna s trudom probivalsja svet tusklogo oktjabrskogo utra.

Wenn man das objektattribut gorjačich in (54) eliminiert, dann ist der Satz keineswegs unverständlich. Es hat sich lediglich eine Umwertung einzelner Komponenten der Aussage vollzogen. Das schnelle Trocknen der Qualle wird auf zwei Umstände zurückgeführt: 1 . die Qualle liegt auf steinen (und nicht mehr im Wasser), 2. die materielle Beschaffenheit des Körpers. Die Schnelligkeit des Trocknens erscheint von untergeordneter Bedeutung für die Aussage des Satzes zu sein. Anders ist dies beim Originalsatz. Hier wird die Schnelligkeit des Vorgangs besonders hervorgehoben und durch das dem objekt zugordnete Attribut plausibel motiviert: "Weil die Meduse auf heißen steinen liegt, trocknet sie schnell." Die Subjektattribute, die auf konstitutive Merkmale des Medusenkörpers verweisen, spielen nur eine untergeoranete Rolle bei der Motivierungsbeziehung. Sie explizieren die grundsätzlichen Voraussetzungen für den vom Prädikat bezeichneten Prozeß.

Die Ersetzung von gorjačich durch andere Attribute unterliegt keinen besonders strengen Beschränkungen. Auch andere Eigenschaften der steine können als Ursachen für das schnelle Trocknen angesehen werden:

(54') Ee studenistoe, zybkoe telo ... bystro sochnet na $\left\{\begin{array}{l}\text { ploskich } \\ \text { kruglych } \\ \text { tolstych } \\ \text { zelenych }\end{array}\right\}$ kamnjach.

Die objektiven kausalen Zusammenhänge bleiben dabei vage. 
Satz (55) ist analog zu (53) zu interpretieren. Auch er ist ohne die Information der Attribute nicht vernünftig zu verstehen. Erst die Eigenschaft "heiß" macht die ganze Aussage plausibel. Es ist dabei von untergeordneter Bedeutung, daß das erste Attribut, Cernych, das zweite motiviert. Die Attribuierungsrestriktionen sind ziemlich strikt. Adjektive, die nicht das Merkmal [heiß] signalisieren, können in (55) nicht verwendet werden :

(55') Ékzamenacionnye vedomosti na

$$
\left\{\begin{array}{l}
\star \text { polirovannych } \\
\star \text { kruglych } \\
{ }^{\star} \text { grjaznych }
\end{array}\right\}
$$

stolach svoračivalis' v trubki.

Denkbar sind bestenfalls noch Attribute wie mokryj, die ebenfalls einen Grund für den vom Prädikat bezeichneten Prozeß nennen. Letztlich entscheidend ist jedoch der Makrokontext.

Eine prädikatmotivierende subjektattribution ist zwar nicht grundsätzlich ausgeschlossen - es müßte die Erwärmtheit bzw. Durchfeuchtetheit der Unterlagen zum Ausdruck gebracht werden aber kaum unter den gegebenen lexikalisch-syntaktischen Bedingungen realisierbar.

Das letzte Beispiel zeichnet sich dadurch aus, daß zwei Motivationsstränge vorhanden $z u$ sein scheinen:

(56') Skvoz' okna s trudom probivalsja svet tusklogo oktjabrskogo utra.

(56") Skvoz' rešetとatye figurnye okna s trudom probivalsja svet oktjabrskogo utra.

Welcher Bezug dominiert? Mir scheint, daß der Satz im Sinn von (56") $z u$ interpretieren ist. Eine gewisse Bestätigung dafür ist, daß einerseits tusklyj durch jarkij ersetzt werden kann, ohne daß die motivierende Funktion von rešetčatye figurnye beeinträchtigt wird, daß andererseits eine ähnliche Operation bei rešetとatye nicht zum gleichen Ergebnis führt: "Skvoz. ogromnye okna s trudom ...

Die Interpretation (56") wird weiterhin dadurch gestutzt, daß es sich bei den in Rede stehenden Fenstern um die einer Gefängniszelle handelt. Die zentrale Funktion von (56) ist somit: 
"Die ... Fenster (der Zelle) lassen kaum Licht durch."

Diese Beispiele genügen, um die Besonderheit der Prädikate von $\mathrm{P}_{4}$ deutlich werden $z$ u lassen. Es hat sich gezeigt, daß sich die Attributionsmöglichkeiten grundsätzlich an den außersprachlichen Verhältnissen orientieren, die nicht beliebige Kausalbeziehungen zulassen. Diese Striktheit wird dann etwas gemildert, wenn das prädikat nicht unbedingt auf die Motivationsfunktion des Attributs angewiesen ist. In diesem Fall sind auch nichtmotivierende Attribute zulässig.

$\underline{P_{5}}$

"Helfen" ist sicherlich eine markierte Handlung. Sie findet nicht ohne Grund, nicht ohne irgendeinen Anlaß statt. Ausgangspunkt für motivierende Begründungen ist in erster Linie das objekt, es ist aber nicht auszuschließen, daß "Helfen" eigennützigen zwecken dient. Wie dem auch sei, Sätze, in denen ein helfenPrädikat vorkommt, verlangen in irgendeiner weise eine motivierende Begründung. Diese kann sowohl über den Kontext geleistet als auch im Satz selbst realisiert werden. Sehen wir uns an einem einfachen Beispiel an, welche Möglichkeiten die Attribution bietet:

(57) Ona pomogaet ženščine.

Dieser Satz ist in zweierlei Hinsicht vage. Wir wissen nicht, aus welchem Grund der Frau geholfen wird, und wissen auch nicht, worin die Hilfe eigentlich besteht. Setzen wir ein objektattribut ein, dann wird zunächst die erste Vagheit aufgehoben:

(57') Ona pomogaet bol'noj ženščine.

Diesen Satz kann man sicherlich im Sinn eines Kausalgefüges interpretieren: "Sie hilft der Frau, weil diese krank ist", oder genauer: "Sie hilft der Frau, weil diese wegen ihrer Krankheit bestimmte Dinge nicht oder nur schlecht oder unter großen Mühen tun kann."

Da die Motivationen für Hilfe recht unterschiedlich sein können, sind die Attributionsmöglichkeiten beim objekt kaum restringiert, zumindest beim isolierten Satz. Es sind sowohl Adjektve 
mit dem Merkmal [hilflos] als auch solche, die auf positive Eigenschaften referieren, denkbar. Vgl.

(57') Ona pomogaet

$$
\left\{\begin{array}{l}
\text { priležnoj } \\
\text { skromnoj } \\
\text { simpatičnoj }
\end{array}\right\} \text { ženščine. }
$$

Genau betrachtet, sind diese Attribute nur teilmotivierend. Die eigentliche Ursache für die Handlung ist eine reale oder vermutete Hilfsbedürtigkeit auf seiten des Patiens. Die Attribute in (57') explizieren somit vor allem Agensmotive. Natürlich können nicht beliebige Adjektive Motivierungsfunktion haben. Nicht setzbar sind beispielsweise Adjektive, die auf positiv bewertete körperliche Eigenschaften bzw. körperliche Erscheinungsformen referieren:

(57'1) Ona pomogaet $\left\{\begin{array}{l}\text { ?̌rernoglazoj } \\ \text { ?strojnoj } \\ \text { ?milovidnoj } \\ \text { ?krasivoj }\end{array}\right\} \quad$ ženščine.

Adjektive, die auf negativ bewertete Eigenschaften referieren, geraten mit der Verbsemantik in Konflikt und können ebenfalls nicht verwendet werden:

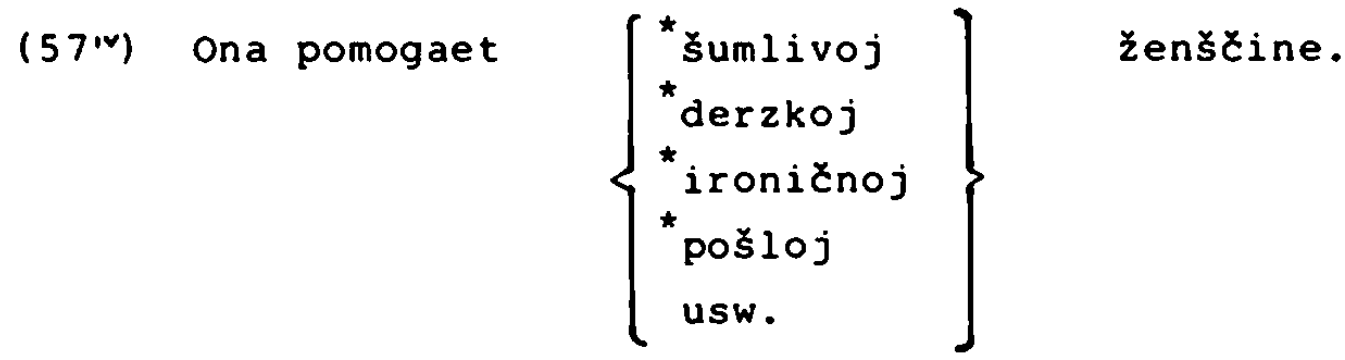

Soviel zunächst zur objektattribution. Wie sieht es mit der subjektattribution aus? Im Grunde genommen sind die Attributionsmöglichkeiten beschränkt. Auf den ersten Blick sind zwei Typen von Adjektiven denkbar: erstens solche, die das Merkmal [ hilfsbereit] haben, und zweitens solche, die über eine Antonymiebeziehung motiviert sind. Im ersten Fall sind die Attribute nur teilmotivierend:

(58) $\left\{\begin{array}{l}\text { Zabotlivyj } \\ \text { Zalostlivyj }\end{array}\right\}$ paren' pomogaet ženščine.

Die Hilfsbedüftigkeit des Patiens wird durch diese Aussage nicht in Frage gestellt. Dies ailt auch für den Fall, daß die 
Hilfe auf der Basis von Dankbarkeit erfolgt:

(58') Blagodarnyj paren' pomogaet ženščine.

Sehen wir uns nun folgenden Fall an:

(58') Sil'nyj paren' pomogaet slaboj ženščine.

Vysokij paren' pomogaet malen'koj ženščine.

Umnyj paren' pomogaet glupoj ženščine.

Hier zeigt sich ein interessantes Phänomen. Während im ersten Beispiel das objektattribut allein das Prädikat motivieren kann, bedarf es bei den beiden übrigen Beispielen des Zusammenwirkens von subjekt- und objektattribut. Das zweite Beispiel würde man etwa wie folgt interpretieren:

"Er hilft der kleinen Frau, weil er groß/größer ist." "Klein" allein signalisiert noch keine Hilfsbedürtigkeit, das entsprechende Attribut ist somit nicht prädikatmotivierend. Erst im Rahmen der Antonymie wird die Hilfsbedurftigkeit des Patiens erkennbar. Trotz der wichtigen Rolle des Subjektattributs, würde ich auch hier von einer objektorientiertheit sprechen. Es versteht sich von selbst, daß nicht jedes antonyme Paar einen Satz nach (58') bilden kann. Zumindest nicht ohne einen beträchtlichen kontextuellen Aufwand (vgl. tolstyj: tonkij).

Einen Fall von motivierender subjektattribution scheint es dennoch zu geben:

(59) Skučajuščij paren' pomagaet krestjaninu.

Man kann davon ausgehen, daß die "Hilfsbedürftigkeit" des Bauern schwächer motivierend ist als die Langweile des Agens. Dies hängt sicherlich auch damit zusammen, daß sich in (59) die Semantik von pomogat' der von rabotat' nähert.

Sehen wir uns nach diesen überlegungen ein Beispiel an, in dem die Bedeutung "helfen" indirekt durch das verb posadit' ausgedrückt wird.

(60) Zabotlivyj mladšij lejtenant, preispolnennyj raspoloženija $\underline{k}$ simpatičnomu neznakomcu, posadil ego na prochodjaščij poezd.

Der Satz enthält eine Subjektattribution und indirekt über die 
Partizipialkonstruktion auch eine objektattribution. Zur leichteren Handhabung bilde ich $(60)$ ein wenig um.

(60.) Zabotlivyj mladšij lejtenant posadil simpatiénogo neznakomca na prochodjaščij poezd.

Trotz der zwei Attribute ist der Grund für die Hilfe des Leutnants unbekannt. D.h., daß beide Attribute nur teilmotivierend sind. Das erste expliziert eine für die Aktion "helfen" notwendige Voraussetzung auf der Seite des Agens, das zweite eine Eigenschaft des Patiens, die als handlungsauslösend angesehen werden kann. Hilfsbedürftigkeit allein genügt nicht für das $\mathrm{Zu}-$ standekommen der Situation "helfen". Es stellt sich die Frage, ob die verursachende Hilflosigkeit des Patiens überhaupt attributiv ausgedrückt werden kann. Dies scheint kein problem $z u$ sein, wenn man einmal von kontextuellen Gegebenheiten absieht. vgl.

(60') Zabotlivyj mlaď̌ij lejtenant posadil $\left\{\begin{array}{l}\text { bol' nogo } \\ \text { bespomoščnogo } \\ \text { ranenogo }\end{array}\right.$ neznakomca na poezd.

Gewisse Schwierigkeiten ergeben sich aber, wenn das auslösende Moment simpatičnyj zusammen mit einem dieser Ausarücke realisiert werden soll:

(60“') ?Zabotlivyj mladšij lejtenant posadil bespomoščnogo simpatičnogo neznakomca na poezd.

Die Funktion, die simpatičnyj in (60') hatte, kann in $\left(60^{\prime \prime \prime}\right)$ nicht in der gleichen weise verwirklicht werden, da das ursachenennende Attribut über simpatičnyj dominiert.

Es bleibt zum Schluß noch $z$ u prüfen, welcher Art die Funktion von subjekt- und objektattribut allein genommen ist:

(60"'a) Zabotlivyj mladšij lejtenant posadil neznakomca na poezd.

(60'b) Mladšij lejtenant posadil simpatičnogo neznakomca na poezd.

Das Ergebnis ist etwas überrachend. Während im Fall (a) noch ein Bezug zwischen Attribut und Prädikat zu erkennen ist, er- 
weist er sich in (b) als gestört. Dies erklärt sich daraus, daß durch die Tilgung von zabotlivyj das prädikat posadil nicht mehr die Bedeutung "helfen" hat. Vgl. dazu analog:

(60'"c) Mladšij lejtenant posadil

neznakomca na poezd.

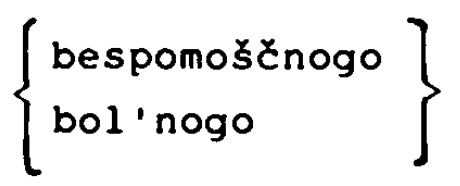

Soviel vorerst zur Prädikatsgruppe "helfen".

$\underline{P_{6}}$

Bit' Celoveka als ein Prädikat der physischen Einwirkung bezeichnet ebenso wie pomogat' eine Handlung, die nicht routinemäßig durchgeführt wird (vor allem bei bestimmten Personenkonstellationen) und in der Regel auf einen konkreten Anlaß $z$ urückgeht. Man kann deshalb davon ausgehen, daß eine Versprachlichung dieses Sachverhalts mit der Explizierung der diese Handlung auslösenden Gründe einhergeht. Das Beispiel, das ich hier betrachten will, bringt durch das performative verb pozvolit, einen zusätzlichen Aspekt in die Problematik. Ich werde dies zum Anlaß nehmen, auch kurz auf die Rolle modaler Elemente einzugehen.

(61) Ja ne pozvolju vam bit'! Bit' slabuju, p'januju ženščinu.

Eine motivierende Beziehung zwischen den Attributen und bit' ist nicht zu erkennen. "Schwäche" und "Trunkenheit" seitens des Betroffenen sind kein Anlaß, jemanden zum Schlagen anzuregen. Die eigentliche Beziehung zwischen Attribut und prädikativem Element ist in (61) auch nicht die zu bit'. sondern zu ne pozvolju. Allerdings liegt keine Begründungsrelation vor. (61) könnte man etwa wie folgt interpretieren:

"Ich erlaube euch nicht, die schwache und betrunkene Frau zu schlagen, weil Frauen $z u$ schlagen und zumal schwache und betrunkene äußerst verwerflich ist." Es geht also bei (61) um den Grad der Verwerflichkeit. Dies hat Einfluß auf die Setzung von Attributen: 
$(6 \pi$ ) Ja ne pozvolju vam bit'! Bit'

そ̌enščinu.

$$
\left\{\begin{array}{l}
{ }^{\star} \text { skromnuju } \\
\text { krasivuju } \\
\text { * } \text { strojnuju } \\
\text { *bogatuju } \\
\text { "nevysokuju } \\
{ }^{\star} \text { cernovolosuju }
\end{array}\right\}
$$

I Akzeptabel erscheint allein krasivuju, das ebenfalls einen hothen Grad von Verwerflichkeit zum Ausdruck bringt. Den eigentllichen Grund für den performativen Akt nennt aber auch dieses fAttribut nicht, denn einen plausiblen Grund, außer dem, daß nman Frauen nicht schlägt, gibt es nicht. Ein Satz wie schlagt c diese Frau nicht, denn sie hat es nicht getan wirkt in unser rem Kulturkreis, zumindest in bestimmten schichten, sehr beffremdlich. Die in (61) bzw. (61') wirksamen Restriktionen bet treffen somit nur den Aspekt der Verwerflichkeit.

Interessant ist (61) auch mit einem Agens der dritten Person:

(61') Ivan ne pozvolit/pozvoljaet vam bit'! Bit' slabuju p'januju ženščinu.

IIst es möglich, über eine subjektattribution einen Begründungsz zusammenhang herzustellen?

(61'i) $\left.\begin{array}{l}\text { Dobryj } \\ \text { Milostivyj }\end{array}\right\} \quad$ Ivan ne pozvolit/pozvoljaet vam bit'!

Bit' slabuju, p'januju ženščinu.

IDie zulässigkeit dieser Attribute würde voraussetzen, daß es lunter normalen Umständen nicht ungewöhnlich ist, Frauen zu sschlagen, und daß es im vorliegenden Fall allein von den angef führten Eigenschaften des Ivan abhängt, daß die Handlung unterssagt wird. Eine subjektattribution ist also nicht grundsätzlich Lunmọ̣̈lich, wenngleich nur wenige Adjektive für (61) in Frage kkommen.

CUm die mit bit' verbundenen Restriktionen beschreiben zu könr.nen, ist es notwendig, (61') umzubilden:

(6i) Ivan b'et parnja.

CDie Cbjektposition läßt eine Reihe von Attributen zu: 
(62') Ivan b'et $\left\{\begin{array}{l}\text { derzkogo } \\ \text { p'janogo } \\ \text { lenivogo } \\ \text { truslivogo } \\ \text { ryževatogo } \\ \text { chudoščvogo } \\ \text { ljubopytnogo } \\ \text { rassejannogo }\end{array}\right\}$ parnja.

Für die meisten dieser Attribute ist eine prädikatmotivierende Funktion denkbar, absolut zwingend erscheint sie jedoch nicht in jedem Fall. Interessant ist, daß diese Attribute nicht unmittelbar beobachtbare Merkmale des objekts, sondern viel eher Erfahrungen des subjektgegenstandes in bezug auf den objektgegenstand bezeichnen. Deshalb muß der objektgegenstand auch als definit angesehen werden. Beobachtbare Eigenschaften wie ryževatyj und chudošcavyj signalisieren, daß es sich um einen indefiniten Gegenstand handelt, vorausgesetzt sie werden nicht restriktiv eingesetzt.

Es ist nicht überraschend, daß auch die subjektattribution prädikatmotivierend sein kann:

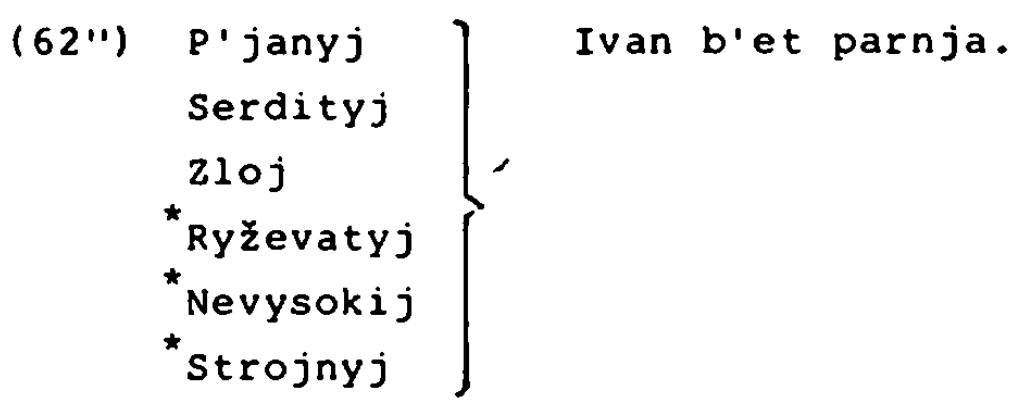

Prädikatmotivierend sind offensichtlich aber nur Adjektive, die auf Merkmale wie [erregt] oder [unkontrolliert handelnd] hinweisen.

Die Überprüfung der Möglichkeit, subjekt- und objektattribute gleichzeitig zu realisieren, zeigt, daß in beiden positionen Attribute vorkommen können. Es scheint das objektattribut über das subjektattribut $z u$ dominieren.

$$
\text { (62) } \left.\left.\begin{array}{l}
\text { p'janyj } \\
\text { Serdityj } \\
z l o j
\end{array}\right\} \quad \begin{array}{l}
\text { Ivan b'et } \\
\text { lenivogo } \\
\text { truslivogo } \\
\text { ljubopytnogo }
\end{array}\right\} \text { parnja. }
$$


Nicht mehr motivierend ist $\mathrm{p}^{\prime} j a n y j$ in beiden Positionen.

(62M P'janyj Ivan b'et p'janogo parnja.

Wie angekündigt, sei jetzt noch kurz auf den Einfluß modaler Elemente auf die Attribuierungsmöglichkeiten eingegangen.

Einen ersten Eindruck hat bereits (61) vermittelt.

Sehen wir uns die Einsetzungsmöglichkeiten in folgenden drei Sätzen an:

(63) Ivan chočt bit' parnja.

(64) Ivan dolžen bit' parnja.

(65) Ivan možet bit' parnja.

Wenn man einmal von der Künstlichkeit dieser sätze absieht, dann zeigt sich, daß die einzelnen Modi in unterschiedlicher Weise die Verwendung von Attributen restringieren.

(63') Ivan chočet bit'

$$
\left\{\begin{array}{l}
\text { derzkogo } \\
\text { lenivogo } \\
\text { truslivogo } \\
\text { ljubopytnogo } \\
\text { ryževatogo } \\
\text { tolstogo }
\end{array}\right\} \text { parnja. }
$$

Zunächst ist festzustellen, daß alle Attribute im Rahmen von (63) akzeptabel sind. Die ersten vier können als motivierend angesehen werden, allerdings scheint die Attribution nicht die beste Lösung für eine Motivierung der Handlung zu sein. Interessant ist, daß die beiden letzten Attribute, die keine Motivationsbeziehung suggerieren, anders als in (62') nicht auf einen unbestimmten, sondern auf einen bestimmten Gegenstand verweisen.

(64') Ivan dolžen bit. $\left\{\begin{array}{l}\text { ?derzkogo } \\ \text { ? lenivogo } \\ ? \text { truslivogo } \\ ? \text { ljubopytnogo } \\ ? \text { ryževatogo } \\ ? \text { tolstogo }\end{array}\right\}$ parnja.

Alle Attribute wirken in Verbindung mit dolžen mehr oder minder befremdlich, soweit sie nicht restriktiver Natur sind. Dies 
hängt damit zusammen, daß "müssen" nicht objektorientiert ist, sondern, genauer gesagt, seine Motivation von außerhalb des Satzes erhält.

(65') Ivan možet bit.

$$
\left\{\begin{array}{l}
{ }^{\star} \text { derzkogo } \\
\vdots \\
\text { sil'nogo }
\end{array}\right\}
$$

parnja

Hier scheiden offensichtlich alle die Attribute aus, die nicht auf körperliche kräfte referieren.

Zum Schluß sei noch kurz auf die Rolle des Genus verbi bei der setzung von Attributen eingegangen.

Da bit' keine Passivform zuläßt, bilde ich (61) in einen unbestimmt-persönlichen Satz um:

$$
\left.\begin{array}{l}
\text { Derzkogo } \\
\text { p'janogo } \\
\text { Lenivogo } \\
\text { Truslivogo }
\end{array}\right\} \quad \text { parnja bili. }
$$

Die Akzeptabilität dieser Attribute zeigt, daß der Genuswechsel die Motivationsbeziehungen offensichtlich nicht beeinflußt. Die prädikatmotivierenden Objektattribute des Aktivsatzes haben auch als subjektattribute im Passivsatz motivierende Funktion. Vgl. dazu noch:

(67) Ivan nasil'no vytaščil na scenu soprotivljajuščujusja Asju. - Soprotivljajuščajasja Asja byla nasil'no vytaščena na scenu.

Die Ergebnisse dieser ersten Analyse bedürfen noch einer gründlichen überprüfung.

$\underline{7}$

Ich komme nun $z u$ zwei Beispielen, die ein prädikat des "physischen Zustands" enthalten. Markierte Zustände und Zustandsveränderungen haben in der Regel einen konkreten Anlaß, der - wie sich zeigen wird - auch über Attribute versprachlicht werden kann. Eine Ausnahme scheint byt' bol'nym/bol'noj darzu- 
stellen, denn es läßt sich kein motivierendes subjektattribut dazu finden - zumindest habe ich bisher keines gefunden. Sehen wir uns die konkreten Beispiele an:

(68) V tesnom, zastegnutom na vse pugovicy kitele, v zamusolennom galstuke, rezinkoj stjagivajušem plotnuju క̌eju, on Kuvstroval sebja neujutno.

Die Motivation für das Prädikat ist klar: "Weil der Kittel zu eng ... war und der ... Schlips den dicken Hals ... zusammenzog, fühlte $X$ sich unbequem."

Es hängt mit der Eigenart des Prädikats zusammen, daß die Attributsposition nur mit Adjektiven besetzt werden kann, die das Merkmal [(zu) eng] haben. Diese Eigenart ist auch dafür verantwortlich, daß beide objekte attribuiert werden müssen, zumal das Attribut des ersten Nomens sich nicht auch noch auf das zweite erstreckt.

Eine Subjektattribution ist bei dem gegebenen Prädikat nicht möglich :

(68') *Bol'noj Ivan Cuvstroval sebja neujutno.

(68') ${ }^{\star} v$ tesnom, zastegnutom na vse pugovicy kitele, bol'noj Ivan Cuvstroval sebja neujutno.

Nun zu unserem zweiten Beispiel:

(69) Slaben'kie devuški padali v obmorok.

Sicherlich kann man das subjektattribut als prädikatmotivierend ansehen, es gibt einen plausiblen Grund für die zustandsveränderung an. Die motivierende Beziehung unterliegt, den Beispielen unter $\mathrm{P}_{4}$ entsprechend, objektiven Kausalbeziehungen. Dies bedeutet, daß slaben'kie nur durch solche Attribute ersetzt werden kann, die irgendwie auf ein Merkmal [ Schwäche] hinweisen: ranenye, ispugannye u.a. Die setzung nichtmotivierender Attribute ist nicht möglich. Dies ist darauf zurückzuführen, daß in Verbindung mit dem Plural das Attribut restriktiver Natur ist. Der Satz

(69.) Krasivye devuski padali $v$ obmorok würde bedeuten, daß nur die hübschen Mädchen ohnmächtig wurden bzw. daß alle Mädchen hübsch waren und ohnmächtig wurden. Es 
erscheint aber nicht möglich, für diese Aussage eine plausible Erklärung zu finden.

Angesichts dieser Beispiele läßt sich fast voraussagen, daß bei Prädikaten des Typs $\mathrm{P}_{7}$ relativ starke Restriktionen bezüglich der Attributionsmöglichkeiten bestehen. Es muß weiteren Untersuchungen vorbehalten bleiben, diese Vermutung $z u$ bestätigen.

$\underline{P_{8}}$

Die Prädikate, die vorläufig unter dem Begriff "erfolgreiche/ nichterfolgreiche Handlung" zusammengefaßt werden, zeichnen sich dadurch aus, daß sie ausgesprochen subjektorientiert sind. Es ist somit zu erwarten, daß motivierende Beziehungen vor allem von subjektattributen ausgehen. Sehen wir uns dazu folgende Beispiele an:

(70) V dežurnoj komnate gorničnaja neožidanno oprokinula cajnik s kipjatkom.

Es besteht kein Zweifel, daß diese Aussage nicht unbedingt begründungsbedurftig ist. Dies hängt damit zusammen, daß es sich bei oprokinut. hier nicht um eine kontrollierte, sondern um eine unbeabsichtigte Handlung handelt. Dennoch bereitet es keine Mühe, für Sachverhalte dieser Art eine plausible Begründung $z u$ rekonstruieren.

(70') V dežurnoj komnate

$$
\left\{\begin{array}{l}
\text { nervnaja } \\
\text { smuščnnaja } \\
\text { ustalaja }
\end{array}\right\}
$$

gorničnaja

neožidanno oprokinula čajnik s kipjatkom.

Es ist leicht einzusehen, daß nicht alle Merkmale, die auf die von gorničnaja bezeichnete Person zutreffen, prädikatmotivierend sein können.

$$
\text { (70") V dežurnoj komnate }\left\{\begin{array}{c}
\text { krasivaja } \\
\text { ?belozubaja } \\
\text { ?strojnaja } \\
\text { ?golodnaja }
\end{array} \mid\right. \text { gorničnaja }
$$


$\left(70^{\prime \prime}\right)$

$$
\left|\begin{array}{l}
\text { ?razočarovannaja } \\
\text { ?dobroserdečnaja } \\
\text { ?sil'no razmalevannaja }
\end{array}\right|
$$

... oprokinula Čajnik s kipjatkom.

Diese Attribute sind nicht nur nicht motivierend, sondern bis auf krasivaja auch nicht motivierbar, d.h. sie signalisieren eine Beziehung zum Prädikat, die ohne Grundlage ist. Krasivaja hat, wie vielleicht auch molodaja, einen neutralen status. Diese Merkmale müssen nicht erst über eine spezielle Konstruktion in den Text eingefürt werden.

Die Attribuierung des Akkusativobjekts ist, wie oben angedeutet, ohne Relevanz für das Prädikat und unterliegt den gleichen Bedingungen wie die Attribuierung bei $P_{0}$-Prädikaten.

Etwas anders ist die Situation bei der Umstandsangabe. Hier ist eine prädikatmotivierende Attribution durchaus denkbar :

(70'i) V $\quad\left\{\begin{array}{l}u z k o j \\ \text { temnoj }\end{array}\right\}$ dežurnoj komnate ...

Die von den Attributen genannten Bedingungen sind zweifellos als Begründungen für die nichterfolgreiche bzw. unerwünschte Handlung plausibel.

Für (70) gilt also: die subjektposition läßt grundsätzlich nur motivierende Attribute zu. Eine Ausnahme stellen krasivyj und molodoj dar. Motivierend sind Attribute mit einem Merkmal [ begünstigt unkontrollierte Handlung]. Die erste objektposition ermöglicht keine prädikatmotiverenden Attribute, während die zweite motivierende Attribute erlaubt, wobei nur solche in Frage kommen, die ebenfalls auf das Merkmal [begüstigt unkontrollierte Handlung] verweisen.

Nun noch ein anderes Beispiel:

(71) Ona stala provodnicej $v$ poezde Moskva-Suchumi. Krasivaja blondinka imela uspech u passažirov s Černymi usikami.

Dieses Beispiel weist eine Besonderheit auf, die wir bisher noch nicht beobachtet haben. Das attribuierte substantiv blondinka ist ein Amalgam aus einer Farben- und Personenbezeichnung. Im Russischen kann dies zufälligerweise nicht durch 
eine Verbindung Adjektiv + Substantiv ausgedrückt werden:

*blond - devuška. Ich weise mit Absicht auf dieses Phänomen hin, denn es ist offensichtlich, daß das zusammen mit der Personenbezeichnung realisierte Farbmerkmal, das in (71) eine Motivationsbeziehung zum Prädikatsausdruck eingeht, und zwar mit dem restriktiven Attribut als einer Komponente des prädikats (blondinka $\rightarrow$ s cernymi usikami)prädikatmotivierend ist. Daß das inhärente Prädikat tatsächlich diese Funktion hat, läßt sich anhand einiger Modifikationen von (71) demonstrieren.

(71') Blondinka imela uspech u passažirov s černymi usikami.

(71') Krasivaja devuška imela uspech u passažirov s černymi usikami.

(71'1) Krasivaja devuška (blondinka) imela uspech u passažirov.

Bei (71') bleibt die Motivationsbeziehung des Originalsatzes erhalten. Die zweite Variante suggeriert eine Motivationsbeziehung zwischen krasivaja und Prädikatskomplex, allerdings ist ohne weitere Erläuterungen nicht plausibel, welche Rolle die schwarzen Schnurrbärte in diesem zusammenhang spielen. Streicht man diese Konstituente des Prädikats, dann ruft die prädikatmotivierende Funktion des Attributs keine Zweifel hervor (vgl. (71'l)).

Die Motivationsbeziehung $z$ wischen blondinka und dem Prädikat bleibt auch erhalten, wenn ich in (71') eines der folgenden Adjektive einsetze: strojnaja, ljubeznaja, tolstaja, polnaja.

Setze ich die gleichen Attribute für krasivaja in (71") ein, dann erhalte ich ziemlich problematische Sätze. Schuld daran ist die restriktive Bestimmung bei passažirov.

Die gleiche Operation führt bei (71'") zu unterschiedlicien Ergebnissen.

(71'“a) Ljubeznaja devuška imela uspech u passažirov.

(71“'b) strojnaja devuška imela uspech u passažirov.

(71'“c) Tolstaja devuška imela uspech u passažirov.

(71'“d) Polnaja devuška imela uspech u passažirov. 
Für die (a)-Variante kann zweifellos eine prädikatmotivierende Funktion des Attributs angenommen werden. Bei den anderen Varianten drängt sich eine solche Interpretation nicht auf. Es ist überhaupt die Frage, ob im Kontext von (71) Attributionen dieser Art möglich sind. Ich werde diesen Punkt in einem speziellen Kapitel ausführlicher behandeln.

Ohne mich im Augenblick noch eingehender mit diesem Typ von Prädikaten beschäftigen zu können, sei doch noch erwähnt, daß nicht in jedem Fall nichttriviale Begründungen für erfolgreiche/nichterfolgreiche Handlungen gefunden werden können. Vgl.

(72) Igor' uže uspevaet svjazat'sja po radio s Kuz'mičom i dokladyvaet.

Welche Eigenschaft von Igor' könnte für den Erfolg der Handlung verantwortlich gemacht werden?

$\underline{P_{9}}$

Ein Beispiel soll genügen um diesen Prädikatstyp vorzustellen:

(73) Ispugannaja devuška kričala.

Kričala als spontane Handlung ist markiert und somit motivierbar. Interessanterweise haben neben ispugannaja nicht viele Attribute diese Funktion. Es sieht so aus, als ob zwar generell etwas darüber ausgesagt werden kann, welche Adjektivattribute bei $\mathrm{P}_{9}$-Prädikaten niemals motivierende Funktion haben, im einzelnen scheinen die subtypen von $P_{9}$ jedoch über ganz eigene Restriktionen $z u$ verfügen. Siehe dazu

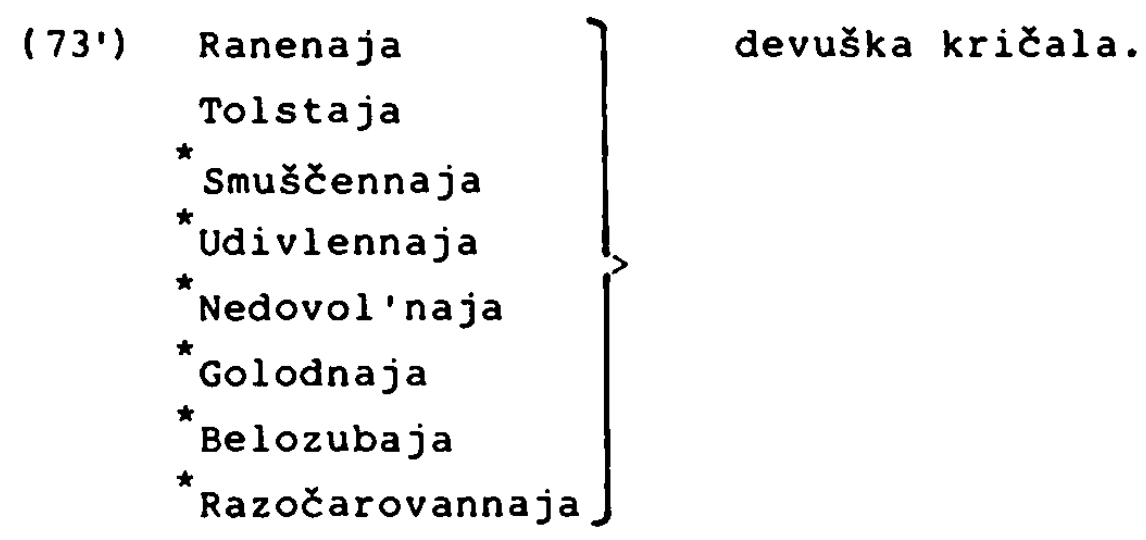


Die Akzeptabilität von tolstaja beruht darauf, daß dieses Attribut beschreibende Funktion hat, vorausgesetzt, es liegt keine anaphorische Beziehung zum Vorsatz vor. Von den übrigen Attributen ist belozubaja absolut unmotiviert, während die anderen z.T. nur deshalb nicht akzeptabel sind, weil sie beim falschen Prädikat stehen:

(73') Razočarovannaja
Golodnaja J devuška zaplakala.

Es sei unter Bezug auf das Adjektiv ispugannaja nur am Rande erwähnt, daß ein und dasselbe Adjektiv für ganz unterschiedliche (zumindest auf den ersten Blick) Ereignisse motivierend sein kann. $\mathrm{Vgl}$.:

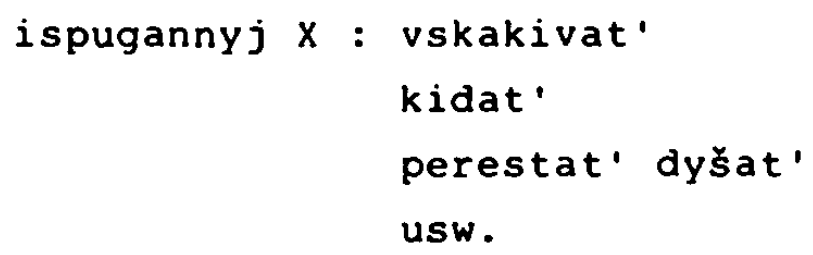

Sicherlich kann nicht für ein beliebiges Adjektiv eine Liste der Prädikate aufgestellt werden, für die es motivierende Funktion haben kann. Es wäre aber dennoch interessant, sich der Motivationsbeziehung auch von dieser seite zu nähern.

$\underline{10}$

Die Prädikate dieser Gruppe sind eindeutig subjektorientiert. Motivierende Beziehungen sind somit relativ beschränkt. Vgl.

(74) Varvara terebit kroj skaterti.

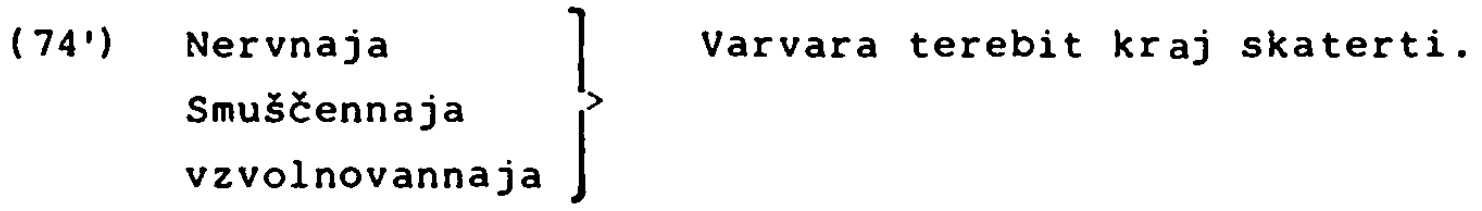

Die Attributierungsmöglichkeiten können durch eine Reihe anderer Faktoren beeinflußt werden. So ist es beispielsweise nicht möglich, die prädikatmotivierende Beziehung in (74') auch bei koordinierten Prädikaten zu erhalten: 


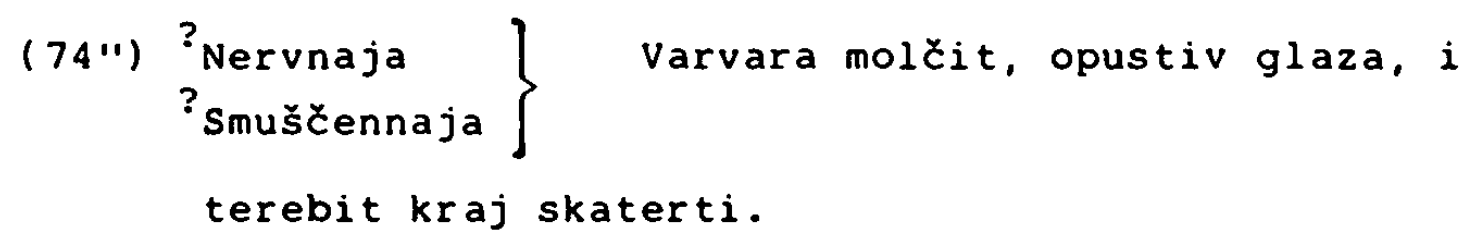

Motiviert werden könnte hier nur das Vorderkonjunkt, denn der Skopus des Attributs erfaßt das koordinierte prädikat nicht.

Beeinflußt wird die Attribution auch durch die Einbettung von Sätzen wie (74) in andere sätze. Vgl.

(75) I ja vižu, kak varvara kusaet guby.

(75') I ja vižu, kak

$$
\left\{\begin{array}{l}
\text { nervnaja } \\
\text { smuščnnaja } \\
\text { molodaja } \\
\text { krasivaja } \\
\text { tolstaja } \\
? \text { strojnaja } \\
\text { ?belozubaja }
\end{array}\right\}
$$

Varvara

kusaet guby.

Das Besondere an (75') besteht darin, daß einerseits nur solche motivierenden Attribute möglich sind, die auf beobachtbare Merkmale verweisen bzw. von denen der Subjektgegenstand des übergeordneten Satzes Kenntnis hat, und daß andererseits

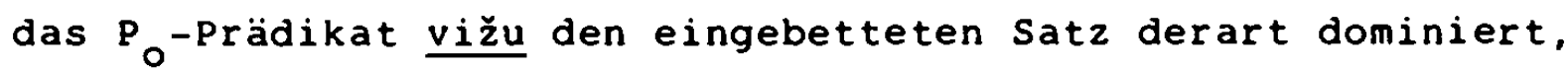
daß auch nichtmotivierende (und neutrale) Adjektivattribute möglich sind. Die Grenzen werden durch die jeweilige Markiertheit der Adjektive bestimmt.

(74) und (75) bieten auch Gelegenheit, auf die "Konkurrenz" von Attribut und Adverb einzugehen. Von dieser kann eigentlich nur dann die Rede sein, wenn die Attribute nichtmotivierend sind, denn die Adverbien können nicht motivieren:

(74'") Varvara nervno terebit kraj skaterti.

Das Adverb fixiert nur äußerlich beobachtbare Merkmale, eine Handlungsursache nennt es nicht.

Ich habe meine Prädikatsliste auf Seite 18 offengelassen. Es bleibt den weiteren Untersuchungen vorbehalten, Modifikationen und Ergänzungen einzubringen. 


\section{Negierte Prädikate}

Ich möchte an einigen Beispielen nachweisen, daß auch fir negierte Prädikate Motivationsbeziehungen eine Rolle spielen. Es kann sicherlich nicht behauptet werden, daß diese Beziehung für alle negierten Prädikate relevant ist - die Beschränkungen bedürfen einer eingehenden Untersuchung.

Ich will hier zunächst die Fälle ausklammern, in denen die Attribute obligatorischer Natur sind. Also Beispiele der $\$ 01-$ genden Art:

(76) Rebenok $v$ šube ne možet begat'.

(77) V cholodnom more nel'zja kupat'sja.

(Russkaja grammatika,1981,S.138)

Mir geht es um sätze wie (78):

(78) Ostorožnyj Sandalov $v$ poezdke ne byl, on nachodilsja v Moskve...

Dieser Satz ist etwa folgendermaßen zu interpretieren:

"Sandalov (selbst) machte die Reise nicht mit (im Gegensatz zu den anderen Mitgliedern der Gruppe), weil er vorsichtig war (=weil er mit der Fahrt keine Risiken eingehen wollte)."

Die kausale Interpretation wird vom negierten Prädikat nahegelegt. Allerdings wird sie erwartungsgemäß nicht von beliebigen Attributen erfült:

(78') $\left.\begin{array}{l}\text { ? Strojnyj } \\ \text { *Cernoglazyj }\end{array}\right\} \quad$ Sandalov ...

Prädikatmotivierend sind dagegen Adjektive, die entweder physische Defizite bezeichnen (ihre Setzbarkeit wird letztlich aber vom Kontext bestimmt) oder auf eine geistige Auseinandersetzung mit der durchzuführenden Handlung hinweisen.

(78') $\left.\begin{array}{l}\text { Bol'noj } \\ \text { Umnyj } \\ \text { Truslivyj }\end{array}\right\}$

Sandalov $v$ poezdke ne byl $\ldots$ 
Ein weiteres Beispiel:

(79) Kolossal'nuju posylku privez. Mne ee domoj nesti nel'zja.

Das Attribut gibt auch hier eine zufriedenstellende Begründung für die Nichtdurchführbarkeit der Handlung an. Natürlich sind auch andere Begründungen denkbar. Nur, über das Mittel der Attribution sind die Möglichkeiten beschränkt:

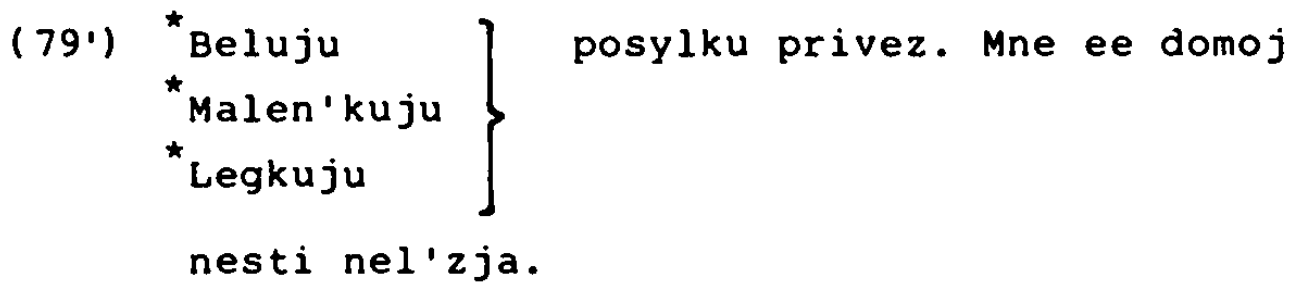

Zum Schluß noch ein Beispiel, in dem das subjektattribut nicht prädikatmotivierend fungiert. Der Grund dafür scheint zu sein, daß das Attribut das nichtnegierte Prädikat motiviert und somit bei negiertem prädikat eine andere Funktion übernimmt:

(80) Ostorožnyj Semen P., navernoe, i sam ne podozrevaet, skol'ko kradennych veščj oselo u nego $v$ dome.

Hier muß ostorožnyj als Teil einer obwohl-Beziehung angesehen werden.

Die Ersetzungsmöglichkeiten für ostorožnyj sind übrigens äußerst gering.

\section{Motivierende Sachverhaltsbeziehungen}

Ich komme nun zu den Fällen, bei denen es mir schwergefallen ist, für die Setzbarkeit/Nichtsetzbarkeit eines Attributs einen bestimmten Prädikatstyp verantwortlich $z$ u machen. Am ehesten wäre dies noch in folgenden Fällen möglich gewesen, für die direkte Rede in Verbindung mit Verben des Sagens charakteristisch ist.

(81) Tak, tak, tak! - skazal zaintrigirovannyj vrač.

(82) O'kej! - probormotal dovol'nyj Bunjakov.

(83) Postoj! - zavopila oglušennaja i potrjasennaja Asja.

(84) Vitaliju spasibo, - dobavljaet blagodarnaja Alla. 
Diese Beispiele unterscheiden sich von den bisher besprochenen dadurch, daß die Attribute nicht eine Beziehung zum Prädikat/Verb, sondern zu dem jeweils zugeordneten Inhaltssatz (ausgedrückt durch die direkte Rede) eingehen. Die Sätze (81) bis (84) können in zweifacher Weise interpretiert werden, (82) 2.B. so:

1. "Weil Bunjakov zufrieden war, murmelte er 'okay'."

2. "Die Äußerung 'okay' zeigt, daß Bunjakov zufrieden war." Ich glaube, daß sich diese Interpretationen nicht gegenseitig ausschließen.

Während für (82) relativ einfach die Beziehung zwischen Attribut und direkter Rede herzustellen war, sind die übrigen Beispiele, abgesehen von ( 84 ), wesentlich problematischer, da vom Inhaltssatz kein Hinweis auf konkrete Eigenschaften der Subjektgegenstände gegeben wird. Erst das Attribut selbst entschlüsselt die Äußerung. Bei (83) wird die Interpretation durch das markierte Prädikat zavopila unterstützt.

Es wäre höchst interessant, zu untersuchen, welcher Grad von Beliebigkeit bei der "Interpretation" der direkten Rede durch die Subjektattribute im Einzelfall vorliegt. Leider kann ich hier nicht näher auf diese Frage eingehen. Auch anhand der Beispiele (81) bis (84) läßt sich die Konkurrenz von Attribut und Adverb noch einmal behandeln. Vgl.

(85) - Pomnite éto, tovarišč Gurin?

- Vrode pripominaju, - smuščenno otozvalsja Gurin / otozvalsja smuščennyj Gurin.

(86) Esli vse budut vyigryvat' po motociklu, razoritsja strana, - nasmešlivo skazal otec

/ skazal nasmešlivyj otec.

Der Vergleich der Varianten macht deutlich, daß von einer Konkurrenz zwischen Attribut und Adverb nicht die Rede sein kann. Das Adverb charakterisiert stets Form und/oder Inhalt der wörtlichen Rede, ist aber niemals Konstituente einer Motivationsbeziehung.

Ich komme nun $z u$ einem anderen Fall von Motivation. Sehen wir uns zunächst das Beispiel an: 
(87) On pisal i dyšal na obmorožennye, negnuščiesja pal'cy, dyšal i snova pisal.

Das Besondere dieses Satzes besteht darin, daß die Abfolge der Ereignisse pisal und dyšal nicht in irgendeinem natürlichen, sachlich bedingten Zusammenhang zueinander steht. Es ist vielmehr so, daß bei entsprechendem Kontext die zweite Handlung unerwartet eintritt. Bei fehlender kontextueller Vorbereitung muß der Rezipient, will er die Verbindung als vernüftig beurteilen, eine erklärende Erläuterung haben, eine motivierende Begründung. In unserem Beispiel wird das Informationsdefizit durch das objektattribut abgedeckt. Wie in all unseren Beispielen vorher, unterliegt auch hier die Attribution strengen Restriktionen.

(87') On pisal i dyšal na

$$
\left\{\begin{array}{l}
{ }^{*} \text { dlinnye } \\
{ }^{*} \text { krasivye } \\
{ }^{\star} \text { blednye } \\
\text { zanemelye } \\
\text { cholodnye }
\end{array}\right\}
$$$$
\text { pal'cy ... }
$$

In (87) sind nur prädikatmotivierende Attribute möglich. Diese müssen auf das Merkmal [steif, unbeweglich] verweisen. Die Frage der Subjektattribution stellt sich für den konkreten Satz (87) nicht. Ihr stehen Pronomen und koordinierte Prädikate im Wege.

Besondere Beachtung verdienen noch folgende Beispiele:

(88) Viktor sdelal bol'šoj zakaz, a kogda dovol'nyj oficiant ušel ...

(89) Tak i nazvali mal'čika Vanej, Ivanom. Sčastlivaja babuška bystro nakryla stol.

(90) Vidja, kak majutsja ego kollegi, sovestlivyj Enén prichodil na ékzameny čašče obyčnogo.

Auf den ersten Blick scheint allen drei Sätzen gemeinsam $z u$ sein, daß das Attribut motiviert, aber nicht prädikatmotivierend ist. Bei genauer Betrachtung zeigen sich jedoch einige Unterschiede. Dovol'nyj in (88) hat eindeutig keine motivierende Funktion, es ist durch den Vorsatz motiviert. Die Ersetzungsmöglichkeiten des Attributs unterliegen den Restriktio- 
nen, die für $P_{0}$-prädikate gelten. Es ist somit durchaus akzeptabel, für dovol'nyj Attribute wie ry̌̌yj, tolstyj, ljubeznyj einzusetzen. Motiviert sind diese Attribute natürlich nicht. In (89) hat das Attribut offensichtlich eine Funktion fuir die Textkohärenz. Dadurch, daß es durch den Kontext motiviert ist, stellt es auch den zusammenhang zwischen den beiden sätzen her. Die Ersetzungsmöglichkeiten für sčastlivaja sind gering. Nichtmotivierte Attribute vermögen nicht die Textkohärenz sicherzustellen und kommen somit für (89) nicht in Frage. Sovestlivyj in (90) ist teilmotivierend. Allerdings würde ein Satz wie $\left(90^{\circ}\right)$

(90') Sovestlivyj Enến prichodil na ékzameny čašče obyčnogo. nicht verstanden werden, da die eigentliche Begründung für das Prädikat nicht vorliegt. Sovestlivyj expliziert somit nur eine für die Handlung notwendige Voraussetzung beim Agenten. Geht man davon aus, daß mit Enên eine aus dem Kontext wohl bekannte Person bezeichnet wird, dann bleiben für die subjektattribution nur motivierte Attribute ubrig.

Bevor ich die Ergebnisse dieser Untersuchung zusammenfasse und ihre Relevanz für die Sprachbeschreibung bewerte, sei noch kurz auf das Phänomen der implizierten Attribute eingegangen.

Implizierte Attribute

Es gibt eine Vielzahl von fällen, in denen die Attribute nicht aus Gründen der prädikatmotivierenden Funktion oder aus Gründen der Einfühung wichtiger Informationen in den Text gesetzt werden, sondern deshalb, weil sie verstärkenden Charakter haben, indem sie implizit vorhandene Information explizit nennen. Für diese Attribute ist es typisch, daß sie praktisch nur durch synonyme ersetzt werden können. Die Attribute, genauer der Inhalt der Attribute kann sowohl im Prädikat als auch in den Nominalausdrücken implizit enthalten sein. Dazu einige Beispiele:

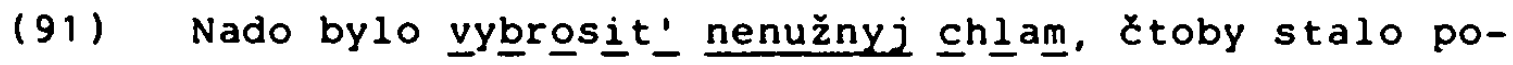
prostornee. 
(92) U Michaila tože byli osnovanija radovat'sja.

vo-pervych, on izㅁalㅣalsja_ot opostylevšej kabinetnoj raboty. Vo vtorych, nakonec-to pojavilsja dolgoždannyj šans vypolnit' važnoe zadanie Markova.

(93) Možno bylo by tol'ko požaleț' étogo čeloveka, za ego neskladnuju sud'bu, esli by ...

(94) Meždu tem nastojčivye usilija molodogo čeloveka,

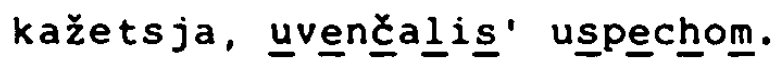

(95) Ona pošla tuda. Po sovetú mnogoopytnoj materi zachvatila s soboj kol'co.

Diese Beispiele mögen genügen. Sie belegen einen besonderen Fall der Attributsverwendung. Er hat fast phraseologischen Charakter. Interessant und wichtig ist, daß die Attributionsmöglichkeiten in hohem Maße restringiert und damit weitgehend voraussagbar sind.

\section{Zusammenfassung}

Ich habe in dieser Arbeit nachzuweisen versucht, daß die Setzbarkeit von Attributen in hohem Maße vom Satzprädikat bzw. der Prädikatsphrase bestimmt wird. Es hat sich gezeigt, daß es für die Beschreibung attributiver Konstruktionen absolut ungenügend ist, sich mit selektionalen Restriktionen zufrieden zu geben, zumal diese, genau genommen, noch nicht einmal linguistischer Natur sind. Die Rolle des über die unmittelbare Nominalphrase hinausgehenden Kontextes ist bisher nicht in seiner großen Bedeutung gewuirdigt worden. Er aber ist es, der die $\mathrm{Zu}-$ lässigkeit von Attributen, wenn keine syntaktischen und idiomatischen Hindernisse mehr im Wege stehen, letztlich bestimmt. Ich habe versucht, die $z u$ beobachtenden Regularitäten durch eine Klassifizierung von Prädikaten in systematischer Weise darzustellen, bin mir aber im klaren darüber, daß dieser Versuch noch nicht vollkommen ist. Die wesentliche Aufgabe scheint mir dennoch erfült. Es wird sicherlich noch umfangreicherer Untersuchungen bedüren, bevor alle mit diesem Ansatz aufgeworfenen Fragen und Probleme beantwortet bzw. gelöst und in 
ihrer Bedeutung für die Sprachbeschreibung gewürdigt werden können.

\section{Literatur}

1. Ermakova, O.P., Kontekstno obuslovlennaja sočetaemost. identificirujuščich suščstvitel'nych s prilagatel'nymi.

In: Sintaksis teksta, Moskva 1979. 153-161

2. Girke, W., Motivationelle Restriktionen.

In: Slavistische Linguistik 1978, München $1979,17-38$

3. Vasilevskaja, L.I., Sintaksičeskie vozmožnosti imeni sobstvennogo. II.

In: Problemy strukturnoj lingvistik: 1978 , Moskva 1981, 98-107

Quellen
A. Adamov,
Inspektor Losev. Dilogija: Zlym vetrom. Petlja. Kišinev 1985
V. Ardamatskij.
Sud. Moskva 1980
I. Grekova,
Kafedra. Moskva 1980
L. Lenč,
Dušespasitel'naja beseda. Moskva 1979
Priključenija
1979
v. Pronin,
Ošibka v ob-ekte. Moskva 1980
N. Sizov,
Nevydumannye rasskazy. Moskva 1980
o. Smelev,
V. Vostokov,
Vozvraščenie rezidenta. Moskva 1981
s. Vysockij,
Krutoj povorot. Moskva 1979
A.P. Cechov,
Izbrannye proizvedenija $v$ trech tomach. T.2, Moskva 1967 
Zur Attribuierbarkeit zweiterwähnter substantive

E.V. Padučeva hat in ihrem Buch "O semantike sintaksisa" und auch anderswo ${ }^{1}$ auf ein interessantes Phänomen hingewiesen. Sie macht darauf aufmerksam, daß bei der Zweiterwähnung von Substantiven folgende Attributionsrestriktion vorliegt: Ein gegebenes Nomen kann nur bei seinem ersten, nicht aber bei seinem zweiten Auftreten attribuiert werden. Sätze wie der folgende seien, so sagt sie, zumindest abweichend:

(1) My našli v čulane čajnik, i vskipjatili v žestjanom čajnike 2 vodu.

[Hervorhebungen hier und im folgenden von mir]

Den abweichenden Charakter dieses Satzes führt Padučeva darauf zurück, daß durch die Einführung des Attributs žestjanoj die

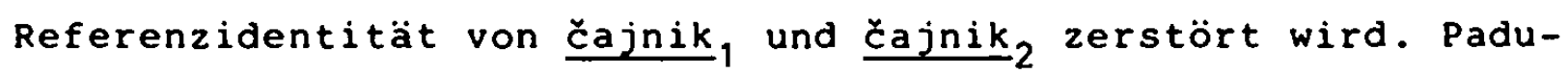
čevas These ist auf den ersten Blick plausibel, aber folgende Beispiele zwingen $z u$ einer Problematisierung:

(2) Povesiv ee sumku na plečo, Chilkov podošel k dverjam. stekljannye dveri byli zaperty.

(3) Klejsterov snimal komnatu v derevjannom dome u odnoj staruški, ljubitel'nicy cvetov. Ich bylo polno na oknach, na polu, v kadkach. I čisten'kaja staruškas sedoj golovoj, $v$ cvetastom chalate tože byla pochoža na kakoe-to rastenie.

(4) Na vtoroj den' maja, kogda mat' neizmenno povjazyvala černyj platok, a ... Marija prinesla $v$ dom ščenka s okrovavlennymi lapami. Krupnyj, s otvislymi ušami ščenok, ispeščrennyj pjatnami po šokoladnoj šersti doverčivo l'nul $k$ svoej spasatel'nice...

(5) Butovych chata stojala u samogo morja na vysokom, krutom beregu. Niže letali čajki, vyše lastočki. Krasnyj glinistyj bereg uvalami spuskalsja $k$ morju.

Es wäre zu einfach, die angeführten Beispiele als Performanzphänomen abzutun, denn abweichend wie (1) sind sie nicht. Es ist zweifellos nicht der Normalfall, daß definiten Nomen über die Attribution neue Merkmale zugewiesen werden, dennoch scheint 
es

grundsätzlich möglich zu sein.

Zur Erklärung der von mir angeführten Gegenbeispiele bzw. der von Padučeva formulierten Restriktion ist es notwendig, kurz auf die Rolle von Attribution und Prädikation bei der Merkmalzuweisung einzugehen. ${ }^{2}$ Die zentrale Funktion der Attribution besteht darin, indefiniten Nomina Merkmale zuzuweisen, die der Prädikation darin, definite Nomina näher zu charakterisieren. Vgl.

(6) Za stolikom vozle lifta nemolodaja polnaja ženščina... cto-to zapisyvaet $v$ tetrad'.

(7) V antrakte on stal $v$ očered' $v$ bufet vypit' piva. očered' byla bol'šaja.

Charakteristisch für den Satz mit attributiver Konstruktion ist, daß er eine Existenzaussage enthält, die offensichtlich in besonderem Maß dafür geeignet ist, einen Gegenstand mitsamt seinen (beobachtbaren) Merkmalen in den Text einzufuhren. Ist ein Nomen definit aufgrund expliziter vorerwähntheit, ist es grundsätzlich problematisch, neue Merkmale uber Attribute zuzuweisen, denn die Vorerwähntheit betrifft auch die Attribute und zeigt somit eine Bekanntheit der entsprechenden Merkmale an. Attribute bei definiten Nomina liefern also normalerweise keine neue Information, sondern fungieren als Epitheta ornantia bzw. als identifikatorische Merkmale. Die Beispiele (2) bis (5) scheinen gegen diese Grunduberlegung $2 u$ sprechen. Da sie als real gegeben angesehen werden müssen (und ihre zahl noch erweitert werden könntel, muß die Attribution differenzierter gesehen werden. Zunächst muß überprüft werden, ob Padučeva tatsächlich eine Restriktion formuliert hat. Eine genauere Betrachtung zeigt, daß Beispiel (1) als Beleg anfechtbar ist und zwar aus dem einfachen Grund, daß ein Nomen wieder aufgenommen, d.h. wiederholt wurde, obwohl eine pronominale Fortsetzung das naheliegendste gewesen wäre. Ich behaupte, daß (1) gegen die Pronominalisierungsregeln des Russischen verstößt ${ }^{3}$, denn es gibt keinen Grund, čajnik nicht $z u$ pronominalisieren. Es soll eine enge Bindung und nicht eine Zäsur angezeigt werden. Sieht man sich unter diesem Aspekt die Beispiele (2) bis (5) an, stellt man fest, daß in keinem der Beispiele das zweiterwähnte Nomen pronominalisiert werden darf. 
ohne daß Kohärenz-oder Referenzprobleme entstehen. Die Wiederholung des Nomens signalisiert in allen Fällen eine zäsur bzw. dient der Sicherung der Koreferenz. Erst- und Zweiterwähnung zeigen jeweils verschiedene Themen an, die dargestellten Sachverhalte stehen nicht in einem unmittelbaren thematischen $\mathrm{Zu}-$ sammenhang. Allenfalls sind in (2) die Sachverhalte etwas enger aneinander gebunden, jedoch nicht so eng, daß eine Pronominalisierung notwendig erscheint. Aus diesen Beobachtungen ergibt sich, daß entgegen Padučeva zweiterwähnte Nomina grundsätzlich attribuiert werden können (nichtattribuierbare werden ohnehin automatisch pronominalisiert). Die Attribute können allerdings nicht beliebiger Natur sein. Die zugewiesenen Merkmale müssen beobachtbar oder situativ/textuell erschließbar sein. Realisierte Attributionen suggerieren, daß die betreffenden Merkmale auch für den Rezipienten ermittelbar sind. Interessanterweise ist eine Attribution nur dann möglich, wenn die attributiven Merkmale im Vortext nicht versprachlicht worden sind, denn eine entsprechende Versprachlichung durch Attribution oder Prädikation fürt, wie die Modifikationen von (2) zeigen, zu einer Reihe von unerwünschten Ergebnissen:

(2')? Povesiv ee [sumku] na plečo, Chilkov podošel k stekljannym dverjam. Stekljannye dveri byli zaperty.

(2'1)? Povesiv ee [sumkul na plečo, Chilkov podošel k dverjam. Dveri stekljannye. Stekljannye dveri byli zaperty.

Wenn wir stekljannym dverjam in (2') als definite Nominalphrase verstehen, dann setzt dies voraus, daß dieser Gegenstand irgendwie bereits textuell etabliert ist. Außerdem scheint eine besondere Motivation für eine so spezifische Benennung des Gegenstandes erforderlich zu sein. Schließlich erzeugt die wiederholung des Attributs bei der wiederaufnahme von dveri eine unerwünschte Redundanz. Wenn wir die ersterwähnte Phrase indefinit verstehen, dann könnte man davon ausgehen, daß mehrere Türen zur Wahl stehen. Darüber hinaus ist auch in diesem Fall die wiederholung des Attributs redundant. Noch problematischer ist (2''). Diese Modifikation zeigt ganz deutlich, daß die Prädikation nicht notwendigerweise eine Vorstufe für die Attribution darstellt. 
Ganz im Gegenteil, es scheint eher die Ausnahme zu sein, daß ein Attribut prädikativ vorbereitet wird ${ }^{4}$. Die in (2 $)^{\prime}$ realisierte Informationswiederholung führt zu einem nichtakzeptablen Satz. Man muß davon ausgehen, daß prädikative Adjektive grundsätzlich anders motiviert sind als attributive und nicht dazu dienen, attributive vorzubereiten. Vergleiche dazu folgende Beispiele mit prädikativen Adjektiven, bei denen es schwerfälit, sich eine anschließende attributive Verwendung der Adjektive (bei gleichem Bezugsnomen) vorzustellen.

(8) Dlja mladšich brat'ev on [Sajkin] vrode otca: strog. spravediv, vzyskatelen.

(9) Predloženie interesnoe, - skazal Selivanov - Takaja proverka, konečno, možet vyvesti nas na prestupnikov...

Die hier angeschnittene Problematik bedarf naturlich noch einer eingehenden Untersuchung.

Ich muß nun zwangsläufig auch noch auf die frage eingehen, warum das Problem der Attribuierung des zweiterwähnten Nomens nicht dadurch gelöst wird, daß die entsprechenden Merkmale einfach dem ersterwähnten Nomen zugewiesen werden. Diese "Lösung" ist in vielfacher Weise problematisch. Sehen wir uns dazu Beispiel (3) näher an. Die Vorverlagerung des Attributs čisten'kaja ist zum einen dadurch restringiert, daß das bezeichnete Merkmal beim Erstvorkommen von staruška unmotiviert ist, d.h. in keiner vernünftigen Beziehung zum Prädikat oder einem anderen Satzglied steht. Nimmt man die anderen Attribute noch hinzu, wird die Situation noch schwieriger. Der zweite Effekt der Vorverlagerung des Attributs bzw. der Attribute besteht darin, daß nun der Satz mit dem Zweitvorkommen von staruška schlecht motiviert ist. Ähnliche Probleme wirft auch (4) auf. Während beim Erstvorkommen von ščenok das Attribut $s$ okrovavlennymi lapami die prädikative Aussage motiviert, würde die Hinzufügung der später realisierten Merkmale die Motivationsbeziehung verdunkeln bzw. das Interesse des Rezipienten in eine andere Richtung lenken. Eine weitere Folge wäre, daß durch die Tilgung der Attribute beim Zweitvorkommen von ščenok dieser satz eine nicht begründete enge Bindung an den Vorgängersatz signalisieren würde. Dies bedeutet, daß in (4) die Attribute beim Zweitvorkommen von ščenok die Zasur zwischen den beiden Vorkommen dieser Phrase verstärken. 
In (5) schließlich führt eine Vorwegnahme der Attribute einerseits $z u$ einer inhomogenen häufung von Attributen beim Antezedens, andererseits wird durch die Merkmalentnahme im zweiten Satz plötzlich das Merkmal uvalami mit besonderem textuellen Gewicht ausgestattet. Diese Beobachtungen zeigen, daß Attribuierungen auch aus Gründen der Verteilung der kommunikativen Gewichte in sätzen restringiert werden und keineswegs nur durch semantische Unverträglichkeitsbedingungen.

Sehr häufig enthalten Konstruktionen mit attribuierten zweiterwähnten Nomina das Pronomen étot, das explizit signalisiert, daß das durch das Attribut zugewiesene Merkmal als bekannt, erschlossen usw. verstanden werden soll:

(10) Očnuju stavku provodili v kabinete načal'nika operativnoj časti sledstvennogo izoljatora. Eta komnata byla pobol'še... Meždu étimi dvumja i ostal'nymi uže prolegal nevidimyj rubež nravstvennogo protivostojanija, i prjamaja bor'ba dobra i zla prochodila i zdes', v étoj seroj komnate.

(11) ... stupeni lestnic proseli i častično obrušalis'. spuskajas' po étim ščerbatym stupenjam.... Enén každyj raz gor'kim slovom pominal architektora...

Von besonderem Interesse ist vor allem in Hinsicht auf die oben geführte Diskussion Beispiel (11). Es zeigt, daß es Wege gibt, attributiv zugewiesene Merkmale kontextuell vorzubereiten. In (11) sind es die Verbalprädikate, die die Merkmalzuweisung als motiviert erscheinen lassen, ohne daß es $z u$ den oben besprochenen Konflikten kommt. Dies ist offensichtlich dem Umstand $z u$ verdanken, daß keine lexemgetreue wiederholung vorliegt und damit keine Redundanz erzeugt wird. In den nachfolgenden Beispielen werden noch andere Möglichkeiten der kontextuellen Vorbereitung attributiver Merkmale vorgestellt:

(12) Dal'še, vperedi, lug, prorezannyj glubokim ovragom, sploš zarosšim kustarnikom i bolotnymi travami, - letom k nemu i ne podstupiš'sja. skvoz' gustoj kustarnik čut' vidneetsja na toj storone ovraga starinnaja monastyrskaja časovenka. 
(13) Kornilov počuvstroval, čto ne usnet, odelsja i vyšel na verchnjuju palubu. Rezkij veter čut' ne sbil ego $s$ nog. Priderživajas' rukoj za poručen', on prošel po mokroj palube na nos i stal v zatiške.

(14) Podolgu vsmatrivalsja on $v$ potemnevšie ikony, v rez'bu po derevu, ukrašavšuju dva-tri stoletija nazad krest'janskie izby. Počernevšie ot vremeni doski ne utratili svoej zamančivosti.

In Beispiel (12) wird das Attribut gustoj durch die Phrase sploš' zarosšim vorbereitet und durch čut' vidneetsja motiviert. In (13) signalisiert die Phrase rezkij veter in Verbindung mit unserem Weltwissen, daß das Attribut mokryj motiviert ist. Interessant ist, daß bei dieser Art von Merkmalzuweisung eine die kommunikative struktur des Textes belastende Redundanz vermieden wird. Beispiel (14) zeigt eine weitere Möglichkeit, definiten Nomen über die Attribution neue Merkmale zuzuschreiben. Es handelt sich um die periphrastische Wiederaufnahme eines Nomens. Diese scheint die Attributionsmöglichkeiten eher zu begünstigen. Vgl. noch

(15) Kogda Kornilov, vyzvannyj zvonkom Bugaeva, priechal na Petrogradskuju, dver' $v$ kvartiru chudožnika byla uže otkryta... Pervoe, čto brosilos' v glaza Kornilovu v étoj ogromnoj svetloj komnate, bol'šoe neokončennoe polotno na mol'berte.

(16) Iz senej $v$ čulan vela nizkaja dverca. Zarov ščelknul vyključatelem. Nebol'šaja gluchaja komnatka byla zastavlena bankami i solenijami.

(17) Iz okna byli vidny... Skol'ko pomnil sebja Kornilov. on vsegda žil $v$ étom bol'šom krasivom dome nomer vosem' na Petrovskoj naberežnoj.

Diese Beispiele demonstrieren die vielfältigen Möglichkeiten der periphrastischen bzw. anaphorischen wiederaufnahme. Ein weiteres Beispiel dieser Art: 
(18) Vlasov otyskal obituju černym dermatinom dver. s tabličkoj "Administrator". Nebol'šaja komnatka... pokazalas' emu sovsem krošečnoj iz-za ogromnogo pis'mennogo stola...

Der Grund für die Attribuierbarkeit des "zweiterwähnten" Nomens ist, daß das durch die Teil-Ganzes-Beziehung verliehene Merkmal der Vorerwähntheit über die faktische Nichtvorerwähntheit dominiert. Bemerkenswert sind auch die folgenden beiden Beispiele:

(19) Nastja uslychala pozadi sebja šagi. Bylo pochože, čto kto-to dogonjal ee. Skoree vsego éto byl mužčina. Sneg žestko skripel pod ego nogami. Devuška ogljanulas' $i v$ vysokom strojnom parne uznal Fedora Kopteva.

(20) Ona stala provodnicej $v$ poezde Moskva-Suchumi. Krasivaja blondinka imela uspech u passažirov s černymi usikami.

(19) belegt, daß auch ein Prädikatsnomen eine anaphorische Beziehung einleiten kann, wobei interessanterweise bei der "wiederaufnahme" gleich drei neue Merkmale zugewiesen werden (auch paren' liefert ein neues Merkmal). Die Basis für die Merkmalzuweisung liefert zum einen die Situation der optischen wahrnehmung (ogljanulas') , zum andern die zäsur zwischen devuška ogljanulas' und $i$...uznala.

wie (20) zeigt, kann auch ein Pronomen durch eine deskriptive Phrase wiederaufgenommen werden, was bedeutet, daß sowohl über das attributive Adjektiv als auch über das Nomen neue Merkmale eingefüht werden.

Besondere Formen der Zweiterwähnung mit attributiver Merkmalzuweisung enthalten auch (21) und (22).

(21) Vargin togda tol'ko ženilsja i žil so svoej molodoj ženoj $v$ tesnoj kamorke sovchoznogo baraka.

(22) Ona menja javno ne uznaet, no pytaetsja ulybat'sja. Lučše by mne ne uvidet' etoj žalkoj, bessmyslennoj ulybki.

In beiden Beispielen wird ein Verb nominal wiederaufgenommen. Die wiederaufnahme verhält sich bezüglich der Attribution so 
wie die in den vorher besprochenen Beispielen. Es bestätigt sich auch hier, daß bei der Nichtnotwendigkeit bzw. der Unmöglichkeit einer Pronominalisierung ein Nomen auch bei der Zweiterwähnung attribuiert werden kann.

Ich schließe die Betrachtung mit einem Hinweis auf die Isolierung $a b$, die ein weniger restringiertes Mittel der Merkmalzuweisung bei definiten Nomina darstellt:

(23) My vyšli na slabo osveščennuju gorodskuju ploščad'. Rjadom s vychodom iz metro vysilis' ugrjumye ... steny starinnoj cerkvi. Ploščad', prjamougol'naja počti kvadratnaja, byla bezljudna.

(24) - Teper'k direktoru, skazala Lora. - Ja vas provožu. Lora šla rjadom - dlinnaja, tonkaja, otvlečennaja...

Der Vollständigkeit halber sei angemerkt, daß Eigennamen eine Attribution (natürlich mit anderer Funktion) durch Beobachtung gewonnener Merkmale nicht ausschließen.

(25) Amerikanec okazalsja plantatorom, korolem chlopka, zvali ego Džo, ego ženu Még, ee podrugu Klêr ... Rjadom so mnoj sidela chorošen'kaja Klèr ...

Entgegen Padučeva ist am Ende unserer überlegungen festzustellen. daß zweiterwähnte substantive grundsätzlich attribuierbar sind. Der entscheidende Punkt ist dabei, daß Padučeva einen Beleg angefürt hat, in dem die Wiederaufnahme des Antezedens durch ein Nomen problematisch ist. In den Fällen, in denen das Nomen keiner Pronominalisierung unterliegt, da zwischen den beiden Vorkommen der Nomina eine wie immer geartete thematische zäsur liegt. können auch bei der Zweiterwähnung neue Merkmale zugewiesen werden, allerdings nicht beliebige, sondern offensichtlich nur solche, die gleichsam situativ gewonnen werden können oder textuell vorbereitet sind. 


\section{Anmerkungen}

1. Z.B. auch in Padučeva, Anaphoric relations ...

2. siehe dazu näher das Kapitel "Prä-, post- und interponierte isolierte Adjektive"

3. siehe dazu Girke, w., Zum Problem der Pronominalisierung im Russischen ...

4. Ob die prädikative Vorbereitung eines Attributs immer, wie in nachfolgendem Beispiel, zu einer restriktiven oder identifikatorischen Funktion des Attributs fürt, ist im einzelnen noch zu überprüfen: - Dala ja adres, dala. I kvitok ona vam, ne bespokojtes', sama prineset. Ona devka očen' chorošaja. Ušel ja $v$ nekotorom nedoumenii ... Chorošaja devka dejstvitel'no javilas' $i$...

\section{Literatur}

Arutjunova, N.D., Nomination und Text. In: Linguistische Studien.

Reihe A, Arbeitsberichte. Berlin 1982, S. $157-191$

Birkenmaier, W., Artikelfunktionen in einer artikellosen sprache. München 1979

Girke, W., Zum Problem der Pronominalisierung im Russischen.

In: Slavistische Linguistik 1984. München 1985, S. $54-83$

Obst, U., Studien zur zweidimensionalen syntagmatischen substitution in modernen prosatexten des Russischen. München 1981

Padučeva, E.V., Anaphoric relations and their representation

in the deep structure of a text. In: M. Bierwisch, K.E. Heidolph (eds.), Progress in Linguistics. A collection of papers. Paris 1970 , S. $224-232$

Padučeva, E.V., O semantike sintaksisa. Moskva 1974 
Quellen
A. Adamov, Zlym vetrom. Moskva 1975
V. Ardamatskij, Sud. Moskva 1980
J. Bondarev, Bereg. Moskva 1982
I. Grekova, Kafedra. Moskva 1980
I. Grekova, Porogi. Moskva 1986
E. Ivanov, Negromkij vystrel. Moskva 1977
A. Kron, Bessonica. M. 1980
S. Krutilin, Grechi naši tjažkie. Moskva 1982
Ogonek 1964, 33
Priključenija 1977. Moskva 1977
v. Ščerbakova, Fevral' - krivye dorogi. Moskva 1982
I. Vasilenko, Konec firmy Benjaeva. Kiev 1981
L. Vasil'eva, ... i 24 žemčužiny. Moskva 1982
S. Vysockij, Krutoj povorot. Moskva 1979 
Attribution und Teil-Ganzes-Relation

Die Verwendung adjektivischer Attribute wird, so scheint es, auch von der sog. Teil-Ganzes-Relation bestimmt. Denn die Kookkurrenz von "Ganzem" und "Teil" verlangt unter bestimmten Bedingungen obligatorisch die Erweiterung des Teils um ein Attribut. Der Grund hierfür ist kommunikativer Art bzw. das Ganze wird durch unser Weltwissen determiniert. 1 Wenn wir wissen, welche Teile notwendigerweise $2 u$ einem Gegenstand gehören, dann ist unter normalen Umständen eine Aussage mit dem Inhalt, daß $X$ einen Teil $Y$ hat, trivial und damit ohne kommunikativen wert. Ich schließe hierbei den Fall aus, daß die Aussage " $X$ hat einen Teil Y" lehrbuchhaften bzw. deskriptiven (einführenden) charakter hat. Sehen wir uns dazu ein Beispiel näher an:

(1) Čelovek $v$ sjurtuke, s nebritym licom is zaspannymi glazami.

[Hervorhebungen hier und im folgenden von mir]

Die Obligatorik der Attribute in diesem Beispiel ist leicht einsichtig, wenn wir davon ausgehen, daß sich diese Aussage auf die aktuale und nicht irgendeine mögliche Welt bezieht. (1') mit getilgten Attributen liefert keine neue Information:

(1') * Čelovek v sjurtuke, s licom i s glazami.

Interessanterweise sind die Attribute in (1) nicht einfach obligatorisch, sondern sie sind der entscheidende Informationsträger. Die Substantive liefern redundante Information. Ihre Funktion besteht im wesentlichen darin, die kategorialen Voraussetzungen für die Attribution $2 u$ schaffen. Dies verdeutlicht die folgende Variante:

(1'i) Čelovek $v$ sjurtuke, nebrit i zaspan.

Diese Variante zeigt, daß auf die Nennung des Teils und damit auf die Attribution nur dann verzichtet werden kann, wenn die Merkmalsbezeichnungen einen anderen syntaktischen status haben. 
Die Frage ist also, so scheint es, wie (1) und (1"') distribuiert sind.

Ich werde diese Frage am Ende noch einmal aufgreifen.

Auch in dem folgenden Beispiel sind die Attribute obligatorisch, redundante Information liefert aber die Bezeichnung des Ganzen (die allerdings syntaktisch gesehen obligatorisch ist) und nicht die Bezeichnung der Teile:

(2) U nego krugloe lico s vzdernutym nosom, gustye, surovye brovi i chmurye glaza.

In diesem Beispiel geht es im Unterschied zu (1) um die Charakterisierung des Teils. Die Nennung des Ganzen hat, semantisch gesehen, vor allem die Funktion der Referenzsicherung. Sehen wir uns dazu folgende Umbildung an:

(2') Ego lico kruglo, nos vzdernut, brovi gusty, glaza chmury.

Wie auch schon bei dem obigen Besipiel wird hier deutlich, daß das adjektivische Element die entscheidende Information liefert. Bemerkenswert ist auch, daß die attributive Beziehung zwischen

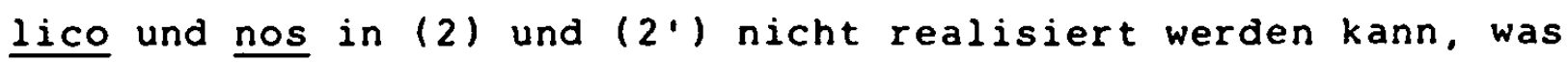
u.a. eine Motivation für die Wahl von (2) zu sein scheint.

Es ist wichtig darauf hinzuweisen, daß die beobachtete Restriktion nicht bei jedem beliebigen zusammentreffen von Bezeichnungen des Ganzen und der Teile wirksam wird. Wenn das vom Adjektiv/Attribut bezeichnete Merkmal nicht im kommunikativen Zentrum steht, entfält die Attributsobligatorik. Vgl. dazu die nachstehenden beiden sätze miteinander:

(3) U Valeriana Afamas'eviča ogromnye, puchlye, rozovye ruki.

(4) ... a namorščiv tjaželyj, kvadratnyj lob, skazal tak...

In (3) sind die Attribute obligatorisch, in (4) sind sie es nicht. Die Nichtobligatorik der Attribute in (4) hängt wohl vor allem damit zusammen, daß namorščiv keine Existenzaussage zum Ausdruck bringt, sondern durch seine reichere semantik nichtvoraus- 
sagbare Informationen in den Text einbringt.

Eine weitere Besonderheit ist erwähnenswert. In den bisherigen Beispielen war stets von sog. unveräußerlichen Teilen bzw. von Teilen organischer Ganzheiten (čelovek) die Rede. Die Versprachlichung der Relation Ganzes: veräußerlicher Teil unterliegt nicht den gleichen strengen Restriktionen. Vgl. dazu

(5) Čelovek s sedoj borodoj. 2

(5') Čelovek s borodoj.

Ich will hier nicht der Frage nachgehen, welche distributionellen Unterschiede zwischen diesen Sätzen bestehen und stelle lediglich fest, daß das Attribut in diesem Fall getilgt werden kann. Interessant sind die Verhältnisse bei Kleidungsstücken. Handelt es sich bei dem Kleidungsstück um einen zentralen Teil, ist die Attributsobligatorik größer als bei einem weniger zentralen Teil. Vgl.

(1) Čelovek v sjurtuke...

(6) Odet professor $v$ pomjatye vel'vetovye brjuki koričnevogo cveta i takuju že ves'ma élegantnuju kurtku.

Brjuki und kurtka bezeichnen kleidungsstücke, auf die man normalerweise nicht verzichten kann. Ihre Existenz ist (ohne speziellen Kontext) mit hoher Wahrscheinlichkeit voraussagbar. Das bedeutet, daß die Attribute in (6) nicht ohne weiteres getilgt werden können. Am ehesten kann noch auf die Attribute bei kurtku verzichtet werden, was zeigt, daß brjuki einen noch zentraleren Gegenstand bezeichnet:

(6') Odet professor $v$ pomjatye vel'vetovye brjuki koričnevogo cveta i kurtku.

(6') ? Odet professor $v$ brjuki i ves'ma élegantnuju kurtku. (6"') ist nur in einem speziellen kontext akzeptabel. Die Erwähnung von brjuki muß motiviert sein. 
Ein letztes Beispiel zu diesem Typ von Teil-Ganzes-Relation:

(7) Krasavicas želtymi kosami, v krasnoj šubke, v krasnych culkach i belych botinkach.

Obwohl wir es in diesem Beispiel nur mit veräußerlichen Teilen $z u$ tun haben, sind die Attribute nicht tilgbar, und zwar aus zwei Gründen: erstens, die aufgezählten Teile sind heterogener Natur (Körperteil, Kleidungsstück), wobei zentrale und weniger zentrale kookkurrieren; zweitens, in diesem Beispiel kommen nur Farbadjektive vor. Sie erscheinen kommunikativ stark hervorgehoben. Die Tilgung auch nur einzelner Attribute verändert somit die Akzeptabilität des Satzes:

(7') ?Krasavica s kosami, v krasnoj šubke, v krasnych čulkach i belych botinkach.

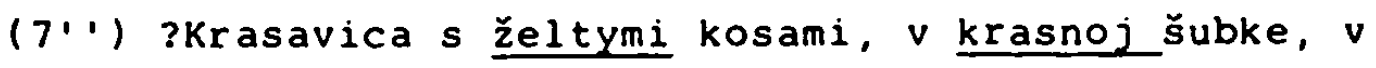
éulkach i belych botinkach.

Auch Teile von Artefakten können unter bestimmten Bedingungen als veräußerlich angesehen werden:

(8) Das Haus meiner Eltern hat 10 Fenster.

Eine Tilgung des Quantors, der wie ein normales Attribut funktioniert, führt normalerweise zu einem wenig akzeptablen Satz, da Fenster in der Regel als mit hoher Wahrscheinlichkeit voraussagbare Teile eines Hauses gelten:

( ' $^{\prime}$ ?Das Haus meiner Eltern hat Fenster.

Es ist aber ohne weiteres eine situation denkbar, in der ein Artefakt wie Haus ohne Fenster gebaut wird. Sicher ist auch hier mit zentralen und weniger zentralen Teilen zu rechnen, so daß man von einer abgestuften Attributsobligatorik ausgehen muß.

Ich verlasse nun den gegenständlichen Bereich der Teil-Ganzes-Relation und gehe über zu einem weniger bekannten und weniger untersuchten ${ }^{3}$ Phänomen, der Beziehung zwischen Sachverhalten 
(versprachlicht durch Verben bzw. Prädikate) und Komponenten dieser Sachverhalte (versprachlicht durch substantive). Ich will zeigen, daß hier mit ähnlichen Restriktionen wie bei den oben angeführten fällen $z u$ rechnen ist. Worauf ich aufmerksam machen will, ist folgendes: Sachverhalte wie beispielsweise "wohnen" sind dadurch charakterisiert, daß sie nur an einer bestimmten Lokalität oder in einem bestimmten Raum realisiert werden können. In bezug auf mitteleuropäische Gegebenheiten heißt dies konkret, daß die Menschen normalerweise in Häusern leben. Alle Abweichungen davon stellen Sonderfälle dar (z.B. das Wohnen in Zelten, Wohnwagen, Höhlen usw.) Dieses Wissen gehört $2 u$ unserem Weltwissen. Aus diesem Grund teilen wir in der Regel auch niemandem mit, daß Her $x$ in einem Haus wohnt. Der Satz

(9) Professor $N$ živet v kvartire. enthält unter normalen Umständen keine relevante Information und wird somit nicht geäußert werden. Zu einer sinnvollen Äusserung wird (9) erst dann, wenn kvartira attribuiert wird:

(9') Professor $N$ živet v $\left\{\begin{array}{l}\text { duchkomnatnoj } \\ \text { malen'koj } \\ \text { ujutnoj } \\ \text { krasivoj } \\ \\ - \\ \end{array}\right\}$

Das Attribut liefert somit die erforderliche neue Information und folglich auch die Motivation für die Äußerung. Vgl. dazu folgende Umbilaung:

(9“) Kvartira, v kotoroj professor N živet, dvuchkomnatnaja. Analog $2 u(9)$ ist auch folgendes Beispiel $2 u$ interpretieren:

(10) Pjatenkov ležal v odnomestnoj palate.

Die Mitteilung, daß ein Kranker in einem Krankenzimmer liegt, ist trivial und muß deshalb angereichert werden. 
Eine interessante Variante der Beziehung Sachverhalt: Aktant liefert folgendes Beispiel:

(11) Na ètom večere bylo mnogo umnych ljudej i velis' interesnye razgovory.

Das Attribut interesnye ist obligatorisch, da der Gegenstand razgovory zentraler Teil des Sachverhalts "večer" ist. Die eigentlich neue Information liefert somit das Adjektiv interesnye.

Weitere Belege für die prädikatdeterminierte Attributsobligatorik sind die folgenden Beispiele:

(12) Rebjata obmenivalis' markami, spisyvali zadački, učilis' po zatrepannym, iz tret'ich ruk, učebnikam, gde...

(13) Kucharka gotovit obed na ogromnol plite.

Sowohl učit'sja als auch gotovit' obed lassen mit hoher wahrscheinlichkeit Aussagen über den Modus der jeweiligen Handlung zu, mit der Konsequenz, daß Aussagen über den Modus näher spezifiziert werden müssen. Auch die Konstellation ugnat': pochititeli löst obligatorisch eine Attribuierung aus:

(14) Est' u nas podozrenie, čto "Volgu" vášu ugnali opytnye pochititeli.

Bedingt ist die Attribuierung in diesem Fall durch die Semantik des subjekts. Es referiert nicht auf konkrete Personen (die nicht vorausgesagt werden können), sondern auf eine Eigenschaft von Personen. Diese ist voraussagbar.

Leichter als in den beiden Beispielen ist die Teil-Ganzes-Relation in folgenden Sätzen zu erkennen:

(15) Posle topki ostavalsja černyj sloistyj pepel.

(16) Bystrymi šagami vošel $\mathrm{N}$.

(17) ... zakričal strašnym golosom. ${ }^{4}$ 
(18) ... proiznes zagadočnye slova.

Ich will es bei diesen Beispielen bewenden lassen und versuchen, das zuletzt beobachtete Phänomen in genereller Weise zu beschreiben. Alle angeführten Fälle, in denen das Prädikat die Attribuierung auslöst, zeichnen sich dadurch aus, daß der Modus des prädikativen Sachverhalts voraussagbar ist. Immer dann also, wenn es darum geht, den Inhalt "typische Realisierung (typ real) der Handlung/des Prozesses" zu versprachlichen, muß zur vermeidung von Trivialität über Attribute neue Information in den Text eingebracht werden. Etwas formelhafter ausgedrückt: wenn die typische Realisierung von $P_{i}$ (= beliebiges Prädikat) der Modus $M_{i}$ ist und $M_{i}$ mit Hilfe von Substantiven versprachlicht wird, dann müssen die entsprechenden Substantive durch Attribute modifiziert werden.

Ich möchte mich nicht mit diesen überlegungen zufrieden geben, zumal die Beschreibung der Attributsobligatorik recht umständlich erscheint. Ich habe oben schon festgestellt, daß sich Konstruktionen dieser Art dadurch auszeichnen, daß das Attribut im zentrum des kommunikativen Interesses steht. D.h. die Motivation für die Produktion dieser Äußerungen ist in dem vom Attribut bezeichneten Merkmal zu suchen. Es ist das rhematische Element. Es stellt sich dabei die Frage, warum das rhematische Element nicht entsprechend rhematisiert wird, d.h. die Finalposition des Satzes besetzt. Daß es passende Konstruktionen dafür gibt, haben Umbildungen wie die folgende bereits gezeigt:

(13') Plita, na kotoroj kucharka gotovit obed, ogromna.

(13') setzt allerdings voraus, daß das subjekt in gewissem Sinn vorerwähnt ist... Genau das gilt aber für den Ausgangssatz (13) nicht. Aus diesen überlegungen muß die Schlußfolgerung gezogen werden, daß die eigentliche frage um die es hier geht, nicht die nach der obligatorik des Attributs ist, sondern die nach der Motiviertheit von Konstruktionen dieser Art bzw. die nach der Leistungsfähigkeit syntaktischer Konstruktionen unter den Bedingungen des Textes und der Distribution konkurrierender Konstruktionen. 


\section{Fußnoten}

$1 \mathrm{vgl}$. Vol'f, Prilagatel'noe ...

2 dieses Beispiel ist aus Vol'f genommen

3 dieses Problem wird auch von Vol'f behandelt

4 die Beispiele (17) und (18) sind aus Vol'f genommen

\section{Literatur}

Vol'f, E.M., Prilagatel'noe v tekste. In: Lingvistika i poétika. Moskva 1979, S. $118-135$

Quelien

Cechov, A., Izbrannye proizvedenija v trech tomach; t.2. Mcskva 1967

Cernenok, M., Posledstvija neustranimy. Moskva 1984

Grekova, I., Kafedra. Moskva 1980

Lenč, L., Dušespasitel'naja beseda. Moskva 1979

Smelev, O., Vostokov, V., Vozvraščenie rezidenta. Moskva 1981

vysockij, S., Krutoj povorot. Moskva 1979 
Die multiple Attribution

Attributive Konstruktionen mit mehreren adjektivischen Attributen sind in der Literatur fast ausschließlich unter dem Aspekt der Attributsfolge betrachtet worden. Trotz großer Bemühungen ist es jedoch bisher noch nicht gelungen, die zugrundeliegenden Regularitäten aufzudecken. Ich will hier versuchen $z$ u zeigen, um welche Probleme es im einzelnen geht und wie einige der Schwierigkeiten beseitigt werden können. Daß hier nur Lösungsangebote für einen Teilbereich der Problematik gemacht werden können, hängt mit der Komplexität des Phänomens zusammen. Die konkrete Untersuchung wird sehr schnell deutlich machen, daß im Augenblick nur kleine Schritte möglich sind.

Die multiple Attribution ist aber auch noch in anderer Hinsicht interessant. Beispielsweise bezüglich der Frage der Fakultativität bzw. Obligatorik der kookkurrierenden Attribute bzw. der Frage, ob multiple Attributionen einfache Erweiterungen singulärer Attributionen darstellen, d.h. ob multiple Attributionen einen eigenen, durch seine struktur gekennzeichneten Attributionstyp darstellen. Nicht uninteressant erscheint für die Betrachtung dieser Problematik die Frage der Beziehungen zwischen den determinierenden Elementen einer attributiven Konstruktion. Ich werde deshalb auch kurz auf diesen punkt eingehen.

Ich beginne mit dem Verhältnis multipler Attributionen zu den durch Tilgung einer der adjektivischen Konstituenten (bei der Existenz von zwei Attributen) gewonnenen singulären Attributionen unter dem Aspekt der wechselseitigen Ersetzbarkeit. Sehen wir uns einmal folgendes Beispiel an:

\section{(1) Kogda Vlasov podošel k dverjam, časovoj proverjal dokumenty u bol'šogo krasivogo mužčiny.}

[Hervorhebungen und Tilgungen hier und im folgenden von mir] Die Tilgung eines der Attribute führt $z u$ einem, vorsichtig gesagt, problematischen Satz: 
(1')? Kogda Vlasov podošel k dverjam, časovoj proverjal dokumenty u bolšogo mužčiny.

(111) ? Kogda Vlasov podošel k dverjam, časovoj proverjal dokumenty u krasivogo mužčiny.

Der abweichende Charakter dieser Sätze rührt daher, daß die singulären Attribute nicht geeignet sind, in der vom prädikat bezeichneten Situation den Referenten von mužčina ausreichend zu konkretisieren. Es gibt weder in (1') noch in $\left(11^{\prime \prime}\right)$ einen sinnvollen Zusammenhang 2 wischen der Handlung proverjat' dokumenty und dem Merkmal bol'šoj bzw. krasivyj. Da beide Merkmalbezeichnungen keine Motivationsbeziehung zum Prädikat eingehen, gleichzeitig aber wegen ihrer selegierenden Rolle ein besonderes kommunikatives Gewicht beanspruchen, ist ihre Verwendung in der singulären Attribution inakzeptabel. Das Interessante ist nun, daß in der multiplen Attribution, an der beide Adjektive beteiligt sind, die Unmotiviertheit der Einzelattribute neutralisiert bzw. aufgehoben ist. Da sich die multiple Attribution von der singulären nur durch mehrere zusätzliche stellen unterscheidet, muß das beobachtete Phänomen auf die kommunikative Potenz der mehrstelligen struktur zurückgeführt werden. Diese Potenz besteht offensichtlich darin, daß die einzelnen Adjektivattribute nicht mehr zum Zweck der Aussonderung eines Gegenstandes verwendet werden, sondern aufgrund des Eigengewichts der Struktur der fakultativen Merkmalzuweisung dienen. Dies ist dadurch bedingt, daß mužčina/y im sinn von nekotoryj mužčina interpretiert wird. Mit anderen worten, das kommunikative Gewicht der komplexen struktur führt zu einer kommunikativen Verselbständigung des adjektivischen und substantivischen Teils des syntagmas. Eine Beziehung zwischen Prädikat und Attribut wird nicht signalisiert.

Sehen wir uns noch einige weitere Beispiele an.

(2) Oni ostanovilis' u nebol'šogo krasivogo doma, okrašennogo jarkoj krasnokoričnevoj kraskoj, s belymi vyčurnymi naličnikami. 
(3) Ol'ga Michajlovna obladala naturoj nervičeskogo sklada. Eto osobenno projavilos' posle rodov i vyrazilos' dovol'no original'nym obrazom. Molodaja, cvetuščaja ženščina vdrug vozomnila sebja bespovorotno čachnuščim suščestvom, obrečennoe na bystroe ugasanie.

(4) Tol'ko tjažkaja, nepopravimaja beda ostavljaet na licach takoj sled.

(5) Za moim stolikom sidjat nemolodaja ustalaja ženščina i paren's devuškoj...

(6) Na polu, ot steny do steny, pušistyj krasivyj kover, $v$ odnom uglu bol'šoj, kažetsja, cvetnoj televizor, a $v$ drugom na special'noj, iz černogo dereva podstavke dlinnaja uzkaja vaza.

(7) My s viktorom uselis' na malen'kij potertyj divančik.

Beispiel (2) unterscheidet sich von (1) nur dadurch, daß neben pränominalen Attributen auch noch ein postnominales vorkommt. Dieses Attribut scheint allerdings keinen Einfluß auf die Tilgbarkeit/Nichttilgbarkeit eines der pränominalen Attribute zu haben:

(2')? Oni ostanovilis' u nebol'šogo doma, okrašennogo jarkoj krasno-koričnevoj kraskoj, s belymi vyčurnymi naličnikami.

Es zeigt sich, daß das postnominale Partizipialattribut nicht als Ersatz für das getilgte pränominale Attribut dienen kann. Auf das interessante Verhältnis dieser beiden Attributstypen kann hier leider nicht weiter eingegangen werden. Beispiel (3) weicht ein wenig von den ersten beiden ab. Das attribuierte Nomen ist definit. Für unser Problem scheint dies nicht unerheblich zu sein, vgl.

(3')? Ol'ga Michajlovna obladala naturoj nervičeskogo sklada. Eto osobenno projavilos' posle rodov i vyrazilos' dovol'no original'nym obrazom. Molodaja ženščina varug vozomnila sebja bespovorotno čachnušcim suščestvom... 
(3“) ? Ol'ga Michajlovna obladala naturoj nervičeskogo sklada. Eto osobenno projavilos' posle rodov i vyrazilos' dovol'no original'nym obrazom. Cvetuščaja ženščina vdrug vozomnila sebja bespovorotno čachnuščim suščestvom.

Die Problematik von (3') bzw. (3') besteht darin, daß einerseits die Motiviertheit der Attribute in bezug auf das Prädikat vozomnila sebja bespovorotno Čachnuščim suščestvom nicht klar ist, eher noch in (3') als in (3'), und andererseits die Koreferenz zwischen der Nominalphrase und dem vorausgehenden Nomen gestört ist, vor allem in (3'). Eine Rolle spielt hierbei möglicherweise der zeitreferentielle Unterschied zwischen den betroffenen Teilsätzen.

In Beispiel (4) ist die multiple Attribution so konstruiert, daß nur die Tilgung des ersten Attributs zu einem nichtakzeptablen satz führt:

(4') Tol'ko tjažkaja beda ostavljaet na licach takoj sled.

(4'") ? Tol'ko nepopravimaja beda ostavljaet na licach takoj sled.

Die Ursache für die Nichtakzeptabilität von (4') liegt darin, daß das Attribut nepopravimaja kein usuelles Merkmal von beda nennt, d.h. markiert ist (s. dazu später), und somit eher für eine prädikative als für eine attributive Funktion bestimmt ist. In verbindung mit dem Attribut tjažkaja bzw. der komplexen struktur der multiplen Attribution wird die Prädikativität von nepopravimaja neutralisiert.

Beispiel (5) ist (4) sehr ähnlich. Auch hier ist das zweite Attribut, aber nicht das erste tilgbar. Ustalaja ist ein Zustandsadjektiv, das, da es nicht kontextuell motiviert ist und kein usuelles Merkmal von ženščina nennt, in diesem Kontext nicht als singuläres Attribut verwendet werden kann. Erst durch die multiple Attribution werden Bedingungen geschaffen, die erlauben, das markierte Element attributiv zu verwenden.

Ganz analog sind die Verhältnisse in (6) und (7), so daß hier nicht näher auf sie eingegangen werden muß. 
Es ist im Augenblick noch nicht möglich, das für die beschriebenen Restriktionen wirksame Merkmal "nicht usuell" bzw. "markiert" in systematischer Weise zu erfassen. Wir müssen uns deshalb damit begnügen, das phänomen als solches an einigen Beispielen aufgezeigt $z u$ haben. Weitere Untersuchungen werden zeigen müssen, ob für ein gegebenes substantiv angegeben werden kann, welche Attribute markiert und welche nicht markiert sind, und welche Rolle das prädikat bzw. der Typ der Aussage für die Bildbarkeit singulärer Attributionen bei einem gegebenen Adjektiv spielt. Dabei wird auch zu klären sein, ob multiple Attributionen bewußt ausgenutzt werden, um die Beschränkungen der singulären Attribution $z u$ überwinden. Die angeführten Beispiele, $z u$ denen leicht weitere aufgeführt werden könnten, lassen den Eindruck aufkommen, daß die multiple Attribution eine eigenständige, mit spezifischen Funktionen ausgestattete Konstruktion darstellt. Dies bedarf aber noch einer gründichen Untersuchung.

Es muß an dieser stelle noch kurz auf einen Sonderfall der multiplen Attribution, der konstruktionell bedingt ist, eingegangen werden. Es handelt sich dabei um die Apposition, und zwar um den Fall, daß das Nomen relativ bedeutungsleer ist. Für alle Fälle dieser Art gilt, daß das Bezugsnomen von wenigstens zwei Attributen näher bestimmt sein muß. Diese müssen nicht notwendigerweise beide adjektivischer Natur sein. Vgl.

(8) Žena professora, nekrasivaja, srednich let Ženščina, prinesla podogretoe sake.

(9) Frau Veber, požilaja simpatičnaja ženščina, vdova služaščego, suščestvovala na malen'kuju pensiju...

Welches Attribut ich auch immer tilge, das Ergebnis ist ein inakzeptbaler Satz:

( ' $^{\prime}$ ? Žena professora, nekrasivaja Ženščina, prinesla podogretoe sake...

(9.)? Frau Veber, simpatičnaja ženščina, vdova služaščego, suščstrovala na malen'kuju pensiju... 
Die Ursache für diese Restriktion ist darin zu sehen, daß eine Apposition ein bestimmtes kommunikatives Gewicht haben muß, um überhaupt motiviert $z u$ sein. Wie dieses kommunikative Gewicht $z u$ messen bzw. $z u$ errechnen ist, ist noch unklar. Feststeht, zumindest in bezug auf die angefühten Beispiele, die sich leicht vermehren lassen, daß die Apposition mindestens zwei neue Merkmale in den Text einfüren muß, um kommunikativ relevant zu sein. Da der nominale Teil der Apposition keine neue Information trägt, - das attribuierte Nomen wiederholt ein Merkmal des vorausgehenden Nomens, - muß die erforderliche Information über die Attribute eingebracht werden. Das problem der singulären Attribution stellt sich in diesem Fall nicht. Die bisher betrachteten Beispiele haben erkennen lassen, daß zwischen den adjektivischen Konstituenten der attributiven Konstruktion unterschiediliche Beziehungen bestehen. Wenngleich bezüglich der Tilgbarkeit/Nichttilgbarkeit eines der Attribute in einer komplexen Attribution mit zwei Konstituenten bisher noch nicht $z u$ erkennen ist, ob es eine Korrelation mit dem Typ der Beziehung zwischen den Attributen gibt, scheint es dennoch notwendig, einmal grundsätzlich auf dieses Phänomen einzugehen. Für die Beschreibung der Abfolge scheint es ohnehin von Bedeutung zu sein.

Man kann von mindestens vier Typen von Beziehungen ausgehen ich beschränke mich dabei auf die struktur $A_{1} A_{2} N$.

1. $A_{1}$ und $A_{2}$ stehen in keiner Beziehung zueinander

Beispiele: molodoj vesnuščatyj paren'

pyšnoe goluboe odejalo pokryvalo ego

2. $A_{2}$ expliziert, spezifiziert bzw. verstärkt die Bedeutung von $A_{1}$

Beispiele: tjažkaja nepopravimaja beda vošla tverdoj uverennoj pochodkoj besstrašnyj mužestvennyj krasavec u nego čestnye, iskrennie stremlenija

wie leicht $2 u$ sehen ist, sind $A_{1}$ und $A_{2}$ in einigen Fällen fast synonym. 
3. $A_{1}$ nennt ein Merkmal, und $A_{2}$ bewertet dieses Merkmal

Beispiele: malen'kij ujutnyj nomer

$$
\text { dikaja, romantičeskaja natura }
$$

4. $A_{2}$ nennt ein Merkmal, das eine Begründung für $A_{1}$ darstellt. Beispiele: ... ležal odin-odinešenek v cholodnoj, netoplennoj izbe.

Ekzamennacionnye vedomosti na černych gorjačich stolach svoračivalis' $v$ trubki.

...dlja otvlečenija prazdnych ruk smontiroval special'noe ustrojstvo tipa dvernogo zvonka

s zamančivoj krasnoj knopkoj

...i na kriki "avtora, avtora!" nasil'no vytašcil na scenu soprotivljajuščujusja smuščennuju Asju

Zumindest Typ 2 und Typ 3 lassen erkennen, daß die Abfolge der Attribute durch die internen semantischen Beziehungen bestimmt wird. Typ 4 legt ebenfalls die Annahme einer strikten Abfolge nahe, ganz geklärt scheint mir dies allerdings noch nicht zu sein. Vgl. dazu folgendes Beispiel, das eine konsekutive Beziehung realisiert:

(10) On pisal i dyšal na obmorožennye, negnuščiesja pal'cy, dyšal i snova pisal.

Typ 1 ist bezüglich der Abfolge unergiebig. Dafür wirft er ein Problem auf, das die Bildung multipler Attributionen betrifft. Es geht hierbei um die Vereinbarkeit von Merkmalen bzw. Verträglichkeiten von Adjektiven im attributiven Verbund. In der Literatur wird diesem Problem wenig Beachtung geschenkt, was sicherlich damit zusammenhängt, daß Unverträgliches zu keinem sprachlichen Phänomen wird und sich somit der Beobachtung entzieht. Nichtsdestoweniger müssen wir uns auch mit Restriktionen dieser Art beschäftigen, allein schon deshalb, um bewußt zu machen, daß nicht nur die Merkmalsträger bestimmen, welche Merkmalszuweisungen zulässig sind und welche nicht. Bei der Betrachtung der prädikatmotivierenden Funktion haben wir gesehen, daß selektional zulässige Adjektivattribute aufgrund 
satzinterner Gegebenheiten restringiert sein können. Es ist $\mathrm{zu}$ vermuten, daß die Häufung von Attributen bzw. Merkmalen unter entsprechenden Bedingungen noch kompliziertere situationen voraussetzen. Entscheidend ist in diesen Fällen vor allem die Prädikatssemantik. Es ist auffällig, daß adjektivische Mehrfachattributionen in der Mehrzahl der Fälle mit Existenzprädikaten bzw. unmarkierten ${ }^{1}$ Prädikaten auftreten. zu den seltenen Ausnahmen zählen Fälle wie

(11) On vsegda nedoljubival étogo boltlivogo, azartnogo starika.

Nedoljubivat' ist zwar ein Prädikat, das verhältnismäßig leicht, d.h. durch sehr viele Adjektive motiviert werden kann, dennoch scheinen auch hier nicht beliebige Adjektivkombinationen möglich zu sein:

(11')? On vsegda nadoljubival étogo boltlivogo, krasivogo starika.

Bei anderen Prädikaten sind die Restriktionen noch stärker. Die Unvereinbarkeit von Adjektivattributen kann auch durch die Unvereinbarkeit von Standpunkten, durch Verfahren der Merkmalgewinnung bedingt sein. Es ist in solchen Fällen sogar schwierig, unmarkierte prädikate zu finden, vgl.

(12)? Dort war eine schöne ironische Frau

kranke ironische Frau

dicke ironische Frau

aufgeregte ironische Frau

listige ironische Frau

einfache ironische Frau

blonde ironische Frau

Alle diese Kombinationen sind mehr oder minder abweichend. Ich muß mich mit diesen knappen Hinweisen auf das problem der Verträglichkeit von Adjektiven, das nur indirekt mit unserem eigentlichen Problem $z u$ tun hat, begnügen. 2 
Nun zum Problem der Abfolge pränominaler adjektivischer Attribute. Ich beschränke mich hierbei auf Ketten ohne Konjunktionen. Ob konjunktionale Gefüge den gleichen Gesetzmäßigkeiten unterliegen wie die asyndetischen ist zunächst noch unklar und bedarf einer speziellen Untersuchung. Hier jedenfalls soll dieser Typ nicht berücksichtigt werden, ebensowenig wie die Abfolge von Adjektiven in prädikativer Funktion.

Ausgangspunkt dieser Betrachtungen ist die Tatsache, daß außersprachliche Fakten, in welchem Verhältnis sie auch zueinander stehen, in die lineare ordnung der Sprachen gepreßt werden müssen. Ein sprachlicher Text ist somit nicht mit einem Bild $\mathrm{zu}$ vergleichen, dessen spezifik eben darin besteht, Sachverhalte simultan, nicht linear geordnet, zu vermitteln. Die Beschränktheit des Bildes seinerseits, Linearitäten darzustellen (man braucht dazu Bildreihen), ${ }^{3}$ ist die stärke des Textes. Auf unsere Problematik bezogen sieht die Sache folgendermaßen aus. Wenn man einem Gegenstand zwei oder mehr Merkmale gleichzeitig zuschreiben will, etwa "groß", "grün" und "dick", dann male ich diesen Gegenstand in dem Fall groß, grün und dick. Die Merkmale liegen simultan vor. Im Fall der Versprachlichung der Merkmalszuweisung müssen die Merkmale in eine lineare ordnung gebracht werden. So werden sie auch perzipiert. Es stellt sich jetzt natürlich die Frage, wie die Linearisierung geregelt ist, ob sie beliebiger Natur ist oder irgendwelchen Restriktionen unterliegt. Die bisherige Forschung $z u$ diesem Problem macht deutlich, daß die Abfolge nicht beliebiger Natur ist. Allerdings liegen bislang noch keine absolut zufriedenstellenden Ergebnisse vor. Keine Ausnahme macht hierbei die Arbeit von R. Posner ${ }^{4}$, die den letzten stand der Forschung repräsentiert. Einwände lassen sich sowohl gegen den latenten Universalitätsanspruch als auch gegen die Vermischung der Ebenen von syntax und Wortbildung vorbringen. Nicht gut gelöst ist auch die empirische Basis, denn das Inventar der Adjektive ist keineswegs homogen. Der entscheidende Mangel dieser und anderer Arbeiten scheint mir jedoch darin zu liegen, daß der kontextuelle bzw. textuelle Aspekt weitgehend vernachlässigt wird. Posners pragmatischer Gesichtspunkt ist kein Ersatz für einen textuellen 
Ansatz. Aber gehen wir die Probleme der Reihe nach durch Bezugspunkt ist vor allem Posners Arbeit.

In der Literatur werden, grob gesagt, zwei Lösungsangebote gemacht. Im einen Fall wird syntaktisch argumentiert, im anderen Fall semantisch. Der syntaktische Ansatz, vertreten vor allem durch $Z$. Vendler, ist zwar interessant, kann aber die tatsächlich auftretenden Linearisierungen, zumindest die im Russischen, nicht erklären. Auch R. Posner kritisiert den syntaktischen Ansatz und zeigt dessen Grenzen auf. Allerdings stützt er sich dabei auf ungeeignetes Material, nämlich auf Wortbildungsphänomene. Dabei lassen sich beliebig viele syntagmen mit adjektivischen Attributen anführen, die die explanative Kraft der syntaktischen Kriterien in Frage stellen. Man muß sich auch grundsätzlich fragen, warum die größere oder geringere Komplexität der Tiefenstrukturen attributiver Verbindungen die Reihenfolge der Attribute bestimmen soll. Wie nachstehendes Beispiel zeigt, ist es eben nicht so, daß das vom Bezugsnomen weiter entfernt stehende Attribut die komplexere Tiefenstruktur aufweist (vorausgesetzt, es gelingt, die jeweils angemessene Tiefenstruktur $2 u$ finden).

(13) Noč' on provel v Rybackom u staroj drjachloj babki.

Ist staraja babka tatsächlich komplexer als drjachlaja babka? Gerade das Russische liefert viele Beispiele dafür, daß als komplex angesehene attributive verbindungen wie etwa die mit evaluativen Adjektiven nicht $2 u$ einer substantivfernen Position dieser Adjektive führen. Dazu später einige konkrete Beispiele. Beim semantischen Ansatz ragen zwei Gesichtspunkte heraus. Der eine besagt, daß die geringere stellenzahl in größerer Substantivnähe zum Ausdruck kommt, der andere, daß das Attribut näher am Bezugssubstantiv steht, das eine Eigenschaft bezeichnet, die an den von den Substantiven bezeichneten Gegenständen weniger veränderlich ist. Sehen wir uns diese Gesichtspunkte näher an. Der erste Gesichtspunkt beinhaltet, daß Attribute um so näher am Bezugssubstantiv zu stehen scheinen, je weniger andere Gegenstände für die Festlegung der jeweils bezeichneten Einheit eine Rolle spielen. 
Die Stelligkeit der Adjektive wird wie folgt bestimmt:

1. Adjektive, die manifeste Eigenschaften wie den Stoff, die Farbe oder die Form eines Gegenstandes bezeichnen, sind einstellig.

2. Bezugsabhängige Eigenschaften wie die Größe oder Geschwindigkeit eines Gegenstandes sind zweistellig.

3. Adjektive, die nicht nur bezugs-, sondern auch sprecherabhängige Eigenschaften bezeichnen, sind dreistellig.

Nach diesen Feststellungen stehen wertende Adjektive immer vor allen übrigen. Posner beansprucht dies zumindest für das Deutsche. ob dies für das Deutsche tatsächlich gilt, habe ich nicht überprüf, für das Russische wenigstens trifft dies nicht unbedingt $z u . V g l$.

(14) Gorod byl zatjanut syrym, protivnym tumanom. 5

Hier steht das wertende Adjektiv unmittelbar vor dem Bezugsadjektiv.

Es lassen sich leicht noch weitere Beispiele dieser Art anfüren. Da ich in anderem Zusammenhang noch auf sie zu sprechen komme, verzichte ich hier auf sie.

Das Kriterium der Veränderlichkeit liefert vom Ansatz her eine bessere Möglichkeit für die Beschreibung der Attributsfolge. Es gibt mehr semantische Klassen und damit mehr Abfolgeschemata. Posner postuliert folgende Linearisierungen:

Stoff vor Zweck

Zeit vor stoff

Raum vor Zeit

Farbe vor Raum

Form vor Farbe

Größe vor Form

Zutaten vor Größe

wertung vor Zutaten

Für die Beschreibungspraxis ist diese Liste allerdings nur teilweise geeignet. Dies hängt vor allem damit zusammen, daß das 
Inventar der semantischen Klassen $z$ u klein ist und frequente Adjektivtypen nicht erfaßt werden. Zugegeben, Posner hat diese Liste in bezug auf das substantiv vase formuliert, aber auch für Vasen gilt, daß sie feucht oder rissig sein können. Diese Merkmale werden von Posners Klassen nicht erfaßt. Grundsätzlich gilt natürlich, daß Klassifizierungen von Adjektiven so aussehen sollten, daß alle Adjektive und damit auch alle substantive erfaßt werden. Im Augenblick gibt es leider keine Liste, die diesen Anforderungen gerecht wird. Entweder sind die Inventare zu klein oder wie im Fall von Neubauer [1] und Šramm [4] 2 u groß. Ein besonderes problem stellt in diesem Zusammenhang das der Klassifikation zugrunde gelegte Prinzip dar, das normalerweise nicht durch die Notwendigkeit der Beschreibung syntaktischer Probleme bestimmt wird. Nicht übersehen werden sollte auch die Frage der Terminologie. Von diesem Aspekt aber einmal abgesehen, befriedigt die Lösung Posners auch in anderer Hinsicht nicht. Die vorgeschlagenen Linearisierungen lassen sich nicht ohne weiteres für das Russische nachvollziehen, was darauf zurückzuführen ist, daß weder einzelsprachliche spezifika berücksichtigt werden, noch der sprachliche Kontext im weitesten Sinn als einflußreicher Faktor in Betracht gezogen wird. Es ist beispielsweise $z u$ uiberprüfen, ob sich das Verhältnis Attribut:Prädikat auf die Abfolge auswirkt. Auf die Relevanz der semantischen Beziehung zwischen den Attributen habe ich bereits hingewiesen. Noch ein ganz anderer Punkt muß erwähnt werden, und zwar die Rolle der Morphologisiertheit einer Sprache für die Realisierung der Abfolge der Attribute. Hierbei sind zwei Aspekte wichtig. Einmal, die Frage des Inventars - das Russische verfügt uber weit mehr Adjektive als das Deutsche, bedingt durch die relativ freie Bildbarkeit relationaler Adjektive - zum anderen, die eindeutige morphologische struktur erlaubt größere syntaktische Freiheiten als eine schwach ausgeprägte Morphologie. Ich habe hier vor allem die Kompositaelemente Fluß-, Weltusw. im Auge, die aufgrund ihrer morphologischen Unselbständigkeit fest an das Bezugsnomen gebunden sind. Wie ich gleich zeigen werde, sieht dies im Russischen anders aus. Dort können sogar Beziehungsadjektive vor qualitativen Adjektiven stehen: 
(15) Zemlja pod nogami pyl'na, gorjača; cepočkoj pečatajutsja na nej detskie bosen'kie sledy.

(16) Na golove nebrežno sdvinutaja nabok kletčataja modnaja kepka - "Komsomolka".

(17) Ljuda Veličko rodilas' i rosla v provincii, v odnom iz srednerusskich neperspektivnych gorodkov.

Die meisten dieser Abfolgen sind umkehrbar, vgl.

(18) Chudoščavyj pojavilsja iz otelja v soprovoždenii celoveka $v$ žamševom serom polupal'to $i$ zelenovatom sljape.

(19) Vozle ich otelja dežuril mordastyj tip $v$ serom zamšvom pal'to. 6

Die angeführten Beispiele zeigen, daß universale Regeln nicht sehr sinnvoll sind, daß vielmehr mit einzelsprachspezifischen Idiomatisierungen gerechnet werden muß. Noch deutlicher als durch die obigen Beispiele wird dies durch die nachfolgenden unterstrichen.

(20) Odet on v skromnyj kostjum, korotkoe nejlonovoe zagraničnoe pal'to rasstegnuto...

(21) Byl ešče A. Kiselev, serebrjannyj olimpiskij prizer...

(22) Moskovskaja Ljudina žizn' kazalos' otsjuda skazočnoj.

Auf die Problematik der Beziehungsadjektive und Possessivadjektive werde ich im weiteren nicht mehr eingehen, sondern mich ausschließlich auf die Qualitätsadjektive beschränken. Dabei werde ich mich ausschließlich auf empirisches Material stüzen und keine eigenen Beispiele konstruieren, um vor allem die wirkung des kontextuellen Faktors bzw. um Häufigkeiten und Tendenzen zeigen zu können. Die Problematik der Klassifizierung der Adjektive (und auch der Substantive) zwingt mich dazu, mich auf sechs Klassen von Adjektiven zu beschränken, wobei Unsicherheiten bei der Zuordnung der Adjektive zu den einzelnen 
Klassen ohnehin als Problemfaktor erhalten bleiben. Folgende Klassen werden berücksichtigt: Evaluationsadjektive (A-Eval), dimensionale Adjektive (A-Dim), Farb-bzw. Helligkeitsadjektive (A-Color), Altersadjektive (A-Temp), Eigenschaftsadjektive (A-Propr) und Zustandsadjektive (A-Stat).

Der Einfachheit halber bestimme ich hier die einzelnen Klassen extensional:

A-Eval: krasivyj, interesnyj, milen'kij, udivitel'nyj, simpatičnyj, idiotskij, ujutnyj, neujutnyj. protivnyj...

A-Dim: malen'kij, glubokij, bol'šoj, ogromnyj, tolsten'kij, dlinnyj, nizen'kij, vysokij, nizkij, širokij, polnyj (čelovek), uzkoplečij, prodolgovatyj. uzkij...

A-Color: koričnevyj, golubovatyj, temnyj, seryj, blednyj, rozovyj...

A-Temp: staryj, moloden'kij, staren'kij, novyj, nemolodoj...

A-Propr: opytnyj, zvonkij (golos), skromnyj, tverdyj, uverennyj, uprjamyj, naivnyj, beschitrostnyj, ozornoj, razudalyj, tupoj, bessmyslennyj, vdum¿̌ivyj, trezvyj, čestnyj, iskrennij...

A-stat: rvanyj, utertyj, neoprjatnyj, prochladnyj, tichij, syroj, suchoj, vodjanistyj, vpalyj, nestrižennyj. cholenyj, bol'noj, ustalyj...

1. Multiple Attributionen mit A-Eval

In meinem Korpus dominieren die Beispiele, in denen das Evaluationsadjektiv direkt am Bezugssubstantiv steht. Am häufigsten ist dabei die Verbindung mit einem A-Dim. Diese empirische Feststellung ist der Aussage Posners in bezug auf das Deutsche diametral entgegengesetzt.

Hier die Beispiele:

(23) Oni ostanovilis' u nebol'šogo krasivogo doma, okraక̌nnogo krasno-koričnevoj kraskoj, s belymi vyčurnymi naličnikami. 
(24) I pered nami - strojnyj, krasivyj paren'.

(25) Eto byl vysokij, seroglazyj, očen' krasivyj človek.

(26) Nikto iz plennych ne uspel, navernoe, $v$ tu minutu osoznat', Cto éta russkaja frejlejn s uzkim krasivym licom i suchimi, nikogo ne vidjaščimi glazami možet sdelat'...

(27) Meženin sokrušenno opustil resnicy, podvigal po skulam želvakami, otčego malen'kie, po-ženski krasivye uši ego, kazalos' zverovato prižalis'.

(28) Michail predpolagal uzret' nečto gorillopodobnoe, no pered nim byl chorošo složennyj, krasivyj paren's neskol'ko prezritel'noj grimasoj.

(29) No totčas zametil v zerkale naglovato-derzkuju poluuchmylku Meženina, pokazavšujusja lišnej, čužoj na ego polnovatom, krasivom lice.

(30) A vmesto étogo prines kljuc, gromadnyj idiotskij ključ.

(31) ... chotelos' uvidet' dlinnuju miluju rožu Il'i.

(32) Skazat', Čto ee samoljubiju l'stivo čuvstvo, kotoroe ona vozbudila $v$ molodom interesnom ital'jance, - znacit skazat' liš' polovinu.

(33) Ona $v$ legkom fioletovom pal'tiške neobyčajno izjaščnogo pokroja, pyšnuju pričesku prikryvaet cvetnaja jarkaja kosynka, v rukach bol'šaja krasivaja kožanaja sumka.

Welche Erklärung gibt es für diese Abfolge, oder ist diese Abfolge nicht als Abweichung von der Norm und damit nicht als erklärungswürdig anzusehen ${ }^{7}$ zunächst ist festzustellen, daß bei einer übersetzung dieser Beispiele ins Deutsche bei vielen von ihnen die Reihenfolge der Attribute nicht verändert würde. Dies bedeutet, daß man auch für das Deutsche nicht unbedingt die strenge Abfolgeregelung im Sinn von Posner akzeptieren muß. 
Dies bedeutet gleichzeitig, daß die angeführten Fälle nicht von vornherein als Idiosynkrasien des Russischen eingestuft werden können, was nicht ausschließt, đaß das eine oder andere Beispiel typisch für das Russische ist. Wenn man die Abfolge der Attribute in den angeführten Beispielen verändert, dann zeigt sich, daß wir entweder weniger akzeptable Sätze erhalten oder daß sich die Bedeutung des syntagmas verändert. Vgl: z.B.:

(23') Oni ostanovilis' u krasivogo nebol'šogo doma, okrašennogo...

(25') Eto byl očen' krasivyj, vysokij, seroglazyj čelovek.

(26') Nikto iz plennych ne uspel, navernoe, $v$ tu minutu osoznat', Čto éta russkaja frejlejn s krasivym uzkim licom i suchimi, nikogo ne vidjaščimi glazami možet sdelat'...

(23') scheint mir weniger akzeptabel $z$ u sein als (23), was ich darauf zurückführe, daß einmal Prädikatssemantik und Attributssemantik in Konflikt geraten und zum anderen die postnominalen Merkmale nicht mit den pränominalen harmonieren. Entscheidend ist offensichtlich die Erstposition des A-Eval, denn sie bedeutet eine kommunikative Hervorhebung. Diese Hervorhebung ist in (23') jedoch nicht motiviert. Das Prädikat ostanovit'sja u impliziert normalerweise keine intentionale Handlung in bezug auf ein evaluatives Merkmal. Die Präponierung des A-Eval bewirkt gleichzeitig, daß die explizierende Funktion der postnominalen Merkmale außer Kraft gesetzt wird. Diese sind plötzlich unmotiviert. Beide Beobachtungen veranlassen zur Hypothese, daß in einer multiplen Attribution die erste Position von besonderer Bedeutung für die Beziehung des Attributs zum Prädikat ist. Weiterhin muß man annehmen, daß eine explizierende Beziehung zwischen zwei Merkmalen auch eine positionelle Nähe der entsprechenden sprachlichen Ausdruicke voraussetzt. Es wird sich zeigen, ob die weiteren Beispiele diese vermutungen bestätigen. Noch ein dritter Punkt ist wichtig, vielleicht weniger bei Beispiel (23') als bei (26'). A-Eval vor A-Dim suggeriert, daB $A-D i m$ das vorausgehende A-Eval motiviert. Bei der umgekehrten 
Abfolge wird dagegen eher die Unabhängigkeit der Merkmale voneinander signalisiert. Vergleicht man jedoch (26) bzw. (26') mit (34) und (35), dann scheint eine Einschränkung angebracht.

(34) Žil ja togda $v$ Myl'nikovom pereulke $v$ bol'šoj neujutnoj kvartire, soveršenno odin.

(35) ... i otyskivaja dežurnuju po étažu v nebol'šom ujutnom cholle s mjagkoj mebel'ju.

Bei dieser Abfolge ist das A-Eval keineswegs unabhängig von dem vorausgehenden $A-D i m$, es besteht vielmehr eine enge motivationelle Beziehung: "groß" und deshalb "ungemütlich" bzw. "klein" und deshalb "gemütlich". Im Unterschied zu allen übrigen Beispielen ist die Beziehung zwischen diesen Attributen fast schon phraseologisiert, was vielleicht eine Erklärung für diese Abfolge ist. Bei einer Veränderung der Abfolge wirkt sich die Beziehung zwischen den Attributen in der Weise aus, daß das nachgestellte Attribut fast als redundant empfunden wird. ähnlich ist auch (36) zu interpretieren:

(36) Gorod byl zytjanut syrym, protivnym tumanom.

Das Attribut syroj mit dem Bezugsnomen tuman impliziert eine negative Bewertung des gesamten Sachverhalts. Das bewertende Attribut ist somit nicht unabhängig. Bei einer Veränderung der Abfolge geschieht das gleiche wie bei den Abfolgen in (34) und (35). Es drängt sich nun folgende Schlußfolgerung auf. Wenn in einer attributiven Konstruktion eines der Attribute eine negative oder eine positive Bewertung impliziert, dann steht das evaluative Attribut unmittelbar vor dem Bezugsnomen. Ist aber eine Implikationsbeziehung nicht gegeben, dann kann eine Motivationsbeziehung nur dadurch erzielt werden, daß das evaluative Attribut dem zweiten Attribut vorausgeht.

Das nachstehende Beispiel scheint dieser Behauptung zu widers prechen: 
(37) ... za kotorym, nakonec, moglo byt' odno poslednee i oblegčajuščee izbavlenie ot tošnotno dušivšej $k$ étomu krasivomu, naglovatomu, kazalos', neprobivaemomu licu.

Es besteht kein Zweifel, daß krasivyj nicht durch die nachfolgenden Attribute motiviert wird. Die Erklärung dafür ist, daß krasivyj ebenso wie die anderen Attribute in den Skopus von nenavist' fällt, d.h. jedes einzelne Attribut liefert für sich eine Motivation für den von nenavist' bezeichneten Zustand. Damit enfällt die Notwendigkeit einer motivierenden Beziehung zwischen den Attributen, Vgl.dagegen

(38) ... popala v dvuchmestnuju komnatu so svoej odnokursnicej Asjej Umanskoj, tolstoj, usatoj devuškoj s krasivymi Černymi glazami.

Beispiel (37) macht endgültig deutlich, daß multiple Attributionen, die ein evaluatives Attribut enthalten, ohne eine Kontextanalyse nicht beschrieben werden können, so daß auch eine Annahme einer bestimmten normativen Linearisierung der Attribute nicht haltbar ist. Die regelhafte Erfassung der Linearisierung der Attribute ist dadurch sicherlich komplizierter. aber nicht unmöglich geworden. Ob eine zufriedenstellende Lösung erreicht werden kann, wird allerdings auch davon abhängen, ob homogene Klasseninventare aufgestellt und die Rolle der weiteren Attribute in der Konstruktion, vor allem deren Beziehung zum Nomen, erfaßt werden können. Vgl. noch die nicht weiter kommentierten Beispiele (39) und (40):

(39) Tam, prjamo na lestničnoj ploščadke, u okošečka v stekljannoj peregorodke sidit dežurnaja, simpatičnaja požilaja tetja $v$ belom chalate.

(40) Na poroge stoit milen'kaja tolstaja starucha v drjanoj mechovoj žiletke.

2. Multiple Attribution mit A-Dim

Ich werde hier nicht alle Kombinationsmöglichkeiten behandeln, 
sondern mich auf die mit A-Stat, A-Color, A-Propr und A-Dim beschränken. .

a) A-Dim und A-Stat

Vorweg ist festzustellen, daß die Aussonderung von A-Stat alles andere als einfach ist. Vor allem die Abgrenzung gegenüber A-Propr bereitet Schwierigkeiten. Da A-Stat und A-Propr aber ähnlich distribuiert sind, fallen die Abgrenzungsprobleme nicht weiter ins Gewicht.

In der Mehrzahl der Fälle liegt folgende Linearisierung vor: A-Dim vor A-Stat.

Hier einige Beispiele:

(41) Na nej dlinnoe rvanoe plat'e i černyj takoj že rvanyj platok.

(42) My s Viktorom uselis' na malen'kij potertyj divančik.

(43) Igor' Vasil'evič okinul bystrym vzgljadom bol'šuju neoprjatnuju komnatu...

(44) Cerez polčasa, vypiv po doroge čašku kofe $v$ malen'kom prochladnom kafeterii, Michail prišel $v$ bol'nicu.

Die Umkehrung der Abfolge führt in den meisten Fällen zu weniger akzeptablen Konstruktionen. Dies hängt im wesentlichen damit zusammen, daß die A-Stat Merkmale bezeichnen, die nicht zum Referenzrahmen der jeweiligen Bezugsnomina gehören. Sie sind somit "markierte" Elemente in der attributiven Konstruktion. Diese Markiertheit macht sich vor allem in der initialen position bemerkbar und zwar in der Weise, daß hier die Attribute kommunikativ besonders hervorgehoben werden. Ich habe oben schon auf dieses Phänomen hingewiesen. Hervorhebungen dieser Art bedüren elner entsprechenden kontextuellen Motivation, sei es durch den vortext, das Prädikat oder den Nachtext, um nur ein paar Möglichkeiten aufuzeigen. In keinem der Beispiele, ausgenommen vielleicht (41), ist eine entsprechende Motivierungsbeziehung zu erkennen. 
(41) läßt zwar auch keine besonders akzeptable Umbildung $2 u$, dennoch zeigt sich in dem wiederholten rvanyj ein potentiell motivierendes Element.

Hier nun einige Beispiele mit der umgekehrten Abfolge:

(45) Tot obeščal pomoč', i Michailu ničego ne ostavalos' delat', kak poselit'sja $v$ tichymmalen'kom otele $i$ zanjat'sja čteniem knižnych novinok.

(46) V gustoj trave kroveneli kapli sozrevajuščej zemljanki. I podberezoviki uže popadalis' $v$ syrom glubokom mchu na granice bolota i lesa.

Die Abfolge der Attribute in (45) ist zweifellos motiviert. Zum einen dadurch, daß tichijotel' assoziativ mit malen'kij otel' verknüpft ist, zum anderen durch die Intentionalität der Handlung mit dem Ziel,sich mit Lesen zu beschäftigen. Die Markiertheit des Attributs tichij ist somit aufgehoben. Eine Veränderung dieser Abfolge ist problematisch.

Ebenfalls nicht abweichend ist die Linearisierung der Attribute in (46). Der Grund dafür ist, daß in der Erstposition das Attribut syroj eine Motivationsbeziehung zum Prädikat eingeht (Feuchtigkeit ist eine Bedingung für das Vorkommen von Pilzen), während es in der zweitposition eine solche Beziehung nicht erzeugt. zumindest ist sie weniger deutlich.

Trotz der gewissen Regularität, die bei der Linearisierung von A-Stat und A-Dim $z u$ beobachten ist, sind noch eingehende Untersuchungen notwendig, bevor Endgültiges gesagt weirden kann.

b) A-Dim und A-Propr

Ich habe oben schon darauf hingewiesen, daß A-Propr in bezug auf A-Dim ähnlich distribuiert ist wie A-Stat. Es ist deshalb mit der Abfolge A-Dim vor A-Propr zu rechnen. Vgl.

(47) Ja nevol'no vspominaju gromadnogo, vichrastogo, samodovol'nogo duraka Tolika.

(48) Medvedev postučal dlinnymi sil'nymi pal'cami po stvolu pistoleta. 
(49) Slovoochotlivyj Senja Bulaev ne mog uderžat'sja ot malen'koj nravoucitel'noj besedy.

Ein interessantes "Gegenbeispiel" ist (50):

(50) Orlov podošel k garažu, v kotorom krutilsja vozle "Moskviča" jurkij, nizenkij čelovek let pjatidesjati s trjapkoj $v$ ruke.

Die Markiertheit des Attributs jurkij, die gelegentlich eine substantivnahe Position verlangt, korrespondiert hier mit der Bedeutung des Prädikats. Sowohl Attribut als auch Prädikat enthalten das semantische Merkmal "schnell" . Bei einer Umkehrung der Wortfolge geht diese assoziative Beziehung verloren, und wir erhalten einen wenig akzeptabeln Satz. (50) widerspricht somit der oben aufgestellten Hypothese nicht, sondern bestätigt die textuelle Relevanz der Erstposition:

c) A-Dim und A-Color

In meinem Korpus dominiert die Abfolge A-Dim vor A-Color. Vgl.

(51) ... uvidel lampu s bol'Šim zelenym abažurom.

(52) V étot moment vysokaja, ryževataja Nataša nasmešlivym tonom ob-javljaet...

(53) A na stene pozadi nego bol'šoe krasnoe pal'to obrazovalos'.

Wenngleich für diese Beispiele gilt, daß eine Umkehrung der Abfolge zu weniger akzeptablen Sätzen führt, bedeutet dies nicht, daß eine Voranstellung von A-Color nicht möglich ist. Eine Voraussetzung dazu ist eine entsprechende kontextuelle Vorbereitung, vgl.

(54) On u menja snova stoit pered glazami, étot tip, v svoem koričnevom plašče, koričnevoj šljape, s černym bol'šim portfelem $v$ ruke.

Die Erstposition von černyj scheint durch die beiden vorausgehenden Attributionen motiviert. Das zweimalige Vorkommen von korið- 
nevyj thematisiert das Merkmal "Farbe", was für die multiple Attribution die Konsequenz hat, daß das $A-C o l o r$ in die kommunikativ wichtigste Position rückt. Eine Umkehrung der Abfolge scheint hier allerdings auch möglich zu sein.

Ich übergehe die Linearisierung von A-Dim und A-Temp, für die ich nur sehr wenig Beispiele habe (hier wenigstens ein Fall: Za stolom vozle lifta nemolodaja polnaja ženščina), und wende mich dem problem der Kookkurrenz von zwei A-Dim zu.

d) A-Dim und A-Dim

Beispiele für diesen Typ von multipler Attribution sind relativ häufig zu finden:

(55) Eto okazyvaetsja nevysokij, plotnyj paren'...

(56) Demin s interesom rassmatrival sidjaščego pered nim dlinnogo uzkoplečego čeloveka s ostronosym licom.

(57) ... vošel vysokij polnyj čelovek s gustymi sedymi volosami.

Es ist leicht $z u$ sehen, daß die dimensionalen Adjektive in eine Reihe von Untergruppen zerfallen, beispielsweise in solche, die die vertikale Ausrichtung eines Gegenstandes betreffen, in solche, die sich auf die horizontale Ausdehnung beziehen oder auf Flächen usw. Ob eine Subklassifizierung dieser Art für eine Beschreibung der Abfolge von Nutzen ist, ist noch zu überprüfen. Die Kookkurrenz dieser Gruppen signalisiert, daß mit ihrer Hilfe die Mehrdimensionalität von Gegenständen wiedergegeben wird. Interessanterweise in meist unsymmetrischer weise, $d . h$. es treten nebeneinander Merkmale des Ganzen und des Teils auf. Vgl. (56). Welchen Regularitäten unterliegt nun diese Abfolge? Es scheint, daß sich auch hier das oben eingefuhrte Merkmal der Markiertheit als nutzlich erweist. Als markiert sehe ich alle die Attribute an, die sich nur auf einen Teil eines Gegenstandes beziehen. Unsere Beispiele bestätigen, daß die Markiertheit des Merkmals zu der substantivnahen Position fürt. Eine Veränderung dieser Abfolge ergibt in allen Beispielen eine weniger akzeptable 
Linearisierung. Hier nun drei Beispiele, in denen der TeilGanzes-Aspekt keine Rolle spielt:

(58) Ešče zdes' bylo dva nizkich sirokich škafa.

(59) ... v rukach u tolstovatogo parnja pojavilas' kakaja-to veščica. Malen'kaja prodolgovataja korobočka, pochožaja na nebol'šuju pačku sigaret.

(60) ... skazal ja v ego uzkuju dlinnuju spinu.

Wenngleich das Merkmal "markiert" hier nicht in bezug auf unterschiedliche Bezugsgrößen verwendet werden kann, muß man nicht auf es verzichten. Wenigestens für (59) und (60) gilt, daß das substantivnahe Attribut ungewöhnlicher und damit auch stärker markiert als das vorausgehende ist. In (59) drückt malen'kaja zweifellos ein allgemeineres Merkmal als prodolgovataja aus - prodolgovataja bezieht sich nur auf eine Dimension -, während in (60) uzkaja in bezug auf spina häufiger und üblicher ist als dlinnaja. Die Spezifik des Gegenstandes ist offensichtlich ein wichtiger Aspekt bei der Beurteilung der Markiertheit von Merkmalen. über diesen allgemeinen Aspekt hinaus zu spezielleren Generalisierungen $z u$ kommen, scheint im Augenblick nicht möglich zu sein.

Problematisch ist nun noch (58). Schränke scheinen nicht von vornherein in bezug auf bestimmte Dimensionen festgelegt zu sein. Es ist deshalb hier und in ähnlich gelagerten Fällen mit einer mehr oder minder idiomatisierten Abfolge zu rechnen. Es wäre auch nicht überraschend, wenn es in diesem Bereich unterschiedliche einzelsprachliche Lösungen gäbe. Aber das sind zunächst nur spekulationen.

3. Multiple Attributionen mit A-Color

Ich beschränke mich auf die Kookkurrenz von A-Color und A-Stat. Es ist auffällig, daß in den meisten Fällen A-Color vor A-Stat steht:

(61) Nadežda G. ... prikryla rot koričnevoj suchoj ladon'ju.

(62) U Savel'eva ... serye, vodjanistye glaza. 
(63) ... polistal ležavšie v nej želtovato-serye peresochšie bumagi $i$...

(64) Blednye, vpalye ščeki pokrylis' rumjancem.

(65) ... a golova sovsem sedaja, prosto griva sedych nestrižennych volos.

(66) Na rozovom cholenom lice pojavljaetsja sosredotočennost'.

Eine Veränderung der Abfolge füht in der Regel zu wenig akzeptablen Sätzen. Dies ist, wie oben schon wiederholt gezeigt, durch die Markiertheit der A-Stat bedingt. Die Zustandsadjektive bezeichnen vorübergehende Merkmale der Gegenstände (mit Ausnahme von vpalye), sie gehören somit nicht zum Referenzrahmen der jeweiligen Bezugsnomina. Der Umkehrung der Abfolge stehen aber auch kontextuelle Faktoren entgegen. In (64) die antonymische Beziehung zwischen blednye und rumjancem, in (65) die wiederholung von sedoj (sedaja, sedych). Aber auch in multiplen Attributionen mit $A$-Color und A-Stat ist die Linearisierung nicht so streng geregelt, daß kontextuelle Faktoren nicht eine Voranstellung von A-stat bewirken könnten, vgl.

(67) Ogromnye vodjanistye serye glaza za steklami očkov teper' smotrjat na menja grustno i otrešenno.

Verantwortlich für diese Abfolge scheint mir vor allem das vorausgehende A-Dim $z$ u sein, das eine engere Bindung von A-Color an das Bezugsnomen bedingt. D.h. das Attribut vodjanistye fält nicht in den Skopus von ogromnye. Vgl. noch (68).

(68) On byl razdražen, bleden, gimasterka namokla na grudi, vlažnye svetlye volosy prilipli ko lbu...

Die Abfolge wird hier durch die Motivationsbeziehung zwischen prilipli und vlažnye bestimmt.

Ähnlich sind die Verhältnisse in (69).

(69) ... podsmatrival iz ... kak prichodili tuda devki $i$ sbrasyvaja s potnych belych tel čerez golovu rubaški. ... kidalis' v gorjačo blestevšuju vodu. 
Auch hier wird die Abfolge durch die Motivationsbeziehung zwischen dem Prädikat (Adverbialpartizip) und dem ersten Attribut bestimmt.

4. Multiple Attributionen mit A-Temp

Berücksichtigt werden Kombinationen mit A-Stat und A-Dim. Posner füht in seiner Arbeit kaum Beispiele für Abfolgen mit A-Temp an. Seinen Ausführungen zum Kriterium der Veränderlichkeit der von einem Attribut bezeichneten Eigenschaft muß man aber entnehmen, daß A-Temp grundsätzlich veränderbare Eigenschaften bezeichnet. Demnach wäre eine substantivferne Position erwartbar. Es hat sich schon oben gezeigt., daß diese Hypothese kaum haltbar ist. Hier weitere Gegenbeispiele, in denen A-Temp zusammen mit Attributen auftritt, die auf Merkmale referieren, die weniger permanent als das zeitmerkmal sind loder wo die größere oder geringere Permanenz der Merkmale im Vergleich zu A-Temp nicht $z$ u entscheiden ist) und dennoch unmittelbar beim Substantiv stehen.

(70) Staryi, bol'noj starik. Nikomu ne nužnyj.

(71) Za moim stolikom sidjat nemolodaja ustalaja ženščina i paren's devuškoj...

(72) Obognuv zdanie, oni očutilis' na malen'koj posypannoj peskom ploščadke, okružennoj čachlymi moloden'kimi topoljami, na davavšimi teni.

(73) Michail otpravilsja v mériju, i tam tščedušnyj staren'kij činounik soobščil emu...

(74) On vybral komnatu $v$ bol'šom novom dome.

(75) Vošla, kutajas' v platok, vysokaja molodaja ženščina.

(76) Dežurnyj, molodoj ulybčivyj tatarin, ... pročital zajavlenie.

(77) Za stolikom vozle lifta nemolodaja polnaja ženščina. 
A-Temp nimmt in diesen Beispielen unterschiedliche Positionen ein. Es ist im Augenblick leider nicht möglich, die diesen Abfolgen zugrundeliegenden Regularitäten aufzudecken bzw. die Kontextfaktoren $z$ bestimmen, die die jeweils vorliegende Abfolge bestimmen. Es ist denkbar, daß lexikalisch-morphologische Faktoren eine Rolle spielen, vgl. molodoj mit nemolodoj, staryj mit staren'kij. sicher ist dies aber nicht. Nur in Einzelfällen läßt sich das Kriterium der Markiertheit in Anwendung bringen (vgl. (75), für eine generelle Erklärung reicht es aber nicht aus. Es bleibt somit im Augenblick nichts anderes übrig, als die Lösung dieser problematik weiteren Untersuchungen vorzubehalten.

\section{Multiple Attributionen mit A-Propr}

A-Propr kookkurriert am häufigsten mit A-Propr. Ich konzentriere mich deshalb auf dieses Phänomen. Die Häufung von A-Propr in einer multiplen Attribution mag auf den ersten Blick überraschen, sie läßt sich aber, zumindest in bezug auf menschliche Merkmalsträger, leicht erklären. Eigenschaften von Gegenständen, hier Menschen, sind meist nicht unmittelbar beobachtbar, sondern sind das Ergebnis von Interpretationen von Handlungen bzw. Nichthandlungen. Damit einhergeht, daß Aussagen über Eigenschaften speziell motiviert sein müssen. Man sagt nicht ohne Grund, daß jemand klug, stark oder bescheiden ist, sondern verwendet Aussagen dieser Art argumentativ. Da andere Merkmale wie Dimensionen, Farben usw. normalerweise beschreibenden Zwecken dienen, ist es einsichtig, daß nur unter besonderen Bedingungen die Äußerungsmotivationen zusammenfallen. Einen solchen Sonderfall scheinen folgende Aussagen darzustellen:

(78) Prichodili sjuda i starye, opytnye kriminalisty. (79) ... sprosil ego na čisto russkom jazyke, sovsem molodym, zvonkim golosom.

Die Verträglichkeit mit A-Temp und A-propr rührt daher, daß A-Propr A-Temp expliziert, d.h. das vorausgehende A-Temp im Sinn eines A-Propr interpretiert. Es wird eine Implikationsbeziehung signalisiert. Es ist deshalb ganz natürlich, daß das 
A-Temp die erste Position im syntagma einnimmt.

Anders ist die situation in $(80)$.

(80) Mne on pokazalsja skromnym molodym čelovekom. In diesem Beispiel geht A-Temp eine ganz enge Beziehung mit dem bedeutungsarmen Substantiv ein, so daß genau genommen keine multiple, sondern nur eine singuläre Attribution vorliegt. Soviel zu den "Sonderfällen".

Die Linearisierung von zwei A-Propr folgt dem Prinzip "Merkmalsnennung vor Merkmalsinterpretation/Merkmalspräzisierung" . Vgl.

(81) ... vošla s podnjatoj golovoj, tverdoj, uverennoj pochodkoj.

(82) ... vse govorilo o tverdom, uprjamom charaktere.

(83) Vse éto nam čitalos' v togdašnich naivnych, beschitrostnych perevodach, kotorye...

(84) V ego ozornoj, razudaloj veselosti bylo čto-to ...

(85) Emu varug otčetlivo predstavilos' tupoe, bessmyslennoe 1 ico.

(86) ... rabotnik ... dolžen byt vdumčivym, trezvym analitikom...

(87) ... čto u nego čestnye, iskrennie stremlenija.

(88) Noč'ju Zelencov byl ošelomlen ostroj, pronzitel'noj bol'ju $v$ serdce.

(89) ... potiraja lipkie svoi ladoni kak chorošie, prjamodušnye, naivnye ljudi rasterjanno ob-jasnjajutsja drug s drugom.

Diese Abfolgen sind in der Regel nicht umkehrbar. Der Grund hierfür ist informationstheoretischer Art. In der Linearität des Textes können nur solche Aussagen aufeinander folgen, die mehr oder neue Information bringen. Ein einfacher Fall dieser 
Art liegt beispielsweise in explikativen Konstruktionen, den d.h.-Konstruktionen, vor. vgl:

(90) X studiert Linguistik, d.h. Sprachwissenschaft.

Diese Äußerung ist nur dann sinnvoll. wenn man davon ausgeht, daß dem Adressaten der Äußerung unterstellt wird, 'Linguistik' enthalte weniger Information als 'Sprachwissenschaft' bzw. der Terminus sei ihm nicht bekannt. Die Umkehrung der Explikation ist in diesem Fall inakzeptabel. Die Linearisierung der meisten der oben angefürten multiplen Attributionen erfolgt genau nach diesem Prinzip. In (81) wird das äußere Merkmal 'tverdaja' durch 'uverennaja' erläutert und verstärkt, in (82) erfährt 'tverdyj' eine Präzisierung durch 'uprjamyj'. Die übrigen Beispiele sind analog zu interpretieren. Keine Ausnahmen stellen (83) und (89) dar. Die Position von naivnyj wird jeweils durch das kookkurrierende Attribut bestimmt.

Die hier beobachteten Beziehungen zwischen Attributen sind bisher nicht systematisch erforscht. Es würde sich lohnen, diesem Phänomen besondere Aufmerksamkeit zu widmen.

Ich ziehe ein kurzes Fazit. Die Beschreibung multipler Attributionen wirft eine Reihe von Problemen auf, von denen das der Linearisierung der Attribute die meiste Aufmerksamkeit beansprucht hat.

Die bisherigen Lösungsansätze, soweit ich sie kenne, sind nicht geeignet, die tatsächlichen Abfolgen in einer gegebenen Sprache $z u$ erfassen. Die Gründe dafür sind u.a., daß die semantische Klassifikation der Adjektive unzureichend ist, daß textuelle und äußerungstheoretische Aspekte weitgehend außer acht gelassen werden.

Ich habe hier zu zeigen versucht, welche Faktoren im einzelnen wirksam werden können. Abgeschlossen ist die problematik damit noch lange nicht. Die Beschäftigung mit der Linearisierung der Attribute macht uns auf Fragen aufmerksam, die weitgehend textlinguistischer Natur sind: 2 . B. auf die Frage der Äußerungsmotivation. Von großem Interesse ist auch der Aspekt der Kookkurrenz von Prädikaten und Attributen, der Kombinierbarkeit von 
Attributen, des kommunikativen Gewichts von strukturen. Dies sind Fragen, auf die wir bisher nur unzureichende Antworten haben.

\section{Anmerkungen}

1. Zu dem Begriff unmarkierte Prädikate siehe das Kapitel "Prädikatmotivierende Attribution".

2. Daß unter bestimmten syntaktischen Bedingungen die Kookkurrenz von Adjektiven weniger restringiert sein kann, zeigt die Isolierung; s. dazu näher das Kapitel "Prä-, post- und interponierte isolierte Adjektive".

3. Es ist mir bewußt, daß mit dieser Anmerkung die bildtheoretischen Möglichkeiten nicht ausgeleuchtet sind, aber für den vorliegenden zweck mag die Ungenauigkeit verzeihlich sein.

4. Posner, R. Ikonismus in der Syntax..., S. 68

5. Einige Beispiele werden mehrmals zitiert. Der Einfachheit halber erhalten sie immer eine neue Nummer.

6. Wenn zamševyj im Deutschen mit einem Adjektiv wiedergegeben wird, dann sind auch im Deutschen Abfolgevarianten möglich.

7. Diese Frage ist durch die Auseinandersetzung mit der Literatur bedingt. Es ist natürlich auch möglich, die eigenen Befunde in den Vordergrund zu stellen und auf solche "Umwege" zu verzichten.

\section{Literatur:}

1. Neubauer, F., Aspekte der Klassifikation von Adjektiven. In: Kasustheorie, Klassifikation, semantische Interpretation. Beiträge zur Lexikologie und Semantik. Herausgegeben von K. Heger und J.S. Petöfi. Hamburg 1977, S. $231-259$

2. Posner R., Ikonismus in der Syntax. Zur naturlichen Stellung der Attribute. In: Zeitschrift für Semiotik 2 (1980), S. $57-82$ 
3. Sussex, R., The deep structure of adjectives in noun phrases. In: JL (1974), S. $111-131$

4. Sramm, A.N., Semantičeskaja klassifikacija kačestvennych prilagatel'nych. In: Voprosy semantiki. Vyp. 2, Leningrad 1976 , s. $27-45$

5. Vendler, Z., Adjectives and nominalizations. The Hague 1968

Die Arbeit von Klavdija Dobrina (Problemy opisanija porjadka prilagatel'nych $v$ atributivnych imenych gruppach russkogo jazyka. In: Wiener Slavistischer Almanach, 19, 1987, S. 159 - 185) ist mir erst nach Abschluß dieses Beitrags zugänglich geworden. Aufgrund der breiteren Fragestellung nimmt diese Arbeit die Ergebnisse meines Beitrags nicht vorweg.

Quellen:

A. Adamov, Zlym vetrom. Moskva 1975

-------, Petlja. Moskva 1976

A. Bezuglov, J. Klarov, Sledstviem ustanovleno. Moskva 1982

J. Bondarev, Bereg. Moskva 1982

I. Grekova, Kafedra. Moskva 1980

A. Kron, Bessonica. Moskva 1980

Ogonek, 164, 7

Pered licom zakona. Moskva 1978

V. Pronin, Ošibka v ob-ekte. Moskva 1980

N. Sizov, Nevydumannye rasskazy. Moskva 1980

O. Smelev, V. Vostokov, Vozvraščenie rezidenta. Moskva 1981 Sport $v$ SSSR

L. Vasil'evna, ... i 24 žemčužiny. Moskva 1982

s. Vysockij, Krutoj povorot. Moskva 1979 
Prä-, post- und interponierte isolierte Adjektive (zum Problem der Merkmalzuweisung)

Die Motivation für dieses Kapitel ist zweifacher Art. Zum einen geht es darum zu beschreiben, ob und wie sich die Isolierung der Adjektive, d.h. ihre Distanzierung vom Bezugsnomen durch Intonation oder Pause auf ihre merkmalzuweisende Funktion auswirkt und welche Unterschiede zur Attribution $z u$ erkennen sind, zum andern geht es um die Beschreibung des Inventars der merkmalzuweisenden konstruktionen bzw. der spezifik der einzelnen konstruktionen, und zwar nur derjenigen, an denen Adjektive beteiligt sind. Die Komplexität dieser Aufgabenstellung bedingt, daß nicht alle Aspekte behandelt und nicht alle Fragen, die auftauchen, beantwortet werden können, zumal in der Literatur eine Beschreibung dieser Art nicht ernsthaft versucht worden ist.

Das Interesse bei den bisherigen Versuchen, die Isolierung zu beschreiben, konzentrierte sich einerseits auf die Möglichkeiten und Bedingungen der Bildung von Isolierungen. wobei 2.T. der Eindruck erweckt wird, es handele sich dabei um distributionelle Varianten der Attribution ${ }^{1}$, und andererseits auf die Beschreibung der Semantik bzw. der Funktion der Isolierung, die allerdings $z$ grob ausfällt, z.T. deshalb, weil in der Regel nur zwei und nicht arei Typen von Isolierungen unterschieden werden. In der neueren Akademiegrammatik beispielsweise wird die Spezifik der Isolierung darin gesehen, daß, in Abhängigkeit vom Bezugswort, das Adjektiv ein Merkmal nennt, das das Prädikatsmerkmal ergänzt oder (selten) eine Umstandsbedeutung erlangt (obstojatel'stvenno-charakterizujušče značenie) oder die Informationsleistung des Adjektivs verstärkt (pri otsutstvii prepozitivnogo prilagatel'nogo obosoblenie postpozitivnogo ad-ektivnogo oborota usilivaet ego informativnost' $)^{2}$.

Die funktionalen Besonderheiten der Isolierung scheinen mir hier nur unzureichend herausgearbeitet $z u$ sein, die Abgrenzung gegenüber den "konkurrierenden" Konstruktionen ist unklar. 
Es stellt sich somit die Aufgabe, die konkurrierenden Konstruktionen vergleichend $z u$ beschreiben, um auf diese Weise nicht nur ein klareres Bild von der Isolierung sondern auch von den anderen merkmalzuweisenden Konstruktionen $z u$ erhalten. Dies bedeutet, daß im folgenden alle in Frage kommenden Konstruktionen in die jeweils anderen umgebildet oder durch sie ersetzt werden, natürlich auch mit der Absicht, die Rolle des Kontextes für die Distribution der Konstruktionen ermitteln zu können.

Hier nun eine Übersicht über die Konstruktionen, die uns im folgenden näher beschäftigen werden:

1. die Konstruktion mit präponiertem isoliertem Adjektiv abgekürzt: A, NV

Beispiel :

(1) Vjalyj, flegmatičnyj, vsegda skučnyj, on javno ne sootvetstvoval obrazu intellektual'nogo syščika, kotoryj sozdalo moe mal'と̌išeskoe voobraženie.

2. die Konstruktion mit postponiertem isoliertem Adjektiv abgekürzt: NV,A

Beispiel:

(2) Vstretila nas žena Savel'eva, Sof'ja Michajlovna, chlopotlivaja, mnogoslovnaja.

3. die Konstruktion mit interponiertem isoliertem Adjektiv abgekürzt: $N, A, V$

Beispiel:

(3) Chozjain nočležki, kudlatyj, v sukonnom kartuze, vnimatel'no menja osmotrel i potreboval "pačport".

4. die appositiv-parenthetische Konstruktion abgekürzt: $N_{i}, A N_{j}$

Beispiel :

(4) Leonid Isaakovič, ščplyj, podvižnyj čelovek let soroka, vstretil menja radušno. 
5. die prädikative Konstruktion mit einem Adjektiv abgekürzt: $N$ - A

Beispiel:

(5) Ona byla sčastliva.

6. die prädikative Konstruktion mit einer Nominalphrase abgekurzt: $N_{i}-A N_{j}$

Beispiel:

(6) Ljubaša byla soveršenno bezobidnoj devuškoj, kotoraja, kak govoritsja, daže muchi ne mogla obidet'.

7. die attributive Konstruktion

abgekürzt: AN

Beispiel:

(7) Pokazalas' nerjašlivaja sedaja golova

Zu diese: Aufzählung ist anzumerken, daß ich bei der Untergliederung einer Konstruktion davon ausgegangen bin, daß die formalen Unterschiede mit funktionalen korrelieren. Ich habe deshalb auch drei Untertypen bei der Isolierung angesetzt, obwohl in der Literatur im allgemeinen nur zwei unterschieden werden.

Präponierte isolierte Adjektive

Sehen wir uns zunächst einige Beispiele an:

(8) Menja besila ee neterpimost'. Mjagkaja i taktičnaja s drugimi, ona nachodila osoboe udovol'stvie obnaruživat' moi slabosti...

(9) Čerez god Almazov uže byl tem, ¿̌to on est', zamestitelem Uspenskogo po administrativnochozjajstvennoj časti, cennejšim i nezamenimym. Rešitel'nyj i nezavisimyj $v$ obščenii s sil'nymi mira sego, Uspenskij byl trogatel'no bespomošcen $v$ denežnych delach.

(10) Žizn' zastavila menja izmenit' ocenku i Gruzdja, i Medvedeva. Čerstuyj i rezkij na pervyj vzgljad. 
Medvedev neožidanno okazalsja isključitel'no duševnym človekom, $k$ kotoromu tjanulis' sotrudniki, čtoby...

Das Besondere bei diesem Verfahren der Merkmalzuweisung besteht darin, daß die präponierten Adjektive eine semantische Relation mit dem Prädikat eingehen. In den vorliegenden Beispielen handelt es sich um eine Art kontrastiver Relation. Diese könnte man folgendermaßen paraphrasieren:

"Während im Fall a X das Merkmal 'positiv' hat, hat $X$ im Fall b das Merkmal 'negativ' und vice versa."

Wie die Paraphrasierung zeigt, bedingen sich die Merkmale der Adjektive und des Prädikats gegenseitig. Die Tilgung eines Merkmals führt, wie die entsprechenden Umbildungen zeigen, zu einem Kohärenzbruch:

(8') *Menja besila ee neterpimost'. Ona nachodila osoboe udovol'stvie obnaruživat' moi slabosti...

(8'') *Menja besila ee neterpimost'. Mjagkaja i taktičnaja s drugimi.

( (') $^{\prime}$, das formal wie eine Konstruktion mit postponierten isolierten Adjektiven aussieht, liefert schon einen ersten Hinweis auf die funktionale spezifik der einzelnen Isolierungen. Der durch die Tilgung der zweiten merkmalzuweisenden Konstruktion entstandene Kohärenzbruch ist auch durch eine Umwandlung der Isolierung in andere Konstruktionen nicht aufzuheben. Es fehlt das Bezugsmerkmal. Wir können somit feststellen, daß die präponierten isolierten Adjektive Konstituenten einer komplexen Merkmalzuweisung darstellen. $O b$ dies schon das entscheidende spezifikum dieser Konstruktion ist, wird sich zeigen, wenn die angekündigten Ersetzungen durchgefüht worden sind. Zuvor sei noch angemerkt, daß die kontrastive Relation, wie sie in (8), (9) und (10) vorliegt, die Besetzungsmöglichkeiten von $A, N$ und $V / P$ restringiert. 
Für A, so scheint es, kommen nur Adjektive in Frage, die auf das Verhalten der Menschen referieren, für $N$ dementsprechend nur Bezeichnungen für Personen. V/P schließlich muß Eigenschaften von Personen bzw. Verhaltensweisen bezeichnen vgl.

(8“') *Gromozdkaja, tjaželobokaja, ona nachodila osoboe udovol'stvie obnaruživat' moi slabosti...

Vergleichen wir nun die präponierte Isolierung mit den übrigen merkmalzuweisenden konstruktionen:

a) $A, \mathrm{NV} \rightarrow \mathrm{NV}, \mathrm{A}$

Beispiel ( $8 \%$ ) hat signalisiert, daß diese Umbildung grundsätzlich problematisch ist. Die entsprechenden Umbildungen von (9) und (10) unterstreichen diesen Eindruck:

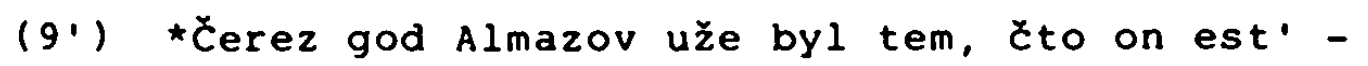
zamestitelem Uspenskogo po administrativnochozjajstvennoj casti, cennejšim i nezamenimym. Uspenskij byl trogatel'no bespomoščen $v$ denežnych delach, rešitel'nyj i nezavisimyj $v$ obščnii s sil'nymi mira sego.

(10') « Žizn' zastavila menja izmenit' ocenku i Gruzdja, i Medvedeva. Medvedev neožidanno okazalsja isključitel'no duševnym čelovekom, k kotoromu tjanulis' sotrudniki, ¿toby... čerstvyj i rezkij na pervyj vzgljad.

Die interdependenten Merkmalzuweisungen sind mit NV, A nicht $z$ u realisieren.

b) $A, N V \rightarrow N, A, V$

(9'1) ? Čerez god Almazov uže byl tem, ¿̌to on est'. zamestitelem Uspenskogo po administrativnochozjajstvennoj časti, cennejšim i nezamenimym. Uspenskij, rešitel'nyj i nezamenimyj $v$ obščenii $s$ sil'nymi mira sego, byl trogatel'no bespomoščen $v$ denežnych delach. 
(10 ') ? Žizn' zastavila menja izmenit' ocenku i Gruzdja, i Medvedeva. Medvedev, čerstuyj i rezkij na pervyj vzgljad, neožidanno okazalsja isključitel'no duševnym čelovekom, k...

Auf den ersten Blick scheinen diese Umbildungen unproblematisch zu sein. Bei genauerem Hinsehen zeigt sich jedoch, daß die durch die Interponierung der Adjektive verursachte Frontierung des Bezugsnomens eine größere Nähe des Bezugsnomens $z u$ seinem Vorgänger nach sich zieht. Daraus resultiert, daß der Effekt der Informationswiederholung entsteht, was seinerseits zur Unterbrechung der ausgeprägt engen Bindung dieses Satzes an den Vortext füht. In isolierter stellung haben diese Adjektive, diese Einschränkung ist notwendig, keine kohärenzstiftenden Potenzen. Zu diesem Aspekt und zu N,A,V später aber mehr.

c) $A, N V \rightarrow N_{i}, A N_{j}$

$$
\begin{gathered}
(9 \cdots, ? \text {... Uspenskij, rešitel'nyj i nezavisimyj v obščenii } \\
\frac{\text { s sil'nymi mira sego čelovek, byl trogatel'no }}{\text { bespomoščen } v \text { denežnych delach. }}
\end{gathered}
$$

Diese Umbildung zeigt die gleichen Restriktionen wie die vorherige. Die Bindung dieses Satzes an den Vortext ist erheblich gestört. Hinzu kommen noch spezifische mit der Einsetzung von $N$ verknüpfte Probleme. Mit dem klassifikatorischen $\mathrm{N}$ wird eine spezielle Kommunikationsabsicht realisiert, die sich nicht mit der präponierter Isolierungen deckt. Dazu mehr im zusammenhang mit der parenthetischen Apposition.

Am Rande sei noch darauf hingewiesen, daß eine Präponierung der Apposition (= präponierte AN-Isolierung) zu keinem akzeptablen Ergebnis führt, weil die Referenz dieser Phrase unklar ist. Nur dann, wenn das subjekt pronominal realisiert ist, scheint eine präponierte AN-Isolierung möglich zu sein, vgl. 
Zelenye, naivnye rebjata [ = žurnalisty], oni $v$ pervye dni neustanno gonjalis' za kakim-to materialom.

d) A, NV $\rightarrow$ AN

( $\left.g^{\prime v}\right)$ *Čerez god Almazov uže byl tem, čto on est'. zamestitelem Uspenskogo po administrativnochozjajstvennoj časti, cennejšim i nezamenimym. Rešitel'nyj i nezavisimyj $v$ obščenii s sil'nymi mira sego Uspenskij byl trogatel'no bespomoščen $v$ denežnych delach.

Auch hier genügt ein Beispiel, um zu zeigen, daß diese Umbildung zu keinem akzeptablen Ergebnis führt. Die Inakzeptabilität der AN-Konstruktion ist dadurch bedingt, daß die Kohärenz des Textfragments verletzt ist. Darüber hinaus wird bei AN kein komplexes Merkmal zugewiesen. Stattdessen wird eher eine Motivationsbeziehung zwischen Attribut und Prädikat suggeriert. Grundsätzlich gilt natürlich für diese Umbildung, daß sie von vornherein bei prononinalen Bezugswörtern scheitert.

e) $A, N V \rightarrow N-A$

(9v) «Čerez god Almazov uže byl tem, čto on est' zamestitelem Uspenskogo po administrativnochozjajstvennoj časti, cennejšim i nezamenimym. Uspenskij byl rešitel'nym i nezavisimym s sil'nymi mira sego. On byl trogatel'no bespomoščn $v$ denežnych delach.

Auch hier läßt sich keine Äquivalenzbeziehung feststellen. zum einen ist die Kohärenz des Textes mehrfach gestört. zum andern fehlt die charakteristische Interdependenz der Merkmalzuveisungen.

f) $A, N V \rightarrow N_{i}-A N_{j}$

$(9$ n) *Čerez god Almazov uže byl tem, ¿̌to on est' zamestitelem Uspenskogo po administrativnochozjajstvennoj časti, cennejšim i nezamenimym. 
Uspenskij byl rešitel'nym i nezavisimym s sil'nymi mira sego čelovekom. On byl...

Die Gründe für die Inakzeptabilität dieser Umbildung entsprechen denen von(e).

Die Umbildungsversuche haben bestätigt, daß präponierte isolierte Adjektive eine ganz spezifische Rolle innerhalb der merkmalzuweisenden Konstruktionen spielen. Charakteristisch ist die Interdependenz von Isolierung und Prädikation. Äußerlich zeigt sich diese enge Beziehung darin, daß ohne Störung der Kohärenz des Textes die präponierte Isolierung nicht getilgt werden kann.

Präponierte isolierte Adjektive erzeugen auch noch andere semantische Relationen. ${ }^{3}$ Man könnte sie mit dem Begriff motivierend-begründend zusammenfassen. Vgl. dazu die folgenden Beispiele:

(11) No Erochin byl nastol'ko ne pochož na ideal'nogo geroja, čto uže pri pervom znakomstve ničego, krome gadlivogo čuvstva, u menja ne vyzval. suetlivyj, nizkolobyj, pryščavyj, postojanno oblizyvajuščij ostrym jazykom tolstye guby, on byl antipatičen...

(12) Mežerickij rabotal glavvračom psichoneurologičeskogo dispansera. Krupnyj, polnyj, s izrjadnoj plešju, okružennoj kak nimbom redkimi solomennogo cveta volosami, tolstogubyj, so svetlymi laskovymi glazami, Boris Matveevič pochodil na kakogo-to dobrogo priručennogo zverja.

(13) Devočka vstretila ego $v$ perednej i robko, molčalivo obradovalas'. Nekrasivaja, chuden'kaja, blizorukaja, ona očen' pochodila na otca.

(14) Postupiv $v$ institut, on uže tverdo orientirovalsja na aspiranturu. Dannye u nego byli. Sposobnyj. načitannyje s chorošej pamjat'ju, on obraščal na sebja vnimanie prepodavatelej. 
(15)

Gromozdkaja, tjaželobokaja, s prekrasnymi černymi

glazami i malen'kim rtom. Asja byla i choroša i durna soboj.

(16) V Borovskom cerkov' ochranjalas' gosudarstvom kak pamjatnik architektury. Nebol'šaja, belokamennaja, ona, kazalos', vyrastala prjamo iz cholma. Ukrašeniem služili uzkie okonca i izjaščnaja makovka.

(17) A bol'še vsego $v$ ogorode makov. strojnye, somknutye. oni pochoži na veseloe vojsko.

Die semantische Relation zwischen den präponierten Adjektiven und dem Prädikat läßt sich in folgender Weise paraphrasieren: "Aufgrund der Eigenschaft a wird $x$ als $b$ bewertet/erreicht $x$ b."

Im Unterschied $z u$ den obigen Konstruktionen sind die Adjektive nicht auf den Typ "Verhaltensadjektiv" beschränkt. Das Inventar ist offener. Das gleiche gilt für die Bezugsnomina. Die Verben bzw. Prädikate dagegen scheinen eine spezielle Klasse zu konstituieren. Ich will sie vorläufig "Ähnlichkeits-bzw. Bewertungsprädikate" nennen. Welche Prädikate im einzelnen zu dieser Klasse gehören, läßt sich im Augenblick noch nicht sagen. Auch noch nicht geklärt ist die frage, ob alle präponierten Adjektive und Präpositionalphrasen innerhalb einer Isolierung in den Skopus des prädikats fallen, d.h. notwendigerweise eine Beziehung zum Prädikat eingehen. Beispiel (12) zumindest spricht nicht für eine absolute Interdependenz. Es erubrigt sich, bei diesen Beispielen die oben angeführten Ersetzungsproben durchzuführen, denn sie bringen keine neuen Erkenntnisse.

Leider kann mit diesen Feststellungen die Beschreibung der präponierten Isolierung noch nicht abgeschlossen werden. Es gibt nämlich Beispiele, in denen keine der genannten semantischen Relationen realisiert $z u$ sein scheint und die gegen die Interdependenz der Merkmalzuweisungen sprechen. Vgl. 
(18) ... zagovorila tetja Daša vmesto privetstvija.

Tolstaja, v telogrejke edva schodivšajasja u nej

na grudi, ona perestala podmetat' $i$ operias'

na čerenok metly.

(19) Pas on [Griška) korov i u nich v Zagor'e.

Pas dva ili tri leta krjadu, i Praskov'ja chorośo znala ego: ne raz vot tak, kak segodnja suetilas'. starajas' ublažit' ego.

vysokij, s ispytym licom, $v$ telogrejke, prožžennoj ne $v$ odnom meste, Griška poutru vygonjal korov v luga...

Kupalova [ 3 ] tendiert dazu, hier einen besonderen Typ von Isolierung $\mathrm{zu}$ sehen:

Meždu tem imenno $v$ takich konstrukcijach priznaki obosoblennych členov realizujutsja v naibolee "čistom" vide, ne osložnjajas' dopolnitel'nymi, soputstvujuščimi, no otnjud' ne objazatel'nymi charakteristikami i uslovijami projavlenija. (s. 117 ).

Eine Beschreibung, die die Bedingungen für die Bildbarkeit/ Nichtbildbarkeit dieser Konstruktion nennt, liefert Kupalova nicht. Die von ihr selbst angefuhrten Beispiele sind heterogen. Problematisch sind vor allem diejenigen mit präponierten partizipien, denn sie lassen ganz klar erkennen, daß die Isolierungen durch den Vortext bedingt sind und das Resultat eines vorausgehenden Ereignisses bezeichnen. Vgl.

(20) Okrylennyj, gordyj neverojatno stol' otvetstvennym poručeniem, polnyj ènergii i žaždy vypolnit' zadanie. echal Andrej na stanciju.

Für die Einordnung und Funktion von Konstruktionen wie (18) und (19) ist es wichtig festzustellen, daß die isolierten Elemente auf äußere Merkmale eines Gegenstandes referieren, während die Prädikate Handlungen verschiedener Art bezeichnen. Vgl. noch 
(21) Dlinnaja, s ogromnymi ot chod'by glazami, ostrižennaja posle bolezni nagolo, povjazannaja platočkom, Katja do noči sidela s knigoj.

(22) ... tonen'kij, vysokij, chudoj, no sil'nyj, zadrav golovu, bežal žen'ka stoletov po doroge, prevrativšejsja $v$ mesivo vsego na odni sutki.

Da die isolierten Adjektive keine Beziehung zum Prädikat eingehen, ist die durch sie realisierte Merkmalzuweisung in gewissem Sinn gleichrangig mit der des prädikats. Mit einem entscheidenden Unterschied: die Isolierung liefert Detailmerkmale des Gegenstandes, die Prädikation die situative Charakterisierung des Gegenstandes. Wenn man will, dann kann man das Verhältnis der beiden Merkmalzuweisungen zueinander als eine Perspektivenerweiterung ansehen. Wie ich später noch zeigen werde, stellt dieser Typ von Isolierung eine komplementäre Ergänzung zur postponierten Isolierung dar. insofern als es dort um eine Perspektivenverengung geht. 4

Ein Beispiel noch zum AbschluB:

(23) Boržanskomu bylo togda godkov trinadcat'. Šstryj, jurkij. Našel pod stenoj lazejku, proskol'znul $v$ nee.

(23) zeigt, daß es im Einzelfall problematisch sein kann, eine Konstruktion als Isolierung zu bestimmen. Trotz formaler Ausgrenzung der Adjektive und einer motivationellen Beziehung $z u$ einem der nachfolgenden Prädikate scheint hier keine Isolierung vorzuliegen. Die Adjektive sind eher prädikativer Natur, wobei das subjekt elliptisch realisiert ist.

Postponierte isolierte Adjektive

Bei der Beschreibung der präponierten isolierten Adjektive haben wir bereits zwei Merkmale der postponierten Isolierung kennengelernt. Nämlich, sie ist fakultativ, und es liegt 
keine semantische Beziehung zum vorausgehenden Prädikat vor. Darüber hinaus wurde angenommen, daß die Funktion dieses Typs von Isolierung darin zu bestehen scheint, einen komplexen Sachverhalt so $z u$ gliedern, daß eine Perspektivenverengung $^{5}$ erzielt wird. D.h., es wird ein Hauptereignis der vom Prädikat bezeichnete Sachverhalt - und ein Nebenereignis - die von den Adjektiven bezeichneten Merkmale unterschieden. Diese Funktion läßt sich zumindest an folgenden Beispielen leicht nachweisen.

(24) Iz-pod arki starogo doma vyšel Andrej Mezencev polnotelyj, krivonogij. On nes na pleče vesla i udockku.

(25) Vperedi, pobleskivaja vetrovym steklom, echal Semen susanin - tolstyj, v cernom kostjume.

(26) Za Ternovskim, operšis' podborodkom o kisti ruk, skrešcennye na spinke stula, sidit Radij Jur'ev - uzkogolovyj, s otkinutoj nazad šapkoj gustych temno -ryžich volos...

(27) Kogda rodilsja vnuček Miša - puchljavyj, Černoglazyj, kosen'kij, - Lidija Michajlovna vspychnula bylo dušoj, poljubila mal'čika...

(28) V načaleijulja priechala Ljuda - chorošen'kaja veselaja, čut'-čut' popolnevšaja. Matvej snačala ee ne uznal.

Diesen Beispielen ist gemeinsam, daß sie eine Existenz- bzw. Erscheinungsaussage realisieren. Die Prädikate, die dazu benutzt werden, sind:

vyšel, echal, sidit, rodilsja, priechala, javilsja... Die postponierten Adjektive ihrerseits referieren auf beobachtbare äußere Merkmale des entsprechenden Gegenstands. wie die Beispiele zeigen, kookkurrieren die Adjektive ohne erkennbare Restriktionen mit Präpositionalphrasen. 
Für die weitere Charakterisierung und Abgrenzung dieser Konstruktion von den übrigen merkmalzuweisenden Konstruktionen bedienen wir uns auch hier der Ersetzungsproben.

g) NV,A $\rightarrow N, A, V$

Diese Umbildung bereitet schon aus rein formalen Gründen Schwierigkeiten. In allen Beispielen nimmt das Bezugsnomen die Finalposition ein. Es gibt somit keine Interposition. Auch da, wo die Wortfolge veränderbar und eine Interposition möglich ist, ist die Umbildung kaum akzeptabel:

(28')? Ljuda, chorošen'kaja, veselaja, čut'-čut' popolnevšaja, priechala v načale ijulja...

Ohne der Analyse von N,A,V-Konstruktionen schon vorzugreifen, kann man feststellen, daß diese Variante keine Perspektivenverengung zum Ausdruck bringt und somit mit der Ausgangskonstruktion nicht äquivalent ist. Worin genau der Unterschied besteht, wird im Zusammenhang mit der Beschreibung der Interposition geklärt.

Auch das folgende Beispiel, das eine (allerdings usuelle) Erscheinungsaussage beinhaltet, läßt sich nicht in eine äquivalente Konstruktion mit Interposition umbilden:

(29) Po večeram Ignatij prichodil k sysoevym - malen'kij, obrosšij.

(29')? Po večeram Ignatij, malen'kij obroš̌ij, prichodil k sysoevym.

h) $N V, A \rightarrow N_{i}, A N_{j}$

Diese Umbildung scheint ebenfalls zu keinem akzeptablen Ergebnis zu führen:

(24')? Iz-pod arki starogo doma vyšel Andrej Mezencev, polnotelyj, krivonogij mužčina/čelovek. On nes na pleče vesla i udočku. 
(27')? Kogda rodilsja vnuček Miša, puchljavyj, černoglazyj. kosen'kij rebenok, Lidija Michajlovna vspychnula bylo dušoj, poljubila mal'čika ...

(28')? V načale ijulja priechala Ljuda, chorošen'kaja, veselaja, čut'-čut' popolnev̌̌aja studentka/devuška/ ženščina. Matvej snačala ee ne uznal.

Die Inakzeptabilität dieser Sätze hat verschiedene Ursachen. (24') ist kein Beispiel für eine perspektivenverengung, sondern signalisiert viel eher, $\triangle a \beta$ hier eine Person vorgestellt werden soll. Dazu später mehr. (27') und vor allem (28') lenken unsere Aufmerksamkeit auf $\mathrm{N}_{j}$. In (27') erscheint rebenok mehr oder minder redundant zu sein. Die ganze Information dieses Lexems ist bereits in vnuček enthalten. Noch deutlicher kommt diese Problematik in (28') zum Ausdruck. Ljuda referiert auf eine aus dem Vortext wohlbekannte person. Dies und die Tatsache, daß hier von "Mutter" und Sohn die Rede ist, sind die Ursachen dafür, daß es kein geeignetes $N_{j}$ gibt, das die dem Satz (28) zugrundeliegende Perspektive wiedergeben könnte. Die Sicht der Eltern, ev. des Autors, aus der dieses Ereignis berichtet wird, erlauben nicht, daß der Tochter, zumal kein Adressat vorhanden ist, eines dieser Klassenmerkmale zugewiesen wird. Natürlich gilt auch für die beiden letzten Beispiele die oben genannte funktionale Besonderheit dieser Konstruktion. Die parenthetische Konstruktion erweist sich somit als ein eigenständiger Typ der Merkmalzuweisung, der gesondert beschrieben werden muß.

i) $\mathrm{NV}, \mathrm{A} \rightarrow \mathrm{AN}$

(24') Iz-pod arki starogo doma vyšel polnotelyj. krivonogij Andrej Mezencev. On nes na pleče vesla i udočku.

(26") ? Za Ternovskim, operšis' podborodkom o kisti ruk, skrescennye na spinke stula, sidit uzkogolovyj, s otkinutoj nazad šapkoj gustych temno-ryžich volos Radij Jur'ev. 
Diese Umbildungen zeigen zweierlei: Erstens, in attributiver stellung haben die Adjektive die Funktion schmückender Beiwörter (ev. auch identifizierende Funktion), d.h. sie referieren auf Merkmale, die bereits an anderer stelle in den Text eingefuhrt wurden. Zweitens, die zusammen mit den Adjektiven auftretenden Präpositionalphrasen eignen sich schlecht für eine attributive Verwendung. Die Postponierung ist in dieser Hinsicht offensichtlich weniger restringiert. Darüber hinaus gilt, daß die Attribute Bestandteil des vom Satz bezeichneten Gesamtereignisses sind, d.h. in den skopus des prädikats fallen. Dies kann, wie eine entsprechende Umbildung von (27) zeigt, zu einem Konflikt zwischen der Semantik des prädikats und der semantik des Attributs führen, in der Weise, daß das attributive Adjektiv auf Merkmale referiert, die nicht zum Prädikatsereignis gehören, sondern diesem zeitlich nachgeordnet sind. Noch offensichtlicher ist dieser Konflikt bei der Umbildung von (28):

(28'') ? V načale ijulja priechala chorošen'kaja, veselaja, Ěut'-čut' popolnev̌aja Ljuda. Matvej snačala ee ne uznal.

Die isolierten Adjektive bezeichnen Merkmale, die erst nach dem Ereignis priechala der von Ljuda bezeichneten Person zugeordnet werden können.

j) $N V, A \rightarrow N-A$

$N$ - A -Konstruktionen können wie die postponierten Isolierungen zur Sachverhaltsgliederung eingesetzt werden. Vgl.

(31) Fljagin vzošel na tribunu. On byl bleden, daže zelenovat.

Der grundsätzliche Unterschied zwischen beiden Konstruktionen scheint darin $z u$ bestehen, daß bei der $N$ - A-Konstruktion den Adjektiven höheres kommunikatives Gewicht zukommt. Sie konstituieren ein eigenständiges prädikat. was natürlich Auswirkungen auf den kontext hat. So steht beispielsweise in (31) die $N$-A-Konstruktion in einer senantischen Beziehung zum vorausgehenden Prädikat bzw. Kontext. Die prädikative Konstruktion ist motiviert. 
Bildet man (31) um, geht diese Beziehung verloren, sieht man einmal davon $a b$, daß diese Umbildung durch die Existenz der Partikel daže behindert wird:

$\left(31^{\prime}\right)$ ? Fljagin vzošel na tribunu - blednyj, daže zelenovatyj.

Die Umbildungen von (24), (25) usw. ergeben kein günstigeres Bild. Vgl.

(24') ? Iz-pod arki starogo doma vyšel Andrej Mezencev. on polnotelyj, krivonogij. / on byl polnotelyj. krivonogij. / on nes na pleče vesla i udočku.

(26“') ? Za Ternovskim, opeř̌is' podborodkom o kisti ruk, skrě̌čnnye na spinke stula, sidit Radij Jur'ev. on uzkogolovyj, s otkinutoj nazad sapkoj gustych temno-ryžich volos...

(24'“) ist dadurch charakterisiert, daß die N - A-Lösung die Kohärenz des Textes beeinträchtigt. Die Prädikation ist unmotiviert und erzeugt eine gewisse Redundanz (durch die wiederholung des subjekts im darauffolgenden satz). Hinzukommt, daß bei Umbildungen dieser Art eine Tempusentscheidung getroffen werden muß. Ohne hier tiefer in diese Problematik eindringen $z u$ können, sei wenigstens angemerkt, daß die Präsensvariante in besonderem Maß das Eigengewicht von N - A hervorzuheben scheint, was u.a. auch zur signalisierung von Fortsetzungserwartungen füht. (26'') macht darauf aufmerksam, daß sich präpositionalphrasen, für die kein kopulaverb rekonstruiert werden kann, schlecht für einen prädikativen Gebrauch eignen (vgl. ona [ est'] $v$ černom kostjume).

Mit diesen Ausführungen zur Ersetzungsoperation (d) ist das komplizierte Verhältnis von postponierter Isolierung und Prädikation keineswegs erschöpfend beschrieben. Es hat sich aber mit aller Deutlichkeit gezeigt, daß von einer Äquivalenzbeziehung nicht die Rede sein kann. Dieses Ergebnis genügt für die vorliegende Beschreibung. 
k) $N V, A \rightarrow N_{i}-A N_{j}$

Auch bei dieser Umbildung läßt sich keine Äquivalenzbeziehung feststellen, soweit diese Umbildung in einem gegebenem Kontext überhaupt sinnvoll ist. Vgl. etwa die Umbildung von (28), die aus verschiedenen Gründen inakzeptabel ist:

(28' ')? V načale ijulja priechala Ljuda. Ona byla chorošen'kaja, čut'-čut' popolnevšaja devuška. Matvej snačala ee ne uznal.

Problematisch ist hier nicht nur die oben schon besprochene Perspektive, aus der devuška gesetzt werden kann, sondern auch die Phrase Čut'-čut' popolnevšaja, die eigentlich auf eine Vortextinformation verweist, was jedoch mit der durch devuška erzielten Klassifizierung nicht verträglich ist.

Das Phänomen der postponierten isolierten Adjektive tritt nicht nur bei einstelligen Prädikationen, wie in den bisherigen Beispielen, sondern auch bei mehrstelligen auf. Dabei stellen sich u.a. folgende Fragen:

1. erfolgt auch hier die Postponierung unter dem Aspekt der Perspektivenverengung?

2. auf welchen Aktanten bezieht sich die Isolierung?

Zur Verdeutlichung der Problematik zunächst ein paar Beispiele:

(32) Praskov'ja videla lico Ziny - malen'koe, napudrennoe, glaza podvedennye sinej kraskoj.

(33) S prazdnikom! S prazdnikom, kol' ne šutite! - otozvalas' baba s koromyslom, razgljadyvaja neznakomogo čeloveka - molodogo, chorošo odetogo.

(34) Na rečnom tramvajčike zašli v bufet, čtoby vypit' po poslednej rjumke kon'jaku, i zdes' vichrov donžuanski podmignul bufetčice, nizen'koj polnogrudoj. černoglazoj, v nakrachmalennom chalatike, naraspev pročital ej liričeskuju stročku iz Bloka... 
Es besteht kein Zweifel, daß auch hier eine Perspektivenverengung vorliegt. Die von den objekten bezeichneten Gegenstände werden neu in den Text eingefüht und sind damit Teil einer Erscheinungsaussage. Auf diese allgemeine Erscheinungsaussage folgen die den Gegenständen zugewiesenen Merkmale in einer Weise, die den Eindruck einer aktuellen Wahrnehmung vermittelt. Die Gegenstände werden als "klein, gepudert", "jung, gut angezogen". usw. empfunden. Wie wir an einem anderen Beispiel noch sehen werden, ist die prädikatssemantik dafür entscheidend, welche Merkmale jeweils als aktuell angesehen werden können. Der Vollständigkeit halber sei noch angemerkt, daß sich bezüglich der Ersetzungsmöglichkeiten durch die anderen merkmalzuweisenden Konstruktionen keine grundsätzlich neuen Erkenntnisse ergeben. Am Rande sei lediglich vermerkt, daß eine Umbildung dieser Konstruktionen, in $A, N V$ und $A, A, V$ schon aus rein syntaktischen Gründen scheitert.

Interessant ist nun folgendes Beispiel:

(35) On deržal ee, legkuju, bol'šeglazuju, odnoj rukoj za spinu, drugoj privyčno, lovko popravljaja postel'. Von den obigen Beispielen unterscheidet sich (35) dadurch, daß kein neues objekt in den Text eingefürt wird. Die Motivation für die isolierten Adjektive ergibt sich daraus, daß sie auf einen in bezug auf die Handlung aktuellen zustand referieren. Zum Verständnis des Kontextes sei gesagt, daß ee eine schwer kranke Frau bezeichnet. Wenn auf diesem Hintergrund nun das prädikat ausgetauscht wird, dann zeigt sich, daß nur solche Prädikate zulässig sind, die die aktuelle Gültigkeit der Adjektivmerkmale nicht in Frage stellen. Vgl.

(35') On celoval ee, legkuju, bol'šeglazuju ... mit

(35') ? On govoril s nej, legkoj, bol'šeglazoj.

Die adjektivischen Merkmale in (35") sind nicht motiviert. Das gleiche Ergebnis läßt sich erzielen, wenn man die Adjektive austauscht:

(35'") ? On deržal ee, moloduju, krasivuju, odnoj rukoj za spinu, drugoj privyčno, lovko popravljaja postel'. 
Die Adjektive referieren auf Merkmale die keinen aktuellen Bezug zur Handlung aufweisen.

Ein neuer Aspekt ergibt sich durch Beispiel (36):

(36) Fizičeskim naslaždeniem bylo slušat' ego reč' - plavnuju, zvučnuju, so staromoskovskim (nyne redkiml proiznošeniem.

Das Besondere bei diesem Beispiel ist, daß die isolierten Adjektive eine semantische Beziehung zum vorausgehenden Prädikat bzw. zur prädikatsphrase eingehen, indem sie eine Explikation für den beschriebenen Zustand liefern. Da die beobachtete "Abweichung" mit der Semantik des prädikats zusammenhängt und durch sie erklärt werden kann, ist es nicht erforderlich, einen neuen Typ von postponierter Isolierung anzusetzen. Der Prädikatsausdruck in (36) ist eindeutig bewertender Natur (fizičeskim naslaždeniem bylo). und Bewertungen sind stets offen für Explikationen.

Unsere zweite Frage, die nach der subjekt-oder objektorientiertheit der Isolierung ist in formaler Hinsicht leicht $z$ u beantworten. Entscheidend ist die Kasuskongruenz. vgl.

(37) Ženja, mladšaja, ta bol'še pochodila na mat' smuglaja, dlinnorukaja, serditaja. Mat', Anna Savišna, byla serditaja ne otrodu, a ot tjaželoj žizni.

(38) Zoja ždala ego u dverej - dolžno byt', v okno uvidela kak on pochodil. Blednaja, no spokojnaja. on posmotrel ej $v$ lico $i$ obmer.

Es besteht kein Zweifel, daß sich in beiden Fällen die Isolierung auf das subjekt bezieht. Die semantische Grundlage hierfür scheint zu sein, in (38), daß es sich hier ungeachtet der formalen Mehrstelligkeit des Prädikats doch um eine Existenzaussage handelt, in (37), daß ein bewertendes und kein aktionales prädikat vorliegt. Letzteres verhindert grundsätzlich, wie wir noch sehen werden, einen subjektbezug. Interessant ist nun noch ein anderes Phänomen, und zwar

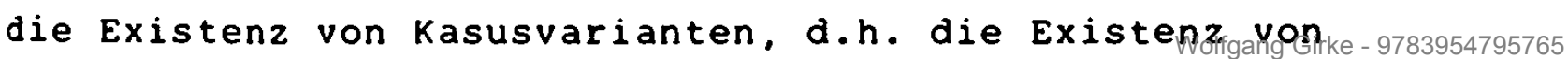


kasuskongruenten und nichtkasuskongruenten adjektivischen Isolierungen. $\mathrm{Vgl}$.

(39) Ja ne byl vinovat $v$ ee smerti. Ja ee ljubil, a ona ljubila drugogo. Bol'šoj, sil'nyj, cto nazyvaetsja, kosaja sažen' $v$ plečach.

(40) A vse-taki on, parazit, ot menja ušel. Na druguju pol'stilsja. Molodaja, krasivaja, nogi kak tvoi jabloki. Plochogo pro nee ne skažu.

(41) Otkrovenno govorja, ja ožidal uvidet' ne takuju Ženšcinu. Malen'kaja, chuden'kaja, s ... - vot kakoj okazalas' Klavdija Potapova Terechova...

Das Besondere an diesen Konstruktionen sehe ich darin, daß die nicht kasuskongruenten Adjektive im Unterschied $z u$ den kongruenten eine schwache Bindung an das Bezugsnomen signalisieren. Dies wiederum bedeutet, daß sie nicht in den skopus des vorausgehenden Prädikats fallen. Für dieses Phänomen sehe ich zwei Interpretationsmöglichkeiten:

Erstens, Skopusbindung besagt, daß der Sachverhalt von innen, d.h. vom Agenten her gesehen wird, Skopusfreiheit, daß der Sachverhalt von außen, vom Textproduzenten her gesehen wird; zweitens, Skopusbindung besagt, daß die Adjektive als Explikationen des semantisch vagen objekts dienen, skopusfreiheit, daß die Adjektive neue Merkmale in den Text einbringen. Vgl. dazu die varianten von (39) und (40), die beide als objekt drugoj/drugaja haben: ${ }^{6}$

(39') ... Ja ee ljubil, a ona ljubila drugogo. Bol'šogo silnogo...

(40') ... Na druguju pol'stilsja. Moloduju, krasivuju ...

Ich tendiere zur zweiten Interpretation, zumal sie auch auf (41) anwendbar ist. In (41) fallen die Adjektive nicht in den skopus von ožidal, was bedeutet, daß die Merkmale neu in den Text eingebracht werden. Eine skopusbindung würde bedeuten, daß das "Erwarten" auch für die adjektivischen Merkmale gilt, die damit als in irgendeiner Weise vorerwähnt angesehen werden müßten. 
Ich begnüge mich mit diesen Anmerkungen zur Kasusvarianz und gehe noch einmal kurz auf die Restriktionen in bezug auf die Adjektive, Nomen und Verben/Prädikate ein. Bei dem häufigsten Typ von Konstruktionen mit postponierten isolierten Adjektiven, denen mit einstelligen Verben, herrschen diejenigen vor, die eine Existenz bzw. Erscheinungsaussage machen, wie z.B. vyšel, echal, sidit...

sie ermöglichen am natürlichsten eine Sachverhaltsgliederung. Absolut unmöglich sind bei diesen konstruktionen Verben/ Prädikate, bei denen die aktionale Bedeutung dominiert. Der Grund hierfür ist, daß diese Prädikate nur solche Adjektive zulassen, mit denen sie eine semantische Beziehung eingehen. Deshalb sind die nachstehenden Beispiele inakzeptabel:

(42) Evgeša vsplesnula rukami, * bol'šeglazaja, molodaja.

(43) Ona zaplakala, * polnotelaja, krivonogaja.

Für die mehrstelligen Prädikate wiederum gilt, daß bei aktionalen Prädikaten nur solche Adjektive möglich sind, deren Bedeutung mit der Aktualität der Prädikatsbedeutung harmoniert:

(44) On obnjal ee - mokruju, smuščnnuju, prižal k sebe i skazal odno slovo: - Moja.

(45) ... potom stala natjagivat' perčatki, tesnye, skripjaščie tonkoj kožej.

(44) läßt sich wie folgt paraphrasieren: "In dem Augenblick, in dem die Umarmung stattfindet, gilt auch, daß die betroffenen Person naß und verwirrt ist." Bei den durch die Adjektive zugewiesenen Merkmale handelt es sich um nichtinhärente Eigenschaften. Ergänzend $z u$ den schon oben angeführten Restriktionen bezüglich der Adjektive sei angemerkt, daß auch bei Erscheinungs-bzw. Existenzaussagen nicht beliebige Adjektive, die auf äußere Merkmale von Gegenständen referieren, gesetzt werden können. So läßt beispielsweise (28) nicht die Adjektive krivonogoja und molodaja $z u$, da sie im gegebenen kontext keinen aktuellen zustand beschreiben, sondern Merkmale einführen, die schon früher 
in den Text hätten eingeführt werden müssen. Bei den mehrstelligen Prädikaten scheinen die Restriktionen zunächst weniger streng $z u$ sein. Bei genauer Betrachtung zeigt sich jedoch, daß die wahl der Adjektive durch den Typ des Prädikats restringiert wird.

Restriktionen im Bereich der Bezugsnomina scheint es kaum zu geben. Neben Personenbezeichnungen finden sich sowohl unbelebte Konkreta als auch Abstrakta, vgl.

(46) Vot oni prichodjat v dom - bol'šoj, kamennyj. trechètažnyj.

(47) Pervoe, cto on ošcutil byl strach. Sil'nyj, bezotčetnyj, neizvestno pered と̌em.

(48) Umyvajas', ja vse vspominal včerašnij večer, gadkij, sumburnyj.

Einschränkungen können allerdings, ohne daß ich hier viel darüber sagen könnte, durch den Typ des prädikats erzeugt werden, zumindest was die Ersetzung von Pronomina und Eigennamen angeht. (vgl. etwa (41))

Meine Schlußbemerkung will ich dem Phänomen widmen, daß in der Postposition in der Regel mehr als eine Einheit auftritt. Dies gilt insbesondere für die einstelligen Erscheinungsbzw. Existenzprädikate. Der Grund hierfür ist darin zu sehen, daß in dieser exponierten, weil satzabschließenden stellung eine einzelne Einheit ein zu geringes kommunikatives Gewicht hat und dazu tendiert, eine enge semantische Beziehung zum Prädikat einzugehen. Die Aufzählung von wenigstens zwei Einheiten dagegen unterstüzt die Isolierung intonatorisch, sichert diesen Elementen eine gewisse Selbstständigkeit und motiviert damit die Perspektivenverengung.

Interponierte isolierte Adjektive

Dieser Typ von Isolierung findet sich relativ häufig in Verbindung mit zweistelligen Prädikaten. Dabei zeigt sich, daß sich die isolierten Adjektive stets auf das Subjekt beziehen, vgl: 
(49) Mat' - smuglaja, bol'šeglazaja, vse ešče krasivaja tichon'ko krestila veročku iz-pod platka.

(50) Tichon Ivanovic - v očkach, bol'šerukij - vskryval konverty i prosmatrival pis'ma.

(51) Ljuda šla domoj, utiraja slezy varežkoj. Cuvstvovala ona sebja bez viny oskorblennoj, oplevannoj... Kak budto student - ne človek. Asja - tolstaja, Cernoglazaja - vstretila ee ulybkoj.

(52) Šum zatich. Učenyj sekretar' - točnyj, ser'eznyje tonkij, kak karandaš, - načal čtenie otzyvov.

(53) Vtorojopponent - tolstyj, medovyj - učel obstanovku i čitat' svoj otzyv ne stal.

Für die weitere Charakterisierung dieser Konstruktion ist es wichtig, festzustellen, daß die Prädikate keine Erscheinungsaussage realisieren, sondern aktionale Bedeutung haben. Liegt keine Aktionsaussage vor bzw. ist die Handlung inaktuell, sind die entsprechenden Sätze wenig akzeptabel. Vgl.

(54) *Vera, bol'šeglazaja, malen'kaja, ponjala, čto...

(55) *Vera, bol'šeglazaja, malen'kaja, dumala, とto...

(56) *Vera,bol'šeglazaja, malen'kaja, naveščala mat' dvaždy $v$ nedelju.

Wenn man berücksichtigt, daß sich bei der postponierten Isolierung bei diesem Prädikatstyp die gleichen Adjektive nur auf das objekt beziehen konnten, dann liegt die vermutung nahe, daß die Interposition dazu dient, eine kommunikativ wenig belastete subjektorientierte Merkmalzuweisung zu realisieren. Eine Äquivalenz mit der AN-Struktur, die neben $N_{i}, A N_{j}$ als Konkurrent in Frage kommt, liegt zumindest bei diesen Beispielen nicht vor. Vgl. z.B. 
(49')? Smuglaja, bol'šeglazaja, vse ešce krasivaja mat. tichon'ko krestila Veročku iz-pod platka.

(50') „V očkach, bol'šerukij Tichon Ivanovič vskryval konverty i prosmatrival pis'ma.

(53') *Tolstyj medovyj vtoroj opponent učel obstanovku i čitat' svoj otzyv ne stal.

Diese Umbildung wird einmal dadurch behindert, daß das Bezugsnomen definit ist bzw. durch einen Eigennamen repräsentiert wird, was die Ersteinfuhrung von Merkmalen ohne spezielle Motivation ausschließt, zum andern stehen dieser Umbilaung syntaktische Hindernisse entgegen wie z.B. die Existenz von Präpositionalphrasen.

Der Vollständigkeit halber sei auch das Verhältnis dieser Konstruktion zur parenthetisch-appositiven Konstruktion überprüft $(k)$ :

(49'')? Mat', smuglaja, bol'šeglazaja ženš̌̌ina vse ešče krasivaja, tichon'ko krestila veročku iz-pod platka.

(51')? ...Asja, tolstaja černoglazaja devuška, vstretila ee ulybkoj.

(52') Šum zatich. Ǔ̌enyj sekretar', točnyj, ser'eznyj. tonkij, kak karandaš čelovek, načal čtenie otzyvov.

Die Inakzeptabilität der ersten beiden Beispiele rührt daher, daß sie eigentlich eine introduktive Aussage signalisieren, d.h. daß ein Gegenstand vorgestellt wird, ohne daß die kontextuellen voraussetzungen dazu gegeben sind. Sowohl die Mutter als auch Asja sind aus dem Vortext her schon lange bekannt. Da, wo eine introduktive Aussage möglich ist, wie in (52), lassen sich kaum Einwände gegen die Umbildung vorbringen. Allerdings sind auch hier Ausgangssatz und modifizierter Satz nicht äquivalent. Die appositive Phrase referiert auf Merkmale, die in bezug auf die gegebene situation nicht oder kaum aktuell sind. Soviel zunächst zum protlem der parenthetisch-appositiven Konstruktion, auf die icr noch einmal zu sprechen komme. 
Es gibt neben den angefuhrten Belegen auch Beispiele, in denen eine semantische Beziehung zwischen den Adjektiven und den Prädikaten zu beobachten ist:

(57) ... k nej srazu raspoložilsja ves' techničeskij personal, $i$ daže starik Antonevič, surovyj i revnivyj. priznal ee srazu i bezogovoročno.

(58) V otvet na udar po ščeke Aleksandr Maksimovič, vspyl'= čivyj po nature, izbil bocmana do poteri soznanija.

Die Erklärung für (57) und (58) ist einfach. Die Prädikate bzw. Prädikatsphrasen enthalten qualitative und damit explikationsfähige Merkmale. In (57) wird dieser spezielle Typ von Aussage schon durch daže angekündigt. Auch hier machen wir die Beobachtung, daß der Prädikatstyp die wahl der Adjektive restringiert. Im Prinzip kommen nur solche Adjektive in Frage, die eine Motivationsbeziehung zum Prädikat eingehen können. Diese Motivationsbeziehung ist es auch, die eine Umbildung von (57) in eine struktur mit AN möglich erscheinen läßt:

(57') ...k nej srazu raspoložilsja ves' techničeskij personal, i daže surovyj i revnivyj starik Antonevič priznal ee srazu i bezogovoročno.

Im Unterschied $z u$ (57) wird hier suggeriert, die Merkmale surovyj und revnivyj seien textuell bekannt bzw. erschließbar.

Interponierte Adjektive treten auch in sätzen mit einstelligen Prädikaten auf. Es ist $z$ erwarten, daß auch diese Verwendung syntaktisch oder semantisch motiviert ist. Hier einige Beispiele:

(59) Sejčas pridu, - šepnul ja, podmignuv, i ol'ga, dovol'naja, isčezla.

(60) Moj mučitel' otpustil menja, i my, krasnye, rasparennye,uselis' drug protiv druga.

(61) Katja vskakivala s posteli i - bosaja, rastrepannaja - vybegala na volju. 
Für diese Beispiele ist charakteristisch, daß die Adjektive Merkmale bezeichnen, die sich auf vorausgegangene Sachverhalte bzw. Ereignisse beziehen. So ist dovol'naja eine Reaktion auf das vorausgegangene Versprechen, während die Adjektive krasnye und rasparennye die Folgen körperlicher Anstrengungen anzeigen. Es ist bemerkenswert und in übereinstimmung mit den Ergebnissen der Postposition, daß keine äquivalente Umbildung in $A, N V$ bzw. NV, A möglich ist:

(59.) Sejčas pridu, - šepnul ja, podmignuv, i, dovol'naja, ol'ga isčezla.

(59') suggeriert, daß zwischen Adjektiv und Prädikat ein motivationeller zusammenhang besteht.

(59"') Sejčas pridu, - Šepnul ja, podmignuv, i ol'ga iscezla, dovol'naja.

Hier wird eine Perspektivenverengung signalisiert, die jedoch unmotiviert ist. Grundsätzlich gilt, daß Adjektive bei der Interponierung nicht in den skopus des prädikats fallen. Die Interponierung ist auch, wie die folgenden Beispiele zeigen, durch syntaktische Bedingungen bzw. durch die unerwünschte Häufung von Merkmalen im prädikativen Bereich bedingt. Es handelt sich hierbei um Fälle, in denen das Prädikat durch ein adjektivisches oder substantivisches prädikatsnomen realisiert wird bzw. in denen das prädikat eine Lokalitätsaussage erzeugt. Vgl.

(62) U Sof'i Savel'evny - krasivoj, temnoglazoj, narjadno sedoj - byli sil'nye malen'kie ruki ...

(63) očered', seraja, kamennaja, byla nesokrušima, kak grečeskaja falanga.

(64) Etot čelovek, intelligentnyj i porjadočnyj, byl organičeskim trusom.

Weder Ersetzungen durch AN noch durch $A, N V(m)$ und NV, A sind möglich.

Es sind m.E. genügend Beispiele besprochen worden, um den Nachweis $2 u$ erbringen, daß die Konstruktion $N, A, V$ einen eigenen Typ im Rahmen der merkmalzuweisenden konstruktionen darstellt, 
auch wenn ihre Spezifik im wesentlichen (aber nicht ganz) darin besteht, Restriktionen anderer Konstruktionen auszugleichen. Auf jeden Fall ist es möglich, durch die Berücksichtigung der stelligkeit der Prädikate und ihrer Semantik die Verwendungsbedingungen von $N, A, V$ klar anzugeben.

Ich will zur Verdeutlichung des Gesagten diesen Abschnitt mit einer Kontrastierung von drei Konstruktionen abschließen, die alle das prädikat sidet' enthalten.

(65) Praskov'ja sidela na lavke ustalaja, poterjannaja $v$ svoich smjatennych cuvstvach.

(66) [ona] Sidela u nego v kabinete - uglovataja, nekrasivaja.

(67) Vera Platovnovna, oglochšaja, oglupevšaja ot slez, sidela vozle groba.

In (65) werden über das Subjekt zwei Aussagen gemacht, erstens eine Existenzaussage (in Verbindung mit einer gewissen Desemantisierung von sidet'), zweitens eine zustandsaussage, die, was das kommunikative Gewicht angeht, über die Existenzaussage dominiert. In (66) dagegen wird eine Perspektivenverengung signalisiert. Ein Gegenstand wird eingeführt, dann werden ihm spezifische äußere Merkmale zugewiesen. In (67) wiederum lassen die interponierten Einheiten einen Bezug zum Vortext und damit eine Unabhängigkeit vom Satzprädikat erkennen.

Die parenthetisch-appositive Konstruktion

Das Spezifische dieser Konstruktion besteht, wie sich schon oben gezeigt hat, darin, daß ein Gegenstand eingeführt und vorgestellt wird. Die zugewiesenen Merkmale, und das ist typisch für eine Vorstellung, sind inaktuell, d.h. sie gelten ubber den aktuellen Zeitraum hinaus. Die Inaktualität wird über das klassifizierende Nomen erreicht. Interessant ist, daß die parenthetische Apposition häufig im Zusammenhang nit Identitätsaussagen auftritt. Vgl. 
(68) Vozglavjaet ee professor Jakovkin - puchlyj, širokiJ. val'jažnyj čelovek so vkraď̌ivoj ulybkoj na okruglom, knizu oplyvšem lice.

(69) Dokladyvaet Nina Ignat'eva Astašova - smuglaja, strelovidnaja ženščina, ne očen'-to krasivaja, ne očen' molodaja $(.$.$) , no...$

(70) Moe detstvo daže sijalo - ono iskrilos', vspychivalo. sredotočiem vsego byl otec. Nizen'kij, lysyj, udivitel'nyj celovek s nebol'šimi svetlo-karimi glazami.

(68) kann man paraphrasieren mit "derjenige, der an ihrer spitze steht, ist Professor Jakovkin." (69) analog: "diejenige, die gerade vorträgt, ist Nina Ignat'eva Astašova." usw.

Der introduktive Charakter dieser sätze macht es unmöglich, sie durch eine NV,A-Konstruktion zu ersetzen, vgl.

(68')? Vozglavjaet ee professor Jakovkin - puchlyje širokij, val'jažnyj...

(69')? Dokladyvaet Nina Ignat'eva Astašova - smuglaja, strelovidnaja...

(70')? ... Sredotočiem byl otec. Nizen'kij, lysyj, udivitel'nyj...

Charakteristisch für diese Sätze ist auch, daß die Prädikate durchweg zustände bezeichnen. Dies gilt auch für (69). Es geht hier nicht um die Handlung der Nina Ignat'eva, sondern um die Feststellung eines Zustandes. Neben Zustandsaussagen treffen wir auch auf Aussagen über usuelle Ereignisse und Resultate von Handlungen:

(71) A vot obščě̌itiem ej povezlo, popala v duuchmestnuju komnatu, so svoej odnokursnicej Asej Umanskoj, tolstoj, usatoj devuškoj s krasivymi, černymi glazami i malen'kim rtom. 
(72) Byli takie specialistki, u kotorych vsegda prigoralo. Osobenno ètim otličalas' aspirantka Galja, vysokaja blednuška $v$ očkach, kotoraja...

(73) Chodil on obedat' $v$ stolovuju na uglu... Tam ego často obsluživala Zoja, bol'šaja spokojnaja devuška. belokuraja i gladkaja, kak dynja.

(74) Neskol'ko let podrjad priezžala iz Moskvy sem'ja generala Ivleva - žena, Mar'ja Ivanovna, ટ̌ernoglazaja tolstucha s večnoj zavivkoj, veselaja...

Die Zustandsbedeutung der Prädikate ist es auch, die die Verwendung von Adjektiven ermöglicht, die nicht auf unmittelbar beobachtbare Merkmale referieren. Vgl.

(75) Za rulem sidel nedavno naznačennyj glavnyj inžener upravlenija, interesnyj ščegolevatyj mužčina.

Das nachstehende Beispiel, das zwar auch Adjektive enthält, die auf durch Erfahrung gewonnene Merkmale referieren, scheint, was die prädikatssemantik angeht, den bisherigen Feststellungen zu widersprechen:

(76) - Vera platonovna, - skazala, vchodja, staršij administrator ol'ga Petrovna, ženščina požilaja, tučnaja, čestnaja, isterčinaja, a po suščestvu - Čistoe zoloto. - Čto takoe?

Es besteht kein Zweifel, daß skazala einen aktuellen Vorgang bezeichnet und keinen Zustand. Entscheidend ist somit nicht, wie vermutet, die Prädikationssemantik, sondern der introduktive Charakter der Aussage, der hier u.a. durch das Adverbialpartizip vchodja angezeigt wird. Wie bei allen vorherigen Beispielen wird durch die Bezugsphrase ein neuer Gegnstand in den Text eingefürt. Analog dazu ist (77) $2 u$ interpretieren:

(77) Vošla zamestitel'nica zavedujuščego, požilaja ženščina $v$ vjazanoj kofte... 
Beispiel (78), das ähnlich aufgebaut ist, ist sehr geeignet, noch einmal den Unterschied zwischen der parenthetischen Apposition und der postponierten Isolierung $z u$ verdeutlichen:

(78) Pod večer prišla učastkovyj vrač - seraja, izmučennaja, krugi pod glazami .... osmotrela

Es liegt hier eindeutig keine introduktive Aussage vor. Die Ärztin soll nicht vorgestellt werden, sondern ihr Erscheinen (nach vorheriger Anforderung) und die dabei auffallenden äußeren Merkmale sollen beschrieben werden. Das Ergebnis ist eine Perspektivenverengung.

Bei der Beschreibung der Interposition der Adjektive ist aufgefallen, daß bei bewertenden bzw. qualifizierten Prädikatsphrasen eine semantische Beziehung zwischen den Adjektiven und den Prädikaten möglich ist. Das gleiche Phänomen läßt sich bei interponierten Appositionen feststellen. Interessant ist dabei, daß in diesen Fällen die $N_{i}-A N_{j}-$ Konstruktion durch die $N, A, V-K o n s t r u k t i o n$ ersetzt werden kann, vgl.

(79) Novyj zavedujuščij- mužik krepkij, solenyj - bystro vyvel Užika na čistuju vodu, obnaružil ...

(79') Novyj zavedujušcij, krepkij, solenyj, bystro vyvel Užika na čistuju vodu, obnaružil ...

Ich will die Betrachtung der parenthetischen Apposition nicht abschließen, ohne nicht kurz auf eine aufällige Besonderheit eingegangen zu sein. Es handelt sich um das Phänomen, daß in vielen der hier angeführten Beispielen die Bezugsphrasen ein Substantiv enthalten, das entweder eine Relation (sosedka, otec) oder eine Funktion bzw. einen status bezeichnet (aspirantka, administrator, odnokursnica usw.). Die Häufung dieser Substantive ist kein Zufall, sondern hängt mit ihrer durch ihre semantik begründeten spezifischen Rolle bei den introduktorischen Aussagen zusammen. Eine ihrer Funktionen besteht darin, dem Rezipienten zu signalisieren, daß es hier um einen Gegenstand geht, den er aus dem Text heraus nicnt kennt. Würde man beispielsweise in (71) und (72) dieses Nomen tilgen, dann würde dem Rezipienten suggeriert, er kenne die betreffenden Personen. Das zweite ist, daß die in diesen wörtern verarbeitete Information, das vorwissen des Textpro- 
duzenten, bezüglich der Informationsbedürfnisse des Rezipienten unmotiviert erscheint. Sie hilft ihm nicht, seine Unkenntnis $z u$ beseitigen, obwohl ihm suggeriert wird, es handele sich hier um eine Vorstellung. Es ist deshalb ganz plausibel, daß durch die Apposition zusätzliche leicht interpretierbare Beschreibungsmerkmale geliefert werden. Ohne diese Angaben ist der introduktorische Charakter dieser Sätze, der ja im Vorwissen des Textproduzenten begründet liegt, gefährdet. Sehen wir uns zur verdeutlichung noch einmal (77) an.

In diesem Satz wird mit Hilfe eines Verbs des Erscheinens eine Person auf, wenn man so will, sensorischer Basis vorgestellt (vošla). Die tatsächliche Bezeichnung dieser Person erfolgt aber mit einer Funktionsbezeichnung, die dem Rezipienten keine visuelle Vorstellung vermittelt. Es entsteht somit ein Konflikt zwischen der signalisierten und der tatsächlichen Vorstellung der Person. Und genau diesen Konflikt beseitigt die parenthetische Apposition. Natürlich darf man nicht übersehen, daß Funktionsbezeichnungen der angeführten Art ohnehin nicht ohne weiteres attribuierbar sind (verschärft durch die Existenz von Adjektiven wie novyj) und somit andere merkmalzuweisende Konstruktionen von vorne herein nicht in Frage kommen. Ich begnüge mich mit diesen Feststellungen zur Apposition. die in keiner Weise als vollständig angesehen werden können, die aber genügen, um die Spezifik dieser Konstruktion eindeutig herauszustellen.

Die prädikative Verwendung der Adjektive $\left(N-A, N_{i}-A N_{j}\right)$

Es konnte bereits wiederholt gezeigt werden, daß das entscheidende Spezifikum dieser Konstruktionen in der besonderen kommunikativen Rolle der Adjektivphrasen begründet liegt. Die Umbildung anderer merkmalzuweisender Konstruktionen in eine prädikative bleibt in der Regel nicht ohne Auswirkung auf die Kohärenz des Textes.' Das gleiche gilt für den umgekehrten Vorgang. Hinzu kommt hier, daß in vielen Fällen die formalen voraussetzungen für eine Deprädikativierung fehlen, 
was letztlich ebenfalls die funktionale Einzigartigkeit dieser konstruktion unterstreicht. Vgl.

(80) Do sich por ne mogu ponjat' prirodu etoj nenavisti. Ljubaša byla soveršenno bezobidnoj devuškoj, kotoraja, kak govoritsja, daže muchi ne mogla obidet.'

Es ist hier nicht möglich, sich eingehend mit der prädikativen Verwendung der Adjektive $z$ u beschäftigen. Das muß einer gesonderten Betrachtung vorbehalten bleiben. Ich beschränke mich deshalb auf einige wichtige Aspekte und versuche, vor allem die Gemeinsamkeiten und die Unterschiede der "konkurrierenden" Konstruktionen herauszustellen.

Der prädikative Charakter von A bzw. AN impliziert, daß das Nomen, auf das sie sich beziehen, d.h. das subjekt, stets definit ist. Hieraus ergibt sich eine eindeutige Abgrenzung gegenüber der attributiven Konstruktion, für die charakteristisch ist, daß das Bezugsnomen indefinit ist. ${ }^{8} \mathrm{Vgl}$.

(81) ol'ga byla sčastliva.

(82) Direktor vpolne nadežnyj čelovek.

mit

(83) - Idemte, idemte, - govorit mne podžarnyj sedovatyj čelovek $v$ mechovoj kepke koričnevoj dublenki ...

(84) I tut že iz pod-ezda vyskakivaet vysokaja gibkaja figura i bežit $k$ nam. Eto Lena.

Wenn man die Frage der obligatorik/Fakultativität bzw. Restriktivität/Nichtrestriktivität auch bezüglich der prädikativen Einheiten stellt, eine Frage, die bei der Attribution ja von zentralem Interesse ist, dann ergibt sich, daß man sie nur in bezug auf den ganzen Satz stellen kann. D.h. um danach $z u$ fragen, ob und wie die gesamte konstruktior. textuell motiviert ist. Man kann diesen Gedanken weiter spinnen und sich die Frage stellen, ob, eine textuelle Motiviertheit vorausgesetzt, Ähnlichkeiten und Parallelen zur Attribution festzustellen sind. Leider gibt es m.w. bisher noch keine Arbeiten zu dieser Problematik, so daßich mich hier mit der problemstellung begnügen muß. 
Nun $z u$ den Unterschieden zwischen $N-A$ und $N_{i}-A N_{j}$. Das wichtigste ist, daß die $N_{i}-A N_{j}$-Konstruktion eine inaktuelle, generelle bzw. absolute, klassifizierende Aussage realisiert, während die $N$ - A-Konstruktion aktuelle bzw. relationale Sachverhalte bezeichnet. Dazu einige Beispiele:

$N_{i}-A N_{j}$

(85) Na Edika éto proizvelo sil'nejšee vpečatlenie. on voobšče čelovek vpečatlitel'nyj, temperamentnyj i énergičnyj ...

(86) Stepan Matveevic byl tichim, privetlivym Čelovekom. vojna ostavila mnogo otmetin na nem. $K$ tomu že on stradal ot ...

Den Subjekten werden hier Merkmale zugeschrieben, die nichts mit der aktuellen situation der handlung zu tun haben und auch nicht aus der gegebenen situation erschlossen werden, sondern die auf einem Vorwissen basieren, das eine Verabsolutierung erlaubt und damit eine Klassifizierung der Gegenstände ermöglicht.

Die Distribution von $\mathrm{N}_{i}-\mathrm{AN}_{j}$ wird auch durch die lexikalische Realisierung der einzelnen Konstituenten bestimmt. Interessant sind vor allem $N_{j}$ und $A$. In der position von $N_{j}$ finden wir zwei Typen von substantiven, bedeutungsarme wie devuška, paren'. čelovek, mužčina usw. und bedeutungsreiche wie mechanik, chudožnik usw. vgl.

(87) To, cto radiomaster dejstvitel'no Łestnyj $i$ duševnyj čelovek, govorili sledovatelju i načl'nik ... i ...

(88) Chovancev byl chorošij terapevt.

(89) On byl zajadlym kartežnikom i $v$ odnu iz p'janych nočej proigralsja $v$ puch i prach.

Im Fall von (87), d.h. des bedeutungsleeren $N_{j}$, bezieht sich das adjektivische Merkmal unmittelbar auf das subjekt, $N_{j}$ selbst signalisiert nur den klassifizierenden Charakter des Prädikats. Anders ist der Charakter der Merkmalzuweisung im Fall des bedeutungsreichen $N_{j}$. Hier geht das Adjektiv eine Beziehung $z u N_{j}$ ein, und nur die Gesamtphrase kann als Merkmal 
für das Subjekt interpretiert werden. Für unsere Abgrenzungsproblematik ist dieses Phänomen insofern interessant, als diese Konstruktionen nie mit $N$ - A konkurrieren. Auch bei den Adjektiven wirkt sich die Spezifik der $N_{i}-A N_{j}$ Konstruktion aus. Eine Reihe von Adjektiven tritt nur in dieser Konstruktion auf bzw. realisieren nur hier eine ganz spezifische Bedeutung. Dazu gehören u.a. vidnyj, interesnyj. legkij. Vgl.

(90) Mužčina on byl, kak nazyvaetsja, vidnyj ...

$\left(90^{\prime}\right) \star$ On byl, kak nazyvaetsja, vidnyj $\ldots$

(91) Svetka udivitel'no legkij čelovek, i za éto ee ešče bol'še l jublju.

(91')? Svetka udivitel'no legkaja/legka, i ... Weiterhin ist für $N_{i}$ - AN $j$ charakteristisch, daß an $N_{j}$ ein Relativsatz angefügt werden kann und daß diese Konstruktion auch die Isolierung von Adjektiven zuläßt. In beiden Fällen wird dadurch eine reichere bzw. komplexere Merkmalzuweisung möglich. Vgl.

(80) Ljubaša byla soveršenno bezobidnoj devuškoj, kotoraja, kak govoritsja, daže muchi ne mogla obidet'.

(92) - Direktor skazal, čto vy priglašaete menja na progulku ...V golose - nasmeška, a vzgljad meždu tem ser'eznyj, cepkij.

Effektnaja ženščina Elizaveta Pavlouna Romašina. vysokaja, strojnaja.

Soviel $2 u N_{i}-A N_{j}$.

$N-A$

(93) On segodnja osobenno chmur i sderžan.

(94) Ona gotovitsja k kakomu-to dokladu, no terpeliva so mnoj kak angel.

In diesen Beispielen geht es ohne Zweifel um die Zuweisung aktueller Merkmale. Deutliche Hinweise darauf liefern die temporale Markierung segodnja sowie das relationale Merkmal so mnoj. Beide schränken die Gültigkeit der Merkmale ein. 
Zwei weitere Beispiele:

(95) Teper' ja mogu razgljadet' ego kak sleduet pri dnevnom svete.

on chudošcav i vysok, chotja i zametno niže menja.

(96) Ej protiven i strašen Mušanskij.

Explizit signalisiert wird die Aktualität der Merkmalzuweisung durch teper' sowie razgljadet' bzw. durch das restringierende ej.

Es ließen sich noch eine Reihe von interessanten Einzelbeispielen anführen, die spezielle Aspekte des Unterschieds zwischen $N-A$ und $N_{i}-A N_{j}$ anzeigen, aber da eine Generalisierung vorerst nicht möglich ist, will ich hier darauf verzichten. Stattdessen sei noch festgehalten, daß N - A keine Restriktionen bezüglich stataler Adjektive kennt, vgl.

(97) Varvara p'jana.

aber

(97') *Varvara p'janaja Zenšcina.

und daß N - A Konstruktionen problemlos negiert werden können:

(98) Mat' bol'na ne byla.

aber

(98') *Mat' ne byla bol'noj ženščinoj.

Und schließlich zeigt sich eine weitere Besonderheit von $N$ - A darin, daß sie vor allem bei belebten substantiven mit $N_{i}-A_{j}$ konkurriert. Bei unbelebten substantiven gibt es probleme mit dem Hyperonym, bzw. die Notwendigkeit für klassifizierende Aussagen scheint gering $z u$ sein. In den von mir untersuchten Texten habe ich kaum Belege finden können.

Ich schließe diesen Abschnitt mit der Betrachtung einer Konstruktion $a b$, die zwischen den in Rede stehenden Konstruktionen zu stehen scheint. Es handelt sich um Konstruktionen mit dem Kopulaverb okazat'sja/okazyvat'sja.Vgl.

(99) Saša okazalsja milym, dobrodušnym parnem. 
Die Spezifik dieser Konstruktion besteht darin, daß es einerseits um eine aktuelle Merkmalzuweisung geht, die Merkmale werden als bis zu dem gegebenen Textzeitpunkt als unbekannt eingefürt, andererseits werden Merkmale zugewiesen, die eindeutig klassifikatorischer und nicht aktueller Natur sind. 9

\section{Zus ammenfassung}

Die Betrachtung der verschiedenen merkmalzuweisenden Konstruktionen hat als wichtigstes Ergebnis erbracht, daß formale Unterschiede stets mit inhaltlichen bzw. funktionalen korrelieren. Dies haben die verschiedenen Typen der Isolierung gezeigt ebenso wie die prädikativen Varianten. Weiterhin hat sich gezeigt, daß die Isolierung keine Variante der Attribution darstellt, sondern als ein eigener Typ der Merkmalzuweisung angesehen werden muß. Es ist nun möglich, die Merkmalzuweisung als ein differenziertes system von Operationen, die an kommunikativen, semantischen, syntaktischen und perspektivischen Gegebenheiten bzw. Bedürfnissen orientiert sind, darzustellen. Wenngleich mehr Fragen aufgeworfen als gelöst wurden und manches nur oberflächlich behandelt werden konnte, so ist unser Verständnis von der Funktion und Distribution sprachlicher Mittel vertieft worden.

Zum Abschluß seien die Hauptfunktionen der beschriebenen Konstruktionen noch einmal im zusammenhang aufgeführt. Ich habe bewußt darauf verzichtet, die Abgrenzung mit Hilfe binärer Merkmale durchzuführen, da sie zuviel Redundanz in die Beschreibung bringen.

AN

$\mathbf{N}-\mathbf{A}$

$N_{i}-A N_{j}$
: Einführung eines Merkmals über ein indefinites Nomen

: einem definiten Nomen wird ein Merkmal zugewiesen. Die Merkmalzuweisung selbst beansprucht ein besonderes kommunikatives Gewicht. Die zugewiesenen Merkmale sind aktuell bzw. relational

: einem definiten Nomen wird ein Merkmal zugewiesen. Die Merkmalzuweisung selbst beansprucht ein besonderes kommunikatives Gewicht. Die zugewiesenen Merkmale sind inaktuell, klassifizierend 
$A, N V$

NV, A

$N, A, V$

$N_{i} \cdot A_{j}$

: einem definiten Nomen wird ein Merkmal zugewiesen, das eine semantische Beziehung mit dem Verb/Prädikat eingeht (komplexe Merkmalzuweisung) bzw. eine Perspektivenerweiterung signalisiert

: das dem Nomen zugewiesene Merkmal signalisiert eine Perspektivenverengung; sie ist bei einstelligen Prädikaten subjekt- bei zweistelligen objektorientiert

: bei zweistelligen Verben realisiert die Merkmalzuweisung eine subjektorientierte Perspektivenverengung, bei einstelligen wird $N$ ein Merkmal zugewiesen, das als Resultat eines vorausgehenden Ereignisses angesehen wird

: die Merkmalzuweisung ist Konstituente einer introduktorischen Aussage: $N_{i}$ ist definit

\section{Anmerkungen}

1 Vgl. Furašov [2], Prokopovič [5], - bei Prokopovič heißt es beispielsweise auf seite 114: Opredelenija pri ličnych mestoimenijach, za neznačitel'nymi isključenijami, vsegda obosobljajutsja ...

ob -jasnjaetsja éto samoj grammatičeskoj prirodoj mestoimenij: ličnym mestoimeniem ne svojstvenno, za redkimi isključenijami, imet' pri sebe neobosoblennye opredelenija.

Russkaja Grammatika [7] , S. S 185

3 Daneben gibt es auch noch die graduierend-vergleichende Relation, die der Kontrastierung nicht unähnlich ist. Vgl. Maloobščitel'nyj po nature, on posle smerti ženy stal ešče zamknutee i neljudimee.

4 Probleme scheint folgendes Beispiel zu bereiten: Ich $z i-$ tiere es im größeren Kontext:

Doktor Tušnov i ego supruga ne otnosilis' k ljudjam, vyzyvajuščm simpatiju. Togda my delili vsech na p'jat' točno razgraničennych kategorij: svoi, sočuvstvujuščie, obyvateli, vragi, sočuvstvujuščie vragam.

Doktora ja srazu že i bezogovoročno otnes $k$ poslednim. 
Vstrepannyj, suetlivyj, v zasalennom chalate, iz-pod kotorogo boltalis' štripki kal'son, Tušnov vstrečaja menja na kuchne ili $v$ koridore, neizmenno sprašival: slychali novost'? Net?

Hier liegt weder eine komplexe Merkmalzuweisung noch das Phänomen der Perspektivenerweiterung vor. Die einfachste Erklärung für diese Position der Adjektive scheint mir $2 u$ sein, alle syntaktischen Einheiten von vstrepannyj bis zu neizmenno sprašival als Explikationen des klassifikatorischen Merkmals otnes $k$ poslednim $z u$ verstehen. Für diese Funktion der Adjektive und Präpositionalphrasen kommt offensichtlich keine andere syntaktische Position in Frage.

5 Vgl. dazu auch Ejchbaum [1\} : Strukturnaja organizacija predloženija s obosobleniem predpolagaet rasčlenennoe izloženie soobščenij. (s. 36)

In diesem Zusammenhang sei noch auf eine Vielzahl von Beispielen verwiesen, die der postponierten Isolierung formal sehr ähnlich sind, deren wesen aber darin besteht, vage Bezugsphrasen zu explizieren, vgl.

- Var'ja s. ... byla v svoem rode čelovek primečatel'nyj. Sedaja, prjamaja, krasivaja.

- Voznikali, šumeli i otmirali novye metody obučenija, kompleksnyj, Dal'ton-plan, brigadno-laboratornyj.

- Soboj A. byla krasavica - vysoka, rovna, smugla bez rumjanca

usw.

7 In der Funktion des sekundären Prädikats können nicht beliebige Adjektive auftreten, z.B. nicht alle, die postponiert vorkommen, vgl.

vot, odnaždy večerom Aleksandr Ivanovič prišel mračnovatyj /*prišel tolstyj, malen'kij

Die Adjektive müssen veränderlich Zustände anzeigen.

8 Auf die "Ausnahmen" bzw. die speziell motivierten Attribuierungen definiter Nomina bin ich schon an anderer stelle eingegangen. Siehe dazu vor allem die Abschnitte 
"Prädikatmotivierende Attribution" und "Attribution und Zweiterwähnung".

9 Interessant sind in diesem Zusammenhang auch noch Beispiele mit dem pronominalen subjekt éto, vgl. Ingu ja ugadyvaju srazu, vse ostal'nye ženšciny zdes' znacitel'no starše.

Eto oxen' chudaja vysokaja černovolosaja devuška, nekrasivaja.

Auf eine nähere Beschreibung dieser Konstruktion muß hier verzichtet werden. S. aber Padučva (4) S. $171 \mathrm{ff}$.

Li teraturverzeichnis

1. Ejchbaum, G.N. Aspekty izučenija obosoblennych と̌lenov predloženija. In: Vestnik Leningradskogo universiteta. Istorija, Jazyk, Literatura. 1974, 2, S. $129-137$

2. Furašov, V.I. Sočetaemnost' slov i obosoblenie opredelenij $v$ sovremennom russkom literaturnom jazyke.

In: Materialy VIII konferencii prepodavatelej russkogo jazyka pedagogičeskich institutov moskovskoj zony. lotv. red: N.A. Kondrašov). Lingvistǐ̌eskij sbornik. vyp. 2, Čast' pervaja. Moskva 1973, S. $204-212$

3. Kupalova, A. Ju., Škol'nye pravila i jazykovaja dejstvitel'nost'. In: Russkaja reč', 1972, 2, S. $115-119$

4. Padučeva, E.V., Vyskazyvanie i ego sootnesennost' s dejstvitel'nost'ju. Moskva 1985

5. Prokopovič, N.N., Metodika izučenija obosoblennych opredelenij. In: Izvestija akademii pedagogiðeskich nauk RSFSR. vYP. 10,1947 , S. $103-148$

6. Russkaja Grammatika. Praha 1979

7. Russkaja Grammatika, Tom II. Moskva 1980

8. Ružička, R., Studien zum Verhältnis von syntax und Semantik im modernen Russischen. I. Berlin 1980 
Quellen:

Bezuglov, A., Prokuror. Moskva 1984

Klarov, Ju., Sledstviem ustanovleno. Moskva 1982

Grekova, I., Kafedra. Moskva 1980

Kron, A., Bessonica. Moskva 1980

Krutilin, S., Grechi naši tjažkie. Moskva 1982

Perov, Ju., Kosvennye uliki. Moskva 1982

Russkaja Grammatika. Moskva 1980

Sapožnikov, L., Stepanidin, G., Tri versii. Moskva 1985

Sizov, N., Nevydumannye rassakzy. Moskva 1980

Vasil'eva, L., ...i 24 žemčužiny. Moskva 1982 
Adjektivische Attribute und Indefinitheit

Trotz einer umfangreichen Literatur zur Indefinitheit/ Definitheit im Russischen ist, so scheint mir, die herausragende Rolle der adjektivischen Attribute für die Signalisierung von Indefinitheit mehr oder minder übersehen worden. Soweit uberhaupt darauf aufmerksam gemacht wird, wird in der Regel übersehen, daß die einzelnen Attributstypen sorgfältig unterschieden werden müssen. 1 präpositionalphrasen, Relativsätze und partizipiale Nebensätze spielen im Rahmen der Indefinitheits-/Definitheitsproblematik durchaus nicht die gleiche Rolle wie Adjektive. Mit diesen konkurriert allenfalls ein bestimmter Typ von Genitivattributen. Es wird in dieser Arbeit darum gehen, einerseits die verschiedenen Attributstypen in ihrer Relevanz für die Herstellung von Indefinitheit bzw. Definitheit zu charakterisieren, und andererseits auch kurz auf das Indefinitpronomen kakoj-to einzugehen. Die Zahlwörter, von denen odin schon ausführlich beschrieben wurde, werden nicht behandelt werden. Wenn die Darstellung der Indefinitheit/Definitheit im Russischen immer noch nicht ganz zufriedenstellt, dann hängt dies auch damit zusammen, daß meist undifferenziert von indefiniten oder definiten Phrasen gesprochen wird. Wichtig ist aber, wenigstens vier Typen auf der Basis ihrer referentiellen Eigenschaften $z u$ unterscheiden. In bezug auf die Indefinitheit, die in dieser Arbeit im Zentrum stehen soll, sind dies: ${ }^{2}$

1. indefinit-spezifisch referierende Phrasen

2. indefinit-nichtspezifisch referierende Phrasen

3. indefinit-generisch referierende Phrasen

4. prädikativ verwendete Phrasen

Im Hinblick auf die adjektivischen Attribute sind vor allem die Typen 1 und 4 von besonderem Interesse. Dies läßt sich leicht an einigen Beispielen verdeutlichen.

zu 1 .

Za okošečkom milovidnaja i soveršenno nepristupnaja ženščina. 
Ženščina referiert in diesem Beispiel auf einen konkreten, individualisierten Gegenstand, der unter dem Aspekt seiner kommunikativ-textuellen Rolle unbestimmt, d.h. nicht vorerwähnt ist. Für die weitere Betrachtung ist von wichtigkeit, daß es hier um eine aktuelle, unmittelbar erlebte situation geht und nicht um eine berichtete Situation. Diese Unterscheidung wird in der Regel nicht getroffen, scheint mir aber äußerst wichtig zu sein.

Zu 2

Sejčas poprošu mašinu.

Mašinu referiert, anders als ženščina im vorausgehenden Beispiel, nicht auf einen konkreten individualisierten Gegenstand, der materiell gegeben und beobachtbar ist, sondern auf ein Element einer bestimmten Klasse.

zu 3

Razve možno vsju žizn' prožit's ženščinoj bez...

Ženščinoj referiert hier generisch, d.h. auf eine Klasse bzw. auf alle Gegenstände, die das Merkmal "ženščina" haben.

Zu 4

a) A zamestitel' direktora, požiloj mužčina, s brjuškan i ...

b) Eto byl molodoj mužčina s malen'koj borodkoj i tonkimi usikami.

In beiden Sätzen wird mužčina jeweils prädikativ verwendet, d.h. nichtreferentiell. In (a) tritt mužčina als appositives Element in (b) als Prädikatsnomen auf. In diesen Funktionen ist mužčina ein Klassifikator.

Die Relevanz der Unterscheidung von vier Referenztypen läßt sich sehr einfach anhand von Tilgungs- bzw. Einsetzungsoperationen zeigen. Wenn im ersten Beispiel die adjektivischen Attribute getilgt werden, dann wird ženščina entweder als definit interpretiert (wobei sich sicher auch die intonatorischen Eigenschaften des Satzes ändernl oder als indefinit 
mit besonderer Gewichtung des Merkmals "natuirliches Geschlecht". Im letzten Fall ist sicherlich immer ein Kontrast im spiel. Wenn wir im zweiten Fall ein Attribut einfügen, so wird dieses restriktiv interpretiert, d.h. die Extension von mašinu wird eingeschränkt. Das Attribut hat in diesem Fall keine Relevanz für die Signalisierung von Indefinitheit brw. Definitheit. Ähnlich ist die Funktion adjektivischer Attribute im dritten Beispiel. Im vierten Beispiel schließlich fürt die Tilgung des Attributs $z u$ einem wenig akzeptablen Satz. Das gleiche gilt für die Tilgung von molodoj im fünten Beispiel. Die Präpositionalphrase allein kann also in den letzten beiden sätzen die Indefinitheit der Phrase nicht in ausreichendem Maß sicherstellen. Wenngleich nicht das ganze spektrum indefinit-nichtspezifisch referierender Phrasen mit unserem Beispiel abgedeckt ist, läßt sich doch insgesamt feststellen, daß es sicherlich nützlich ist, bei der Beschreibung der Indefinitheit Unterschiede in der Referenz $z$ u berücksichtigen. Ich werde mich hier nur mit Phrasen des ersten und des vierten Typs beschäftigen.

\section{Indefinit-spezifisch referierende Phrasen}

(Erscheinens- und Existenzaussagen)

Es ist leider nicht möglich, auf die Distribution dieses Phrasentyps in den einzelnen Textsorten bzw. Texten näher einzugehen, obwohl Angaben daruber (wie natürlich ganz allgemein über das Vorkommen indefiniter substantivelvon großem Interesse wären. Ich kann im Augenblick nur feststellen, daß dieser Typ in narrativen, handlungsreichen Texten im Vergleich $z u$ wissenschaftlichen Texten eine hohe Frequenz hat. In letzteren spielt das Erscheinen von beobachtbaren Gegenständen keine Rolle. Aber wenn man einmal von diesem Extrem absieht, findet man sicherlich auch andere Texte, in der weitgehend auf das Einführen oder wiedereinführen von belebten und unbelebten Gegenständen verzichtet wird. Die Relevanz solcher Befunde für den Textaufbau bzw. die kommunikativen Möglichkeiten müßte eigens untersucht werden. 
Ich beginne meine Betrachtung mit einem typischen Beispiel:

(1) V komnatu vošla polnaja požilaja ženščina $v$ belom chalate.

Diese Erscheinungsaussage ist in vielerlei Hinsicht typisch. Sie ist typisch bezüglich des verwendeten verbs, das eine relativ hohe Frequenz aufweist. Ebenso typisch ist die Verwendung eines semantisch armen, nur auf die Merkmale "natürliches Geschlecht" und "Alter" orientierten Klassifikators. Bei etwas mehr als 100 gesammelten Belegen fanden sich in etwa 90 Fällen Klassifikatoren dieser Art: ženščina (32), mužčina (19), paren'. parenek (12), čelovek, molodoj čelovek (12), devica, devuška (6), starik, staričok, staruška (7), mal'čik, mal'čugan, mal'čiška (3). Wesentlich seltener traten semantisch reichere klassifikatoren auf. Wörter wie dojarka, armjanka, priemšc̆ica, oficer, general. letčik, kapitanmilicii, sekretarša, dežurnaja und ochotnik setzen mehr oder minder spezifische situationen voraus: "Hotel". "Büro", "Armee", "Jagd" usw.

Typisch sind weiterhin die verwendeten Adjektivattribute. Sie gehören den semantischen Klassen "Dimension" bzw. "Tempus" an, die zwei Drittel aller adjektivischen Attribute ausmachen, wobei Dimensionsadjektive vor Tempusadjektiven rangieren. Eine hohe Frequenz haben auch noch Farbadjektive, die vor Bewertungs - und Zustandsadjektiven kommen. Und typisch ist schließlich, daß neben den adjektivischen Attributen eine Präpositionalphrase als Attribut auftritt. Der semantische Bereich der Präpositionalphrasem erfaßt im wesentlichen vier semantische Mikrobereiche: "Kleidung", "Haar", "sonstige Körperteile", "Brille", wobei "Kleidung" absolut dominiert $(60 \%)$. Unser Beispielsatz enthält somit eine mit hoher Wahrscheinlichkeit voraussagbare Attributskombination. Diesen Attributen ist gemeinsam, daß sie auf leicht beobachtbare und leicht zu ermittelnde Merkmale referieren, was für die in Rede stehenden Aussagen bzw. die entsprechenden situationen höchst relevant ist. Die entscheidende Frage ist nun, welche Rolle die Attribute bzw. die formalen Varianten für die signalisierung von Definitheit spielen. Für den durch (1) vertretenen Satztyp läßt sich sagen, daß es die adjektivischen Attribute sind, 
die für die signalisierung von Indefinitheit verantwortlich sind, und nicht etwa die wortfolge oder die präpositionalattribute. Letztere tendieren dazu, wenn sie nicht im Verbund mit adjektivischen Attributen auftreten, Definitheit anzuzeigen. Oder genauer, aufgrund meines empirischen Materials läßt sich feststellen, daß eine ausschließliche Determination durch Präpositionalphrasen bei indefiniten Phrasen äußerst selten ist. Eher ist damit $z$ u rechnen, daß sie bei der wiederaufnahme von Phrasen eingesetzt werden. Bei prädikativ verwendeten Nominalphrasen habe ich keinen einzigen Fall gefunden, in dem eine Präpositionalphrase als alleiniges Attribut auftritt. Sehen wir uns nun einige Beispiele an:

(2) ... na poroge pojavljaetsja vysokij chudoščavyj čelovek s sedymi volosami.

(2') ... na poroge pojavljaetsja čelovek.

(2'l) ?... na poroge pojavljaetsja čelovek s sedymi volosami.

[Hervorhebungen und Tilgungen hier und anderswo von mir]

(2') ist nur dann interpretierbar, wenn čelovek entweder als definit interpretiert wird, wobei das Erscheinen des Menschen offensichtlich als überraschend empfunden wird, oder wenn sich aus dem Kontext ein Kontrast ergibt (2.B. zu einem Tier). In beiden Fällen müssen wir von einer gegenüber (2) veränderten Intonationsstruktur ausgehen. Mit Hilfe der Wortfolge kann zwischen Definitheit und Indefinitheit nicht unterschieden werden. Nachstehendes Beispiel zeigt, daß Erscheinensaussagen grundsätzlich nur die wortfolge $V-N$ aufweisen:

(3) $v$ étot moment $v$ komnatu zachodit valja Denisov.

Valja Denisov ist trivialerweise eine definite Phrase, sie ist aber wie die indefinite Phrase in (1) nicht vorerwähnt bzw. sie ist Teil einer Erscheinungsaussage. Eine Veränderung der Wortfolge führt in diesem Fall immer $2 u$ einer Veränderung der Verbsemantik und damit $z u$ einer anderen Aussage. 
Sehen wir uns ein weiteres Beispiel an, in dem die Wortfolge $v$ - N grammatikalisiert ist:
(4) - Gospodi! Molodaja-to ... - proiznesla seden'kaja ženščina.

Die Nominalphrase ist eindeutig indefinit. Dies hängt aber allein von der Existenz des adjektivischen Attributs ab. Vgl.

(4') - Gospodi! Molodaja-to ... - proiznesla ženščina.

Ženščina wird hier als definit aufgefaßt.

Die Variante (2') ist problematisch, weil hier die determinierte phrase eher als definit denn als indefinit interpretiert wird. Ich werde später noch auf einen spezielien fall eingehen, in dem auch eine Determinierung durch Präpositionalphrasen $z u$ einer indefiniten Interpretation führt.

Sehen wir uns noch ein weiteres Beispiel an.

(5) Chlopnula kalitka. V ogradu vošel sedoj, pochožij na sostarivšegosja borca mužčina v svetlom kostjume ...

Bei diesem Beispiel will ich darauf aufmerksam machen, daß die Tilgung eines pränominalen Attributs die indefinite Interpretation der Phrase nicht beeinträchtigt:

\section{(5') ... v ogradu vošel pochožij na sostarivšegosja borea mužčina v svetlom kostjume ...}

Wenn beide pränominalen Attribute getilgt werden, tendiert die Nominalphrase dazu, eher definit als indefinit aufgefaßt $z u$ werden :

(5'1) ...V ogradu vošel mužčina v svetlom kostjume ...

Der Vollständigkeit halber soll auch Beispiel (4) daraufhin überprift werden, ob eine Präpositionalphrase eine definite Interpretation nahelegt: 


\section{(4') - Gospodi! Molodaja-to ... - priznesla ženščina v beževoj jubke.}

Die Nominalphrase scheint definit zu sein. Eine Erklärung für diese Rolle der Präpositionalphrase könnte sein, daß sie bei fehlendem pränominalen Attribut syntaktisch und intonatorisch enger an das Bezugsnomen gebunden wird. Zwar läßt sich mit Hilfe eines präpositionalen Attributs kaum eine vernünftige Klasse bilden, aber dafür eignet sich diese Phrase besser dazu, für eine Identifikation notwendige distinktive Merkmale zu liefern. Wenn durch die Existenz pränominaler Attribute die Bindung der Präpositionalphrase an das Bezugsnomen gelockert wird, stützt diese die indefinite Interpretation des Nomens .

Drei Beispiele in meinem Material scheinen die oben beschriebene Rolle allein determinierender Präpositionalphrasen $z u$ widerlegen:

(6) ... no ostanovilsja poodal', ot verenicy avtomobilej, ožidavšich svoej očeredi pered vorotami cecha.

Pervym k nemu podošel mužčina v zanošennoj specodežde s ispitym počernevšim licom.

- Zamok dlja zapaski ne nužen?

(7) Ljudej, krome nee, bylo ešče neskol'ko. U doski stojal korotyšs golovoj, pochožej na svernutogo eža, i čto-to dokazyval, stuča melom. Emu vozražala ženščina v temnom.

Eine Erklärung für die indefinite Interpretation der Nominalphrase in (6) trotz des präpositionalen Attributs könnte die durch pervym signalisierte Aufzählung sein, die die Erscheinensaussage etwas in den Hintergrund drängt und die identifizierenden Merkmale stärker betont. Vgl.

(6') ... K nemu podošel mužčina v zanošennoj specodežde ...

Jetzt wird die Nominalphrase eher definit interpretiert. Problematisch ist (7), denn es ist gar nicht so klar, daß ženščina $v$ temnom tatsächlich indefinit ist. Es könnte auch 
eine definite Phrase vorliegen. Auf jeden Fall ist $2 u$ beachten, daß hier keine Erscheinensaussage vorliegt, bestenfalls eine verdeckte Existenzaussage. Dies wirkt sich insofern aus, als die uns interessierende Phrase nach Einfügung eines adjektivischen Attributs immer noch definit $2 u$ sein scheint.

(7') ... Emu vozražala chuden'kaja ženščina v temnom.

Eindeutig ist die situation, wenn 2 wei adjektivische Attribute gegeben sind:

(7', ... Emu vozražala chuden'kaja sedaja ženščina.

Jetzt liegt Indefinitheit vor.

Unproblematisch ist dagegen die Phrase korotyš s ... Die indefinite Interpretation wird $z$ einem durch die semantische Komplexität des Nomens (durch die Nominalisierung eines Adjektivs) und zum andern durch die Determinierung durch eine indefinite Phrase ( pochožej na) bewirkt.

Es verträgt sich mit den bisherigen Feststellungen zu der Rolle der Präpositionalphrasen, daß sie auch Verbindungen mit Eigennamen eingehen:

(8) ... šumno vorvalas' Anna Kirillovna v jarko-golubom džempere, s jarko-oranževymi volosami.

(9) Vperedi opernym šagom šel Fabrickij v lyžnom kostjume i vjazanoj šapočke.

Ein paar weitere Beispiele zur Untermauerung des Gesagten:

(10) Za stolom sidela ešče nestaraja, krasivaja snežnosedaja ženščina s takimi že kak u Soni, traurno-černymi glazami.

(11) v uglu u pul'ta stojal vysokij, očen' krasivyj molodoj čelovek $v$ naušnikach, kak budto ... 
(12) Jaša vedet menja čerez ogromnyj, zalityj mašinami dvor. $v$ komnatuške načal'nika odnoj iz kolonn nas dožidaetsja vichrastyj parenek $v$ očkach i kožanoj kurtke na "molnii".

(13) Na ovoščebaze prišedšich vstretila surovaja tolstaja ženščina v vatnom kombinezone.

(14) Neožidanno dver' dači beššumno priotkrylas'. S ulicy v kuchnju zagljanul nebrityj staričok v železnodorožnoj furažke i tichon'ko sprosil ...

(15) Dver otkryl chuden'kij-zagorevšij mal'čik v novoj škol'noj forme.

Ungeachtet der Existenz verschiedener Verben ist all diesen Sätzen gemeinsam, daß die subjektphrase indefinit ist, wobei in allen Fällen die adjektivischen Attribute die entscheidende Rolle spielen. Eines Kommentars bedarf allerdings Beispiel (15) bzw. der dritte angekündigte satz mit präpositionalen Determinatoren:

(16) Vot nakonec i dom, kotoryj mne nužen ...

Dver' mne otkryvaet devuška v pušistoj koričnevoj koftočke i sovsem koroten'koj beževoj jubke.

Die Indeterminiertheit der Phrase devuška $\underline{v}$... wird trotz des Fehlens adjektivischer Attribute, so scheint es, durch eine Besonderheit bewirkt. Wir haben hier koordinierte Präpositionalphrasen vorliegen, wobei die Konjunkte auf ein und denselben Mikrobereich referieren. Es mag unter bestimnten Bedingungen (etwa nach einem Verb wie videt'/vidiš') eine Koordination dieser Art durchaus mit einer definiten Interpretation der Nominalphrase verträglich sein, hier jedoch bewirkt die Reihung der Präpositionalphrasen eindeutig eine indefinite Interpretation. Hinzukommt, daß das Hinterkonjunkt aufgrund des Intensifikators sovsem kaum geeignet erscheint, eine definite Lesart auszulösen. Die Rolle der Adjektivattribute, die hier unnötig erscheinen, wird also durch eine "Verlängerung" der 
Präpositionalphrase bewirkt, was sich auf die Enge der Bindung der präpositionalen Determinatoren an das Bezugsnomen auswirkt. 4 Wir haben uns bisher nur mit Beispielen mit invertierter Wortfolge beschäfigt. Es gibt aber auch indefinit-spezifische subjektphrasen in präverbaler stellung:

(17) U vychoda požilaja dežurnaja v sukonnoj kurtke rešala krossword.

(18) Molčat rebjata, glaza opustili.

- Nu, tak kak že?...

šcuplyj, vichrastyj parenek stal neochotno ob-jasnjat'.

(19) Zatem ja snova podnimajus' na tret'ij étaž i otyskivaju dežurnuju po étažu $v$ nebol'šom ujutnom cholle s mjagkoj mebel'ju i neizmennym televizorom. Za stolikom vozle lifta nemolodaja polnaja ženščina $v$ očkach i belosnežnom chrustjaščm chalate čto-to zapisyvaet $v$ tetrad'.

(20) Bližajšim ot Gostinogo dvora byl Sennoj rynok. Tuda že bez osobogo éntuziazma i poechal Lebedev.

Nebrityj chmuryj starik vzjal ključ, podkinul slegka $v$ temnoj kostistoj ladoni i tut že vernul Lebedevu.

Interessant an diesen Beispielen ist, daß die Indefinitheit wiederum mit speziellen Mitteln angezeigt werden muß. Entscheidend ist dabei, daß dem präverbalen subjekt wenigstens zwei Attribute zugeordnet werden müssen. Einzelne Attribute, auch adjektivische, signalisieren eher eine definite als eine indefinite Phrase, was u.a. damit zusammenhängen mag, daß indefinite Phrasen auf diese Weise von wiederaufnahmen, die sich mit einem Attribut begnügen, abgegrenzt werden können: 5

$\left(17^{\prime}\right)$ U vchoda požilaja dežurnaja rešala krossword.

(18') Ščuplyj parenek stal neochotno ob-jasnjat'.

Diese Beispiele zeigen auf alle Fälle, daß zwischen Thematisierung und Definitheit eine Affinität besteht und Indefinitheit eigens markiert sein muß. 6 
"Unwirksam" sind natürlich Attributshäufungen bei vorerwähnten Phrasen. Diese bleiben trivialerweise definit:

(21) ... no razgovor s podpolkovnikom Kornilovym ostavil u Vladimira Filippoviča choršee vpečatlenie. Požiloj suchoščavyj podpolkovnik chot' i vygljadel chmurym, razgovor vel po delu...

Die Notwendigkeit, die Indefinitheit bzw. die Definitheit zu markieren, betrifft natürlich auch phrasen in anderen syntaktischen Positionen. Vgl.

(22) Liš' sledovatel' Limakin razgovarival so strižennym pod boks vysokim mužčinoj.

(23) Golubev soskol'znul s podokonnika i $v$ dverjach čut' ne stolknulsja s zagljanuvšim v kabinet vysokim plečistym mužčinoj.

(24) ... staričok stojal nepodaleku ot dači Tumanova $i$ uvlečenno čto-to rasskazyval vysokoj dorodnoj ženščine $v$ krasnoj vjazanoj kofte.

(25) Anton Birjukov ulučil udobnuju minutu, poka očerednoj molokovoz pristraivalsja pod razgruzku, podošel $k$ moloden'koj priemnice $v$ belom chalate i sprosil $\circ \ldots$

(26) Zamok ščelknul, i dver' priotkrylas'. Demin uvidel pered soboj polnuju nizkorosluju ženščinu s dlinnymi svetlymi volosami. v tel'njaške i v mužskich pižamnych brjukach.

Die Tilgung der adjektivischen Attribute führt auch hier dazu. daß die verbleibende Phrase als definit interpretiert wird. Eine Ausnahme stellt (26) dar, da durch die Häufung von Präpositionalphrasen eine enge Bindung dieses Determinators an das Nomen behindert wird.

Auch bei Genitivattributen wird bei spezifischer Referenz die Indefinitheit mit Hilfe adjektivischer Atribute angezeigt: 
(27) Vse éto nachodilos' pod prismotrom chuden'kogo černjavogo mal'čugana

(28) Jasin zastal ego $v$ obščestve molodoj neznakomoj ženščiny.

Bei einer Tilgung der Adjektive ruht die gesamte rhematische Last auf dem Genitivattribut mit dem Ergebnis, daß kontrastiv besonderes Gewicht auf dem Merkmal "natuirliches Geschlecht" bzw. dem Merkmal "Alter" liegt. Eine definite Interpretation scheint auch möglich $z u$ sein. Ich habe keinen Beleg mit Präpositionalphrasen als zusätzlichen Determinatoren gefunden und ändere deshalb (28) um, um zu beobachten, welche Rolle präpositionalphrasen in dieser konstruktion spielen:

(28') Jasin zastal ego $v$ obščestve molodoj neznakomoj ženščiny s dlinnymi volosami.

Mir scheint dieser Satz ein wenig problematisch zu sein und zwar deshalb, weil die präpositionalphrase für die syntaktische Funktion des nominalen Attributs überfluissig ist und schwach gebunden erscheint. Sehen wir uns noch folgendes Paar an:

$\left(28^{\prime \prime)}\right.$ ? Jasin zastal ego $v$ obščestve molodoj neznakomoj ženščiny s bol'šoj korzinoj.

(29) Za Nikol'skim oni obognali neskol'ko mal'čišek s bol'šimi korzinami.

Diese Beispiele verdeutlichen vielleicht noch besser, daß in der Konstruktion mit dem Genitivattribut die präpositionalphrase syntaktisch weniger fest an das Bezugsnomen gebunden ist und somit auch anders gebunden sein kann.

Der Vollständigkeit halber bilde ich (28) noch so um, daß als Determinator nur eine Präpositionalphrase auftritt:

$$
\begin{aligned}
& \text { (28,') Jasin zastal ego } v \text { obščestve ženščiny s dlinnymi } \\
& \text { volosami. }
\end{aligned}
$$


Es ist leicht zu sehen, daß hier die präpositionalphrase eng an das Bezugsnomen gebunden ist und somit eine definite Lesart signalisiert.

Bevor ich mich Beispielen zuwende, in denen indefinite spezifische Referenz ohne Hilfe adjektivischer Attribute realisiert wird, will ich noch eine kurze Anmerkung zur Kookkurrenz adjektivischer und präpositionaler Attribute machen. Ganz allgemein läßt sich feststellen, daß die meisten indefinit-spezifisch referierenden Phrasen wenigstens zwei Attribute enthalten. Am häufigsten findet sich dabei die Verbindung von adjektivischem und präpositionalem Attribut, wohingegen die verwendung von zwei adjektivischen Attributen seltener ist und in gewissem sinn restringiert erscheint. Grundsätzlich wird offensichtlich durch die Häufung von Attributen erreicht, daß die rhematische Last auf mehrere Träger verteilt wird. Auf diese Weise werden einzelne Attribute nicht fokussiert und eventuell explikationsbedürtig gemacht:

(30) V dverjach stoit chuden'kaja ženščina v zastirannom sinem chalate i beloj kosynke.

(30') V dverjach stoit chuden'kaja ženščina.

In (30') wird die ganze Aufmerksamkeit auf das durch das Adjektiv bezeichnete Merkmal gelenkt und eine gewisse Fortsetzungserwartungausgelöst (vermutlich spielt auch die semantik der Adjektive hierbei eine wichtige Rolle). Ist das Bezugsnomen semantisch komplex, wirkt sich die Existenz nur eines einzigen adjektivischen Attributs weniger gravierend aus:

(31) Rjadom stojal rozovolicyj mužičok.

Analog $z u$ betrachten sind die Verhältnisse bei Verben des Sagens, die keine reine Existenzaussage beinhalten:

(32) - Da puskaj polučit, - otozvalas' dorodnaja staraja ženščina. 
Es ist hier nicht möglich, ausführlich auf die Distribution der adjektivischen und präpositionalen Attribute einzugehen, es sei deshalb nur noch eine kurze Bemerkung zur Determinierung durch mehrere adjektivische Attribute gemacht. In den folgenden Beispielen scheint ein Präpositionalattribut überflüssig $z$ sein, da dieses mehr Information liefert als mit der verbsemantik, die mehr als eine Existenzaussage beinhaltet, verträglich ist:

(33) Za nizkim zaborom staraja černovolosaja armjanka sobirala $v$ pletenuju korzinu perespevšie slivy.

(33')? Za nizkim zaborom staraja černovolosaja armjanka $\underline{v}$ belom perednike sobirala $v$ pletenuju korzinu perespevšie slivy.

Die Problematik von (33') scheint darauf $z$ u beruhen, daß die Präpositionalphrase nur ungenügend an die Bezugsphrase gebunden ist, was offensichtlich durch das prädikat mit Aktionsbedeutung verursacht wird.

Ein weiteres Beispiel:

(34) A ona otkrovenno flirtovala s dlinnym černjavym parnem, rabotnikom kakogo-to televizionnogo atel'e.

(34')? A ona flirtovala s dlinnym černjavym parnem $v$ krasnoj kurtke, rabotnikom kakogo-to televizionnogo atel'e.

Interessant ist hier, daß Präpositionalphrase und Apposition in Konkurrenz treten. Beide tendieren dazu, einen Abschluß zu signalisieren. Hier wird aber trotz Abschlußsignal eine weitere Merkmalzuweisung vorgenommen. Im übrigen scheint die indefinite Phrase in objektposition problemlos ein präpositionalattribut zuzulassen.

Daß mit den verschiedensten Faktoren gerechnet werden muß, wenn die Akzeptabilität oder Nichtakzeptabilität einer Determination durch eine präpositionalphrase beurteilt werden soll, zeigt das folgende Beispiel: 
(35) Ja podnimajus' na vtoroj étaž znakomogo mne uže administrativnogo korpusa i čerez minutu zdorovajus' $s$ nevysokoj černovolosoj ženščinoj v strogom kostjume - sekretarem direktora zoej Fedorovnoj.

Hier liegt mit ženščinoj ein semantisch armer Klassifikator vor. Dies mag der eine Grund für die Notwendigkeit der Präpositionalphrase sein. Einen zweiten Grund sehe ich darin, daß die Präpositionalphrase die Apposition zu motivieren scheint, und damit die ganze Aussage.

Grundsätzlich festzuhalten ist, daß für die Existenz/Nichtexistenz von präpositionalphrasen in Fällen der obigen Art sowohl die syntaktische position der indefiniten Phrase als auch die Verbsemantik eine Rolle spielen. Ich komme nun $z u$ Beispielen, in denen indefinit-spezifische Referenz nicht mit der Existenz adjektivischer Attribute korreliert. Ich will vier Typen unterscheiden:

1. Das indefinite Nomen tritt ohne ein determinierendes Element auf.

2. Anstelle eines Adjektivs steht das Indefinitpronomen kakoj-to.

3. Anstelle eines Adjektivs steht ein Zahlwort.

4. Das indefinite Nomen wird durch ein Genitivattribut des Typs malen'kogo rosta determiniert.

Der erste Typ ist naturgemäß der problematischste, da er der bisher vertretenen Auffassung von der Rolle der adjektivischen Attribute entgegensteht. Ich habe oben bei einigen Beispielen darauf hingewiesen, daß für nichtdeterminierte indefinite Nomina charakteristisch ist, daß die Merkmale "natürliches Geschlecht" und "Alter" besonders hervorgehoben werden. Es ist einsichtig, daß eine Betonung dieser Merkmale dann am leichtesten erreicht wird, wenn keine wie immer gearteten Merkmalzuweisungen vorliegen, dafür aber eine Kontrastierung auf der Basis der oben genannten Merkmale möglich ist. Sehen wir uns zunächst ein paar Beispiele an:

(36) Po Tverskomu bul'varu ne speša šli mužčina i ženščina.

(37) Patrul'nym narjadom zaderžany dvoe podozritel'nych graždan - molodoj čelovek i ženščina. 
(38) A delo byla tak. Po universitetskomu prospektu šla ženščina, katja vperedi sebja detskuju koljasku.

$\cdot$

-

V éto vremja iz-pod arki dvora vyšel paren' i podošel

$k$ lejtenantu i ženščine.

Beispiel (36) läßt bei normaler Intonation nur eine indefinite Lesung der Substantive $z u$. Es geht in diesem Satz zweifellos um eine Fokussierung des natürlichen Geschlechts, was durch den Kontrast von mužčina und ženščina begünstigt wird. Gleichzeitig werden durch die Unvollständigkeit und damit Nichtabgerundetheit der Information Fortsetzungssignale gesetzt. Die Einsetzung von Attributen hätte zur Folge, daß die Opposition "männliches Geschlecht" "weibliches Geschlecht" durch eine andere Opposition überlagert würde bzw. andere Fortsetzungserwartungen ausgelöst wurden. Bemerkenswert ist, daß bei einer Attribuierung des ersten Substantivs der ursprüngliche Kontrast erhalten bleibt. Das zweite substantiv kann nicht als einziges attribuiert werden.

Beispiel (37) bereitet ebenfalls keine Schwierigkeiten. Es geht eindeutig um die besondere Betonung des Merkmals "natürliches Geschlecht" und "Alter". Vielleicht hätte dieses Beispiel hier nicht angeführt werden dürfen, da es um einen Bericht und nicht um eine aktuelle Beschreibung geht. Die Einsetzung von Attributen müßte hier speziell motiviert sein. Etwas anders ist die situation in (38), das eine Explikation zu (37) darstellt. Vielleicht ist das der Grund, warum trotz eines gewissen textuellen Abstands zwischen ženščina und paren' die Hervorhebung des Merkmals "natuirliches Geschlecht" funktioniert. Adjektivische Attribute wïden in (38) als störend empfunden:

$\left(38^{\prime}\right)$ ? ... Po universitetskomu prospektu šla nebol'šaja chuden'kaja ženščina, katja vperedi sebja detskuju koljasku ...

$v$ èto vremja iz-pod arki dvora vyšel molodoj černjavyj paren' $i$... 
Auch in Beispiel (39) ist bei normaler Intonation das Nomen nur als indefinit $z u$ interpretieren. Die Betonung des Merkmals "Sexus" erzeugt eine gewissen Spannung, die durch den Nachtext prompt aufgelöst wird. Es scheint, daß es problematisch ist, in (39) anstelle des Appelativums einen Eigennamen $2 u$ haben.

(39) K domu Oparinych podošel mužčina. Aksin'ja Mironovna gljanula i achnula. Eto ...

Sehen wir uns noch ein paar weitere Beispiele an:

(40) K koncu pogruzki k pričalu pod-echal "gazik", iz nego vyšel mužčina, vedja na povodke lajku.

Abgesehen davon, daß aufgrund des anaphorischen Themas mužčina auf keinen Fall als definit interpretiert werden kann, erklärt sich die Attributslosigkeit auch hier durch die spannung, die im Hinblick auf die Textfortsetzung erzeugt werden soll. Man kann (40) als eine Aussage ansehen, die eine in gewissem Sinn stereotype (erwartbare) Abfolge bzw. Verkettung von Ereignissen schildert. In einer solchen Abfolge haben Statik erzeugende Attribute keinen Platz.

Ähnlich motiviert ist die Attributlosigkeit der Nominalphrase in (41):

(41) V konce ulicy akkuratno pobelennoe zdanie. Na prostornom kryl'ce ženščina vytirala trjapkoj pol i stupen'ki.

Auch hier wird durch das Fehlen von Attributen die Erwähnung der Frau durch ihre Rolle im fortlaufenden Text motiviert (sie wird befragt). Adjektivische und präpositionale Attribute wirden eine statische Situation erzeugen.

Noch ein letztes Beispiel dieser Art:

(42) ... i uvidel okolo kamyšej nebol'šuju golubuju lodku i čeloveka $v$ nej.

Es besteht kein Zweifel, daß čelovek als indefinit aufzufassen ist. Allerdings soll, wie bei den obigen Beispielen 
nicht der Eindruck eines statischen Bildes erzeugt werden, das für den weiteren Text keine Rolle spielt, sondern es soll eine bestimmte Textentwicklung vorbereitet werden. Der Beobachter wird mit dem Menschen im Boot Kontakt aufnehmen. Das ist der Grund, warum die indefinit-spezifische Referenz nicht durch adjektivische Attribute angezeigt wird.

Die Beispiele (36) bis (42) sprechen nicht gegen unsere These, daß adjektivische Attribute von besonderer Bedeutung für die signalisierung von indefinit-spezifischer Referenz sind, sondern zeigen vielmehr, wie im Zusammenspiel mit dem Kontext die Möglichkeit der Attribuierung/Nichtattribuierung ausgenützt werden kann.

Da es in diesem Beitrag vor allem um Adjektive geht, will ich nur kurz auf das Indefinitpronomen kakoj-to eingehen. Dieses Pronomen ist in zweierlei Hinsicht interessant. Zum einen kann es als alleiniger Determinator eines Nomens auftreten, zum andern auch im Verbund mit adjektivischen Attributen. Sehen wir uns zunächst die Beispiele an:

(43) Staršij lejtenant uechal.

Kakoj-to požiloj mužčina, ogljanuvšis' po storonam, perešel dorogu.

(44) S nej ešče kakaja-to sil'no razmalevannaja devica $i$ dvoe molodych 1 judej artističeskogo vida $i$ pritom ves'ma bojkich.

(45) Razmyšljaja, ja ne speša bredu po ulicam i vskore okazyvajus' vozle komissionnogo magazina.

Okolo nego po-prežnemu topčutsja zevaki, razgljadyvaja vystavlennye $v$ vitrine vešči.

Neožidanno okolo menja okazyvaetsja kakoj-to jurkij parenek $v$ berete i nemyslimo pestroj nubaške...

In diesen Beispielen treten zwei Aspekte der Funktion von kakoj-to zutage. Im ersten Satz hat kakoj-to die Funktion, die initiale Phrase, die mit dem attributiven Adjektiv allein 
als definit interpretiert würde, als indefinit zu markieren. Vgl. dazu $(17 \%)$. In den beiden anderen sätze hat kakoj-to vor allem pragmatische Funktion, es drückt die Einstellung des Sprechers $z u$ den betreffenden Personen bzw. ihren Merkmalen aus. Auf den Charakter der Indefinitheit nimmt kakoj-to hier keinen Einfluß.

Anders ist die situation, wenn kakoj-to als alleiniger pränominaler Determinator auftritt:

(46) Očered' zagudela. Kakoj-to paren' v krasnoj kurtke, kosaja sažen' $v$ plečach, probivalsja vpered ...

(47) Kakoj-to paren' pytaetsja daže ee uvesti ot menja, no ...

(48) - Ej, Galka! A nu podojdi, čto skažu. My ogljadyvaemsja. Okolo vorot stoit kakoj-to paren'. $v$ temnote mne trudno ego razgljadet'.

In (46) und (47) funktioniert das Indefinitpronomen wie in (43). Es sichert die indefinite Leseart. Kakoj-to ersetzt in diesen Beispielen adjektivische Attribute und enthebt damit den Sprecher der Notwendigkeit, charakteristische Merkmale der betreffenden Personen $z u$ nennen. Dafür realisiert kakoj-to zusätzlich pragmatische Funktionen. Ein idealer Ersatz für Adjektive ist kakoj-to in (48), denn da werden Umstände genannt, die eine Beschreibung der Person behindern, wobei aber dennoch Indefinitheit angezeigt werden muß. Dazu noch folgendes paar:

(49) Nakonec ja podsaživajus' k odnomu iz stolov i očen' polnaja sedaja ženščina načinaet vmeste so mnoj perelistyvat' bol'šuju knigu s zapisjami ... - Veročku ja pomnju, - ulybaetsja ženščina.

(50) - Von on! ... Von! ... Idet! ... - vosklicaet kakajato ženščina nedaleko ot menja.

Im ersten Fall steht nach dem Verb des Sagens eine definite Phrase. Im zweiten Beispiel wird explizit angezeigt, daß in gleicher Position die Phrase indefinit ist. 
Soviel zu dieser Problematik, die sicherlich noch weiterer Untersuchungen bedarf.

Ich werde auf die Numeralia, die ebenfalls für adjektivische Attribute in Ersatzfunktion treten können, nicht weiter eingehen. Zu odin ist ohnehin schon reichlich Literatur vorhanden. Ich will aber noch einige Anmerkungen zu Attributen wie vysokogo rosta, let vos'mi machen. Diese Attribute können sowohl mit adjektivischen Attributen (und isolierten Adjektiven) kookkurrieren als auch allein die Indefinitheit des Bezugsnomens sicherstellen, vgl.

(51) ... vošel solidnyj vysokolobyj mužčina let pod pjat'desjat.

(52) V kabinet vošel mužčina let soroka, vysokij, sutulovatyj.

(53) Tut im povstrečalsja čelovek pensionnogo vozrasta, on šel raskačivaja rukami.

(54) Vysokaja, polnaja starucha s surovym licom deržit za ruku devočku let semi ...

Genitivatttribute dieser art sind eindeutige signale für Indefinitheit, was sich auch daran zeigt, daß sie auf keinen fall bei der anaphorischen wiederaufnahme von Nominalphrasen verwendet werden können. Vgl. dazu die modifizierte fortsetzung von (52):

$\left(52^{\prime}\right)$ *... Devočka let semi ispuganno žmetsja k staruche. bzw.

(53) *Etot čelovek pensionnogo vozrasta ...

Ich schließe hiermit zunächst einmal die Betrachtung indefinitspezifisch referierender Personenbezeichnungen ab und wende mich kurz Substantiven mit Referenz auf unbelebte Gegenstände zu. Im Prinzip gilt auch hier, daß Indefinitheit mit Hilfe von adjektivischen Attributen angezeigt wird, wobei allerdings, wie mir scheint, die Grenze zwischen adjektivischen und nichtadjektivischen Attributen weniger scharf ist als bei Personen- 
bezeichnungen. Der Grund hierfür scheint mir zu sein, daß es in vielen fällen recht schwer ist, Adjektive für kommunikativ relevante Merkmale zu finden. Bemerkenswert ist auch, daß bei unbelebten Gegenständen Erscheinungsaussagen naturgemäß eine geringe Rolle spielen (erscheinen können natürlich Fahrzeuge jeder Art) und die subjektposition somit nur (mit den genannten Einschränkungen) bei Existenzaussagen realisiert ist. Häufiger als bei Personenbezeichnungen treffen wir indefinite Phrasen in Objekt-, Attribut und Adverbialfunktion an. Es ist nicht möglich, die Indefinitheitsproblematik in all diesen syntaktischen Positionen in der notwendigen Breite $z$ u behandeln, ich beschränke mich deshalb darauf, die wichtigsten und interessantesten Phänomene vorzustellen.

Erscheinensaussagen

(54) Neožidanno u vchoda v rajotdel ostanovilsja noven'kij zelenyj "uazik".

(55) K koncu pogruzki k pričalu pod-echal "gazik" ...

(56) K cerkvi kak raz pod-echal gruzovik.

Der Unterschied zwischen (54) und den beiden übrigen Sätzen besteht darin, daß in den letzten beiden sätzen eine weniger statische, funktional ausgerichtete situation vorliegt, bei der das Hauptaugenmerk auf den Prozeßablauf und nicht auf irgendwelche Merkmale der beteiligten Gegenstände gerichtet wird. Die Gegenstände selbst sind dabei weniger individualisiert als der Gegenstand in (54). Eine definite Interpretation müßte in (55) und (56) durch eine Possessivrelation angezeigt werden.

Existenzaussagen

(57) V teni navesa stojala staraja tachta. Na nej obložkoj kverchu ležal razvernutyj učebnik fiziki za desjatyj klass ... 
(58) V bolšom kresle ... dremal staršij lejtenant, rjadom s nim stojal tolstyj černyj portfel' ...

(59) Kornilov ogljadelsja. Nepodaleku stojala ešče odna dača, bol'šaja, odnoêtažnaja ... A za sosnami, metrach $v$ pjatistach, vidnelsja goluben'kij domik.

In all diesen Beispielen hat die Tilgung der attributiven Adjektive erhebliche Konsequenzen. Entweder werden die betroffenen substantive, soweit dies intonatorisch machbar ist, als definit interpretiert, oder es werden komische Effekte erzielt, wie etwa in (58), wo stojal dann nicht als reines Existenzverb, sondern in seinem konkreten sinn aufgefaßt wird. Interessant ist, daß bei Verben wie sverkat' und pobleskivat. die signalisierung von Indefinitheit nicht auf Existenz von Adjektiven zurückgehen muß, da diese Verben bereits "adjektivische" Merkmale der Gegenstände enthalten:

(60) Natal'ja Nikolaevna otkryla korobočku. Tam na golubom šelke sverkalo kol'cos zolotoj rozočkoj ...

(61) ... nevdaleke pobleskivalo ozero i bylo slyšno ... Wenn wir in (60) sverkalo durch ležalo ersetzen, tendiert das. Substantiv dazu, als definit interpretiert zu werden.

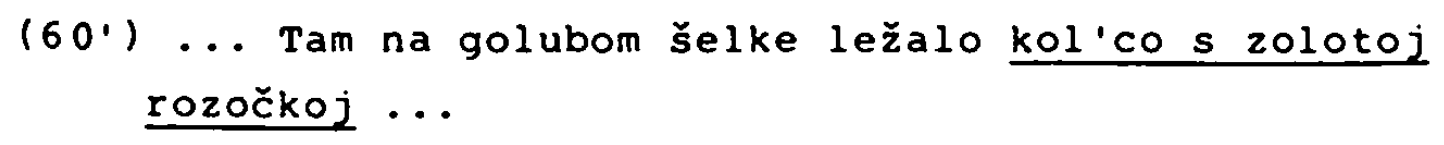

Vgl. damit

(62) Nepodaleku, na malen'kom suchom vzgorke, porosšem židen'koj travoj, ležalo tolstoe korotkoe brevno.

Hier ist eine definite Interpretation ausgeschlossen.

Die Bedingungen für eine Aufhebung der "Attributsobligatorik" bei der Signalisierung von Indefinitheit sind mit diesen Beispielen sicher nicht alle erfaßt. Dennoch ziehe ich es vor, auf ein interessantes Phänomen im Zusammenhang mit indefiniten Phrasen in objektposition hinzuweisen. 
Hier die Beispiele:

(63) Potom sunul ruku vo vnutrennij karman [postradavšego], na mgnovenie zamer i tut že vytaščil bol'šoj černyj pistolet ...

Učastkovyj neskol'ko sekund smotrel na pistolet, potom vynul platok, zavernul v nego oružie i sprjatal v sumku. Iz drugogo karmana vytaščil ključi na tonkom kolečke.

(64) Anton prisel na kortočki, slegka povernul trup i dostal iz karmana smjatuju pačku "Mal'boro" s razmokšimi sigaretami. Zatem izvlek nebol'šuju gazovuju zažigalku.

(65) Iz drugogo vnutrennego karmana sledovatel' dostal importnuju avtoručku $s$... i vmestitel'nyj bumažnik.

(66) Birjukov vzjal iz podstavki karandaš. Risuja na listke perekidnogo kalendarja bol'šoj voprositel'nyj znak. zagovoril ...

Das Interessante an diesen Beispielen ist, daß die Existenz von Attributen mit der Nichtintentionalität der Handlung, das Fehlen von Attributen mit der Intentionalität der Handlung korreliert. Anders gesagt, mit Hilfe der Attribute wird das für den Handelnden und den Beobachtenden überraschende Erscheinen eines Gegenstandes angezeigt, während im anderen Fall signalisiert wird, daß die Handlung bewußt und zielgerichtet durchgeführt wird. So wird im ersten Teil von (63) ein überraschendes Ergebnis angezeigt, während vynul platok eine gezielte, geplante Handlung darstellt. In beiden Fällen sind die objektphrasen indefinit. Im letzten Satz von (63) und in (64) und (65) sind wieder Belege für Handlungen, deren objekte vorher nicht bekannt sind und die somit überraschungen bringen. (66) dagegen beschreibt eine funktional ausgerichtete Handlung, deren objekt zwar nicht konkret, aber dennoch als integraler Teil der Handlung als bekannt vorausgesetzt ist. Deshalb fehlt hier das adjektivische Attribut. Die Tilgung der Attribute in (63) und den anderen sätzen führt nun nicht automatisch dazu, daß die dargestellten Handlungen als funktional orientiert bzw. als stereotyp ablaufend aufgefaßt werden. 
Was sich ändert, ist, daß das Nomen nun als definit interpretiert wird (was natürlich einen entsprechend motivierenden vortext voraussetzt):

(63') Potom sunul ruku vo vnutrennij karman, na mgnovenie zamer i tut že vytaščil pistolet.

Ob ein nichtattribuiertes Nomen als indefinit oder als definit aufgefaßt wird, hängt somit entscheidend davon $a b$, ob die betreffende Handlung in einem funktionalen Zusammenhang $z u$ einer anderen Handlung steht oder nicht.

Ein par weitere Beispiele für Attribute bei Objektphrasen:

(67) - On v larek pošel, a mne karaulit' velel, - kivnul on na skljanki.

En'šin podnjal nebol'šuju dosku. Na nej...

(68) Murenin raskryl staruju rukopisnuju knigu i pročital vsluch.

(69) ... i vbežal v topolevuju rošču vozle ozera, u starogo požarnogo nastila. Prislonilsja k tolstomu topolju, koe-kak perevel dychanie.

Die Tilgung der Attribute füht in allen drei Beispielen zur Uminterpretation der Nomina. Ungeachtet des Kontextes werden sie als definit interpretiert. $\mathrm{Zu}(68)$ ist noch anzumerken, daß staruju rukopisnuju knigu auch als definit aufgefaßt werden kann, allerdings nur wenn diese Phrase als periphrastische wendung eingesetzt wird.

Unproblematisch sind auch die folgenden Beispiele:

(70) On otkryl duer' i ...

Za širokim stolom pokrytym čistoj skatert'ju ... sidela starucha.

(71) V uglu masterskoj stojal dlinnyj stol i takaja že skam'ja. Dolgačeva sprosila mechanizatorov prisest' k stolu.

(72) Gurov dostal iz stola tonen'kuju papku, raskryl e... 
Die Attribute zeigen an, daß der Gegenstand nicht vorerwähnt bzw. indefinit ist, das Fehlen der Attribute dagegen signalisiert. daß die Existenz der Gegenstände bekannt oder erschließbar ist. Diesen Prinzipien scheint nachstehendes Beispiel zu widersprechen:

(73) Chozjajka ... priglasila menja k stolu pit' čaj. Ja uselsja za nebol'šoj, kvadratnyj, pokrytyj uzorčatoj, tjaželoj. s petuchami skatert'ju stol i načal pit' iz ogromnoj puzatoj raspisnoj čaški.

Das erste Vorkommen von stol ist sicherlich definit. Schwieriger ist die Beurteilung des zweiten Vorkommens. Von der Textlogik her müßte stol definit sein. In diesem Fall verwundert die Vielzahl der Attribute. Sie ließen sich allerdings aus der gewählten Perspektive, der ich-Perspektive, erklären. Der sprecher registriert beim setzen für ihn interessante Merkmale, wobei diese Merkmale keine restriktive Funktion haben, weil man davon ausgehen muß, daß es hier nur um einen einzigen Tisch gehen kann. Auch für die zweite Möglichkeit, die indefinite Interpretation, läßt sich eine Erklärung finden. In diesem Fall werden die von den Attributen bezeichneten Merkmale besonders hervorgehoben und als auffälig behandelt. Von diesen beiden Möglichkeiten bevorzuge ich die erste, wobei ich annehme, daß die beiden Vorkommen von stol nicht koreferent sind. Man könnte den Satz dann folgendermaßen lesen: "Ich setzte mich an den kleinen, quadratischen ... Tisch. der da stand, und ...". Es liegt in diesem Fall eine spezielle Art von Definitheit vor, eine, die nicht auf Vorerwähntheit beruht, sondern situativ aufgrund der Unikalität des Gegenstandes festgelegt wird. Von Bedeutung ist hierbei sicherlich, daß stol als Teil eines bereits gegebenen Ganzen verstanden wird.

Ich verzichte auf die Diskussion von Beispielen mit indefinitem Genitivattribut und solchen mit Präpositionalphrasen und gehe dafür kurz auf die Rolle von Relativsätzen für die Signalisierung von indefinit-spezifischer Referenz ein.

Der Relativsatz ist, das kann vorweg festgestellt werden. kein Konkurrent für die adjektivischen Attribute. Er ist dann 
möglich, wenn die indefinite Phrase eine funktionale Charakterisierung erhält oder wenn der Relativsatz irgendwie restriktiv interpretiert wird. Sehen wir uns dazu die zwei Beispiele an, die ich gefunden habe:

(74) - Na vse éti voprosy vam otvetit drugoj doktor. On sejčas $k$ vam zajdet.

Totčas že posle uchoda Marii Fedorovny vošel mužčina, kotoryj prinosil Zasekinu zavtrak.

- Nu kak? Otdyšalis'?

(75) - On priechal: S nim ženščina, kotoraja menja znaet.

Adjektivische Attribute scheinen in dem einen wie im anderen Fall unangebracht $z u$ sein, was damit zusammenhängt, daß es in beiden Fällen um die Bezeichnung einer Person aufgrund ihrer Funktion (im weitesten Sinn) geht. Die Klassifikatoren spielen hier eher die Rolle von Nominalisatoren. Deshalb muß die Indefinitheit nicht mit attributiven Adjektiven angezeigt werden. vgl.

(75')? - On priechal. S nim polnaja ženščina, kotoraja menja znaet.

Ebenfalls kein Konkurrent für die adjektivischen Attribute sind postnominale Partizipialphrasen. Wie die nachstehenden Beispiele zeigen, können sie zwar problemlos zusammen mit adjektivischen Attributen auftreten, als alleinige Determinatoren sind sie in ihrer verwendung jedoch stark eingeschränkt:

(76) Čerez neskol'ko minut vošla nevysokaja milovidnaja ženščina, odetaja $v$ seryj legkij kostjum $\ldots$

(77) V komnatu vošel širokoplečij molodoj mužčina, kompleksiej ne ustupajuščij "grossmejsteru" [gemeint ist ein vorerwähnter schachspieler].

Die Nominalphrasen sind eindeutig indefinit. Eine Tilgung der adjektivischen Attribute füht hier nicht zu einer definiten Interpretation, sondern macht die sätze inakzeptabel. 
Akzeptabel ist dagegen der partizipiale Determinator in (78):

(78) - Eto ty, Petro? - sprosil mužčina, sidevšijza bol'šuščim stolom i obernulsja

Der Grund für die Akzeptabilität dieses Satzes und die Nichteinsetzbarkeit eines partizipialen Determinators wie odetyj v... scheint darin $z u$ bestehen, daß "mužčina" lokalisiert werden muß, um identifizierbar zu werden. Eine Lokalisierung leistet ein Determinator odetyj $v \ldots$ nicht. Die Einsetzung von adjektivischen Attributen macht aus mužčina, sidevšij... eine indefinite Phrase. Die Definitheit von mužčina, sidevšij... basiert im übrigen nicht auf einer Vorerwähnung, sondern kommt durch den individualisierenden Einfluß der Partizipialphrase zustande.

Ich begnüge mich mit diesen Bemerkungen und schließe gleichzeitig die Betrachtung der indefinit-spezifisch referierenden phrasen ab.

\section{Prädikativ verwendete Nomina}

\section{a) Prädikatsnomina \\ b) Appositionen}

a) Die Konkurrenz der attributiven Mittel wird bei den Prädikatsnomina eindeutig zugunsten der Adjektive entschieden. Sie treten allein, aber auch im Verbund mit Präpositionalphrasen auf. Allein stehen können auch die genitivischen Attribute des Typs srednego vozrasta. Allerdings haben diese nur ein kleines Spektrum. Die Dominanz der Adjektive in dieser Position erklärt sich aus ihrem klassifikatorischen Charakter, eine Eigenschaft die Präpositionalphrasen in der Struktur Eto byl/a... nicht haben:

(79) Eto byla ženščina nekrasivaja, polnaja, s goroj suetlo-zolotych krašennych volos.

(79')? Eto byla ženščina s goroj svetlo-zolotych krašennych volos. 
(79'1) Ona byla ženščina s goroj svetlo-zolotych krašennych volos.

(80) Eto byl molodoj mužčina s malen'koj borodkoj i tonkimi usikami.

(80')? Eto byl mužčina s borodkoj i tonkimi usikami.

( 80 "') On byl mužčina s borodkoj i tonkimi usikami.

Der Unterschied $z$ wischen $\left(79^{\circ}\right)$ und $\left(80^{\prime \prime}\right)$ besteht darin, daß es im ersten Fall um eine aktuelle, beobachtbare situation geht, im zweiten Fall um eine inaktuelle. Deshalb sind da auch Attribute möglich, die auf nichtbeobachtbare Merkmale referieren:

$(79 \cdots)$ Ona byla umnaja ženščina.

Bei der Kopula okazat'sja ist nur ein Prädikatsnomen mit adjektivischem Determinator möglich:

(81) Dežurnaja po étažu okazalas', meždu pročim, ves'ma simpatičnoj ženščinoj, molodoj, izjaščnoj, privetinvoj ...

b) Ähnlich, aber nicht identisch sind die Verhältnisse bei der Apposition (ich beschränke mich auf Appositionen zu Personenbezeichnungen). Grundsätzlich gilt, daß bei spezifischer Referenz und aktueller situation substantive in Appositionsfunktion determiniert sein müssen. In Frage kommt dabei allerdings nur die Kombination Adjektivattribut - Präpositionalattribut, zumindest bei definitem Antezedens.

Unter bestimmten Voraussetzungen kann das Adjektivattribut durch ein Genitivattribut ersetzt werden. Die besondere Ausprägung der Apposition erklärt sich daraus, daß einerseits die Präpositionalphrasen allein keine für die klassenbildung erforderliche Information liefern, und andererseits die semantische Leistung der Adjektive nicht ausreicht, um uber die Klassenbildung hinaus der appositiven Phrase die offensichtlich notwendige semantisch-kommunikative selbständigkeit 
zu sichern. Beide Attributstypen müssen hier zusammenwirken. Sehen wir uns nun die Beispiele an:

(82) Staršaja gorničnaja, požilaja polnaja ženščina v belom perednike ... rasskazyvaet ...

(82')? Staršaja gorničnaja, požilaja polnaja ženščina, rasskazyvaet ...

(83) Tam ... sidit dežurnaja, simpatičnaja požilaja tetja $\underline{v}$ belom chalate.

(83')? Tam ... sidit dežurnaja, simpatičnaja požilaja tetja.

(84) A za nim, za znamenonoscem, stojal barabanščik - ser'eznyj mal'čugan v očkach.

(84')? A za nim, za znamenonoscem, stojal barabanščik - ser'eznyj mal'čugan.

(85) Zameten byl Il'ja korinc - ton'kij, udlinnenyj junoša

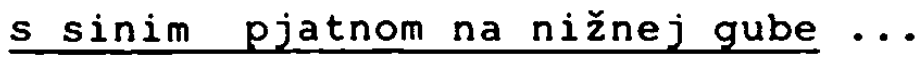

(85')? Zameten byl Il'ja Korinc - ton'kij udlinnenyj junoša.

Es ist wohl nicht allein die Semantik der Präpositionalphrase, die der Apposition die geforderte Selbständigkeit sichert, auch die intonatorische Rolle des postnominalen Determinierers scheint eine Rolle zu spielen.

Adjektivische Attribute sind als alleinige Determinierer dann denkbar, wenn die Apposition eine motivationelle Beziehung zum Prädikat eingeht. In meinem Material habe ich allerdings keinen entsprechenden Beleg gefunden.

Eine Anmerkung ist noch nötig. Geht das Hyponym dem Hyperonym voraus, dann genügt ein Genitivattribut, um die Apposition im erforderlichen Umfang $z u$ verselbständigen:

(86) A ona otkrovenno flirtovala s dilinnym, černjavym parnem, rabotnikom kakogo-to televizionnogo atel'e.

Interessanterweise sind in diesem Fall adjektivische Attribute nicht nur überflüssig, sondern sogar unerwünscht. 
Der Satz wird inakzeptabel:

$\left(8^{\prime}\right)$ ? A ona otkrovenno flirtovala s dlinnym, černjavym parnem, chorošim rabotnikom kakogo-to televizionnogo atel'e.

Es ist ebenfalls nicht möglich, ersatzweise eine Präpositionalphrase einzusetzen:

(86') ? A ona otkrovenno flirtovala s dlinnym, černjavym parnem, rabotnikom vočkach.

(86\%) ? A ona otkrovenno flirtovala s dlinnym, černjavym parnem, rabotnikom iz Leningrada.

Im letzten Fall scheint keine Koreferenz von parnem und rabotnikom vorzuliegen. Durch den Einschub eines Adjektivs läßt sich allerdings ein akzeptabler Satz herstellen:

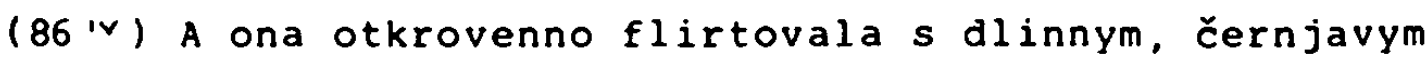
parnem, izvestnym rabotnikom iz Leningrada.

Vgl.

(87) I ešče plačet $v$ nomere krasivaja sedaja ženščina, izvestnaja aktrisa iz Leningrada.

Es bedarf keiner weiteren Erklärung, daß hier nicht beliebige Attribute eingesetzt werden können.

Eine nicht 2 u unterschätzende Bestätigung für die bisherigen Ergebnisse bezüglich der Rolle der adjektivischen Attribute liefert die Untersuchung der anaphorischen wiederaufnahme indefinit-spezifisch referierender Phrasen. Nur in zwei Fällen fanden sich beim Substituens vorerwähnte adjektivische Attribute. Interessanterweise in sätzen mit dem verb smotret'/posmotret., das ohnehin eher ein definites als ein indefinites objekt erlaubt. vgl.

(88) A ona otkrovenno flirtovala s di innym, černjavym parnem... Paren'... Potanin smotrel na Ninel', na černjavogo parnja. 
Die Notwendigkeit für die Wiederholung eines solchen Merkmals ist kontextuell bedingt, $d . h$. dann erforderlich, wenn aufgrund komplizierter Textsituationen, die wiederholung des Appelativums nicht ausreicht, um die gemeinte Person zu identifizieren. Da in (87) nur zwei adjektivische Attribute zur verfügung stehen, muß eines von ihnen das erforderliche Merkmal liefern. Nichtvorerwähnte Substantive haben in einer solchen situation ohnehin keine Relevanz. Ist der Abstand zwischen der Erst- und der Zweiterwähnung übermäßig groß, dann kann es sein, daß die wiederholung eines einzigen Merkmals nicht ausreicht. In nachstehendem Beispiel liegen zwischen der Erst- und Zweiteinfürung der Person 51 Seiten. Dies erklärt die Hinzunahme eines zweiten Merkmals, das im übrigen aus einer Lokalphrase gewonnen wurde:

\section{(89) ...i ešče plačet $v$ nomere krasivaja sedaja ženščina, izvestnaja aktrisa iz Leningrada ... Pered glazami u menja voznikaet sedaja ženščina v nomere gostinicy.}

Genausowenig häufig wie die wiederholung von attributiven Adjektiven ist überraschenderweise die wiederaufnahme von Präpositionalphrasen (zumindest in meinem Material), obwohl sie besser geeignet sind, distinktive Merkmale zu liefern:

(90) Licom k tablo, spinoj $k$ vošedšim stojala tonkaja devuška v černoj vodolazke ... Devuška v vodolazke ... .

In der überwältigenden Mehrzahl der Fälle tritt als substituens entweder ein Pronomen, das nichtattribuierte Appelatịum oder, etwas überraschend, ein Eigenname auf. In den Fällen, in denen pränominale Attribute vorkommen, sind die Attribute entweder Derivate vorausgehender Verben oder wiederaufgenommene Elemente von Prädikaten, Präpositionalphrasen oder Isolierungen. Auf die einzelnen Phänomene, die gesondert untersucht werden müßten, kann ich hier leider nicht eingehen. Die Beobachtungen bei den Substituten bestätigen, daß spezifisch referierende Substantive ohne adjektivische Attribute in der Regel als definit aufgefaßt werden. Auf die "abweichenden" Fälle bin ich oben eingegangen. 
Dieser Beitrag ist nicht als eine erschöpfende Beschreibung der Definitheits-/Indefinitheitsproblematik im Russischen anzusehen. Es wurde nur ein Teilbereich behandelt, in dem adjektivische Attribute eine besondere Rolle spielen. Von besonderer Bedeutung ist die Beobachtung, daß die einzelnen Attributstypen in funktionaler Hinsicht eine klare Spezialisierung erkennen lassen. Bemerkenswert ist dabei vor allem die Abgrenzung der adjektivischen von den präpositionalen Attributen.

\section{Anmerkungen}

1. Bei Birkenmaier z.B. Wird undifferenziert von attributiven Ergänzungen gesprochen: "Die attributiven Ergänzungen bei den definiten Nomen sind im Vergleich $2 u$ den referenzgleichen indefiniten Nomen weniger umfangreich ..." und "Je mehr attributive Ergänzungen also bei einem Nomen in Anfangsposition stehen, und je spezifischer diese attributiven Ergänzungen sind, desto eher wird das Nomen auch im Russischen als indefinit aufgefaßt ..." (s. 69)

2. Ich habe mich hierbei a B. Miemietz angelehnt. Vgl. S. 87

3. Vgl. auch einen Satz wie: "Ich habe ein Auto gekauft" mit "Ich habe ein rotes Auto gekauft." Das Attribut rot bedarf sicherlich einer speziellen kontextuellen Vorbereitung, aber wie immer diese aussieht, auf jeden Fall wird die Extension von Auto eingeschränkt.

4. Vgl. auch noch folgende (später gefundene) Beispiele: - otkryla im staruška s polnym licom i v nakinutoj na pleči šali.

- V komnatu vošla ženščina $v$ temnom chalate so švabroj v ruke.

Auch im letzten Beispiel wird durch die Häufung von Präpositionalphrasen die indefinite Interpretation gesichert.

5. Interessant ist in diesem Zusammenhang folgendes Beispiel. da hier die präponierten Attribute Definitheit anzeigen: 
Čerez polčasa on byl uže na pervoj kolonke. Nemolodaja, grubovataja blondinka ostalas' bezučastna $k$ Petinoj obvorožitel'noj ulybke i razdražennym tonom skazala ... Die Erklärung für die Attributshäufung und Definitheit ist, daß die blondinka in der gegebenen situation als Teil des Ganzen erschlossen werden kann, ohne daß es einer vorerwähnung bedarf (Tankstelle: Bedienung).

Bemerkenswert ist bei diesem Beispiel, daß die Definitheit bzw. die Akzeptabilität des Satzes ausgerechnet durch die adjektivischen Attribute gesichert wird. Vgl. ?... Blondinka ostalas' bezučastna $k$...

Präpositionale Attribute sind hier im übrigen nicht akzeptabel:

?... Blondinka s polnym licom/v temnom chalate ostalas' bezučastna $k$...

Die Nominalphrase wüde zwar auch als definit interpretiert werden, allerdings eindeutig auf ein Antezedens verweisen.

6. Vgl. dazu auch periphrastische wiederaufnahmen, für die die Existenz eines Attributs typisch ist: Razueva suetlivo vstala, otkryla servant, našla pis'mo [def.].

Granskaja pročla nebol'šoe poslanie [def.], v kotoram ...

7. Bei indefinitem Antezedens scheinen die Verbältnisse etwas "lockerer" zu sein. Vgl.

- Kakoj tam zvonok, celyj nabat. - usmechnulsja odin iz ponjatych -požiloj suchoparyj mužčina, imeja $v$ vidu sobaku.

-- Volk, da i tol'ko - potverdila drugaja ponjataja ženščina let tridcati.

Li teraturverzeichnis:

Birkenmaier, W., Artikelfunktionen in einer artikellosen Sprache. München 1979

Miemietz, B., Nominalgruppen als Textverweismittel. Minchen 1987 
Quellen:

Adamov, A., 2lym vetrom. Moskva 1975

--------, Petlja. Moskva 1976

--- Idet rozysk. Moskva 1986

Bezuglov, A., Prokuror. Moskva 1984

Cernenok, M., Posledstvija neustranimy. Moskva 1984

Grekova, I., Porogi. Moskva 1986

Kron, A., Bessonica. Moskva 1980

Krutilin, S., Grechi naši tjažkie. Moskva 1982

Ogonek 1964, 16

Peunov, V., Bez prava na pomilovanie. Kiev 1985

Pronin, V., Ošibka v ob-ekte. Moskva 1980

Sacharnov, S., Buchta komandora. Moskva 1983

Sizov, N., Vevydumannye rasskazy. Moskva 1980

Vasil'eva, L., ... i 24 žemčužiny. Moskva 1982

vysockij, S., Sreda obitanija. Moskva 1983 


\section{SPECIAIKA PHICOCOEIAE SCADICAE}

Herausgegeben van Olexa Harbatsch, Gerd Freidhof und Peter Kasta

Supplementband 17: J. Marvan, Česke stupňovån1. Degrees of comparison in Czech. 1986, 232 S., DM 56.-

Supplementband 18: Torsten Schmitt, Kasusgrammatik Konstruktive Logik - Temporaler Ausdruck. 1986, 237 S., DM 56.-

Supplementband 19: G. Bentschel, Vokalperzeption und Natürliche Phonologie. Eine kontrastive Untersuchung zum Deutschen und Polnischen. 1986, 348 S., DM 80.-

Supplementband 20: W. Eismann, Von der Volkskunst zur proletarischen Kunst. Theorien zur Sprache der Iiteratur in RuBland und der Sowjetunion. 1986, 359 S., DM 90.-

Supplementband 21: H. Spraul, Untersuchungen zur Satzsemantik russischer sătze mit freien Adverbialen. 1986, 290 S., DM 68.-

Band 61:

The Slavonic Calvinist ReadingPrimer in Trinity College Dublin Library. A facsimile edition with an introduction by C.B. Roberts. 1986, XXX+192 S., DM 44.-

Band 71:

Dasselbe. Part 2: Word-List to the Confession and Catechism. Compiled by C.B. Roberts. 1987, 89 S., DM 24.- 
SPECIRIXA PHICOCOGIAE SCADICAE

Herausgegeben van 0 . Harbatsch, G. Freidhat und $P$. Kasta

verlag Otta sagner

Bd. 33: Dj. Daničić, Istorija oblika srpskoga ili hrvatskoga jezika do svršetka XVII vijeka. U Biogradu 1874. München 1981 , 400 S., DM 80.-

Bd. 40: P. Kosta, Eine russische Kosmographie aus dem 17. Jahrhundert (Sprachwissenschaftliche Analyse mit Textedition und Faksimile). München 1982, $471 \mathrm{~s}$., DM 90.-

Bd. 52: W.J. Rosa, Cechořečnost seu Grammatica linguae Bohemicae. Micro-Pragae 1672. Ed. by Jiři Marvan. München 1983, XXIX + 520 S., DM 56.-

Bd. 65: S.K. Bulič, Cerkovnoslavjanskie elementy $v$ sovr. lit. I narodnom russkom jazyke. SPb. 1893. Nachdruck und Nachwort von P. Kosta. München 1986, 409+ VII S., DM 82.-

Bd. 66: J. Tuwim, Pegaz Dęba. Reprint and Introduction by J. Sawicka. München 1986, XXIII + 431 S., DM 86.-

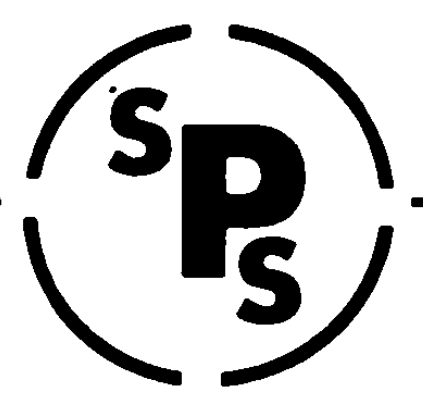

